(Aus der Königl. Universitäts-Frauenklinik München.)

\title{
Die Follikelatresie während der Schwangerschaft, insbesondere die Hypertrophie und Hyperplasie der Theca interna-Zellen (Theca-Luteïnzellen) und ihre Beziehungen zur Corpus luteum-Bildung.
}

\author{
Von \\ Privatdocent Dr. Ludwig Seitz, \\ Oberarzt der Klinik. \\ (Hierzu Tafel VI-IX.) \\ I.
}

Die Follikelatresie ausserhalb der Schwangerschaft ist wiederholt Gegenstand von Untersuchungen gewesen; meist beschäftigen sich die vorliegenden Arbeiten mit der Morphologie dieses Vorganges, eine geringere Anzahl ventilirt die Frage, ob es sich dabei um einen physiologischen oder ausschliesslich pathologischen Process handelt.

Was nun die letztere Frage anlangt, so steht nunmehr soviel fest, dass nicht nur unter pathologischen Verhältnissen eine Follikelatresie stattfindet, sondern dass sie auch an ganz normalen Ovarien regelmässig zu beobachten ist und dass sie von der Zeit nach der Geburt bis zum Aufhören der Geschlechtsthätigkeit anhält.

Wie verhalten sich nun speciell die Follikel während der Schwangerschaft? Bleiben sie auf der Entwicklungsstufe unverändert stehen, auf der sie sich im Momente der Conception befanden, oder bilden sie sich in dem Stadium, in dem sie sich gerade befinden, zurück oder wachsen sie erst noch weiter, um dann erst der Atresie zu verfallen, oder aber findet auch während der Schwangerschaft eine regelmässige Reifung der Follikel, ein Platzen derselben und ein Freiwerden des Eies, also eine regelrechte Ovulation statt?

Wir greifen zunächst die letzte Frage nach dem Fortbestehen der Ovulation während der Schwangerschaft heraus, weil sie wiederArchiv für Gynäkologie. Bd. 77. H. 2. 
holt Gegenstand der Diskussion gewesen ist, während sich mit den ersteren Fragen nur wenige Autoren eingehender beschäftigt haben. Sie ist naturgemäss auch die wichtigste. Die Ansichten der Autoren über diesen Gegenstand sind getheilt, wenn auch betont werden muss, dass in neuerer Zeit die MehrzahJ daran festhält, dass eine regelrechte Eireifung während der Gravidität nicht vorkommt. In diesem Sinne sprechen sich, um nur die monographischen Abhandlungen zu nennen, Wendeler in Martin's Erkrankungen der Eierstöcke (S. 89) und Strassmann in v. Winckel's Handbuch der Geburtshilfe (Bd. I. H. 1. S. 107 und 143) aus, während dagegen Gebhard in seiner Arbeit "Menstruation" (Veit, Handbuch der Gynäkologie Bd. III. H. 1. S. 18) das Sistiren der Ovulation während der Schwangerschaft für nicht sicher erwiesen hält.

Der Beweis für die Reifung des Follikels kann erbracht werden 1. durch das Auffinden eines sprungreifen oder eines frisch gesprungenen Follikels mit allen Charakteristica eines solchen, 2. durch das Auffinden eines ganz jungen Corpus luteum. Der letztere Weg führt nur dann zu einem sichern' Resultate, wenn neben der makroskopischen Beschreibung auch eine zuverlässige mikroskopische Beschreibung vorliegt. Nicht selten liest man in den Arbeiten, dass neben dem grossen Corpus luteum ein zweites oder drittes kleineres Corpus luteum sich vorfand. Es ist ganz unrichtig, solche Gebilde ohne weiteres als echte gelbe Körper, d. h. solche, die aus einem geplatzten Follikel hervorgegangen sind, anzusprechen; in der Regel handelt es sich um grössere atretisch zu Grunde gegangene Follikel, die nur bei oberflächlicher Betrachtung als aus einem geplatzten Follikel hervorgegangen angesehen werden können. Ich verweise auf die Figuren 9 u. 13, wo 2 kleine Corpora atretica abgebildet sind, die auch mikroskopisch sehr grosse Aehnlichkeit mit echten gelben Körpern haben, und auf eine Beobachtung im 3. Theil dieser Abhandlung, wo ein sogenanntes atypisches Corpus luteum (Leopold) beschrieben ist, in das, ohne dass es zum Platzen gekommen wäre, eine Blutung stattfand. Auch könnte ein grösseres und noch relativ frisch aussehendes Corpus albicans ohne mikroskopische Untersuchung irrthümlich als Corpus luteum angesprochen werden.

Aus diesen Gründen ist es berechtigt, gegen alle Mittheilungen aus der Literatur, die der mikroskopischen Untersuchung entbehren, skeptisch zu sein, manche stammen auch noch aus der Zeit, wo histologische Untersuchungen überhaupt nicht oder mit technisch 
ungenügenden Mitteln vorgenommen wurden. Ich kann daher voll und ganz Cosentino beistimmen, wenn er die vor seiner Beobachtung veröffentlichten Mittheilungen über die Persistenz der Ovulation während der Schwangerschaft als nicht genügend fundirt erklärt. Dies gilt von den Beobachtungen von Scanzoni, Meigs in gleicher Weise wie von den Angaben von Bajardi, von Cazzi und Berté. Cosentino selbst hat bei einer im 6. Monat schwangern, plötzlich verstorbenen Frau verschiedene Entwicklungsstadien der Follikel und 1 frisch geplatzten Follikel, ferner 2 frische Corpora lutea gefunden, von denen das eine von dem befruchteten $\mathrm{Ei}$, das andere weit kleinere von einem grössern, während der Schwangerschaft ungeplatzt zu Grunde gegangenen Follikel herstammt. Es kann nach der Beschreibung (Abbildungen sind zwar erwähnt, finden sich aber im Archivio di obst. e di gin. nicht!) keinem Zweifel unterliegen, dass es sich wirklich um einen geplatzten Follikel handelt, allein ein vollständig reifer Follikel ist es nicht; denn das $\mathrm{Ei}$ befand sich noch innerhalb der Granulosa; es hat sich das $\mathrm{Ei}$ nicht gelöst, wie das bei einem reifen Eie eintritt. Es handelt sich demnach um das Bersten eines nicht ganz reifen Follikels, das vielleicht mit Stauungserscheinungen (plötzlicher Tod in Folge chronischen Herzfehlers) zusammenhängt. Ausserdem handelt es sich um eine Schwangerschaft von noch nicht 6 Monaten. Es käme der Beobachtung für die späteren Monate keine Beweiskraft zu.

Eine zweite Beobachtung, die sich auf anatomische Befunde stützt, stammt von Slavjansky. Er sah bei einer im 3. Monat an rupturirter Tubenschwangerschaft verstorbenen Gravida ausser dem Corpus luteum gravid. $\left.{ }^{1}\right)$ noch ein junges Corp. lut., das sich angeblich aus einem während der Schwangerschaft geplatzten Follikel gebildet hatte, sowie zahlreiche Follikel in den verschiedensten Stadien der Entwicklung. Auf die Schwierigkeit der Deutung von Corpora lutea wurde breits oben hingewiesen.

Hierher gehört auch eine Beobachtung von Krönig, welcher Befruchtung nach einem am 4. Wochenbettstage erfolgten Coitus eintreten sah. Da die Spermatozoen sich innerhalb der Genitalien längere Zeit am Leben zu erhalten vermögen, so kann die Conception auch zu einem erheblich spätern Termin als am 4. Wochenbettstag

1) Ich halte die Bezeichnung Corp. lut. graviditatis und menstruationis für richtiger als verum und spurium, da die beiden letzteren Áusdrücke den Anschein erwecken könnten, als ob es sich dabei um principiell verschiedene Dinge handelt. 
erfolgt sein. Immerhin muss man eine ungewöhnlich rasche Reifung eines Follikels post partum annebmen, wenn man nicht der Ansicht huldigen will; dass der geplatzte Follikel bereits während der Schwangerschaft bis zu einem der Reife nahen Zustand sich entwickelt hat. Der Fall ist übrigens, insofern nicht ganz einwandfrei, als er auf Angaben der Schwangeren gegründet ist, wie dies auch $\mathrm{Zweifel}$ in der Discussion hervorhob.

Die von Waldeyer ohne Bemerkung über den Inhalt citirte Arbeit von Vitanza (Sulla maturità e cad. periodica dell'ovula nella donna e nei mammiferi durante la gravidanza, Atti della Soc. Ital. di Ostetricia e Ginecol. Vol. IV. 1897) war mir leider nicht zugängig und ich kann daher über seinen Inhalt nicht referiren.

Von einem gewissen Interesse ist es, einige von den bei Thieren gemachten Beobachtungen zum Vergleiche heranzuziehen. Ein Beweismaterial für die Beurtheilung menschlicher Verhältnisse können sie bei den grossen Abweichungen in der Häufigkeit und der Dauer der Sehwangerschaft und anderer Lmstände selbstverständlich nicht abgeben.

Stratz, der an einem einwandfreien, grossen Material bei Tupaja, Sorex und Tarsius Studien gemacht hat, kommt zu der Ansicht, dass während der Schwangerschaft zwar die Eireifung, aber nicht die Eibildung cessirt, dass eine fortwährende Neubildung von Eiern stattfindet, welche, bis zu einer gewissen Grösse gelangt, der Atresie verfallen. Zuerst atresiren die grösseren Follikel, selbst dann, wenn sie schon die Befruchtungsfähigkeit erlangt haben, dann schreitet die Degeneration zu den mittleren und kleineren fort. Stratz bestätigt die Behauptung von Flemming, dass die vorhandenen Follikel meist nur klein sind in der zweiten Hälfte der Schwangerschaft und dass es sich ursprünglich um viel grössere Follikel gehandelt hat; denn was sollte auch sonst aus den verschiedenen reifen Follikeln geworden sein, deren beginnende Atresie man im Anfange der Gravidität beobachten kann. Nach Stratz ist die Follikelatresie in der Schwangerschaft so ausgeprägt, dass er zu dem Schlusse kommt: „Finden wir in einem Ovarium - von pathologischen Zuständen abgesehen - alle Follikel atretisch, so können wir annehmen, dass es sich um Schwangerschaft handelt." ${ }_{n}$ Mit beginnender Schwangerschaft steigt die Zahl der auch mit schwacher Vergrösserung wahrnehmbaren atresirenden Follikel, um am Ende der Schwangerschaft und im Beginn des Puerperium ihren Höhepunkt zu erreichen." Je weiter das Puerperium bei den ge- 
nannten Thieren fortschreitet, desto häufiger werden wieder normalo Follikel (und frische Corpora lutea) wahrgenommen.

Aus diesen Beobachtungen von Stratz geht klar hervor, dass die Follikelatresie, die bekanntlich auch im nicht graviden Zustand häufig vorkommt; während der Schwangerschaft wenigstens für diese Thierspecies ungewöhnlich an Häufigkeit zunimmt. Davon aber, dass die Follikelatresie eine Abweichung in ihrer Morphologie von der ausserhalb der Schwangerschaft aufweise, dass sie etwas. Charakteristisches habe, davon ist nirgends die Rede.

Mit diesen Befunden von Stratz an den erwähnten Species steht der von Franz Cohn an Kaninchenovarien erhobene Befund in einem gewissen Gegensatz, dass sich "in mehreren Ovarien während der Gravidität sprungreife, über die Ovarialoberfläche stark hervorragende, sehr grosse Follikel neben mittleren und kleineren Follikeln" vorfanden. Diese Erscheinung ist, wie auch Cohn hervorhebt, bei der sprichwörtlichen Fruchtbarkeit des Kaninchens nichts Auffallendes, an die eben abgelaufene Gravidität schliesst sich sofort eine neue an, ausserdem ist die Tragzeit zu kurz, um inzwischen ganz junge Follikel heranreifen zu lassen. Auch die Thatsache steht damit im Einklang, dass die Ovarien von schwangeren Kaninchen ausser den gelben Körpern der bestehenden Gravidität noch die Corpora lutea der vorigen, ja sogar der vorletzten Schwangerschaft enthalten, während dagegen Stratz bei Tarsius und Tupaja fand, dass sich die Corpora lutea nur in der ersten Hälfte der Schwangerschaft erhalten und sich in der zweiten Hälfte bis auf spärliche Reste zurückbilden.

Abgesehen von den häufig gebärenden Thieren mit der kurzen Tragzeit scheint nach den Befunden von Stratz das Gesetz zu bestehen, dass während der Schwangerschaft wohl noch eine Weiterentwicklung, aber keine Eireifung stattfindet und dass die vorhandenen grösseren Follikel der Atresie verfallen.

Für den Menschen ist bisher noch nicht mit Sicherheit nachgewiesen, dass während der Schwangerschaft eine regelrechte Ovulation vorkommt. Bisher sind mit Sicherheit nur bis zum 6: Monat und nur 1 mal Follikel gefunden (Cosentino), welche sich in einem weiter fortgeschrittenen Entwicklungsstadium befanden, nicht aber $\mathrm{zu}$ völliger Reife gelangt waren. An meinem Material (Ovarien von 36 verschiedenen Frauen) habe jch trotz genauer makroskopischer Besichtigung und der Durchsicht einer sehr grossen Anzahl mikroskopischer Schnitte nicht ein einziges Mal einen frisch 
geborstenen oder reifen oder auch nur der Reife nahen Follikel beobachtet. Wir müssen also auf Grund unseres Materials den Satz beim Menschen bestätigen: Während der Schwangerschaft findet eine 0vulation nicht statt.

Wenn nun keine Reifung der Follikel stattfindet, verharren dann die Follikel auf dem Zustande, in dem sie beim Eintritt der Conception sich befanden oder. gehen sie in dem Entwicklungsstadium, in dem sie eben sind, zu Grunde oder entwickeln sie sich erst noch weiter, um dann schliesslich der Atresie zu verfallen?

Ausser den bereits citirten Befunden von Stratz und von Flemming bei Thieren fand ich nur eine einzige aut die Verhältnisse beim Menschen bezügliche Bemerkung bei Sinéty, der sagt: er habe den Eindruck, als ob die Zahl der atretischen Follikel viel zahlreicher wäre, als ausserhalb der Schwangerschaft.

Nach meinen Beobachtungen verfallen nun sämmtliche grössere Follikel bis zum Schlusse der Schwangerschaft der Atresie. Dies tritt bei der Minderzahl in dem Entwicklungsstadium ein, in dem sie sich bis zur Zeit der Conception befanden, die Mehrzahl jedoch entwickelt sich bis zu einem gewissen Stadium weiter, um dann erst der Atrophie zu verfallen. Die Atresie kann namentlich in den späteren Monaten auch kleine Follikel, d. h. solche, welche noch gar keine Follikelhöhle aufweisen, betreffen, die Primordialfollikel werden anscheinend nicht mehr betroffen als ausserhalb der Schwangerschaft, sofern man nur tadellos conservirte Präparate verwendet. Präparate, die nicht ganz frisch der plötzlich Verschiedenen entnommen werden oder nicht durch Operation gewonnen sind, täuschen häufig eine Follikelatresie vor, nicht allein an den Primärfollikeln, noch in viel höherem Grade an den grösseren Follikeln. Bei den letzteren findet man das Granulosaepithel von der Unterlage abgelöst und in den Follikelraum dislocirt, die Epithelien auseinanderfallend, desgleichen die des Discus, das Eichen selbst in Degeneration begriffen. Es ist unmöglich, an solchen Präparaten nachträglich Entstandenes von den intra vitam erfolgten Veränderungen zu scheiden; man darf daher zu diesen Untersuchungen nur vorzüglich fixirte Präparate (Gruppe I unserer Fälle) benutzen, will man zuverlässige Resultate gewinnen.

Womit lässt sich nun die supponirte Weiterentwicklung der Follikel beweisen? Bereits in den ersten Monaten verfällt eine Anzahl der Follikel der Atresie. Der Vorrat an grösseren Follikeln 
würde nun alsbald aufgebraucht sein, wenn nicht neue heranwüchsen. Wir sehen neben den verödenden Follikeln daher stets auch eine Anzahl heranwachsender Follikel. Die Verödung kann auch schon heranwachsende Follikel (ohne Follikellumen) betreffen; in der Regel tritt sie jedoch erst dann ein, wenn die Follikel 1-4 mm Durchmesser erreicht haben. Zuerst degenerirt das Ei; man glaubt häufig nach dem Verhalten des Granulosaepithels einen ganz frischen Follikel vor sich zu haben, da stösst man bei den tiefen Schnitten auf das Ei und findet dasselbe degenerirt. Meist liegt es noch im Discus, umgeben von mehr oder minder gelockerten Epithelien, sein Protoplasma und sein Kern zerfällt und bildet schliesslich eine homogene Masse, welche sich mit Eosin leuchtend roth färbt. Auch. Theilungserscheinungen am degenerirenden Ei habe ich einmal beobachtet. Henneguy nennt diesen Vorgang die Dégénérescence par fragmentation. Ausbildung einer regelrechten Spindel am degenerirenden $\mathrm{Ei}$, wie dies recht häufig bei älteren Follikeln zu beobachten ist, habe ich nicht gesehen. Vielleicht war hierzu die Entwicklung der Follikel nicht weit genug gediehen. Nur ein paarmal habe ich ein intaktes Ei gefunden - alle Follikel wurden übrigens nicht daraufhin untersucht, - und ich bin daher berechtigt zu sagen, dass an grössern Follikeln ein unversehrtes $\mathrm{Ei}$ wenigstens in den späteren Monaten sehr selten gefunden wird. Das grösste und besterhaltene ist in Taf. VI, Fig. 2 dargestellt. Meist ist übrigens nicht allein das Ei, sondern auch der Discus und das Granulosaepithel mehr oder weniger ausgedehnt der Degeneration verfallen. Im Discus und im Epithel sind zahlreiche Epithelvakuolen zu finden, die fälschlich zu der Annahme von mehreren Eiern Veranlassung geben können und wiederholt gegeben haben (Call und Exner). Die Epithelien sind auseinandergerückt, manchmal sind sie in Zügen ins Lumen des Follikels dislocirt (wohl meist arteficiell), ihre Kerne zeigen chromatolytische Figuren, wie dies Flemming zuerst genauer beschrieben hat. Bestehen einmal diese Veränderungen in Epithel und Discus, so braucht man weiter nicht mehr nach dem Ei zu sehen, um sich von dem atretischen Zustande des Follikels zu überzeugen. Es kommen übrigens in Bezug auf das Verhalten von Granulosaepithel und Discus mancherlei Variationen vor. So sah ich einige Male, wie das ausserhalb der Schwangerschaft schon längst bekannt ist, dass der Discus mit dem degenerirten $\mathrm{Ei}$ allein noch der Wand aufsass; während das Granulosaepithel ringsum 
verloren gegangen war, in anderen Fällen, dass aus dem Follikelepithel Zellen ausgefallen waren, sodass warzenartige Prominenzen zurückblieben (Taf. VIII, Fig. 15) oder dass nur an der einen oder der andern Stelle noch Follikelepithel aufsass.

lch möchte hierbei nicht versäumen, zu bemerken, dass auch in der Schwangerschaft wie ausserhalb derselben zu Grunde gegangene Follikel gefunden werden, welche keinen Inhalt, es sei denn eine homogene geronnene Masse, keine Epithel- und keine Wandbekleidung haben, sondern direkt an die Stromazellen anstossen; manchmal trennt sie davon ein schmaler Saum hyalinen Gewebes. Man hat den Eindruck, als handle es sich um einfache cystische Hohlräume. Das typische Verhalten der atresirenden Follikel in der Schwangerschaft ist jedoch, dass die Zellen ihrer Theca interna sich zu den luteinhaltigen Zellen umwandeln, die ich im Folgenden zum Unterschiede von den (epithelialen) Luteïnzellen des Corpas luteum Thecaluteïnzellen nennen will.

Was die Art der degenerativen Vorgänge am Ei und Follikelepithel anlangt, konnte ich demnach während der Schwangerschaft keine Unterschiede feststellen gegenüber jenen ausserhalb derselben. Da sich Verschiedenheiten ausschliesslich in dem Verhalten der Theca zeigten, sei es mir gestattet, hier vorher noch kurz die Veränderungen an einem atresirenden Follikel ausserhalb der Schwangerschaft zu besprechen.

Durch Resorption des Liquor folliculi wird der intrafolliculare Druck herabgesetzt, die Wände des Follikels sinken zusammen und stülpen sich ein; dies geschieht zum Theil rein passiv, zum Theil wächst das Ovarialstroma aktiv gegen das Follikellumen vor. Dabei verdickt sich die Wand einmal dadurch, dass die Zellen der Theca interna gegen einander verschoben werden und dadurch, dass die Zellen durch Fettaufnahme sich selbst etwas vergrössern. An der inneren Grenze der Theca interna erscheint eine Membran, die noch zu besprechende Glasmembran, die fast nie an atrophirenden Follikeln vermisst wird, wenn sie häufig auch nur einen mehr oder minder grossen Theil der Peripherie umgiebt. Innerhalb dieser Glasmembran tritt ein reticuläres lockeres Bindegewebe auf, das früher, so von Slaviansky, wegen seines Aussehens fälschlich als Schleimgewebe angesprochen wurde. In ihm findet man gelegentlich Granulosaepithelien und Reste des Eies eingelagert.

Das innerhalb der Glasmembran auftretende reticuläre Bindegewebe leiten die meisten Autoren von der Theca externa ab, die 
Zellen der Theca interna haben mit der Ausfüllung dieses Raumes selbst gar nichts zu thun (Kretschmar u. Bulius, Rabl).

Schottländer leitet sie von der Theca interna $a b$, da die Zellen sehr gross sind und deutlich epitheloiden Charakter haben. Da unter den Beobachtungen Schottländers verschiedene Ovarien gravider Frauen waren, so haben vermuthlich die bei Graviden gewöhnlichen, damals noch unbekannten Befunde zu dieser Deutung Veranlassung gegeben (Fig. 39 u. 40 der citirten Abhandlung). Es haben die Untersuchungen von H. Rabl an Katzen und Nagethieren mit Bestimmtheit ergeben, dass sich nur die Theca externa daran betheiligt. Wenn die Theca interna Antheil hätte, kämen nur die spindeligen, nicht die epitheloiden Zellen dieser Schicht in Betracht. Für den Menschen kann ich die Beobachtungen von Bulius und Kretschmar und von Rabl in vollem Umfange bestätigen, jenseits der Glasmembran habe ich epitheloide Abkömmlinge der Theca interna nie gesehen. Während der Schwangerschaft spielt die Ausfüllung des Follikelhohlraumes keine so grosse Rolle, da derselbe durch die mächtig wachsende Theca interna vielfach auf ein Minimum reducirt wird.

Die Glasmembran, wie sie Grohe zuerst beschrieben hat, auch Basalmembran, Membrana propria genannt, ist jener schmale, hyaline Streifen, der zwischen Theca interna und Follikelepithel häufig gefunden wird. Ueber ihr physiologisehes Vorkommen und über ihre Genese ist viel gestritten worden.

v. Koelliker hat zuerst die structurlose Membran in allen Fällen vorgefunden, hat jedoch später selbst das physiologische Vorkommen einer Basalmembran angezweifelt; Waldeyer, der sie bei Vögeln gesehen hat, vermisst sie bei jungen Eiern von Säugethieren bestimmt und zieht das Auftreten an reifen Eiern unter normalen Verhältnissen ebenfalls in Zweifel. Wagener und Slaviansky haben sie beim Menschen beschrieben, Vogel behauptet, die Basalmembran an älteren Follikeln stets gesehen zu haben, Franz Cobn fand sie beim Kaninchen, Clark hat sie an den Verdauungspräparaten beim Schwein, schwerer auch beim Nenschen stets darzustellen vermocht als ein flächenhaftes Netzwerk feinster reticulärer Fasern, dem die unterste Lage der Granulosazellen pallisadenartig angeordnet, mit kleinem, fussartigem Fortsatz aufsitzen.

Die Mehrzahl der Schriftsteller hat sich dagegen gegen das Vorkommen einer Glasmembran als physiologischer Erscheinung ausgesprochen; so sah sie Benckiser am normalen Follikel des Schweines nie, Hoelzl erklärt jedes Auftreten einer Glasmembran beim Menschen als ein pathologisches Phänomen, das er auf eine degenerirende Sklerose der Theca folliculi zurückführt. Ich kann 
in dieser Beziehung voll und ganz Hoelzl zustimmen. Während der Schwangerschaft bleibt am menschlichen Follikel, auch dann, wenn er der $\Lambda$ tresie verfällt, häufig die Bildung einer Glasmembran aus oder ist viel geringer entwickelt, voraussichtlich weil die Ernährungsverhältnisse durch den erhöhten Blutzufluss von der Theca interna aus besonders günstige sind. Ich bin mit Schottländer, Hoelzl, Bulius und Kretschmar der Ansicht, dass sich die Membran durch Degeneration der Theca interna-Zellen bildet. Zum Studium dieser Vorgänge ist gerade das puerperale Material geeignet. Während in der Gravidität an den Follikeln nur selten von der Glasmembran etwas festzustellen ist, ändert sich das Bild am Ovarium von puerperalen Frauen oder solchen, die während der Schwangerschaft von acuten oder jenen chronischen Krankheiten verstorben sind, die mit Unterernährung aller Organe einhergehen. Hier sieht man fast ausnahmslos die Glasmembran und zwar in der Regel um so breiter, je voluminöser die Schicht der Theca interna war. Dafür spricht ferner der Umstand, dass man in der Membran selbst oder ihr zur Seite degenerirende Kerne beobachten kann. H. Rabl fasst die Glasmembran als ein Ausscheidungsproduct der Theca interna-Zellen auf und stellt den Vorgang in Parallele mit der Bildung von Bindegewebsfibrillen und der elastischen Substanzen; er will dementsprechend nie Degenerationserscheinungen in den Zellen beobachtet haben, mit Ausnahme bei einer 3-4 Wochen schwangeren Frau, wo die Zellen Chromatolyse zeigten. Die in der Membran gefundenen Zellen sieht Rabl hauptsächlich als durchwandernde an, andere werden vielleicht allmälig von dem Hyalin umwachsen. Ich sehe die Beweisführung Rabl's nicht für zwingend an und nach meinen Erfahrungen am Menschen werden degenerative Processe beim Auftreten der Membran nie vermisst.

Bei der Katze sind zwischen Theca interna und Glasmembran an vielen Stellen kleine Bindegewebszellen eingeschoben; Benckiser fand beim Schwein, Franz Cohn fand auch beim Kaninchen eine sehmale Schicht solcher Zellen. v. Koelliker bezeichnet die Schicht der grossen plasmareichen Zellen als Tunica media und nennt erst die innerste schmale Schicht aus Spindelzellen die Tunica interna. Viele Schriftsteller nehmen an, dass sie beim Menschen vollständig fehlen. Hier gebe ich die Fig. 3 von einem grösseren Follikel aus dem letzten Monat der Schwangerschaft wieder, der deutlich erkennen lässt; dass zwischen den grossen Zellen der 
Theca interna und dem Follikelepithel eine Reihe schmaler Bindegewebszellen gelegen sind. Auch Fig. 18 zeigt ähnliche Verhältnisse.

Zur richtigen Beurtheilung der Wandlungen, welche die Zellen der Theca interna atretischer Follikel während der Schwangerschaft durchmachen, ist es von Bedeutung, die Structur dieser Zellen am normalen wachsenden und am reifen Follikel kennen zu lernen.

Während Waldeyer ehedem nach Injectionen von Zinnoberemulsionen an Kaninchen schliessen zu dürfen glaubte, dass die Mehrzahl der Zellen der Theca interna aus. von den Blutgefässen eingewanderten Leukocyten sich bilden - daher auch Granulationsschicht genannt -, steht nunmehr sicher fest, dass sie aus den fixen Bindegewebszellen, aus den Stromazellen bervorgehen, wie dies zuerst Pflüger und His nachgewiesen haben. Man kanu an geeigneten Präparaten den Uebergang der einen Zellart in die andere beobachten; umgekehrt konnte Sobotta bei Gelegenheit des Studiums der Corpus luteum-Bildung beim Kaninchen direct die Umformung der Theca interna-Zellen in spindelige Bindegewebszellen feststellen.

Bei der Umbildung der Spindelzellen des Stromas zu den Zellen der Theca interna - einen Vorgang, den man am besten an wachsenden Follikeln studirt - sieht man, dass die Stromazellen ihre Spindelform mehr und mehr verlieren, dass ihr Zellleib grösser, polyedrisch, ihr Kern rundlich und voluminöser wird. Alsbald treten im Zellleib kleine Fettkörnchen auf, sodass bei voller Entwickelung die Zellen eine leicht gelbliche Färbung besitzen. Schottländer meint zwar, dass „Fett und fettartige Körper nur in der Theca solcher Follikel vorhanden ist, welche die Merkmale beginnender und fortschreitender Atresie an sich tragen." Allein nach neueren Untersuchungen an einwandfreiem Material, so von Rabl, ist es sicher, dass auch beim Menschen - bei einer Reihe von Sängethieren stand es schon fest - am reifen Eollikel fettund luteïnhaltige Einlagerungen in den Zellen der Theca interna auftreten. Waldeyer erklärt das Platzen reifer Follikel dadurch, dass er eine "Vermehrung der granulirten Zellen seiner Theca interna" annimmt, durch welche der Cumulus oophorus mit dem Ei gegen das Stigma hingeschoben und dieses zur Eröffnung gebracht werden kann. Bei manchen Thieren zeichnen sich die Zellen der Theca interna durch besondere Grösse und durch den reichlichen Gehalt an Fett und Lutein aus. So können nach Sobotta bei der 
Fledermaus die Zellen der Theca interna des Graaf'schen Follikels von den Zellen des ausgebildeten Corpus luteum nicht unterschieden werden. Zugleich mit der Umbildung der Stromazellen zu den Zellen der Theca interna wird das capillare Gefässnetz dichter und reichlicher.

Die Zellen der. Theca interna werden übrigens nicht nur voluminöser, sondern es findet auch eine Neubildung von Zellen statt. So traf Rabl am wachsenden normalen. Follikel Mitosen in sebr grosser Menge, auch Andere haben gelegentlich Zelltheilungen beobachtet; doch ist os übertrieben, von einer ungeheuren. Vermehrung der Zellen zu sprechen, wie es Nagel thut.

Dagegen sab Rabl an den epitheloiden Zellen der Theca interna niemals Mitosen, sobald Degeneration am Follikel aufgetreten war. Es handelt sich hier nur mehr um eine einfache Hypertrophie und Fettinfiltration, welche bereits vor dem Beginn der Atresie begonnen hat.

Wir sehen also demnach bereits an dem wachsenden Follikel, dass die Theca interna eine Vergrösserung und in mässigen Grenzen auch eine Vermehrung ihrer zelligen Elemente erfährt. Diese Thatsache ist für die Beurtheilung einer Hypertropbie dieser Zellen während der Schwangerschaft von Bedeutung.

Während man früher im Allgemeinen die Fettansammlung in den grossen Zellen der Theca interna als ein Zeichen der regressiven Metamorphose angesehen hat, gab ihr Born, ebenso Sobotta eine andere Deutung, sie fassten die Fetteinschlüsse als ein aufgespeichertes Nährmaterial ("Mastform" der Zellen nach Sobotta) auf, das den $Z$ weck habe, schnell aufeinander folgende Theilungen der Thecazellen zu ermöglichen.

Plato, der die fetthaltigen Zellen im Ovarium sorgfältig studirt hat, fand, dass bei der Maus und besonders bei der Katze auch schon an jüngeren Follikeln hauptsächlich die äusseren Thecazellen reichlich Fett enthalten,"während dagegen die nach innen gegen die Membrana granulosa zo gelegenen ärmer an Fetteinlagcrungen sind. Daraus schliesst er, dass die inneren Reihen der Thecazellen ihr Fett an den Follikel abgeben, dass das Fett in flüssigem Zustande die Membrana granulosa passirt, um sich in der Eizelle wieder in fester Form auszuscheiden. Früher hatte bereits Pflüger einem Theil der Zellen dieselbe Function zugeschrieben.

Mit den vergrösserten fett- und luteïnhaltigen Zellen der Theca 
interna: haben morphologisch eine weitgehende Aehnlichkeit die Zellen der sogenannten Markstränge; diese sind bekanntlich bei den verschiedenen Species sehr versehieden stark ausgebildet, am stärksten, wie es scheint, bei dem Maulwurf, wo beinahe das ganze Organ davon erfüllt wird, stark ferner beim Kaninchen und bei den Nagern überhaupt, wo die Zellen einen grossen Theil des Ovarium einnehmen, geringer bei der Katze; bei einzelnen Affen sind sie ebenfalls gefunden worden (bei Cebus capucinus nach $\mathrm{Harz}$ ); während sie bei anderen Affenarten nicht nachweisbar sind. So vermisste sie Mac Leod bei Pithecus satyrus, Cercopithecus entellus, Macacus rhesus, Cynocephalus leucofea, Lemur.

Bei ältern menschlichen Föten, Neugeborenen und jungen Kindern lässt sich noch Markstranggewebe nachweisen. Man kann dieses nach dem Vorgang von v. Koelliker in zwei Arten theilen, in die hohlen Markschläuche und in die soliden Markstränge. Die Reste der Markstränge finden sich bei Föten, Neugeborenen und jüngern Kindern gelegentlich als streifartig angeordnete Zellreihen ohne Lumen bis zwischen die Follikel in die Rindenschicht des Ovariums hinein. Die Markschläuche sind nach dem Hilus ovarii zu in Form eines deutlichen Rete sichtbar (Rieländer). Genetisch sind Markschläuche und Markstränge nach den neuen bestätigenden Untersuchungen von Coert und v. Winiwater nur verschiedene Abschnitte ein und desselben vom Keimepithel abstammenden Complexes von Zellsträngen, in denen man Homologa zu den verschiedenen Kanälchen des Hodens zu erblicken hat.

Während nun die soliden Markstränge beim Erwachsenen nicht mehr aufzufinden sind, wurde dagegen die Persistenz der Markschläuche von v. Franqué beim erwachsenen Weibe bis in die Rindensubstanz hinein festgestellt, desgleichen von Rieländer, der an 50 untersuchten Ovarien erwachsener Frauen $16 \mathrm{Mal}$ die Reste der Markschläuche theils in Form des Rete ovarii, theils in Form der intraovariell verlaufenden Kanälchen, jedoch nur selten bis zur. Rinde reichend, nachweisen konnte. Nach beiden Autoren besteht bei den Schläuchen eine grosse Neigung zu cystischer Degeneration.

Die Reste der Markschläuche im Ovarium erwachsener Frauen unterscheiden sich in ihrer histologischen Structur so scharf und so deutlich von den bei den oben genannten. Thierspecies erwähnten Markzellen, dass eine Verwechslung nicht mit unterlaufen kann. Da sich meine Untersuchungen in der Hauptsache nur auf 
Ovarien Erwachsener beziehen, so können wir weiterhin von der Besprechung der Markschläuche beim Menschen Abstand nehmen.

Schwieriger ist die histogenetische Werthung der Markzellen bei den oben genannten und andern Thierarten insofern, als auch andere Zellen morphologisch die grösste Aehnlichkeit mit den Markzellen aufweisen können. Ohne näher auf die Frage der Genese, die uns hier nicht weiter berührt, einzugehen, sei nur darauf hingewiesen, dass von einer grösseren Anzahl von Autoren die Markzellen zum Theil oder gänzlich von zu Grunde gegangenen Follikeln abgeleitet werden.

H. Rabl, der Untersuchungen bei den Nagethieren und bei der Katze angestellt hat, kommt zu dem Ergebniss, dass bei diesen Thieren an nicht geplatzten und in Rückbildung begriffenen Follikeln die vergrösserten Thecazellen ihre Gestalt beibehalten. Je mehr Follikel degeneriren, eine um so grössere Zahl von Stromazellen wird in epitheloide Zellen umgewandelt. Schliesslich besteht der Eierstock - wie man dies vor Allem beim Kaninchen sieht - in seiner grössten Masse aus jenen Elementen. (Rabl S. 162.) Rabl spricht ferner ganz vorsichtig die Vermuthung aus, dass auch die gelben Körper zur Vermehrung jener Zellen beitragen dürften; denn er hat zwar eine Verkleinerung und Deformirung, nicht aber eine gänzliche Auflösung der Corpora lutea wahrnehmen können. Rabl giebt ferner seiner Ansicht dahin Ausdruck, dass diese aus der Theca interna degenerirter Follikel hervorgegangenen Zellen wiederholt Veranlassung zu falschen Deutungen gegeben haben und dass sicher ein Theil der sog. Markstränge des Ovariums auf jene Bildungen zurückzuführen ist, wenn er auch zugiebt, dass ein anderer Theil mit dem Parovarium zusammenhängen kann. Die Zellen der Theca interna, welche Rabl an den atrophischen Follikeln von Kaninchen und Katzen beobachtet hat und wovon er verschiedene Abbildungen giebt, sind ausserordentlich gross, ganz ähnlich den Luteïnzellen des Corpus luteum und bilden eine scharí abgesetzte, breite Membran ${ }^{1}$ ). Beim Menschen-kommt diese Hypertrophie nach seinen Beobachtungen nur ganz selten vor. Er spricht zwar die Vermuthung aus, dass es vielleicht mit einer bestehenden Schwangerschaft zusammenhängen

1) Nagel meint, die wahre Natur der eigenthümlichen Zellen ist noch nicht sicher bei allen Thierarten bekannt: doch ist er geneigt, dieselben einfach als Corpora lutea auf verschiedenen, zum Theil älteren Rückbildungsstufen anzusehen. 
könne, doch finden sich darüber keine weiteren Belege. Ob dieser hypertrophischen Theca interna bei Kaninchen und bei Katzen eine besondere Funktion zukommt, darüber äussert sich Rabl nicht.

v. Kölliker führt die Nester und Stränge ebenfalls auf atretische Follikel zurück und auf dem gleichen Standpunkt steht v. Ebner, der in dem von ihm herausgegebenen Handbuch der Gewebelehre von v. Kölliker (1902) ausdrücklich hervorhebt, dass die Zellenhaufen durch Wucherung der Zellen der Theca interna atretischer Follikel zu Stande kommen.

Eine specielle Function wurde diesem Gewebe zuerst von französischer Seite zugeschrieben. Es waren wobl ziemlich gleichzeitig Bouin, Limon, Regaud und Policard (letztere am nicht atretischen Follikel), die sich im gleichen Sinne äusserten. Sie bezeichnen das Gewebe als interstitielle Drüse des Ovariums (Glande interstitielle de l'ovaire) und schreiben ihm eine innere Sekretion zu.

Limon hat seine Untersuchungen an den Ovarien von $\mathrm{Ka}-$ ninchen, Maus, Ratte, Meerschweinchen, Fledermaus, Maulwurf, Igel angestellt und gefunden, dass die "interstitiellen Zellen" nicht regellos im Bindegewebe zerstreut sind, sondern wohl individualisirte Haufen und Läppchen bilden, dass sie einen exquisit drüsenepithelartigen Charakter haben. Sie bestehen aus einem feinen alveolären Gerüste, in dessen Maschenräumen durch Osmiumsäure sich schwarz färbende Fetttröpfchen aufgespeichert sind, die sich sofort bei Berührung mit Xylol lösen. Durch diese Ejgenschaften und durch den Mangel an Lutein unterscheiden sich die interstitiellen Zellen von den sonst so ähnlichen Zellen der gelben Körper. Zwischen die interstitiellen Zellen dringen reichlich $\mathrm{Ca}$ pillaren ein, so dass mindestens eine Seite einer solchen Zelle einer Blutcapillare zugekehrt ist. Die Entwicklung der interstitiellen Zellen wurde von Limon an der Ratte und am Kaninchen studirt, bei der Ratte beginnt ihre Entwicklung bereits zur Zeit der Geburt, beim Kaninchen vom 4. Monat nach der Geburt. Nach den Beobachtungen von Limon ist die Regel, dass am Follikel zuerst die Umwandlung der Zellen der Theca interna zu den grossen epitheloiden Zellen erfolgt und dass dann erst das Granulosaepithel und das Ei der Degeneration verfällt. Sind die letzten Reste des Follikelinhalts geschwunden, so sind daraus die interstitiellen Zellhaufen der "Glande interstitielle" geworden. Beim Kaninchen ist insofern eine Abweichung vom Typus vorhanden, als die atretischen 
Vorgänge am Follikel der Umbildung der Zellen der Theca interna in epithelartige Zellen vorausgehen und erst nach dem Zugrundegehen des Follikels die Zellen ihren definitiv epitheloiden Charakter annehmen. Limon leugnet somit jeden Zusammenhang der epitheloiden Zellen mit Resten des Wolff'schen Körpers oder mit dem Keimepithel. Er fasst ferner die Corpora atretica (oder wie er sie nennt, die falschen gelben Körper) nicht als eine Bildung suj generis, sondern nur als ein Uebergangsstadium in der Entwicklung der interstitiellen Drüse auf. Auch Limon betont, wie das bereits RabI gethan, dass diese epitheloiden Zellen den grösseren Theil des sog. Ovarialstromas darstellen, besonders reichlich findet es sich entwickelt beim Kaninchen und bei der Fledermaus.

P. Bouin, dessen Arbeit mir im Original nicht zugängig war, schreibt den Zellen ebenfalls eine innere Sekretion zu.

Franz Cohn, der seine Studien an Kaninchenovarien gemacht hat, theilt die Ansicht von Limon und leitet das interstitielle Gewebe ebenfalls von atretischen Follikeln ab. Er betont die grosse Aehnlichkeit der interstitiellen Zellen beim Kaninchen und beim Hasen mit den Tuteïnzellen des Corpus luteum. Doch beständen verschiedene Unterschiede: Zunächst ist die Art der Bindegewebsvertheilung ganz anders. Im Corpus luteum sind nur wenige höchstens 2-4 Luteinzellen, im Ovarialstroma sind bei weitem grössere Gruppen von interstitiellen. Zellen durch Bindegewebe zusammengefasst. Der gelbe Körper ist weit reichlicher mit Blut versorgt. "Die interstitiellen Zellen zeigen sehr scharfe und gezackte Zellgrenzen, wie sie die Luteïnzellen an den Stellen, wo sie sich berühren, niemals aufweisen. Auch lässt die Färbung mit phosphorwolframsaurem Hämatoxylin deutliche Unterschiede in den Farbennuancen hervortreten." Ausserdem sind die interstitiellen Zellen viel kleiner, enthalten nicht so reichlich Fett wie die Luteïnzellen, bei Osmiumfärbung sind die schwarz gefärbten Tröpfchen kleiner und in feiner Vertheilung vorhanden.

Die interstitiellen Zellen selbst beschreibt Cohn folgendermaassen: Das Protoplasma der interstitiellen Zellen zejgt, hauptsächlich in der Peripherie des Zellkörpers, eine wabige Structur, die durch Einlagerung kleiner, rundlicher Vacuolen bedingt wird. Der Kern wird von einer ziemlich homogenen Ansammlung von Protoplasma umgeben. Das Chromatin der Kerne ist fein vertheilt. Zum Beweise dafür, dass das interstitielle Gewebe sich nicht aus dem Corpus luteum, dessen Zellen es morphologisch so sehr 
ähnelt, herstammt, untersuchte Cohn die Ovarien eines erst 2 Monate alten Kaninchens, in welchem Alter von einer Ovulation noch keine Rede sein kann, und konnte auch hier bereits die interstitiellen Zellen fast vom gleichen Aussehen wie beim erwachsenen Thiere auffinden und beobachten, wie sie in die Zellen der stark gewucherten bindegewebigen Theca atresirender Follikel häufig ohne jede Abgrenzung übergehen. Cohn macht ferner darauf aufmerksam, dass er in fast allen Ovarien in der Peripherie ,hyaline Körper von rundlicher Form und unregelmässigem Umriss, mit Eosin sich roth färbend in einem freien, manchmal auch von einem platten Endothel ausgekleideten Hohlraum vorfand, der allseitig von interstitiellem Gewebe umgeben ist, das häufig eine concentrische Anordnung um den Raum zeigt. Es kann nach Beschreibung und nach Abbildung keinem Zweifel unterliegen, dass es sich, wie auch Cohn annimmt, und wie früher schon Rabl gezeigt hat, um „die letzten Reste atretischer Follikel handelt, deren Theca sich schon völlig zu interstitiellem Gewebe umgewandelt hat."

Montuoro machte seine Untersuchungen am Kaninchenovarium und fand, dass die eigenthümlichen Zellen erst vom 2. und 3. Monat nach der Geburt $a b$ auftreten und da noch in geringer Anzahl, ein Befund, der mit den Untersuchungen von Limon, der um den 4. Monat die ersten interstitiellen Zellen beim Kaninchen beobachtete, ziemlich gut übereinstimmt. Montuoro hält den Namen „interstitielle Zellen ${ }^{*}$ für nicht passend, ausserdem sei derselbe bereits für andere Zellen vergeben und schlägt daher die Bezeichnung Markzellen (cellule midollari) vor. Da jedoch die Genese der Zellen der Markstränge noch nicht genügend geklärt ist, so ist der Name Markzellen nur geeignet, weitere Verwirrung anzurichten. Die Zellen fand Montuoro stets sehr fettreich, ihr Fett löst sich, wie er sagt, im Canadabalsam rasch und findet dieses Verhalten ganz in Uebereinstimmung mit dem Befunde von Limon, welcher jedoch eine Löslichkeit in Xylol, nicht in Canadabalsam festgestellt hatte. Montuoro kommt zum Schlusse seiner, manche Unklarheiten enthaltenden Arbeit zu der Ansicht, dass die interstitiellen Zellen ein specifisches Sekret liefern, das auf dem. Wege der Lymphbahnen in das Blut gelange.

Fassen wir das bisher Erörterte noch einmal kurz zusammen, so ist zunächst zu betonen, dass wie v. Ebner und ferner Waldeyer in dem Handbuch der Entwicklungsgeschichte von 
0. Hertwig hervorhebt, sehr verschiedene Bildungen in den Eierstöcken vorkommen, welche den echten Marksträngen ähneln. Von den echten Marksträngen und ibrer Histogenese sehen wir hier ganz ab und beschränken uns auf folgende Feststellungen:

Es ist bei einer Anzahl von Thieren (bei den Nagern und bei der Katze durch Rabl, bei Kaninchen, Maus, Ratte, Meerschweinehen, Fledermaus, Maulwurf, Igel durch Limon, bei dem Kaninchen durch Frz. Cohn) durch überzeugende Untersuchungen festgestellt, dass die atretischen Follikel bei diesen Thieren nicht vollständig zu Grunde gehen, sondern dass der durch das Verschwinden des Eies, des Follikelepithels und der Follikelflüssigkeit entstandene Defect durch die hypertrophischen Zellen der Theca interna gedeckt wird. Diese Zellen behalten auch nach dem Zugrundegehen der Follikel ihre epitheloide Gestalt, ihre Anordnung und ihre sonstigen Eigenschaften bei. Unter diesen ist nach den Befunden von Bouin-Limon und von Frz. Cohn vor Allem die Production fettartiger Substanzen in ihrem Zellleib zu nennen. Bouin-Limon, denen sich Frz. Cohn anschliesst, schreiben diesen Zellen eine innere Sekretion zu und bezeichnen das Gebilde als interstitielle ovarielle Drüse (glande interstitielle de l'ovaire).

Regaud und Policard haben in den Bindegewebszellen des lebensfrischen (nicht atretischen) Follikels fettähnliche Substanzen im Hundeovarium gefunden, die sie als Producte einer inneren Sekretion auffassen.

Die Einlagerungen in den Luteïnzellen des Corpus luteum, die Regaud und Policard beim lgel fanden, fassen die Autoren ebenfalls als specifische Producte der Zellthätigkeit auf. Frz. Cohn wies die Protoplasmaeinlagerung auch im Corpus luteum des Kaninchen nach und stellte nach seiner Ansicht die BornFränkel'sche Theorie auf eine anatomisch fundirte Basis. Die Theorie nimmt bekanntlich auch beim Menschen eine innere Sekretion der Corpus luteum-Zellen an. Wallart hat neuerdings die fettähnlichen Körper auch in den epitheloiden Zellen der Theca interna von Follikelcysten an einem Blasenmolenovarium nachgewiesen.

Ueber die Persistenz der Zellen der Theea interna atretischer Follikel, wie sie von den genannten Autoren bei verschiedenen Thierspecies beobachtet wurden, ist bisher beim Menschen nichts festgestellt worden. Bei der Follikelatresie im menschlichen 
Ovarium tritt eine Hypertrophie der Theca interna-Zellen nicht ein oder ist nur sehr gering, das gleiche gilt nach Waldeyer für die daraufhin untersuchten Ovarien der Affen; der Follikelraum wird meist mit lockerem Bindegewebe ausgefüllt, die Theca degenerirt hyalin.

Rabl zwar erwähnt, dass auch manchmal beim Menschen eine Hypertrophie der Theca interna-Zellen atretischer Follikel eintreten könne, doch ist nicht sicher, ob dabei nicht schwangere Ovarien mit untergekommen sind. Wenigstens bringt Rabl vermuthungsweise die stark ausgeprägte Wucherung der Theca-Zellen mit der bestehenden Schwangerschaft in Zusammenhang. Es ist demnach ein Nachweis der eigenthümlichen epitheloiden Zellen am Orarium nicht schwangerer Frauen bisher nicht erbracht.

Ich möchte hier nochmals betonen, dass die hier gemeinten epitheloiden Zellen nicht verwechselt werden dürfen mit den dickeren, kürzeren Zellen, welche sich fast in jedem Ovarium zerstreut zwischen den gewöhnlichen Bindegewebszellen, namentlich in der Umgebung der Gefässe gefunden wurden, und auf deren Vorkommen bereits früher hingewiesen wurde [Tourneux, Romiti, Nagel, Guain, Waldeyer]'). Ersterer Autor hat sie als interstitielle Zellen wegen ihrer Aehnlichkeit mit den interstitiellen Zellen des Hodens bezeichnet. Genetisch gehen sie wahrscheinlich aus den gewöhnlichen Stromazellen hervor, ebenso wie die epitheloiden Zellen der Theca interna grösserer Follikel. Für diese Annahme lassen sich namentlich später zu besprechende Beobachtungen in der Schwangerschaft verwerthen. $\mathrm{Da}$ die interstitiellen Zellen 'Tourneux' und die epitheloiden Zellen der Theca interna wachsender sowie der erst später zu besprechenden Theca-Lutein-Zellen atretischer Follikel den letzten gleichen Ursprung aus der Stromazelle haben, so ist im Grunde genommen eine ganz scharfe Trennung, wenigstens in histogenetischer Hinsicht nicht möglich; allein wegen der weitgehenden morphologischen Verschiedenheit und der weiteren Differenzirung der ThecaLuteïnzellen ist eine Trennung zweckmässig und geboten.

Während nun beim Menschen im nicht schwangern Zustand die Zellen der Theca interna atretischer Follikel

1) Die Zellen finden sich auch noch bei verschiedenen anderen älteren Autoren erwähnt, allein es ist manchmal recht schwer, oder ganz unmöglich, zu entscheiden, welche Gebilde die Untersucher im Auge gehabt haben. 
eine nennenswerthe Vergrösserung und Formveränderung nicht erfahren, stellt sich dagegen während der Schwangerschaft eine solche nach meinen Untersuchungen regelmässig ein. Die Zellen vermehren und vergrössern sich, nehmen epitheloide Gestalt an, zeigen einen gelblichen Inhalt und nähern sich in ihrem äusseren Habitus sehr den Luteïnzellen des Corpus luteum. Da ich aber aus weiter hinten zu erörternden Gründen an der genetischen Verschiedenheit der beiden Zellarten festhalte, die ersteren für bindegeweblichen, die Zellen des Corpus luteum für epithelialen Ursprungs halte, möchte ich, wie bereits erwähnt, für die vergrösserten Zellen der Theca interna den Ausdruck Thecaluteïnzellen vorschlagen, womit den leicht eintretenden Verwechslungen der beiden Zellenarten entgegengearbeitet werden soll. Im Folgenden werde ich die veränderten Zellen der Theca interna mit diesem Namen belegen.

Ich habe die alte und die neue Literatur daraufhin durchgesehen, ob bereits von anderer Seite auf die Hypertrophie der Zellen der Theca interna während der Schwangerschaft hingewiesen worden ist. Die meisten Autoren erwähnen davon nichts, andere geben mehr oder minder zutreffende Beschreibungen, ohne jedoch die Veränderungen mit der Schwangersehaft in causalen $\mathrm{Zu}$ sammenhang zu bringen. Nur Sinéty spricht die Hypertrophie der Theca interna an atretischen Follikeln als eine regelmässige Erscheinung der Gravidität an, und in allerneuester Zeit Wallart; ich komme auf ihre Arbeiten noch ausführlicher zu sprechen.

Ich möchte zugleich auch die Arbeiten besprechen, in denen die Veränderungen bereits beschrieben sind, ohne dass die Autoren einen Zusammenhang mit der Schwangerschaft annahmen.

Hierher gehört vielleicht bereits eine Beobachtung über die Rückbildung ungeplatzter Follikel von His (1. c. 1865, S. 197), die ich wörtlich anführen will:

An den gut injicirten Ovarien einer Frau, welche in Folge einer anderweitigen Erkrankung vor der Zeit geboren hatte und 2 Tage nach der Geburt gestorben war, fand ich in grösseren, etwa $1 \mathrm{~cm}$ messenden Follikeln die Innenwand gebildet durch eine gefässlose, eigenthümlich gelbliche und von viel schwarzem Pigment durchsetzte Schicht. Kleinere Follikel derselben Ovarien zeigten an dieser Schicht nichts, sondern waren mit einer anscheinend völlig normalen Interna versehen. Die genauere Verfolgung der Schicht zeigte nun, dass sie, wie dies auch ibrer Lagerung entsprach, nichts anderes war als die veränderte innere Follikelhaut. An verschiedenen Stellen sah man permeable Gefässstämmchen ein Stück weit in dieselbe eindringen, um dann mit einem Male 
zu enden und in einen fibrösen Strang sich fortzusetzen. Das Pigment, in kleinen Zellen eingeschlossen, folgte nachweisbar ähnlichen verzweigten und unter einander bogenförmig zusammenhängenden Strängen, den Resten obliterirter Blutgefässe. Im Uebrigen hatte das Gewebe eine ziemlich homogene Beschaffenheit gewonnen und war in demselben ausser einer feinen, radiären Streifung nicht viel wahrzunehmen. Ueber die Eier und über die Granulosa der fraglichen Follikel kann ich nichts aussagen, indem mir das Präparat nicht frisch genug zuging."

Sinéty, dessen Originalarbeit ich nunmehr ${ }^{1}$ ) erhalten habe, glaubt einmal einen Unterschied zwischen dem Corpus luteum menstr. und dem Corpus luteum gravid. in histologischer Beziehung machen zu müssen. Das letztere zeichne sich von dem ersteren durch die Hypertrophie der Membrana follieuli propria aus (er bezeichnet die Lage als „tissu lymphatique réticulé", modern würde man Luteïnzellenlager sagen). Das Gleiche gelte auch von den nicht geplatzten Follikeln. Ausserhalb werde der Hohlraum des atretischen Follikels durch ein lockeres Bindegewebe (Sinéty gebraucht den Ausdruck Schleimgewebe, tissu muqueuse) ersetzt, die Tunica propria zeige dabei keine Hypertrophie ihrer zelligen Elemente. Diese Hypertrophie trete jedoch an den während der Schwangerschaft verödenden Follikeln deutlich hervor und zwar sei sie um so beträchtlicher, je weiter die Schwangerschaft fortgeschritten ist.

Wenn auch der Mittheilung keine Abbildung beigegeben ist, so geht soviel doch klar hervor, dass Sinéty mit den zelligen Elementen die Zellen der Theca interna meint, und dass er somit als erster die Hypertrophie dieser Elemente an atretischen Follikeln des Menschen während der Schwangerschaft gesehen hat. Freilich ist das Material, auf das er seine Behauptungen stützt, unzureichend, denn er erwähnt nur eine Schwangerschaft von 2-3 Monaten, ferner eine von 6 und endlich eine von 10 Monaten. Sinéty legt dem Umstande, dass sich der gelbe Körper der Gravidität von dem der Menstruation histologisch unterscheiden lasse, eine grössere Bedeutung bei, wie den histologischen Unterschieden zwischen atretischen Follikeln in und ausserhalb der Schwangerschaft. (Gazette des hôpitaux. 1877. p. 727.)

Lebedinsky hat der Ansicht von Sinéty gegenüber den Satz aufgestellt, dass „die Zellen der perifolliculären Schicht atresirender

1) Zur Zeit meiner vorläufigen Mittheilung im Centralblatt für Gynäkologie, 1905, No. 19 hatte ich die Originalarbeit noch nicht in meinen Händen. 
Follikel auch ausserhalb der Schwangerschaft hypertrophisch werden können und dass sie in jeder Hinsicht identisch sind mit den Zellen des wahren Corpus luteum auf der Höhe der Entwickelung". Man sucht jedoch bei Lebedinsky vergebens nach dem Beweismaterial für diesen Ausspruch. Worüber er berichtet, ist einzig und allein über einen eigenthümlichen atretischen Follikel in dem Ovarium eines nicht ganz ausgetragenen, todtgeborenen Mädchens. Dieser atretische Follikel enthielt einen 1,3 cm langen und $1 \mathrm{~cm}$ breiten geronnenen Inhalt und eine $0,2 \mathrm{~cm}$ dicke Wand, die aus den Zellen der gewucherten perifolliculären Schicht gebildet wird. Man hat es demnach mit einer Hypertrophie der Theca interna an einem atretischen Follikel eines Neugeborenen zu thun, eine gewiss interessante Beobachtung, die ich aus eigener Beobachtung an einem Falle bestätigen kann, auf den ich wegen seiner principiellen Wichtigkeit für die Beurtheilung der Theca-Luteïnzellenwucherung noch zurückkommen werde. Allein diese Beobachtung an einem Neugehorenen gestattet nicht die Schlussfolgerung, dass dasselbe Phänomen auch bei der Erwachsenen und ausserhalb der Schwangerschaft eine regelmässige Erscheinung ist.

Schottländer beschreibt die Ovarien von 4 schwangeren bezw. puerperalen Frauen (im Ganzen 6 Ovarien), von denen 2 an acuten septischen Processen zu Grunde gingen, während die 2 anderen starken Blutungen sub partu erlagen; nur die Ovarien der 2 letzteren stellen demnach ein einwandsfreies Beobachtungsmaterial dar. Schottländer erwähnt nichts von Verschiedenheiten in der Rückbildung atresirender Follikel in und ausserhalb der Schwangerschaft; doch zeigen die 2 Figuren 39 und 40, welche den Ovarien von frisch entbundenen Frauen entnommen sind, eine deutliche Hypertrophie der Theca interna: (Arch. f. mikrosk. Anat. Bd. 41.)

Bulius beschreibt in seiner Arbeit: „Osteomalacie und Eierstock" die Ovarien einer Osteomalacischen, die durch Kaiserschnitt am Ende der Schwangerschaft entbunden wurde (Fall 2) und charakterisirte die Tunica interna folgendermassen: "Diese Zellen haben einen grossen Protoplasmaleib, der meist durch Aufnahme von Blutfarbstoff sich bräunlich gefärbt hat. Ihre Gestalt ist sehr verschieden, bald rundlich, bald geschwänzt, bald polygonal. Der runde bläschenförmige Kern färbt sich nur schwach mit Hämatoxylin; nur die Kernkörperchen sind besser gefärbt. Diese Zellen liegen meist in Reihen beisammen, die durch schmale Spindelzollenzüge und Gefässe von einander geschieden sind. Schon bei 
schwacher Vergrösserung lassen sie sich als ein brauner Saum, der sowohl normale Follikel wie jene epithellosen Hohlräume in einer Breite von $0,1 \mathrm{~mm}$ und darüber umgiebt, wahrnehmen." An den 5 übrigen Eierstockspaaren, die von nicht schwangeren osteomalacischen Frauen stammten, wird ein so starkes Hervortreten der Luteinzellenschicht nicht geschildert. Bulius sieht die Veränderung in Fall 2 als zufällige an und bringt sie in keinen Zusammenhang mit der Schwangerschaft.

H. Rabl, der sich mit der Follikelatresie in eingehender Weise beschäftigt hat, beschreibt auf $\mathrm{S}$. 149 das Ovarium einer schwangeren Frau und giebt eine Abbildung von einem atretischen Follikel in Fig. 9, welche die Luteinzellenschicht in ausgeprägter Form erkennen lässt. Er meint, möglicher Weise haben sich jene Follikel während der Gravidität entwickelt und wieder zurückgebildet. "Uebrigens kann ich über diesen Punkt nur Vermuthungen aufstellen."

Auch Böshagen fand an den Ovarien einer Eklamptischen und einer Frühgeburt eine Wucherung der Theca interna. Allein er hält selbst sein Materials nicht für ausreichend, um die Entscheidung zu treffen, ob es sich um eine regelmässige Erscheinung in der Schwangerschaft handelt.

Endlich hat Wallart die Ovarien von 6 im Puerperium gestorbenen Frauen beschrieben und auf Grund dieses Material die Ansicht ausgesprochen, dass die Luteinzellenwucherung in der Schwangerschaft regelmässig vorkomme. Jch habe bereits in einer Erwiderung im Centralblatt f. Gyn. (1905, No. 19) auf die Unzulänglichkeit seines Materials hingewiesen. Ich möchte hier nur noch hervorheben, dass Ovarien puerperaler Frauen wegen der rasch eintretenden regressiven Veränderungen wenig geeignet sind, wie meine Untersuchungen zeigen und dass Ovarien von an septischen Erkrankungen Gestorbenen am besten zur Klärung physiologischer Fragen gar nicht verwendet werden. Immerhin stehe ich nicht an, 1 bezw. 3 seiner Beobachtungen als beweiskräitig anzusehen, doch genügt ein solches Material nicht, um allgemeine Schlüsse auf physiologische Verhältnisse zu ziehen.

Bevor auf weitere Fragen eingegangen werden soll, will ich zunächst über das von mir untersuchte Material berichten. Dasselbe umfasst 37 Ovarien schwangerer und puerperaler Fraven, ein Material, gross genug, um mit einiger Sicherheit Rückschlüsse auf allgemeine Verhältnisse zu machen. Die Conservirung hatte ent- 
weder in Alkohol, die neueren Präparate in Formalin und in Kayserling'scher Lösung stattgefunden, einige Stückchen frisch gewounener Präparate wurden in Flemming'scher Lösung zur Darstellung der Fetteinschlüsse und der Kerntheilungsfiguren gehärtet. Die Färbung der Präparate (meist Paraffineinbettung) geschah mit Hämatoxylin-Eosin, häufig auch mit der van Giesonschen Lösung und einige Male mit Saffranin und mit Sudan III.

Die grösste Wichtigkeit zur richtigen Beurtheilung der einschlägigen Verhältnisse kommt der Gewinnung der Präparate zu. Nach meinen Erfahrungen, wie ich dies gegenüber Wallart im Centralbl. f. Gyn. bereits ausführlich gethan habe, genügt nur operativ gewonnenes Material oder solches, welches aus der noch Jebenswarmen Leiche entnommen wird, allen berechtigten Ansprüchen. Dagegen darf das Material, welches von an fieberhaften oder auszehrenden Krankheiten verstorbenen Frauen herstammt, oder weiches erst Stunden und Tage lang nach erfolgtem Exitus durch Section gewonnen wurde, nur mit aller Vorsicht verwerthet werden und kann meines Erachtens allein nicht die Grundlage für Beurtheilung physiologischer Verhältnisse abgeben. Desgleichen sind auch die Ovarien von puerperalen Frauen, auch wenn sie an nicht fieberhaften Krankheiten zu Grunde gegangen sinả, wenig geeignet, da hier die Rückbildungsvorgänge bereits im vollen Gange sind.

Ich theile daher mein Material zweckmässig in 3 Gruppen ein. Die erste Gruppe umfasst jene Fälle (18 im Ganzen), in denen die Ovarien frisch durch Operation oder durch Entfernung aus der lebensfrischen Leiche gewonnen wurden. Auf sie hauptsächlich stätzen sich meine Behauptungen und sie allein sind meines Erachtens geeignet, ein einwandsfreies Material zu liefern. Wie viel gerade beim Studium der Ovarialveränderungen auf ein einwandfreies Material ankommt, wird mir Jeder bestätigen, der sich eingehender mit dieser Frage beschäftigt hat.

Die 2. Gruppe umfasst eine Reihe von Fällen, die nicht einwandfrei sind, die durch verschiedene Einflüsse (ungenügende Conservirung, fieberhafte Erkrankungen, späte Section) gelitten haben; doch sind bei den verwendeten Ovarien - andere mussten als unbrauchbar ganz bei Seite gelassen werden - die Befunde so, dass sie weiterhin zur Stütze der Ergebnisse am einwandfrejen Material verwendet werden konnten.

Die 3. Gruppe enthält die puerperalen Fälle; sie ist 
klein, meist sind die Frauen infectiösen Krankheiten erlegen, doch gestatten die Präparate im allgemeinen Rückschlüsse auf die Rückbildung der beobachteten Veränderungen zu machen.

\section{Gruppe.}

Fall 1. Br., 27 J. alt, I p. Rechtsseitige Tubargravidität von ca. 6 Wochen. Doppelseitige adhäsive Entzündungen in den Adnexen. Coeliotomie wegen Ruptur am 4. 12.04. Exitus an acuter Enteritis, wahrscheinlich in Folge eines genommenen Abortivmittels.

Makroskopischer Befund an den Ovarien: Das linke Ovarium wird bei der Operation in starke Adhäsionen eingebettet gefunden, seine Grösse ist auch an dem Leichenpräparat nicht genau zu bestimmen.

Rechtes Ovarium, das mit der geplatzten Tube entfernt und in Kayserling conservirt wurde, misst 4,5:1,4:1.6 cm mit sehr schönem Corpus luteum (2:1,8 cm), das in der Mitte einen cystischen Hohlraum von $0,7: 0,5 \mathrm{~cm}$ enthält. Die übrigen Theile des Ovariums sind ziemlich solide, Cysten sind nicht zu sehen.

Mikroskopischer Befund des Corp. lut.: Das Corp. lut. ist von dem Ovarialstroma deutlich abgegrenzt durch eine lockere Bindegewebsschicht mit sehr reichlichen Gefässen, die in ihren äusseren Theilen sich aus spindelförmigen Zellen, zum Theil ein wenig gequollen, in den inneren Abschnitten aus ebensolchen, die jedoch an verschiedenen Stellen von mehr epitheloiden Zellen durchsetzt sind. Die Kerne sind rundlich oder oval, grösser, zeigen mittlere Färbung, das Protoplasma hat an Umfang zugenommen, weist eine gleichmässig röthliche Farbe auf, manchmal zeigt es auch gelbliche Einlagerungen. Während bei den kleineren Zellen der Kern noch recht gut tingirt ist, hat dagegen bei den Zellen mit dem grossen Protoplasma der Kern nur wenig Farbe angenommen und zeigt pyknotische Erscheinungen. Diese Art von Zellen lassen sich in den Septen zwischen den Luteinzellen weit in das Corpus luteum hinein verfolgen. Bei schwacher Vergrösserung scheint die Abgrenzung dieser Zellen gegen die Corp. lut.-Zellen eine haarscharfe zu sein, bei stärkerer Vergrösserung erkennt man jedoch, dass hie und da die Zellen die gleiche Beschaffenheit wie die echten Luteïnzellen angenommen haben und dass eine Unterscheidung nicht mehr möglich ist. Man könnte in diesen Fällen in der That daran denken, dass die Luteïnzellen aus den Epitheloidzellen der Theca interna hervorgegangen sind. Jedoch glaube ich nicht, dass man aus dem morphologischen Verhalten der Zellen allein einen solchen Rückschluss machen darf, man müsste nothwendig ihre Entwickelung von den ersten Stadien an beobachtet haben.

Die Gefässe in dieser Schicht zeigen eine mässige Verdickung ihrer Wandung, die zum Theil die Media, zum Theil die Intima betrifft; auch Blutreste findet man in ihre Wand eingelagert; die Endothelien sind hypertrophirt und sitzen nur locker der Unterlage auf. Manchmal ist es durch die Bindegewebshypertrophie zu einem fast vollständigen Verschluss des Gefässes gekommen.

An die kleinen epitheloiden Zellen schliessen sich die ausgebildeten Luteïnzellen an. Die an der Peripherie gelegenen Luteïnzellen zeichnen 
sich durch ihre Grösse aus, sie haben einen grossen Protoplasmaleib, der durch Eosin eine leicht röthliche Farbe angenommen hat. Bei ganz starker Vergrösserung kann man erkennen, dass die Structur nicht ganz homogen ist, sondern dass sie einen mehr netzartigen Charakter trägt und dass einzelne kleine Granula eingelagert sind. Die Contouren der Zellen sind zum Theil stark verwischt, stellenweise vollständig verschwunden, manchmal sind die Zellen in toto ansgefallen. Die Kerne haben verschiedene Grösse, bald eine runde, bald eine ovale und eckige Form, sind im Ganzen schlecht gefärbt, lassen bei starker Vergrösserung ein fadenförmiges Netzwerk von Chromatin oder Vertheilung desselben in Form von kleinsten Punkten erkennen und weisen 1 oder 2 deutliche Kernkörperchen auf. Oft sind die Kerne eben noch als Jeicht gefärbte Gebilde $z \mathfrak{u}$ beobachten, nicht selten ist vom Kern garnichts zu erkennen und die ganze Zelle ist der hyalinen Nekrose verfallen.

Weiter gegen das Centrum zu sind zwischen die Luteïnzellen kreisförmige Anhäufungen von meist einkernigen Rundzellen eingestreut, die in den mittleren Theilen häufig zu einer vollständigen Nekrose des Gewebes geführt haben. Das Centrum solcher Herde enthält ein Netz aus Fibrin, in das einzelne Zelltrümmer eingelagert sind. In der Umgebung dieser Herde haben die Luteïnzellen am stärksten gelitten und sind grössten Theils der hyalinen Degeneration verfallen; die weiter entfernten Luteïnzellen, namentlich die an der Peripherie haben jedoch unter der kleinzelligen Infiltration, die offenbar vom Centrum des gelben Körpers ausgegangen ist, nicht gelitten.

An die Zone mit den Rundzellenanhäufungen schliesst sich eine ziemlich breite Schicht von Fibrin, in dem einzelne Spindelzellen, manchmal auch Zellen von sternförmiger Gestalt, ferner reichlich Reste rother Blutkörperchen und einige Zelltrümmer enthalten sind. Diese begrenzt die geräumige Höhle im Corpus luteum, die ohne Inhalt ist.

Fassen wir noch einmal den Befund an dem Corpus luteum zusammen, so müssen wir sagen:

Die Abgrenzung des Corpus luteum gegen die Umgebung ist zwar makroskopisch ziemlich scharf, allein mikroskopisch erkennt man, dass die epitheloiden Zellen der. Theca interna an der Peripherie noch vorhanden sind und ohne scharfe Grenze zwischen die Zellen der Theca externa an einzelnen Stellen sich erstrecken. Es ist demnach an dem 6 Wochen alten Corp. lut. grav. die definitive Abgrenzung gegen die Theca ext. einer- und gegen die Luteïnzellen andererseits noch nicht erfolgt. Dieser Befund stimmt mit den Erhebungen Rabl's überein, der die nkleinen epitheloiden" Zellen bis zum Ende des 2. Monats verfolgen konnte. Trotzdem die Abgrenzung von Kapsel- und Corp. lut.-Substanz noch nicht beendigt ist, zeigen sich bereits Rückbildungserscheinungen an den „kleinen epitheloiden" Zellen, an den Gefässen, die theilweise bis zum völligen Verschlusse stenosirt sind und vornehmlich an den eigentlichen Luteïnzellen selbst. Man könnte die degenerativen Vorgänge 
in den Luteinzellen mit der kleinzelligen Infiltration und den entzündlichen Processen in den weiter nach dem Centrum zu gelegenen Partien des Corp. lut. in ursächlichen Zusammenhang bringen. Zweifellos ist auch die theilweise vollständige Nekrose der Zellen in der Umgebung der entzündlichen Herde darauf zurückzuführen; allein nicht erklärt können werden die degenerativen Processe an den Luteïnzellen in den peripheren Theilen, wo von entzündlichen Processen nichts mehr festzustellen ist. Auch sonst in der Ovarialsubstanz lassen sich nirgends entzündliche Herde und degenerative Processe constatiren. Es scheint demnach das Centrum des Corp. lut. allein von den entzündlichen Vorgängen befallen worden zu sein, wiederum ein neuer Beweis, wie sebr der gelbe Körper zu Infectionen prädisponirt ist, wie dies die Arbeiten von Langer, Orthmann gezeigt haben.

Die übrigen Theile des Ovariums zeigen folgende Befunde:

Das Oberfächenepithel ist zum grossen Theil noch erhalten, die Albuginea des Ovariums ist deutlich ausgebildet, an einzelnen Stellen erkennt man eine deutliche Auflockerung und Vermebrung und ungewöhnlich starke Vascularisirung der obersten bindegewebigen Schicht, sodass auch cystiscle Einschlüsse von Oberflächenepithel zu erkennen ist. Von ausgesprochener Deciduazellenbildung ist jedoch keine Rede. Von der Oberfiäche ziemlich entfernt liegend sind grössere Haufen von Zellen inmitten im Stroma, die in inrem morphologischen Verhalten vollständige Uebereinstimmung mit den Deciduazellen in der Uterusschleimhaut zeigen: grosse, polyedrische Zellen mit einem breiten, blassen und ungefärbten Protoplasmaleib und einem mittelgrossen Kern, der in der Regel nur schwach gefärbt ist und körniges Chromatin zeigt. An verschiedenen Zellen scheint es, als ob das Protoplasma mit feinkörnigem, gelblich-weissem Blutpigment angefüllt sei. Zwischen diesen Zellen liegen einzelne Stromazellen, die gewöhnlichen Bau zeigen oder nur leicht gequollen sind. Es handelt sich um die letzten Reste von Luteïnzellen in einem Corpus fibrosum. Wir wollen auf diese Zellen noch an anderer Stelle zurückkommen.

Das übrige Stroma weist keine Besonderheiten auf. Es sind Verdichtungen und Lichtungen in demselben, wie sie in jedem Ovarium angetroffen werden. Primordialfollikel sind für eine 27jährige Person spärlich vorhanden, einzelne gut erhalten, andere in Rückbildung begriffen, die sich in nichts von der ausserhalb der Schwangerschaft unterscheidet. Mehrere Corpora candicantia und fibrosa; in ihrer Nähe finden sich auch obliterirte Gefässe mit hypertrophirten und theilweise vollständig hyalin entarteten Gefässwänden.

Höheres Interesse beanspruchen die grösseren Follikel. Da ist einer zu sehen, dessen Epithel verloren gegangen, der mit einer homogenen Masse ausgefüllt und dessen $W$ and nur mit einigen wenigen übereinander gelegenen typischen Zellen der Theca interna ausgekleidet ist. An einigen Stellen der Circumferenz sind auch diese einer hyalinen Degeneration verfallen. Solche Bilder kann man ausserhalb der Schwangerschaft ebenfalls sehen. 
Zwei andere Follikel haben ihre ursprüngliche runde Gestalt verloren und haben eine $\lambda$-förmige Form angenommen (Taf. VIII, Fig. 4). Dies geschah dadurch, dass an verschiedenen Stellen die Follikelwand durch stärker wuchernde Zellen der Theca interna gegen das Lumen vorgebuchtet ist, sodass sie wulstartige Vorsprünge bilden. Das Follikelepitheil ist in mehrfacher Schicht noch erhalten, die Glasmembran ist nicht sichtbar. Die Zellen der Theca interna sind vermehrt, in 10-20facher Reibe übereinander, sind vergrössert, leicht epitheloid, sehen gelblich aus, ihre Längsachse verläuft senkrecht zur Circumferenz des Follikels, die Abgrenzung gegen die Theca externa ist nicht sehr scharf. Weiter fortgeschritten ist die Entwickelung der Theca interna-Schicht bei einem anderen atretischen Follikel, hier ist das Epithel bereits völlig abgestossen. Diese Bilder habe ich in gleicher Intensität ausserhalb der Schwangerschaft selten zu Gesicht bekommen.

Grössere Follikel, darunter ein fast linsengrosser, sind noch mit 5-6reihigen Epithelien ausgekleidet (Glasmembran nicht sichtbar), darunter die vergrösserten Zellen der Theca interna, die sich in 8-10, manchmal auch bis 15 facher Reihe übereinander lagern. Ihr Protoplasma hat ein gelbliches Aussehen, die Läugsachse der Zelle ist wegen der grösseren Spannung meist parallel oder fast parallel zur Peripherie des Follikels. Andere fast gleich grosse Follikel zeigen die Luteïnzellenhyperplasie nicht oder nur in weit geringerem Grade, in einem Follikel ist das Epithel ganz und die Zellen der Theca interna zum grossen Theil verloren gegangen.

Es sind demnach die Schwangerschaftsveränderungen im Ovarium erst in der Ausbildung begriffen, noch nicht zu voller Entwicklung gediehen: an der Ovarialoberfläche ist stellenweise die Hypertrophie und ödematöse Durchtränkung des Stromas mit starker Gefässentwicklung vorhanden, an einzelnen cystischen und in Rückbildung begriffenen Follikeln ist eine mässige Vergrösserung der Zellen der Theca interna mit epitheloidem Charakter und Luteineinlagerung in das Protoplasma zu beobachten.

Ich möchte noch kurz auf die in Taf. VIII, Fig. 4 wiedergegebene deformirende Follikelatresie zurückkommen, weil sie leicht zu einer anderen Deutung Veranlassung geben kann und gegeben hat. Bulius und Kretschmar geben in Fig. 11 ihrer Arbeit: Angiodystrophia ovariorum eine Abbildung, die in der Figurenerklärung als ein "Follikel mit Wucherung des Epithels" angesprochen wird und von dem sie annehmen, dass daraus ein Ovarialkystom sich entwickeln könne. Der Follikel zeigt starke Faltung und die Entstehung der Faltung erklären sich die Autoren durch Sprossen des Epithels, wobei das Bindegewebe secundär folgt. Die Figur muss jedoch, wie dies bereits Schottländer und Rabl, die anch von den Steffeck'schen Abbildungen annehmen, dass solche Bildungen vorgelegen haben, gethan haben, 
als ein atrophirender Follikel, der eine Wucherung des Epithels nicht erkennen lässt, angesprochen werden. Nach Resorption des Liquor folliculi sinkt in Folge erhöhten Seitendrucks die Follikelwandung stark zusammen; wie unsere Eigur zeigt, kann die starke Entwicklung der Zellen der Theca interna ein weiteres Einbuchten der Wandungen herbeiführen. Chromatolytische Vorgänge am Follikelepithel schliessen für unsere Fälle mit Sicherheit progressive Veränderungen am Epithel aus. Auch an Ovarien nicht schwangerer Frauen habe ich einige Male die genannten Bildungen beobachtet und fast nie chromatolytische Processe in den Follikelepithelien vermisst.

Fall 2. Scheuerer, 41 J., VIII para. Uterus wurde wegen eines beginnenden Portiocarcinoms der hinteren Lippe vaginal total exstirpirt. Im Uterus befand sich ein etwa 7 Wochen alter Fötus in frischem Zustande. Mikroskopische Untersuchung von Decidua zeigte keine entzündlichen Veränderungen.

Beide Ovarien sind ungewöhnlich klein, das eine ist $3: 0,6 \mathrm{~cm}$ breit und $1,7 \mathrm{~cm}$ hoch und enthält ein Corpus luteum, das fasi das ganze Ovarium einnimmt $(1,1: 0,9: 1,1 \mathrm{~cm})$, in der Mitte eine spindelförmig homogene Zone aufweist, um die ein halbmondförmiges Blutextravasat gelagert ist. Das rechte Ovarium, 2:1,3 besteht in seiner Gesammtheit fast nur aus einem Corpus luteum, das in der Mitte einen soliden, weisslich aussebenden Kern zeigt.

Mikroskopische Untersuchung: Soweit noch Ovarialgewebe vorhanden ist, zeigen sich einige spärliche Primärfollikel und verschiedene Corpora albicantia. Die Ovarialoberfläche zeigt keine Veränderung, das Epithel ist grösstentheils abgestossen. Ein atretischer Follikel mit ausgebildeter Luteïnzellenwucherung ist nicht zu ermitteln; jedoch muss ein Gebilde als Anfang einer Luteïnzellenwucherung in einem atresirenden Follikel angesprochen werden. Der Follikel ist Sförmig gewunden, seine Wände stark vorgebuchtet, sein Lumen enthält ausser einigen abgesprengten Follikelzellen keinen Inhalt, das Follikelepithel sitzt noch in Form einiger Zellen der Wand auf, doch ist eine scharfe Grenze nicht vorhanden, die Glasmembran fehlt vollständig. Dagegen sind die Zellen der Theca interna dicker und grösser geworden, ihre Richtung ist radiär zum Follikellumen. Die Schicht ist reichlich von Gefässen durchsetzt und gegen die Theca externa ziemlich scharf abgesetzt.

Das Bild erinnert an das in Fig. 4 wiedergegebene, doch ist im vorliegenden Falle die Entwickelung der Theea interna-Zellen nocb geringer.

Die mikroskopische Untersuchung bestätigt ferner das Vorbandensein von 2 Corpora lutea von ungefähr gleicher Entwicklungsstufe. Dies ist auffällig, da nur eine Frucht im Uterus sich befand, das zweite $\mathrm{Ei}$ ist demnach unbefruchtet zu Grunde gegangen, ein 
Beweis, dass nicht in jedem Falle beim Freiwerden zweier Eier beide befruchtet werden müssen. Bei beiden ist die Abgrenzung gegen das Stroma vollendet, die umgebende faserige Bindegewebsschicht enthält längliche Gefässdurchschnitte, von den kleinen epitheloiden Zellen der Theca interna sind in dem Corp. lut. des rechten Ovariums nur noch ganz spärliche Exemplare, meist nur an den Stellen, wo die bindegewebigen Septen zwischen die Luteïnzellen eindringen, nachzuweisen und bei diesen sind die Zellconturen verwischt, das Protoplasma mit homogenem Netzwerk, die ovalen Kerne schlecht gefärbt. Bei dem Corp. lut. des linken Ovariums sind diese Zellen noch reichlicher vorhanden, auch noch etwas besser gefärbt, doch fehlen sie auf weite Strecken der Peripherie vollständig. Dieser geringe Unterschied zwischen den beiden Corpora lutea ist wohl auf die Verschiedenheit des Ernährungszustandes zurückzuführen, die sich im geringen Maasse auch in dem Verhalten der Luteïnzellen offenbart. Im linken Corp. lut. ist die Luteïnschicht nur schmal, zwischen die Zellen sind bindegewebige Züge von Spindelzellen eingewachsen, die die Zellen in Gruppen von meist nur wenigen Exemplaren zerlegen, die Zellleibconturen sind unscharf oder ganz geschwunden, das Protoplasma leicht bläulich gefärbt und meist homogen, nicht selten durch kleinere und grössere Vacuolen unterbrochen. Der Kern meist schwach gefärbt, von ovaler oder unregelmässiger Gestalt, das Chromatin im Zerfall, häufig ist es ganz zu Grunde gegangen. Nach innen von der Luteïnzellenschicht folgt Fibrin, in dem spindel- und sternförmige Zellen und stellenweise reichlich Reste von rothen Blutkörperchen eingelagert sind.

Das rechte Corp. lut. unterscheidet sich von dem linken nicht weiter, ausser dadurch, dass die Degeneration der Luteïnzellen vielleicht noch etwas weiter fortgeschritten ist und dass central von der Fibrinschicht noch eine ganz homogene Masse folgt.

Auffallend im Vergleich zu dem ersten Falle ist bei diesen 2 gelben Körpern, die nur etwa eine Woche älter sind, die Spärlichkeit der kleinen epitheloiden Zellen, namentlich in dem rechten Corp. lut., und die scharfe Abgrenzung gegen die Umgebung. Die beiden Corp. lut. haben ihre höchste Entwicklung nicht nur erreicht, sondern bereits überschritten und das schon nach 6 Wochen. Die regressive Metamorphose der Luteïnzellen ist bereits im vollen Zuge, die beiden Körper sind absterbende Gebilde. Wenn man im ersten Falle die entzündlichen Processe im Corpus 
luteum für die frühzeitige Rückbildung der Luteïnzellen, die übrigens in den peripheren Partien des gelben Körpers weit geringer waren, hätte verantwortlich machen können, so haben wir in unserem Falle keine derartige Ursache. Die Rückbildung muss also in dem Corp. lut. selbst bezw. in den dazu gehörigen Ovarien gelegen sein und da ist die Annahme wohl berechtigt, dass bei dem relativ alten Individuum, das sich noch dazu in einem schlechten Ernährungszustande befand, und bei der Kleinheit der Ovarien die zur längeren Erhaltung des gelben Körpers erforderliche Hyperämie fehlte.

Mit dieser Annahme steht auch im Einklang die im Vergleich zu den Ovarien gravider Frauen auffallend geringe Blutversorgung, das Fehlen jeglicher Auflockerung und Oedemisirung der oberflächlichen Stromapartien, wie wir dies bereits bei der jüngeren Gravidität des ersten Falles beobachten konnten, und die weit geringere Entwicklung der Theca interna-Zellen.

Fall 3. Greiner, 34 J., IIIp. Linke Tubargravidität von $2 \frac{1}{2}$ Monat, geplatzt. Frucht von $6 \mathrm{~cm}$ Länge aus dem Fruchtsack ausgetreten. Coeliotomie am 5. Januar 1905. Das mit entfernte Ovarium zeigte keine Adhäsionen und misst $3: 2,5: 1,7 \mathrm{~cm}$, enthält ein schönes Corpus lut. $(2,5: 2 \mathrm{~cm})$ mit einem runden cystischen Hohlraum $(0,5: 0,6 \mathrm{~cm})$, der eine leicht gelbliche durchsichtige, etwas zähe Flüssigkeit enthielt.

Mikroskopischer Befund: Das Corpus luteum ist scharf gegen die Umgebung abgesetzt. Die mit Hämatoxylin-Eosin röthlich gefärbten Luteïnzellen contrastiren scharf gegen die bläulichen Zellen der bindegewebigen Septen, die Blutgefässe in der Kapsel sind glatt, nur wenige zeigen jedoch Verdickungen der Wandung und Verengerung des Lumens. An der Peripherie des Corpus lut. sind die kleinen epitheloiden Zellen nicht mehr vorhanden, dagegen ziehen sie in den Septen zwischen die Luteïnzellen hinein, zum Theil untermischt mit Spindelzellen. Stellenweise haben sie in ihrer Lebensfrische stark gelitten, das Protoplasma ist ungetrübt, sieht blasig aus, die äussersten Contouren haben einen röthlichen Ton angenommen, das Kernehromatin ist netzartig und schlecht tingirt. Die Luteïnzellen selbst liegen an den peripheren Partien einander noch fest an, mehr gegen das Centrum jedoch ist eine grosse Anzahl aus dem gegenseitigen Verbande gelöst und liegen frei, die Gestalt ist entsprechend den Druckverhältnissen äusserst versehiedenartig, der übergrosse Zellleib zeichnet sich bei allen Exemplaren durch seine gleichmässige röthliche Farbe aus. Der Kern, meist rund oder oval, etwas blass gefärbt, mit 1 oder 2 Kernkörperchen, zeigt häufig Anhäufungen von Chromatin. Hier und da sieht man, in Protoplasma einer Zelle liegend, kleinere und grössere, scharf umschriebene, leuchtend roth gefärbte Kugeln von homogenem Aussehen. Auf die Luteïnschicht folgt nach innen Fibrin mit einigen Spindelzellen und Resten von rothen Blutkörperchen. In der Mitte 
ist ein cystischer Hohlraum, dessen Inhalt ausgefallen ist. Das Oberflächenepithel ist nur noch an einzelnen Steilen, und zwar in Vertiefungen, aufzufinden, die Albuginea ist schlecht gefärbt, ödematös durchtränkt, zum Theil auch von der Unterlage abgehoben, die Zellen sind theilweise vergrössert, zeigen jedoch keine deciduaähnliche Umwandlung. In der Rinde sind zahlreiche Primärfollikel ohne Veränderungen, einzelne Corpora fibrosa und candicantia. In der Pars vasculosa finden sich Gefässe mit zum Theil stark verdickten Wänden. Die grösseren Follikel sind zum Theil noch erbalten, zum Theil sind sie in Atresie begriffen. An den erhaltenen Follikeln, von denen einer einen Durchmesser von $3,5 \mathrm{~mm}$ hat, steht die Granulosa in etwa 10 facher Lage, in einem Falle auch das unversehrte Ei, die Theca interna von gewöhnlicher Breite und Beschaffenheit, einzelne Zellen mit Mitosen; an jenen cystischen Follikeln, an denen Granulosaepithel und Ei zu Grunde gegangen sind, ist die Thecaluteïnschicht deutlicher ausgebildet. Es verhalten sich die einzelnen cystischen Follikel übrigens recht verschieden, je grösser im Allgemeinen die Cyste ist, desto schmäler ist die Luteïnzellenschicht. Am deutlichsten tritt die Lutemzellenvermehrung an den zusammengefallenen atresirenden Follikeln zu Tage. Der Follikel hat die rundliche Form verloren, sein Durchschnitt ist T-förmig oder S-förmig oder ganz unregelmässig geworden, die Follikelepithelien sind theils erhalten, theils in Abfall begriffen, unter den ins Lumen vorspringenden Partien liegen Polster von Luteïnzellen von 20-40 übereinander, die durch ihre Form und gelbröthliche larbe auffallen. Sie baben zum Theil blasige Structur angenommen, sodass eine Art von Schleimgewebe von schaumigem Aussehen entsteht. Es lässt sich an den Präparaten (cfr. Fig. 4) mit Sicherheit nachweisen, dass diese Zellen von der Theca interna ausgehen. Ist einmal der ganze Follikel vou der blasigen Zellen ausgefüllt, so lässt sich der Nachweis dieser Genese nicht mehr führen.

Zusammenfassung: Bei Tubargravidität im 3. Monat zeigen die cystisch erweiterten Follikel eine geringe, die wachsenden Follikeln eine stärkere und die atresirenden Follikel eine ausgesprochene Entwicklung der Theca interna-Zellen, die mehr oder weniger epitheloide Form und luteïnhaltiges Protoplasma aufweisen. An der Oberfiäche besteht Auflockerung und leichtes Oedem des Gewebes.

Fall 4. Uterus gravidus mit einer $12 \mathrm{~cm}$ langen Frucht ( $3 \frac{1}{2}$. Monate) und Ovarien von einem jugendlichen Individuum. Spirituspräparat. Todesursache unbekannt. Wenn trotzdem diese Ovarien unter der ersten Gruppe aufgeführt werden, so geschieht es, weil das linke Ovarium tadellos, das rechte mit dem Corpus lut. wenigstens so conservirt ist, dass die in Frage kommenden Verhältnisse klar überblickt werden können.

Rechtes Ovarium $4: 3: 1,75 \mathrm{~cm}$ mit sehr grossem Corpus luteum $(1,8: 1,5 \mathrm{~cm})$, das ganz solide jst und in der Mitte einen weisslichen Fleck zeigt. Linkes Ovarium 4,5:2,25:1,5 cm enthält mehrere mit geronnenem Inhalt gefüllte kleine Cystchen. 
Mikroskopischer Befund: Oberflächenepithel zum Theil noch erhalten in Form von theils hohen, theils niedrigen Zellen. Albuginea im Ganzen ohne stärkere Auflockerung, nur an den Stellen, wo in der Tiefe Corpora fibrosa und candicantia liegen, ist regelmässig an der Oberfläche eine Einbuchtung zu sehen, die sich durch einen lockeren und kernärmeren Bau auszeichnet. Hier sieht man einen kolbenartigen Fortsatz, der histologisch ausgezeichnet ist durch seine Zellarmuth und durch den Reichthum an eingelagertem, scholligen Pigment. Die Zellen haben unregelmässige Gestalt, sind theilweise ganz zu Grunde gegangen, theilweise zeigen die Kerne Degenerationserscheinungen. An einer anderen Stelle der Oberfläche ist die Umwandlung eine andere: die Zellen sind vergrössert, in die Länge gezogen, parallel nebeneinander stehend, haben theils eine ganz gleichmässig homogene Structur, theils ein faseriges Aussehen, mehr oder weniger bläulich gefärbt, spindelförmige Kerne nur in geringer Anzahl vorhanden.

Gut erhaltene Primärfollikel sind sehr reichlich vorhanden, einer enthält zwei gut entwickelte Kerne (Doppelei); auch einige wachsende Follikel ohne Besonderheiten sind zu sehen, einer weist eine ungewöhnlich stark entwickelte Theca interna auf. Die grösseren und die eystisch degenerirten Follikel sind ausgezeichnet durch die schöne, stark entwickelte Luteïnzellenschicht. Die Atresie der grösseren Follikel ging in diesem Falle, wie das sonst so häufig beobachtet wird, nicht in der Weise vor sich, dass der Follikel eine unregelmässige, bizarre Gestalt annimmt, hier ist entweder die runde Form beibehalten oder der Follikel ist durch erhöhten Seitendruck einfach abgeplattet und zusammengedrückt worden. Das Follikelepithel ist an den meisten nicht mehr zu sehen; Fig. 5 giebt einen Follikel vom rechten Ovarium wieder, wo das Follikelepithel von der Unterlage abgelöst und in das Lumen in abgerissenen Stücken hineingedrängt ist. Die scharfe Linie der untersten Epithelschicht ist auch hier noch deutlich zu erkennen und dadurch sind wir im Stande, an diesem Follikel, trotzdem er in seiner Lebensfrische etwas gelitten hat, mit Sicherheit festzustellen, dass die darunter gelegene Luteinzellenschicht nur aus Bindegewebszellen hervor ${ }^{-}$ gegangen ist. Deutlicher als an diesem Präparat lässt sich der Nachweis des bindegeweblichen Ursprungs an anderen Fällen erbringen, wofür wir später gelegentlich noch eine Abbildung bringen wollen. Daś Follikelepithel enthält die bekannten Vacuolen, der Dise. proligerus ist hier nicht mehr erhalten. An anderen Follikeln sieht man denselben noch, das Ei selbst aber ist der Degeneration verfallen.

Während bei Fig. 5 die Theca-Luteïnzellenentwickelung erst in den Anfängen begriffen ist und mehr durch die Auflockerung der Zellen in die Augen fällt, ist dagegen bei anderen atretischen Follikeln dieselbe viel stärker ausgebildet. Fig. 6 giebt einen Follikel ebenfalls aus dem rechten Ovarium wieder, von dem man erkennt, wie die nach Form und Tinction scharf gegen die Stromazellen abgesetzten Luteïnzellen sich weit in das Ovarialgewebe hinein erstrecken und auf der einen Breitseite mit den Luteïnzellen der Wand eines cystischen Follikels confluiren.

Einer besonderen Erwähnung bedarf noch das Verhalten des Stromas. Während in den reichlich mit Primordialfollikeln versehenen Rindenpartien das Stroma seine normale Structur aufweist, sind um manche fibrös entartete Stellen, die man mit Recht wohl •als Corpora fibrosa deuten darf, die Zellen grösser, dicker, protoplasmareicher geworden, 
sie haben nicht mehr ausgesprochene Spindelform, sondern häufig eine mebr epitheloide Gestalt angenommen. Man darf diese Umwandlung der Stromazellen in der unmittelbaren Umgebung von Corpora fibrosa als die allerersten Anfänge eines Processes ansehen, der den Zellen den Charakter der Luteïnzelle verleiht, wie sich später noch zeigen lassen wird. Auffallend ist ferner, dass an verschiedenen Stellen die Stromazellen der hyalinen Degeneration verfallen sind, ohne dass sich ein Zusammenhang mit den Residuen eines Follikels oder eines Corp. lut. feststellen liesse.

Das Corpus luteum ist ziemlich scharf begrenzt, an der Peripherie sind nur noch vereinzelte kleine epitheloide Zellen, während sie in den bindegeweblichen Septen weit in das Innere des Corp. lut. zu verfolgen sind; sie zeigen z. Th. Degenerationserscheinungen. Die Gefässe der Kapsel und der Septen sind in der Regel ohne Wandverdickungen. Die Luteinzellen selbst sind in der Mehrzahl nekrotisch, der Kern entweder verschwunden oder mit Degenerationserscheinungen behaftet, der Zellleib diffus rothbläulich gefärbt, von krümeligem Aussehen, z. Th. in Trümmer zerfallend, die Zellgrenzen meist ganz unscharf.

Ein Befund an den Blutgefässen beansprucht noch besonderes Interesse. Es sind in der Nähe des Corp. lut. einige Gefässe mehr oder minder voll mit theils rundlichen, theils polymorphen Zellen angefüllt, die einen oder mehrere Kerne aufweisen. Dass die Lumina ganz ausgestopft sind, wie in den zwei abgebildeten Gefässen (Fig. 7), beobachtet man selten, dagegen begegnet man einigen wenigen Exemplaren im Lumen ziemlich häufig. Dass es sich wirklich um Gefässlumina handelt, ersieht man aus der Auskleidung der Wand mit Endothelien und ferner aus dem Umstande, dass neben den Zellen in anderen Gefässen noch Blut- oder Blutreste zu sehen sind.

Schwieriger $z u$ entscheiden ist die Frage nach der Herkunft dieser Zellen. Zunächst wird man an Wanderzellen denken; mit diesen haben sie auch in ihrem Aeussern eine gewisse Aehnlichkeit. Aber es finden sich nirgends Processe, welche das Auftreten der Leukocyten erklären, das Stroma zeigt nirgends den geringsten Reizzustand, auch in Follikeln und im Corpus luteum selbst feblen Leukocyteninfiltration. Es ist bekannt, dass auch in degenerirenden Follikeln manchmal Rundzellen auftreten, doch sind diese nie in der Menge vorhanden, um zu Gefässverstopfungen zu führen. Es kann sich demnach nur um abgestossene Follikelepithelien oder um aus der Theca interna hervorgegangene Zellen handeln. Wir 
haben gesehen, dass in den atretischen Follikeln die Follikelepithelien zum grossen Theil abgestossen sind. Vergleicht man die chromatolytischen Kernfiguren in den Zellen innerhalb der Gefässe mit denen, wie sie Flemming so vortrefflich von den degenerirenden Follikelepithelien beschreibt, so kann an der Identität beider kein $Z$ weifel bestehen. Die abgestossenen Epithelien sind in die abführenden Venen verschleppt. Nicht ganz auszuschliessen ist die Möglichkeit, dass die Verschleppung mit der Erkrankung zusammenhängt oder dass es sich um einen postmortalen Vorgang handelt. Ich möchte deshalb auf den Befund keinen besonderen Werth legen.

Zusammenfassung: Das Corpus luteum befindet sich grösstentheils in Nekrose, eine Function kann den Luteïnzellen nicht mehr zugeschrieben werden. In den grösseren und in den cystisch degenerirten Follikeln findet sich eine starke Wucherung der Theca interna unter dem Bilde der Theca-Luteïnzellenvermehrung. In den tieferen Partien des Stromas haben Bindegewebszellen in der Umgebung von Corpora fibrosa und kleinere Haufen von Stromazellen ohne Zusammenhang mit einem bestimmten Gebilde eine Vergrösserung und eine Authellung des Protoplasmaleibes erfahren.

Fall 5. (Nummer der Sammlung 351). Uterus myomatosus von Mannskopfgrösse mit Gravidität von $31 / 2$ Monaten (Fötus $12 \mathrm{~cm}$ ) mit dem linken Ovarium supravaginal exstirpirt und in Formalin conservirt. Das rechte Ovarium blieb zuräck; da im linken Ovarium von einem Corpus luteum nichts zu finden ist, so muss dasselbe im rechten gesessen haben. Das Alter der Patientin, von der das Präparat stammt, ist nicht bekannt.

Das linke Ovarium zeigt folgende Maasse: $5: 2,5: 0,5 \mathrm{~cm}$ und jsi ohne cystisch erweiterte Follikel.

Mikroskopischer Befund: Das Oberfächenepithel ist grössten Theils abgestossen, die Albuginea zeigt das gewöhnliche Verhalten, an einigen Schnitten ist sie etwas breiter, blasser gefärbt, zellärmer, zum Theil mit etwas grösseren Zellen versehen, namentlich an Einsenkungen der Oberfläche. Nirgends deciduale Bildungen, nirgends Excrescenzen. Das Stroma ist dichter als gewöhnlich, die Zellen haben meist die regelmässige Spindelform. Corpora candicantia und fibrosa sind nur in geringer Anzahl vorhanden; ebenso fällt die Armuth an Primärfollikeln und noch mehr an grösseren Follikeln auf. Auf vielen Schnitten aus verschiedenen Stellen des Ovariums lassen sich nur 2 Follikel von runder Form auffinden, deren Epithel verloren gegangen ist, und die nur mehr von den Zellen der Theca interna ausgekleidet sind, die in mehrfacher Lage übereinander befindlich das wiederholt geschilderte 
Verbalten, wenn auch nicht in der ausgeprägten Form wie im letzten Falle, zeigen. In der Pars vasculosa finden sich ungewöhnlich starke Verdickungen der Gefässwände.

Zusammenfassung: Ungewöhnlich follikelarmes Ovarium aus dem 4. Monat der Gravidität bei Uterus myomatosus, das keine Deciduabildung und auch sonst keine auffallende Veränderung der Stromazellen, das in den spärlich vorhandenen Follikeln eine mässige Lateinzellenwucherung aufweist.

Fall 6. (Nummer der Sammlung 348). Uterus myomatosus von über Mannskopfgrösse, bestehend aus zahlreichen meist intramuralen Knollen; supravaginal amputirt. Gravidität vom 4. Monat, Frucht noch in Uterus. Ungewöhnliche Hypertrophie der Decidua vera. Das rechte Ovarium wurde bei der Operation zurückgelassen. Linkes Ovarium ist ohne Corpus luteum $(4: 2: 0,7 \mathrm{~cm})$.

Mikroskopischer Befund: Die Hypertrophie der $11 \mathrm{~mm}$ dicken Decidua erklärt sich der Hauptsache nacb durch die Dickenzunahme der compacten Substanz, die Deciduazellen sind gross und reichlich vorhanden, in der spongiösen Substanz finden sich sebr schön ausgebildete und für den 4. Monat der Gravidität ungewöhnlich gut erhaltene Schwangerschaftsdrüsen.

Das Keimepithel ist überall abgestossen, die Albuginea ist nur an wenigen Stellen ohne jede Veränderung; zum Theil ist sie zellärmer und zeigt eine gewisse Auflockerung ilser Bestandtheile, zum Theil gehen jedoch die Veränderungen viel weiter; manchmal nur circumscript (Taf. VIII, Fig. 20), öfters in langen Zügen an der Oberfläche dahinziehend, gelegentlich ragen auch keulen- und pirzelförmige Fortsätze über die Ovarialoberfläche heraus. Wenn diese Fortsätze an den Enden unter zu Grunde geben des Keimepithels zusammenwachsen, so entsteht auf dem Schnitte ein Hohlraum, der mit einem niedrigen Epithel ausgekleidet ist. Das ovarienwärts gelegene Epithel ist in der Regel kräftiger und höher als das der entgegengesetzten Wand, das durch das vermehrte Wachsthum des Stromas stärker gedehnt und ausgezogen ist. Das Stroma selbst hat folgende Beschaffenheit: Durch Oedem sind die Zellen stark auseinandergedrängt, sodass nur noch spärliche Kerne zu sehen sind. In diesem ödematösen Gewebe liegen Gruppen von 10 bis 20 und mehr Zellen, welche durch ihre gleichmässig röthlich-violette Farbe gegen das farblose, ödematöse Gewebe scharf contrastiren, einen ausserordentlich grossen polymorphen Zellleib aufweisen und einen Kern, der nicht selten chromatolytische Erscheinungen zeigt. Das Gewebe zeichnet sich durch einen ungewöhnlichen Reichthum an Gefässen aus, die strotzend mit Blut oder Bluttrümmern gefüllt sind; an einigen Stellen sind Hämorrhagien in das Gewebe erfolgt.

Auch das übrige Stroma weist eine auffallend starke ödematöse Durchtränkung auf, so dass das normal gefärbte Stroma in dem blassen und schlecht gefärbten Gewebe wie einzelne Inseln erscheint. Es ist klar, dass bei dieser Beschaffenheit des Stromas nur wenige Primärfollikel zu finden sind. Auch die Anzahl der wachsenden Follikel ist eine sehr geringe. Auf vielen Schnitten aus mehreren Stücken waren nur 3 Follikel zu 
bemerken. Das Ovarium bietet in dieser Beziehung demnach dasselbe Verhalten wie im vorigen dar. Die Theca interna bei den gefundenen nur eine geringe Vergrösserung, wie Taf. VI, Fig. 8 illustrirt, an der zu erkennen ist, dass in die eine Seite des Follikels eine Blutung erfolgt ist. Dieses Bild zeigt mebr als lange Beschreibungen, dass sich die Luteïnzellen thatsächlich aus den bindegewebigen Zellen der Theca interna entwickeln. Aehnliche Bilder sieht man, wie ich ausdrücklich hervorheben möchte, aucb ausserhalb der Schwangerschaft an wachsenden Follikeln. So babe ich speciell ein solches bei grossen Myomen gesehen. Etliche kleine, ganz der Atrophie verfallene Follikel zeigen eine Vergrösserung der Zellen und erinnern in ihrem Aussehen an kleine Corpora lutea; wir werden auf die Beschreibung dieser Körper bei anderen Fällen, wo die Bilder ausgeprägter sind, näher eingehen. Corpora fibrosa und Corpora candicantia nur in geringer Anzahl vorbanden. An ihnen ebensowenig wie an einer Stelle des Stroma zeigt sich eine luteinzellenähnliche Umwandlung. In einem Corp. fibrosum verschiedene Pigmentzellen mit geblähtem Zellleib. Sehr stark entwickelt sind die Blutgefässe, deren Wände in den inneren Partien der Ovarialsubstanz zum Theil Verdickungen aufweisen.

Zusammenfassung: An der Oberfläche des Ovariums findet sich eine deciduaähnliche Umwandlung des Stromas. Dieselbe geht mit einer starken ödematösen, z. Th. hämorrhagischen Durchtränkung des Gewebes einher und bildet zipfelartige Fortsätze, die durch Verwachsung an den Enden zur Entstehung von keimepitheltragenden Hohlräumen führen.

In dem ödematös durchtränkten und an specifischen Elementen armen Ovarialstroma finden sich etliche Follikel, die eine mittlere Entwicklung der Luteïnschicht aufwoisen; ferner einige ganz atretische kleine Follikel mit beginnender Luteïnzellenbildung. Das Stroma lässt jede luteinzellenähnliche Umwandlung vermissen.

Eine besondere Erwähnung verdient ein merkwürdiges Gebilde, das etwa $1 \mathrm{~mm}$ von der Ovarialoberfläche entfernt ist und durch seine leuchtend rothe Farbe (Hämatoxylin-Eosin) gegen das Ovarialstroma contrastirt. Taf. VI, Fig. 9 giebt eine Abbildung und lässt seine Grösse und die Eigenart der Zellen gut erkennen. Es wird auf Serienschnitten auf seiner geringen Tiefe, die etwa der Breitenausdehnung entspricht, verfolgt und dabei lässt sich feststellen, dass es weder mit den Deciduazellen der Oberfläche noch mit einem nahe gelegenen Corpus fibrosum einen Zusammenhang hat. Da ein Corpus lut. in dem entfernten Ovarium nicht vorhanden, ist eine Verbindung mit diesem von vorneherein auszuschliessen. Die Abgrenzung gegen das umgebende Gewebe ist absolut scharf, an der einen Seite ist lebensfrisches, spindeliges Stroma, auf der anderen Seite ist ein Streifen lockeren, zellarmen, reticulären Ge- 
webes. Die Gefässe sind in der Umgebung etwas reichlicher und an der einen Schmalseite sieht man zugleich mit dem Bindegewebe ein Bündel blutgefüllter Gefässe mitten in das Gebilde hineinziehen. Die bindegeweblichen Zellen vertheilen sich weiterhin zwischen den eigentlichen Parenchymzellen. Diese sind sehr gross in ihren Umrissen, nicht immer scharf von einander getrennt, haben unregelmässige Gestalt, dabei ausgesprochen epithelialen Charakter, der Zellleib ist diffus mit Eosin roth gefärbt und zeigt nur bei sehr starker Vergrösserung ein leicht netzartiges Gefüge und einzelne Granula; auch Vacuolenbildung ist vorbanden. Der Kern hat meist eine ovale Form, ist mässig gut gefärbt, ohne Chromatolyse, und enthält in der Regel ein Kernkörperchen. Mehrere kleinste Capillaren verlaufen zwischen den Zellen.

Es kann nach Abbildung und Beschreibung wohl kaum zweifelhaft sein, dass wir es mit einer eingeschlossenen Gruppe von Luteïnzellen zu thun haben, die sich noch in einem recht gut erhaltenen Zustande befinden. Betreffs der Herkunft kommen drei Gebilde in Betracht. Es könnte ein vom Corpus lut. verum abgeschnürter Theil sein; nach dem Eingangs Erwähnten ist dies mit Sicherheit auszuschliessen. Es könnte sich zweitens um ein altes Corpus lut., event. von der zuletzt dagewesenen Menstruation herrübrendes handeln. Abgesehen davon, dass diese Annahme nach den sonstigen Erfahrungen über den Bestand ron Corpora lut. spur. beim Menschen recht unwahrscheinlich ist, kann man dies mit Bestimmtheit ausschliessen, weil sich unmöglich nur diese circumscripte Parthie des ganzen gelben Körpers erhalten haben kann, während alles Andere, Luteïnzellen sowohl wie bindegewebliches Gefüge spurlos verschwunden wäre. Es bleibt somit nur die dritte Möglichkeit, dass das Gebilde aus einem ungeplatzten Follikel und zwar aus einem relativ noch kleinen hervorgegangen. Es ist die Atresie hier nicht nach dem gewöhnlichen Modus erfolgt, es baben sich vielmehr, - die epitheliale Herkunft der Corpus luteumZellen als sicher angenommen - die Follikelepithelien erhalten, sind hypertrophirt und secundär von der bindegewebigen Kapsel aus mit Bindegewebe durchwachsen und mit Blutgefässen versehen worden. Es ist die Annahme, dass sich das Granulosaepithel in atrophirenden Follikeln noch erhält, scheinbar sehr unwahrscheinlich; denn thatsächlich sieht man, wie dies fast alle Schriftsteller betonen, das Granulosaepithel in der Regel zu Grunde gehen. Dass sich dasselbe erhält, dass zwischen die Epithelien Gefäss- 
sprossen hineinwachsen, ist jedoch ebenfalls beobachtet und wir werden später gleichfalls noch Belege erbringen.

Das Hineinwachsen von Gefässschlingen zwischen das Follikelepithel hat van Beneden zuerst bei der Fledermaus beobachtet. Schulin beobachtete diesen Vorgang auch bei anderen Sängethieren und beim Menschen und hebt hervor, dass die Schlingen mit Vorliebe in den Discus proligerus hineinwachsen und dann fast immer von einem schmalen hyalinen Saume umgeben sind. Dieser Schriftsteller findet die Erscheinung um deswillen besonders interessant, weil in ihr die Uebergangsbrücke zwischen Atresie und Corpus luteum-Bildung angedeutet ist; nach seiner Ansicht beginnt die Corpus luteum-Bildung manchmal schon, ehe der Follikel geplatzt ist. Stratz hat Studien an einem grossen und einwandfreien Material (Tupaja gavanica, Sorex vulgaris und Tarsius spectrum) gemacht und hat das Einwachsen von Gefässschlingen mit grosser Regelmässigkeit an Follikeln gefunden, auch wenn sie völlig normal waren, und zwar sowohl vor der vollkommenen Reife als auch bei völlig reifen und befruchtungsfähigen Follikeln. Stratz hält es für einen für Säugethiere geradezu cbarakteristischen Vorgang. Als erstes Stadium der Gefässentwicklung konnte er das Eindringen von Endothelzellen zwischen die Epithelien wahrnehmen. Er deutet einen ähnlichen Befund von G. Ruge an degenerirenden Eiern von Siredon pisciformis, den dieser für ein weisses Blutkörperchen anspricht, im gleichen Sinne. Auch Rabl erwähnt das Hineinsprossen der Gefässschlingen in den Discus proligerus und giebt in Fig. 17 u. 18 seiner Abhandlung diesbezügliche Abbildungen.

Diese Beobachtungen. stammten von Ovarien nicht schwangerer Thiere bez. Menschen. Taf. VIII, Fig. 15 und Taf. IX, Eig. 30 (letztere vom Blasenmolenovarium) zeigen, dass auch während der Schwangerschaft dieses Einwachsen von Gefässen beobachtet wird und wie, es nach meinen Erfahrungen scheint, sogar häufiger. Gerade in dem Falle, von dem die Fig. 15 stammt, liess sich das Eindringen blutgefüllter Capillaren auch in den Discus proligerus sehr schön verfolgen. Es ist dies bei der ausserordentlich reichen Blutversorgung der Theca int. während der Schwangerschaft nichts sehr Auffälliges. Unter diesen günstigen Umständen wird sich auch das Follikelepithel erhalten und selbst beim Ausbleiben der Follikelruptur, durch Einwachsen von Gefässen und Bindegewebszellen jene Gebilde entstehen, welche wir in ausgebildetem Zustande in Taf. VI 
Fig. 9 und in stark regressiver Metamorphose begriffen in Taf. VIII, Fig. 13 vor uus sehen.

Nimmt man an, dass sich die Zellen aus den Zellen der Theca interna gebildet haben, wie das die Anhänger der bindegeweblichen Natur des Corpus lut. thun werden, so hätten die Theca interna-Zellen ganz das Aussehen und das Verhalten echter Luteïnzellen angenommen. Das ausgebildete Gebilde ist jedoch in keinem Falle geeignet, diese Streitfrage zu lösen.

Diese kleinsten, aus atretischen Follikeln hervorgegangenen Corpora lu tea sind bisher noch von keiner Seite beschrieben worden. An Ovarien nicht gravider Frauen habe ich dergleichen gelbe Körper auch nie gefunden. Ob jedoch derartige Rückbildungsproducte atretischer Follikel nur während der Schwangerschaft vorkommen, kann vorläufig njcht mit Sicherheit bestimmt werden.

Fall 7. (Sammlung No. 539). Rechts. Graviditas isthmica von 4 Monaten (Fötus mit einer Scheitelfusslänge von $16^{1} \frac{1}{2} \mathrm{~cm}$ ). Exitus in Folge Ruptur.

Linkes Ovarium $(3: 2: 1,5 \mathrm{~cm})$ mit einem soliden Corpus luteum $0,3: 0,5$ und einem centralen, linsengrossen, weisslichen Kern. Rechtes Ovarium 4:2,5:1,0 enthält verschiedene kleine Cystchen von gelblicher Farbe. Adhäsionen bestehen an den Ovarien nicht.

Mikroskopischer Befund: Oberfächenepithel an geschützten Stellen noch vorhanden, Albuginea stellenweise aufgelockert, ödematös durchtränkt, reichlich mit Capillaren durchsetzt. Verschiedene Deciduazellen meist einzeln in den oberflächlichen Partien. Stroma ist ungewöhnlich dicht und derb. Anzahl der vorhandenen Primordialfollikel spärlich. An den grösseren Follikeln ist die Granulosa abgelöst, die Epithelien zeigen chromatolytische Figuren, die Eizelle ist, soweit sie gefunden wurde, degenerirt, zeigt homogene Structur und rothe Farbe und noch einen Rest des Kernkörperchens. Die Theca interna tritt zwar an den atrophirenden Follikeln zum Theil deutlich hervor, allein auffällig ist bei einzelnen Follikeln die Kleinheit und die schlechte Ent. wickelung der Zellen. Dies ist hauptsächlich bei jenen atretischen Follikeln der Fall, bei deuen die Innenseite des Follikelraumes ein schmaler hyaliner Saum abgrenzt. Solche Entwickelung der Theca internaschicht sieht man jedoch gelegentlich auch ausserhalb der Schwangerschaft an atretischen Follikeln. Andere Follikel enthalten im Innern eine homogene Masse, die Wand unterscheidet sich nicht von dem Stroma der Umgebung, in wieder anderen dagegen ist die Wucherung der ThecaLuteïnzellen recht gut ausgebildet.

Das Corp. lut. ist scharf abgegrenzt, von den kleinen epitheloiden Zellen ist weder in den peripheren Partien noch in den bindegewebigen Septen etwas nachzuweisen, überall sind nur spindelförmige Zellen vertreten. Das Protoplasma der Luteïnzellen ist gleichmässig roth gefärbt, die Contouren zwischen den einzelnen Zellen verwischt, die Kerne schlecht tingirt, theilweise geschrumpft, das Chromatin zerfallen. 
Während die Abgrenzung des Corp. lut. gegen das umgebende Bindegewebe durchaus scharf ist, lässt sich an.3 Stellen der Peripherie eine Absprengung von Theilen des Corp. lut. constatiren. Die Stellen sind ausserhalb der bindegewebigen Kapsel des gelben Körpers gelegen und von den Corpus luteum-Zellen durch eine schmale Brücke dichten Bindegewebes getrennt. Die eine Stelle, welche Taf. VI, Fig. 10 wiedergiebt, besteht aus 2 rundlichen, von einander getrennten Gruppen von Luteinzellen, welcbe, wie man auf Serienschnitten nachweisen kann, mehr in die Tiefe zu einem Conglomerat confluiren. An der 2. Stelle hat die versprengte Partie eine mehr längliche Form, gleicht aber sonst ganz dem gezeichneten Gebilde, namentlich stimmt der Charakter und die Structur der Zellen völlig miteinander überein. 'An einer 3. Stelle finden sich wiederum 3 Gruppen von Zellen, daneben auch, ganz von Stroma umschlossen, verschiedene kleine Häufchen, die nur aus 4 bis 10 Zellen bestehen. Um ein an der Peripherie des Corp. lut. gelegenes Gefäss, dessen Wände keine Veränderungen zeigen, liegen die bereits bei Fall 4 genauer beschriebenen Zellen.

Es kann keinem Zweifel unterliegen, dass wir es hier an beiden Stellen mit einer echten Absprengung von Stücken des Corpus luteum zu thun haben. Ein Zusammenhang mit dem HauptCorpus luteum lässt sich nirgends mehr nachweisen, wie angelegte Serienschnitte beweisen. Es dürfen solche abgesprengte Partien in und ausserhalb der bindegeweblichen Kapsel nicht mit den.Einschlüssen von Gruppen von Luteïnzellen verwechselt werden, welche nicht selten zwischen den bindegeweblichen Septen des Corp. lut. eingelagert gefunden werden. Echte Absprengung von Luteinpartien gewissermaassen im Status nascendi habe ich bei einem jungen Corp. lut. menstruationis beobachtet, über das später noch berichtet werden soll.

Fall 8. (Sammlung No. 371). Uterus gravidus myomatosus (41/2 Monate) im August 1894 supravaginal amputirt. Die Myome sind multipel, subserös und interstitiell, im ganzen grösser als ein Mannskopf. Fötus liegt innerhalb des unregelmässig gestalteten Uteruscarum, ist $22 \mathrm{~cm}$ lang. Das linke Ovarium wurde zurückgelassen, das rechte Ovarium sehr gross $(6: 3: 2 \mathrm{~cm})$; enthält ein Corpus luteum von $1: 1,5 \mathrm{~cm}$, das einen Hohlraum von $3-5 \mathrm{~mm}$ zeigt und einen weisslich gelben Inhalt hat. Ausserdem sind im Ovarium mehrere linsen- bis erbsengrosse Cystchen von leicht gelblicher Farbe.

Mikroskopischer Befund: Das Oberflächenepithel ist nicht mehr vorhanden. Die Albuginea zeigt fast an der ganzen Peripherie deutliche deciduale Reaction in Form von meist scharf umgrenzten Gruppen grosser Zellen, die nicht selten in der Mitte ein weites, dünnwandiges Gefäss enthalten. Das Stroma ist in der Rindensubstanz von gewöhn- 
licher Dichte, in der Marksubstanz ist eine stellenweise starke ödematöse Durchtränkung nicht zu verkennen. Auf einer ganzen Reihe von Schnitten aus 3 verschieden grossen Stücken ist nur der eine oder der andere Primärfollikel aufufinden, verschiedene sind verödet, ferner ein paar wachsende mittlerer Grösse.

Die Armuth an spezifiischen Elementen äussert sich auch in der geringen Anzahl atretischer Follike]. Ein paar hirsekorngrosse Follikel enthalten kein Ei und kein Epithel mehr, der Inhalt ist eine homogene Masse mit etlichen Zellresten, die Wand wird von innen nach aussen gebildet von einer schmalen Schicht spindeliger Zellen, auf die epitheloide Zellen der Theca interna in 12-20facher Reihe folgen und eine Art Kranz um den Follikel bilden. Durch Spindelzellen und Blutcapillaren sind die Theca interna-Zellen in einzelne kleinere Gruppen abgetheilt. Der Zellleib der Theca-Zellen zeigt gelbliche Farbe, einzelne Zellen enthalten Kerntheilungsfiguren. An einem wachsenden Follikel und an einem linsengrossen ist das Follikelepithel noch erhalten; bei dem ersteren wurde das Ei nicht mehr aufgefunden, gegen das Innere zu blättern die Epithelien ab, der kJeine Follikelraum ist theilweise von Blutresten angefüllt; bei dem letzteren ist das Ei, umgeben von den Epithelien, als homogene rothe Kugel (Kosinhämatoxylinfärbung) noch zu erkennen, der Disc. oophorus enthält grosse, unregelmässig gestaltete Vacuolen und die Epithelien zeigen zum grossen Theil chromatolytische Kerne. Die unmittelbar um das Ei gelegenen Zellen haben ihre concentrische Anordnung beibehalten. An einem anderen Follikel ist das Granulosaepithel im ganzen Umfange abgestossen, nur der Disc. oophorus mit dem degenerirten $\mathrm{Ei}$ ist noch vorhanden. An allen diesen Follikeln ist die Theca interna-Schicht stellenweise verdickt, zum Theil weist sie jedoch auch nur die gewöhnliche Stärke auf, die Wucherung ist erst jm Beginn.

An einigen zusammengesunkenen Follikeln (Corp. atretica) sind die Zellen der Theca interna vergrössert und haben den Charakter der Luteïnzellen angenommen. Der histologische Befund ähnelt ganz dem vom nächsten Fall gegebenen Bilde, nur sind die Theca-Luteïnzellen in unserem Falle noch etwas deutlicher entwickelt. Auch grenzt theilweise ein hyaliner Saum die Thecazellen von dem zellarmen, fibrinösen Kerne ab.

Fall 9. (Sammlung No. 528). Gravidität vom 5. Monat (Fötus $21 \mathrm{~cm}$ lang). Der gravide Uterus lag in einer irreponiblen Hernia inguinalis. Porrooperation. Rechtes Ovarium $5: 3: 0,8 \mathrm{~cm}$ enthält ein sehr schönes Corpus luteum $(1,5: 1,5 \mathrm{~cm})$, das linke Ovarium wurde zurückgelassen. Altes Spirituspräparat vom Jahre 1884, jedoch sehr gut conservirt.

Mikroskopischer Befund: Keimepithel verloren, Albuginea aufgelockert, stellenweise in Form von Pirzeln gewuchert. Stroma arm an Follikeln; auf dem Stück - es wurde in diesem Falle nur ein Stück zur mikroskopischen Untersuchung verwendet - keine grösseren Follikel zu sehen. Ein atretischer Follikel; der die Luteinzellenbildung deutlich erkennen lässt, bedarf einer genaueren Beschreibung. Bein ersten Blick denkt man garnicht an einen Ueberrest eines Follikels (Taf. VI, Fig. 11). Man sieht inmitten des Stromas Zellen, die sich 
durch ihre Grösse und ihre Anordnung von den Zellen der Umgebung: unterscheiden. Bei genauerer Betrachtung erkennt man, dass sie gegen die Umgebung ziemlich scharf durch eine Zone helleren Gewebes $a b-$ gegrenzt sind, in dem ein Kranz von Gefässen verläuft und dass ferner, wie man auf Serienschnitten nachweisen kann, etwas excentrisch von der Mitte ein kleiner, bindegewebiger Kern gelegen ist. Die starke Vergrösserung zeigt, dass das Gebilde aus 2 Arten von Zellen sich zusammensetzt: 1. aus Spindelzellen, gleich den Stromazellen, welche alle gegen das Centrum radiär angeordnet sind und 2. Zellen, die zwischen den ersteren gelegen sind, grösser sind, ovale oder polygonale Gestalt, einen rundlichen Kern; meist mit Anzeichen der Fragmentation und einen verbreiterten Protoplaswaleib aufweisen, der gelbliche, schollige Substanzen enthält. Das Gewebe zeichnet sich ferner durch seinen Reichthum an zarten Capillaren aus.

Es kann nach der Beschreibung keinem Zweifel unterliegen, dass es sich bei diesen Zellen um Luteinzellen handelt und dass das ganze Gebilde von einem Follikel abstammt. Es handelt sich nur darum: Ist es aus einem in Atrophie befindlichen Follikel oder bereits aus einem vollendeten Corpus atreticum durch Zellwucherung hervorgegangen? In letzterem Falle wäre die Atresie des Follikels höchst wahrscheinlich bereits vor Eintritt der Schwangerschaft eingetreten gewesen, es hätte nur eine kleine Narbe bestanden. Namentlich würde die Theca externa und der Gefässkranz der Theca interna nicht mehr bestehen, jedenfalls nicht mehr mit dieser Deutlichkeit sich nachweisen lassen. Daher kommen wir zu der Ansicht, dass es sich nur um einen atretischen Follikel, der eine Vermehrung der Zellen der Theca interna und Umwandlung in Luteinzellen aufweist, handeln kann.

Fall 10. (Sammlung No. 527). Uterus gravidus vom Ende des 6. Monates einer 27 jährigen. IIp., plötzlicher Tod durch Gehirnaffektion. Kind und Placenta sind im Uterus. Unmittelbar nach der Entnahme der Genitalien wurde Formalin in das uneröffnete Cavum uteri injicirt.

Linkes Ovarium $(5,5 \mathrm{~cm}: 1,5: 0,6)$ mit verschiedenen kleinen gelblichen Cystchen von Linsen- bis Erbsengrösse. Rechtes Ovarium $(4,1: 2: 0,6)$ enthält das Corp. lut. $(1,1: 0,9 \mathrm{~cm})$, das in der Mitte blass und derb ist, an der Peripherie gelbe Farbe hat. In der Pars vasculosa des Ovariums liegt ziegelrothes Pigment, kleine gelbliche Follikel in der Rindensubstanz.

Mikroskopischer Befund: Oberflächenepithel nur stellenweise erhalten, Albuginea straff, stellenweise ist sie jedoch aufgelockert, hyperämisch und ödematös durchtränkt und zeigt leichte deciduale Umwandlung. Das Ovarialstroma enthielt einige zu Grunde gegangene Primärfollikel, die meisten sind erhalten und mit einer Epithelschicht umgeben.

Zwischen den Stromazellen sieht man, entfernt von der Ovarialoberfiäche, eigenthümliche, übergrosse, wie gebläht aussehende Zellen, die meist eine kugelige oder ovale Gestalt haben. Der Kern, meist in Einzahl vorbanden, ist klein, im Vergleich zum Zellleib fast winzig zu 
nemuen (Taf. VIII, Fig. 12), sitzt in der Regel central, manchmal auch etwas gegen die Peripherie hinausgedrängt, der Zellleib ist angepfropft von kleinen Körnchen, die zum Theil ein weissliches, zum Theil ein ausgesprochen gelbliches Aussehen zeigen. Es kann keinem Zweifel unterliegen, dass es sich bei diesem Pigment um Blutfarbstoff handelt.

Was die Genese dieser Zellen anlangt, so werden wir auf diese Frage weiter hinten noch ausführlicher eingehen.

Die grösseren Follikel sind meist mit einem homogenen Inhalt ausgefüllt, das Follikelepithel ist verloren gegangen, bei manchen sieht man noch abgelöste Stücke des Epithels im Cystenlumen zerstreut.

Die Wand wird gebildet aus 2 Schichten, einer äusseren, rein bindegewebigen Charakters (Theca externa) und einer inneren, die aus epitheloiden Zellen mit blossem Protoplasmaleib und ovalem Kern sich zusammensetzt. Diese epitheloiden Zellen zeigen gegen die binde. gewebigen keine scharfe Abgrenzung, an manchen Stellen scheinen sie direct in dieselben überzugehen. Sie sind in der Regel in 6-8 Reihen übereinander geschichtet, manchmal ist die Schicht jedoch viel grösser, sodass Hervorragungen gegen das Lamen zu stattfinden. An einigen Stellen, und dies ist namentlich bei den grösseren Cysten der Fall, besteht die Schicht aus einigen wenigen übereinander liegenden Zellen. Zwischen dieser Schicht epitheloider Zellen sieht man, namentlich an ihren breiteren Partien, bindegewebige Zellen eingestreut, ausserdem zeichnet sie sich durch einen ungewöhnlichen Reichthum an Gefässen aus.

Während die epitheloiden Zellen an den grösseren Cysten weiter auseinandergerückt sind und auch in ihrer Färbbarkeit Einbusse erlitten haben, sind dagegen an einzelnen kleineren, durch die grösseren Cysten plattgedrückten Follikel diese Luteinzellen viel besser erhalten. So sieht man z. B. direct der Wand einer grösseren Cyste sich anlehnend einen kleineren, halbmondförmig abgeplatteten, atretischen Follikel, der in der Mitte noch einen schmalen Hohlraum enthält, in der ganzen Pheripherie jedoch von einer vielschichtigen Zone gut erhaltener Luteinzellen umgeben ist, die an den beiden Enden ausserordentlich weit zwischen die an diesen Stellen etwas aufgelockerten Stromazellen sich erstrecken. An anderen Stellen ist das Lumen der atretischen Follikel vollständig verschwunden, man sieht nur einen mebr oder minder breiten Streifen von Luteïnzellen ohne scharfe Umgrenzung gegen die Umgebung und obne fibröses oder hyalines Centrum. Manchmal lassen sich einzelne Züge von Luteïnzellen soweit in das benachbarte Gewebe verfolgen, dass es den Anschein hat, als ob sie an Ort und Stelle aus den Stromazellen entstanden wären. Auch von ganz kleinen Corpora atretica ausgehend sieht man hier und da kleinere Züge von Luteïnzellen. Ueberhaupt ist in diesem Falle die Entwickelung der Luteïnzellen eine so reichliche, dass manchmal auf weite Strecken hin Luteïnzellen zu verfolgen sind. Im Uebrigen ist zu bemerken, dass ganz spärliche Follikel einer einfachen Atresie mit Verlust des Epithels ohne Luteïnzellenwucherung verfallen sind, ferner, dass auch noch einzelne Primärfollikel und ein wachsender Follikel mehr oder minder gut erhalten sind.

Fall 11 (No. 532). G., 28 J., Vp. Gestorben am 10.11. 01 an Nephritis haemorrhagica und vorzeitiger Lösung der Placenta bei normalem Sitze derselben. Eklampsie. Gravidität im Anfang des 7. Monats. Der gravide Uterus wurde excidirt und in Formalin 
conservirt. Rechtes Ovarium $3: 2: 1$ mit einem Corpus lut. (1 cm : $1 \mathrm{~cm})$, das in der Mitte einen kleinen Spalt enthält. Linkes Ovarium $3: 2: 0,5 \mathrm{~cm}$ ohne Cysten.

Mikroskopischer Befund: Das Keimepithel ist zum Theil noch erhalten, die Albuginea zeigt auf weite Strecken keine Veränderung, an anderen Stellen ist sie aufgelockert, vereinzelt sind Gruppen von gut abgegrenzten deciduä̈hnlichen Zellen in ihr, zum Theil etwas entfernt von der Oberfläche.

Das Stroma, das in den oberflächlichen Abschnitten normale Dichte zeigt, ist in den tieferen Partien theilweise ödematös gequollen und auseinandergetrieben. Im rechten Ovarium "mit dem Corpus luteum sind wenig Primärfollikel, zahlreicher im linken Ovarium; bier finden sich auch einige wachsende Follikel, gut erhalten, die jedoch noch keine oder nur eine Andeutung einer Theca interna haben. Einige cystisch erweiterte Follikel enthalten in ihrem Innern eine homogene Substanz, das Epithel ist verschwunden, die Luteinzellenschicht an den einen etwas mehr, an den andern weniger gewuchert, im Ganzen nicht sehr stark ausgebildet. Diese relativ geringe Entwicklung manifestirt sich auch darin, dass an zusammengesunkenen, an einem Spalte noch erkenntlichen atretischen Follikeln die Zellen wenig von ihrem sonstigen Aussehen abweichen. Stärker entwickelt ist die Luteïnzellenschicht im rechten Ovarium, wo das Corpus luteum gelegeu ist. Dieses ist scharf abgegrenzt, die Luteïnzellen sind zum grösseren Theile nekrotisch zu Grunde gegangen. Davon abgetrennt durch eine ziemlich breite Bindegewebswand ist ein rundliches Gebilde (Taf. VIII, Fig. 13), das genau dieselben Zellen als das rechte Corpus luteum enthält und das, auf einer ganzen Reihe von Schnitten verfolgt, keinen Zusammenhang mit dem wirklichen Corpus luteum nachweisen lässt. Von der Peripherie aus strahlen gegen das Centrum zu kleinere bindegewebige Septen, die an ihrer Abgangsstelle noch Gefässe enthalten. Der periphere Gefässkranz tritt bier noch besonders deutlich hervor. Es kann, wie das bereits in Fall 6 des Näheren ausgeführt wurde, keinem Zweifel unterliegen, dass wir es mit einem grösseren atretischen Follikel zu thun haben, der bis in seine Einzelheiten dem wirklichen Corpus luteum gleicht. Nur ist hier, entsprechend dem längeren Bestande der Schwangerschaft, die Degeneration der Zellen schon weiter fortgeschritten, als wie im Falle 6, die Spindelzellen haben wie bei dem echten Corpus luteum desselben Ovariums die Luteïnzellen einzeln abgetrennt und isolirt.

Ausser dem Corpus luteum findet sich neben einzelnen kleinen Corpora candicantia ein sehr grosses Corpus candicans, das vollständig hyalin entartet ist, jedoch noch deutlich die krausenförmige Schicht der früheren Luteïnzellen und den centralen Theil erkennen lässt. Die Gefässe an seiner Peripherie sind durch Bindegewebshypertrophie stenosirt und zum grösseren Theil hyalin entartet. Auch die Gefässe in der Peripherie des Corpus luteum zeigen beginnende Obliteration, besonders stark ist die bindegewebige Verengerung in der Pars vasculosa ausgebildet.

Fall 12. R., 39 J., XIp. Gravidität vom 8. Monat, hochgradige Nephritis mit universellen Oedemen, Erweiterung des 
Muttermundes mit dem Bossi'schen Instrument, Wendung und Extraction, Exitus letalis unmittelbar nach Vollendung der Extraction. Uterus wird sofort nach dem Tode aus der frischen Leiche genommen und in Formalin fixirt. Section: hochgradige Schrumpfniere, Herzinsufficienz. 29. 12. 1904.

Linkes Ovarium $(2,5: 1,5: 4,5 \mathrm{~cm})$ mit solidem, scharf abgesetztem, gelblichem Corpus luteum $(1,2: 1,2 \mathrm{~cm})$, ganz nahe der Oberflache gelegen. Das rechte Ovarium (2:0,9:1,5 cm) enthält einige gelbliche Cystchen ohne deutliche Doppelwand.

Mikroskopischer Befund: Das Keimepithel ist stellenweise noch erhalten und die Albuginea weist an verschiedenen Stellen keine Veränderung auf, an anderen dagegen ist sie zellärmer und hyalin degenerirt, zum Theil zeigt sie eine fleckenweise deciduähnliche Umwandlung (Taf. VI, Fig. 14). Das Stroma zeigt gewöhnliche Dichte, enthält eine Anzahl von gut erhaltenen Primärfollikeln, daneben eine ganze Reihe von grösseren und kleineren, eystisch degenerirten Follikeln, deren Wand zum Theil eine geringe oder gar keine, zum Theil eine ausgeprägte Luteïnzellenwucberung aufweist, die besonders schön bei einem Follikel zu Tage tritt, bei dem die Schicht in Form eines Bandes von der Unterlage abgehoben ist und wo die Breite des Bandes stellenweise wohl 40 Zellen hintereinander ausmachen. In der in Taf. VIII, Fig. 15 gegebenen Abbildung erkennt man, dass die Theca interua epitheloide, luteïnhaltige Zellen in geringer Breite zeigt und dass darüber das Follikelepithel zum Theil noch erhalten ist. Durch Ausfall einzelner Follikelepithelien sind die zottenförmigen Fortsätze entstanden; zwischen den Epithelien sieht man reichliche Capillaren.

Auch kleinere Follikel zeigen eine Luteïnzellenwucherung. In der Pars vasculosa sind die Gefässwände vielfach hypertrophisch, an der Grenze zwischen Pars vasculosa und der Rindensubstanz sind die Stromazellen durch Oedem stark auseinandergedrängt und zeigen reichliche Einlagerungen von Blutschollen.

An einer Stelle des Stromas finden sich auch die grossen gebläbten Zellen mit kleinem Kern und Pigmentkörnchen im Protoplasma. Wir werden auf sie bei der Besprechung des Falles No. 35 noch genauer eingehen, da sie dort besonders schön ausgebildet sind.

Fall 13 (No. 531). Rosa M., 37 J., Xp. 30. 5. 00. Gravidität im 9. Monat. Eklampsia. Nach dem Tode der Mutter sofort Sectio caesarea. Linkes Ovarium $(2,5: 1,1: 0,8 \mathrm{~cm})$ enthält ein $0,7 \mathrm{~cm}$ im Durchmesser aufweisendes solides Corp. lut. Das rechte Ovarium $(2,5: 1,3: 0,6)$ zeigt ein ungewöhnlich grosses Corpus candicans.

Mikroskopischer Befund: Das Keimepithel ist zum Theil erhalten, die Albuginea weist an verschiedenen Stellen Einlagerungen von Haufen decidualer Zellen auf, die meist ganz an der Oberfiäche gelegen sind, zum Theil jedoch tief innerhalb des Stromas aufgefunden werden, manchmal nur 5-10 Zellen zusammen. Ferner finden sich einige pirzelförmige Fortsätze mit deciduaälnnlichen Zellen an der Ovarial- 
oberfläche. Am stärksten ausgebildet ist die deciduale Umwandlung in dem linken Ovarium (mit dem Corpus luteum).

.Das Stroma zeigt normale Dichte, eine ödematöse Durchtränkung ist nirgends festzustellen. In die Augen springt der ungewöhnliche Blutreichthum sowohl in der Rindensubstanz, als auch in der Marksubstanz. Die Gefässe sind strotzend mit Blut gefüllt, zum Theil weisen die Gefässwände die bekannten Verdickungen auf, die bisweilen zur vollständigen Obliteration der Gefässe führen. Primärfollikel sind nur sehr spärlich, die wachsenden Follikel scheinen grösstentheils zu Grunde gegangen zu sein, es lassen sich auf einer Reihe von Schnitten keine nachweisen, und zwar verhalten sich beide Ovarien in dieser Beziehung ganz gleich. Auffallend sind die grossen Corpora candicantia, die bis Erbsengrösse aufweisen, vollständig hyalin degenerirt sind; in ibrer Umgebung zeigt sich keine Luteïnellenreaction. Zahlreiche kleine- Corpora candicantia. Cystische Follikel finden sich nicht vor. Dagegen sind mitten in das Stroma, durch Structur und Farbe hervorstechend, atretische Follikel mit ausgeprägter Luteïnzellenreaction eingestreut (Taf. VII, Fig. . 16). Sie sind zum Theil der Länge nach zusammengedrückt, so dass man kaum mehr das lineare Lumen zu erkennen vermag, andere weisen einen langgestreckten bindegewebigen Kern auf, die Luteinzellenwucherung ist in verschiedener Richtung verschieden stark ausgebildet, zum Theil erstreckt sie sich recht weit in das Stroma hinein, gelegentlich ahmen die Gebilde das Aussehen eines Corpus luteum im Kleinen nach (Taf. VII, Fig. 17).

Das Corpus luteum ist für den 9. Monat der Gravidität gut erhalten. In der Mitte ist ein kleiner hyaliner Kern, die Luteïnzellen liegen compact aneinander, ein Abblättern von den bindegewebigen Septen beobachtet man nirgends. Die Kerne der Luteïnzellen sind grösstentheils erhalten, das Chromatin meist körnig oder fadenförmig zerfallen, die Umrisse der Zellleiber sind unscharf, das Protoplasma meist homogen, einzelne Luteineinlagerungen sind zu erkennen.

Zusammenfassung: Zum Theil starke deciduale Umwandlung in der Albuginea, theilweise mit Bildung von Fortsätzen an der Oberfläche; aber auch Auftreten decidualer Zellhaufen in den tieferen Abschnitten des Stromas, hervorgegangen aus Stromazellen. Starke Gefässentwicklung. Keine cystischen Follikel. Zahlreiche kleine atretische Follikel mit ausgeprägter Luteïnzellenreaction.

Fall 14 (No. 236). O., 37 J., VIIllp. Journ.-No. 1284. 1900. Uterusruptur sub partu. Supravaginale Amputation. Conservirung in Formalin.

Rechtes Ovarium $(6: 0,9: 2,5)$ enthält einige kleine Cysten und mehrere Corp. albicantia. Das linke Ovarium $(4,5: 3: 1 \mathrm{~cm})$ ist mit einem soliden gelben Körper $(0,7: 0,5: 0,6 \mathrm{~cm})$ versehen.

Mikroskopischer Befund: Das Keimepithel ist nur an wenigen Stellen noch erhalten, die Albuginea zeigt an einigen Stellen deciduale Reaktion, ein paar Stellen lassen kleine Fortsätze erkennen. Das Stroma, das fast überall normale Dichte aufweist und nur gegen die Pars vas. culosa zu leicht ödematös durchtränkt ist, enthält eine ziemlich reich- 
liche Anzahl von Primärfollikeln und einige wachsende Follikel. Auch grössere und eystisch degenerirte Follikel sind reichlich vertreten und zeichnen sich durch besonders üppige Luteïnzellenentwickelung aus. Sie bilden vielfach ein breites Band und stechen durch ibre gute Tinktion in die Augen (Taf VII, Fig. 18). Auch an den in Atresie befindlichen Follikeln ist die Luteïnzellenreaktion ungewöhnlich stark ausgeprägt und man sieht häufig wulstartige Verdickungen. Bisweilen erstrecken sich in langem Zuge die Zellen weit zwischen das Stroma hinein. Die Frage, ob es sich dabei um während der Schwangerschaft atretisch gewordene Follikel handelt oder ob die Luteïnzellenwucherung von alten Corpora atretica ausgehen, ist nicht immer sicher zu entscheiden. Bei der Taf. VII, Fig. 19, die nur eine recht geringe Luteïnzellenentwickelung zeigt, kann man sich des Eindruckes übrigens nicht erwehren, als ob die Bindegewebszellen eines Corpus atreticum sich zu Luteïnzellen umzubilden anfingen.

Das solide Corpus luteum ist auch hier noch recht gut erhalten, keine Abblätterung der Luteïnzellen, die Zellcontouren zum Theil noch zu erkennen, der Zellleib ist homogen und gleichmässig rothblau gefärbt, der Kern meist gut tingirt, wenn auch meist Fragmentation zeigend.

Zusammenfassung: Deciduale Umwandlung der Albuginea mit Fortsätzen, üppige Luteïzellenwucherung in den atretischen und cystischen Follikeln.

Fall 15 (No. 510). K., 32 J., IVp. Uterusruptur bei Hydrocephalus. Supravaginale Amputation. Juni 1901.

Linkes Ovarium $(7,8: 3: 0,4 \mathrm{~cm})$ ohne Corpus luteum, das rechte Ovarium fehlt.

Mikroskopischer Befund: Oberflächenepithel fast nirgends erhalten, Albuginea nur leicht aufgelockert, stellenweise deciduale Umwandlung, Stroma ist an einzelnen Partien aufgelockert und reichlich von Primärfollikeln durchsetzt. Sehr starke Luteïnzellenwucherung in cystischen und atretischen Follikeln, wobei die Luteïnzellen von den Enden der atretischen Follikel sich weit in das Stroma hinein erstrecken, doch finden sich auch einzelne solche, die eine stärkere Wucherung vermissen lassen, ferner ist ein Follikel zu sehen, der noch regelmässiges Follikelepithel trägt.

Fall 16 (No. 522). M. Spontane Uterusruptur während der Geburt bei einer 48 Jahre alten Vielgebärenden. Querriss nahe dem Fundus. Exitus während der Eröffnungsperiode.

Linkes Ovarium ungewöhnlich stark in die Länge gezogen $(8,5: 0,5: 1 \mathrm{~cm})$ mit verschiedenen kleinen Corp. albicantia. Rechtes Ovarium $(5,0: 0,6: 3,5)$ mit dem Corpus luteum $(1,2: 1,4)$ von dunkelgelber Farbe, über das Niveau hervorragend, enthält kleine Eystchen, die auf dem Durchschnitt z. Th. ein gelbliches Aussehen zeigen.

Mikroskopischer Befund: Auch hier zeigt sich das Corpus lut. noch relativ gut erhalten, die Luteïnellen sind nur ganz vereinzelt aus- 
gefallen, die Kerne derselben sind zum Theil vorhanden, wenn sie auch die Zeichen der regressiven Metamorphose aufweisen, die Zellleiber zeigen gelbliche Farbe, ihre Contouren sind meist nicht mehr zu erkennen.

Albuginea mit stark decidualer Reaction; Stroma ganz arm an Primärfollikeln, was bei der 48jährigen Person nicht auffallend ist. Auch die atretischen Follikel sind sehr spärlich. Die aufgefundenen lassen die typische Luteïnzellenreaction erkennen.

Fall 17. H., 32 J., IIIp. 31. 10. 05. Uterusruptur sub partu. Supravaginale Amputation. Formalinhäring. Rechtes Ovarium $(3,5: 0,6: 2,0)$ in Adhäsionen eingebettet, enthält verschiedene alte Corpora albicantia von ziemlichem Umfang und einige kleine Cystchen. Das linke Ovarium ist ebenfalls in Adhäsionen eingebettet $(5: 2,3: 1,2)$, ist mit dem Corpus luteum $(1: 1,2 \mathrm{~cm})$ versehen, es ist ganz solide und zeigt einen derben, weisslichen, centralen Kern.

Mikroskopischer Befund: Die Ovarialoberfläche zeigt eine ungewöbnlich starke Auflockerung und ödematöse Durchtränkung der Albuginea und darunter theilweise eine faserig-hyaline Degeneration der Zellen. Häufig wuchert die Albuginea in Form von Fortsätzen über die Ovarialoberfläche hinaus, bisweilen sieht man auch umwachsene Hohlräume, welche mit Keimepithel ausgekleidet sind.

Das Ovarialstroma zeigt ausser einer stärkeren Hyperämie und einer stellenweise ganz geringen ödematösen Durchtränkung keine Besonderheiten. Corpora candicantia und fibrosa sind eingelagert, Primärfollikel in mässiger Menge. Die cystischen Follikel zeigen ein meist sehr breites Band von vollentwickelten Luteïnzellen. Die Luteïnzellenwucherung ist übrigens an demselben Follikel nicht überall gleich stark, an der einen Stelle der Peripherie ist die Entwickelung manchmal ungewöhnlich stark, an einer anderen dagegen ganz gering oder vollständig fehlend. An einem Follikel, an dem die Epithelien noch vorhanden sind, sind die Luteïnzellen weniger gut ausgebildet.

Das Corpus luteum macht einen noch recht lebensfrischen Eindruck, auffallend ist der besonders reichliche Gefässkranz an seiner Peripherie, die Gefässe weisen keine Obliterationserseheinungen auf. Auch mitten in das Corpus hinein zieht ein Bindegewebsnetz mit zahlreichen Gefässen. Das Corp. lut. selbst ist ganz solide, die Zellen fest aneinander liegend, die Contouren scharf abgesetzt, die meisten Kerne noch erhalten, wenn auch mit Erscheinungen der Fragmentation.

Fall 18. K., 23 J., IIIp. 11. 12. 1904 stirbt unmittelbar im Anschluss an die Geburt an Verblutung in Folge Atonia uteri. Wenige Stunden post mortem Entnahme der Genitalien. Conservirung in Kaiserling'scher Lösung. Linkes Ovarium (4:2:1,5) mit k]einen Follikeln, rechtes Ovarium $(5: 2,2: 1,3 \mathrm{~cm})$ enthält ein ziemlich bleiches Corp. lut. $(1,0: 0,6 \mathrm{~cm})$ ohne Cystenbildung im Innern. 
Mikroskopischer Befund: Albuginea ist auf weite Strecken aufgelockert, ödematös durchtränkt, theils abgehoben, theils Fortsätze bildend, die Zellen sind meist spindelförmig, klein, schlecht gefärbt, zum Theil aber grösser, mehr oval, besser gefärbt, zumal in der Umgebung der zahlreichen Capillaren. Das Stroma ist ziemlich reich an Primärfollikeln und enthält einige wachsende Follikel ohne Besonderheiten. Die grösseren Follikel sind zum Theil cystisch degenerirt und enthalten grössten Theils ein breites Luteïnzellenband, an einigen sind die Epithelien noch, wenn auch abgelöst, zu sehen, unter diesen beginnt die Luteinzellenwucherung. Besonders zahlreich sind die zusammengefallenen und atretischen Follikel mit meist sehr stark entwickelter Luteïnzellenwucherung vertreten. Auch an der Peripherie von Corpora atretica sieht man einige veränderte Zellen, die dem Typus der Luteïnzelle sich nähern und ein ähnliches Bild zeigen wie Taf. VII, Fig. 19. Die Blutversorgung ist reichlich. In einem Gefässlumen sieht man dieselben Zellen wie sie auf Seite 237 beschrieben und in Taf. VI, Fig. 7 abgebildet sind.

Das Corp. lut. ist noch mässig gut erhalten. Die Gefässversorgung ist gering, auffallend viel bindegewebige Stränge durchsetzen das Gebilde. Die Luteïnzellen haben theilweise ihren Kern verloren, theilweise ist er in fragmentirter Gestalt noch erhalten, die Umrisse der Zellen sind meist verschwommen.

Fall 19 (No. 237). M., 43 J., VIII p. Spontane Uterusruptur sub partu, Porro'sche Operation. 6. 4. 1901. Formalinconservirung. Rechtes Ovarium $(4,5: 0,7: 2 \mathrm{~cm})$ enthält verschiedene alte Corp. albic., darunter eins, das $1,2 \mathrm{~cm}$ lang und $0,8 \mathrm{~cm}$ breit ist. Das linke Ovarium $(4,5: 0,7: 2,8 \mathrm{~cm})$ ist fest mit dem Fimbrienende verwachsen, mit einem Corp. lut. $(1,0: 0,8)$, das einen derben Kern hat. Einige gelbliche und röthliche Streifen durchziehen die Ovarien, von Blutresten herrührend.

Mikroskopischer Befund: Das Corpus luteum mit derbem centralen Kern ist gut erbalten, fest gefügt und von ungewöhnlich vielen Bindegewebszellen durchzogen. Die Luteïnzellen zeigen auffallend viele und grosse Vacuolen, die Kerne sind in der Regel gut tingirt und die Zellen meist scharf abgesetzt, einzelne jedoch auch bereits der hyalinen Degeneration verfallen. Die Blutgefässversorgung ist eine mässige.

Die Oberfläche des Ovariums zeigt stark hypertrophische Vorgänge, sodass Einbuchtungen und Einschlüsse von Keimepithel entstehen. Besonders deutlich tritt dies bei einem langen, schlauchartigen Gewebe zn Tage, an dessen äusserer Seite das Epithel in Folge der Dehnung ganz niedrig, an dessen innerer Wand das Epithel dagegen normal hoch ist (Taf. VIII, Fig. 20). Ausgebildete deciduazellenähnliche Gebilde sieht man übrigens in den hypertrophischen Theilen der Albuginea selten. Die Zahl der vorhandenen Primär- und grösseren Follikel ist äusserst gering. Man kann daher Luteïnzellenwucherung nur ganz selten beobachten und auch in diesen Fällen nicht so schön wie in den vorhergehenden Fällen. Auch die Anzahl Corpora atretica mit Luteïnzellenentwickelung ist eine recht geringe. Das Stroma ist stellenweise, namentlich in der Umgebung von Corp. fibrosa stark von Hämosiderin schollen durchsetzt. 
Fall 20 (No. 507). H., 31 J., IIIp. Ende der Gravidität. Uterusruptur sub partu. Blasenverletzung. Supravaginale Amputation 11. 3. 1902. Conservirung in Formalin.

Linkes Ovarium $(5: 3: 0,5 \mathrm{~cm})$ enthält das Corpus luteum $(1: 1 \mathrm{~cm})$, solide, aber ohne festeren Kern. Rechtes Ovarium $(5: 1,5: 0,5 \mathrm{~cm})$ ist ziemlich derb, enthält nur ganz wenige Follikel.

Mikroskopischer Befund: Das Epithel ist nur ausnahmsweise erhalten, die Albuginea zeichnet sich durch odematöse Durchtränkung und pirzelförmige Wucherungen aus, zum Theil enthält sie auch schön ausgebildete deciduaähnliche Zellen. Auffallend ist der grosse Blutreichthum der oberflächlichen, Schichten, der stellenweise zur hämorrhagischen Durchsetzung des ganzen Gewebes geführt hat.

Primärfollikel sind fast keine aufzufinden, die spärlichen grösseren und atretischen Follikel zeigen Luteïnzellenwucherungen. Doch muss man viele Schnitte durchsuchen, um Follikel aufzufinden. Das Corpus luteum zeigt die am Ende der Gravidität gewöhnlichen regressiven Zustände.

Fall 21. 42 jühr. Frau, VIIIp. Poliklinik 5. 3. 1905. Gravidität am Ende des 10. Monats. Placenta praevia, starke Blutungen. Exitus an Luftembolie. Section nach 24 Stunden, daher sind die Präparate nicht mehr ideal, gestatten aber ein hinreichendes Urtheil über das Verhalten der Luteinzellen.

Rechtes Ovarium 3,3:3:0,8, linkes Ovarium 4,0:2,5:1, mit Corpus luteum $(1: 1 \mathrm{~cm})$, ganz solide.

Mikroskopischer Befund: Epithel nur in den Einsenkungen zu sehen. Starke Deciduareaction der Albuginea in Form von circumseripten Anhäufungen von Deciduazellen. Verschiedene cystische Abschnürungen des Keimepithels.

Die Primordialfollikel sind auf mehreren Schnitten nur ein Paar aufufinden, die spärlichen cystischen und atretischen zeigen ausgesprochene Luteïnzellenwucherung. Das Corpus luteum, scharf begrenzt, ist von zahlreichen spindelförmigen Zellen durchwachsen, die Luteïnzellen şind klein, zusammengesintert, abblätternd, die Kerne in Chromatolyse.

\section{Gruppe.}

Fall 22. Gravidität aus dem 1.-2. Monat. Es ist ein Leichenpräparat, dessen Herkunft nicht näher bekannt ist. Es handelt sich um ein jugendliches Individuum. Das Ei ist nicht mehr in der Uterushöhle, wohl aber ist noch die ganze Decidua vera in derselben. Das Präparat war in Spiritus conservirt.

Das rechte Ovarium, $4: 3: 1 \mathrm{~cm}$, mit sehr schönem Corpus luteum von $1,75: 1,5 \mathrm{~cm}$, setzt sich scharf gegen die Umgebung $a b$, ist ganz solide. Das Ovarium enthält einige linsengrosse Cysten. Das linke Ovarium, $5: 3,5: 1,5$, ohne Corpus lut. 
Mikroskopischer Befund: Das Corpus luteum ist scharf gegen das umgebende Stromagewebe abgegrenzt, ist im Vergleich zu den jüngeren Follikeln und dem Stroma, die ziemlich gut gefärbt sind, schlecht erhalten. Es lässt sich nicht bestimmen, wieviel dabei mit der Art der Conservirung und wie viel mit degenerativen Vorgängen im gelben Körper zusammenhängt. Sicher sind letztere dabei auch betheiligt, wie aus dem Verhalten von Follikeln hervorgeht.

Das Centrum des Corpus luteum ist ganz structurlos, einzelne Zellreste sind eingelagert. Strahlenartig ziehen Ausläufer peripherwärts bis nahe an die bindegewebige Umbüllung des Corpus, ohne jedoch diese selbst zu erreichen, einige Spindelzellen sind auf ihnen zu erkemnen. Von der Theca interna aus dringen Zellen in das Corpus ein und theilen die Luteïnzellen in Gruppen. Die Zellen zeigen im Allgemeinen noch ihren charakteristischen Bau, manche sind jedoch der Nekrose verfallen, ebenso wie auch ein Theil der Zellen der Theca externa die Structur verloren baben. Die Luteïnzellen selbst liegen abgeblättert zwischen den Septen, zum Theil sind sie ganz ausgefallen, der Kern ist an manchen geschwunden, so dass nur noch eine homogene, gleichmässig gefärbte Masse vorhanden ist.

Was die übrigen Theile des Ovariums anlangt, so ist an verschiedenen Stellen in den Einsenkungen das Oberflächenepithel noch vorhanden, das Stroma zeigt gewöhnliches Verhalten, deciduaähnliche Zellen sind nicht zu sehen, doch ist an einer Stelle ein kurzer Fortsatz mit aufgelockertem Stroma zu sehen. Die Anzahl der Primordialfollikel ist gering, die wachsenden Follikel, die in Mebrzahl vorhanden sind, zum Theil gut erhalten, zeigen keine Vermehrung der Zellen der Theca interna. In mehreren grösseren Follikeln liegt das Epithel abgeblättert im Lumen regellos durcheinander, die Wand ist ausgekleidet von den hypertrophirten Zellen der Theca interna, die in einer Reihe von 10 bis 15 Exemplaren übereinander gelagert sind. Zwischen denselben sind spindelförmige Bindegewebszellen und Capillaren eingelagert. Die Form der Zellen ist zum Theil epitheloid, gelbliche Einlagerungen sieht man selten.

Zusammengefasst handelt es sich hier um Ovarien in einem frühen Stadium der Gravidität: Deciduale Veränderungen der Stromazellen fehlen gänzlich, die Deutung der übrigen Befunde ist durch die z. Th. mangelhafte Conservirung erschwert, doch lässt sich so viel feststellen, dass an den grösseren Follikeln die interne Zellschicht entschieden an Umfang zugenommen und die Zellform sich mehr dem epitheloiden Typus genähert hat. Es handelt sich demnach um die ersten Anfänge einer Luteïnzellenwucherung.

Fall 23 (No. 544). Rechtsseitige Tubargravidität 2.-3. Monat. Präparat gewonnen am 10.5. 1878, in Spiritus conservirt.

Das rechte Ovarium 4,5:1,2:3,7 cm mit sehr schönem Corpus luteum, von 2,0:1,2 cm Durchmesser, die Schichtung ist ausserordentlich deutlich zu sehen, in der Mitte ist ein kleiner Spalt. Linkes Ovarium ohne Corp. lut., 3,8:2,8:1,0 cm. 
Mikroskopischer Befund: Trotz des Alters sind die Präparate ziemlich gut conservirt. Das Corpus luteum ist scharf gegen die Umgebung abgegrenzt, an der Peripherie sind noch verschiedene kleine epitheloide Zellen, in der Mitte ist ein homogen erscheinender Pfropf mit einzelnen degenerirten Zellen; die Zellen der Theca interna sind grösser und ziehen zwischen die Luteïnzellen hinein, die zwischen den kleineren bindegewebigen Septen meist abgesehilfert liegen und in ihrer Tinctionsfähigkeit bereits stark gelitten haben. Es ist demnach das Corpus luteum bereits stark in regressiver Metamorphose begriffen, doch könnte dies zum Theil doch auch durch das Alter und die Conservirung des Präparates vorgetäuscht sein.

Die Albuginea ist auffallend stark aufgelockert, Deciduazellen sind jedoch in derselben nicht zu finden. Das Stroma enthält Primärfollikel, die wachsenden Follikel sind in Atresie begriffen. Sie haben ihre runde Form und die Epitbelbekleidung verloren, ihre Wände sind eingeknickt, so dass ein S- oder $\lambda$-förmiger, manchmal ganz unregelmässiger Hohlraum resultirt. Die Lage der Zellen der Theca interna erscheint dadurch am so dicker, thatsächlich sind sie aber auch vermehrt, sind grösser und tragen epitheloiden Charakter. Diese Zellen erstrecken sich an den Enden der zusammengefallenen Follikel gelegentlich tiefer in das Stroma hinein.

Zusammenfassung: Neben einem in regressiver Metamorphose begriffenen Corpus luteum finden sich atretische Follikel, welche deutlich eine Luteïnzellenschicht erkennen lassen. Gerade an den Stellen, wo Macerationserscheinungen am Präparate vorhanden sind, treten die Zellen der Theca interna besonders deutlich hervor.

Fall 24 (No. 114). Spirituspräparat. Uterus gravidus III. Mens. unbekannter Herkunft. Rechtes Ovarium 3,5:2,5:0,51 mit einem Corpus luteum $(0,9: 0,8 \mathrm{~cm})$, keine Cystenbildung. Linkes Ovarium $4: 2,5: 1,0$.

Mikroskopische Untersuchung: Oberfächenepithel verschwunden, die Albuginea streckenweise etwas aufgelockert, die Zellen in ihr vergrössert (beginnende Deciduazellenbildung). Corpora fibrosa, spärliche Corpora candicantia; von den ersteren fällt eines durch seine Grösse auf. Schlecht erhaltene Primärfollikel sind in geringer Menge vorhanden. Cystisch degenerirte Follikel sind nicht vorhanden. Einzelne atresirende Follikel zeigen zwar eine stärkere Ausbildung ihrer Ausbildung ihrer Theca interna-Zellen, doch in der Mehrzahl derselben sieht man davon nichts mehr; es begrenzt die Follikelwandung ein mehr oder minder breites Band, das entweder nur leicht gefaltet oder krausenartig zusammengelegt ist, so dass das Lumen erheblich verkleinert wird. Das Lumen enthält hie und da noch einige restirende Follikelepithelien, einmal wurde auch das degenerirte Ei gefunden, meist ist es von einem lockeren zarten Netz von Bindegewebszellen ausgefüllt.

Da die Herkunft des Präparates und speciell die Todesursache unbekannt, vielfach auch die Conservirung nicht einwandsfrei ist, können zuverlässige. Schlüsse nicht gezogen werden. 
Fall 25 (No. 18). Leichenpräparat einer Retroflexio uteri gravidi IV. Mens. (Fötus $17 \mathrm{~cm}$ lang). Das rechte Ovarium ist zum Theil entfernt, das linke Ovarium ist klein, $3: 2: 0,3 \mathrm{~cm}$, enthält ein Corpus luteum mit blutigem Kerne und mehrere kleine Cystchen.

Mikroskopischer Befund: Die Albuginea zeigt stellenweise eine ödematöse Durchtränkung des Gewebes, doch nirgends eine ausgesprochene Deciduazellenbildung. Das Stroma des Ovariums enthält nur eine sehr geringe Anzahl von Primärfollikeln, etliche wachsende ohne Besonderheiten und einige leicht cystisch erweiterte Follikel, bei denen das Epithel theilweise abgestossen in dem Lumen des Follikels liegt und die Wand von einem Band mehr oder minder typischer Luteïnzellen ausgekleidet ist. Die Gefässe der Pars vasculosa sind reichlich und zum Theil hypertrophisch.

Fall 26 (No. 561). Gravider Uterus unbekannter Herkunft von 4.-5. Monat; altes Spirituspräparat, das in seiner Conservirung etwas gelitten hat. Rechtes Orarium $3: 2,72: 0,80 \mathrm{~cm}$ mit einem Corpus luteum $(1,2: 1,0)$. Linkes Ovarium $3: 2,75: 0,8$.

Mikroskopischer Befund: Die Albuginea zeigt keinen auffälligen Befund, das Keimepithel ist nirgends mehr erhalten. Das Corpus luteum ist stark in Nekrose begriffen. Wenn auch die Einzelheiten wegen der ungenügenden Conservirung nicht mehr mit Sicherheit zu erkennen sind, so kann man an einigen sich vorfindenden grösseren Follikeln das Luteïnzellenband deutlich feststellen, das zum Theil eine starke Entwicklung zeigt.

Eälle 27-31. Daran schliessen sich ferner noch 5 Fälle, 1 aus dem 8. Monat an Eklampsie verstorben, 1 aus dem 9., gestorben an unbekannter Krankheit und ferner 3 gestorben in Folge Uterusruptur sub partu. Da sich genacere Angaben an den Präparaten nicht finden, und dagegen aus der Conservirung schliessen lässt, dass sie nicht sofort nach der Entfernung aus der Leiche in die fixirende Flüssigkeit gebracht worden sind, so will ich nur so viel erwähnen, dass an allen die Theca interna der meisten Follikel verbreitert erscheint, doch ist vielfach an den Zellen nichts mehr von Einzelheiten zu erkennen. Ganz bei Seite gelassen sind jene Fälle, welche in Folge ungenügender Conservirung oder vorausgegangener Veränderungen durch acute, meist septische Processe kein unzweideutiges Bild von den Structurverhältnissen des Ovariums mehr geben.

\section{Gruppe.}

Die puerperalen Fälle.

Fall 32 (No. 499). 30 J., II p. Uterusruptur und Parametritis, Exitus erfolgt 24 Stunden post part. 1897. Sectionspräparat. 
Rechtes Ovarium vergrössert $(4,5: 3.5: 1,5 \mathrm{~cm})$ enthält das Corpus luteum mit deutlichem fibrösen Keru $(1,5: 1,0 \mathrm{~cm})$. Linkes Ovarium $(3: 2,5: 1,0 \mathrm{~cm})$ zeigt an der Oberfläche leichte Adhäsionen und enthält mehrere erbsengrosse Follikel.

An der Oberfläche erkennt man die stark gewucherte Albuginea, zum Theil in Form von Pirzeln. Einige degenerirte Primärfollikel. Die atretischen und die cystischen Follikel lassen ein Luteïnzellenband erkennen, das meist von der Unterlage abgehoben ist. Die Zellen sind in ihrem Zusammenhang gelockert und haben in ihrer Conservirung gelitten.

Fall 33. J. K. I p., 23 J. alt, stirbt am 3. Tage des Wochenbettes an Eklampsie. Hebammenschule. Febr. 1905. Ein Stück durch die Mitte des Ovariums wird bei der Section herausgeschnitten zur mikroskopischen Untersuchung.

Mikroskopischer Befund: Das Oberflächenepithel ist verloren, die Albuginea ist aufgelockert, an verschiedenen Stellen hebt sie sich brückenartig $a b$ und zeigt an diesen Stellen ein homogenes oder maschiges Aussehen. Einzelne deciduaähnliche Zellen finden sich noch vor, sie sind auffallend blass, hydropisch geschwollen, zum Theil auch bereits zusammengeschrumpft, die Kerne zerfallend. Die Primärfollikel sind spärlich, die Eizellen sind meist homogen und roth, die Follikelepithelien ebenfalls häufig in Zerfall. An verschiedenen Stellen sind Corp. atretica vorhanden, die in der Mitte einen bindegewebigen Kern enthalten; einige haben noch einen kleinen Hohlraum, der nach aussen zu von einem den grössten Theil der Peripherie umfassenden hyalinen Saum begrenzt wird und der in seiner Mitte chromatolytische Follikelepithelien enthält. Ebensolche sind auch in einem Gefässe der Theca interna gelegen. Zwischen den strahlenförmig angeordneten bindezrewebigen Zellen sind grössere epitheloid gelagert, die sich in unserem Falle durch ihre schattenhaften Umrisse mit einem ganz leicht röthlich erscheinenden Tone und durch ihre schlecht gefärbten, in Chromatolyse begriffenen Kerne von den gewöhnlichen Theca interna-Zellen unterscheiden. Es handelt sich offenbar um zu Grunde gehende Zellen; an einzelnen, die frischer sind und bei denen der Kern eine mehr spindelförmige Gestalt hat, besteht die Möglichkeit, dass sie sich wieder zu gewöhnlichen Bindegewebszellen zurückbilden, wie dies auch Sobotta bei der Corpus luteum-Bildung von Maus und Kaninchen annimmt.

Bei den erhaltenen grösseren Follikeln sind die Epithelien abgestossen und liegen im Lumen des Follikels mehr oder weniger unregelmässig zerstreut, manchmal noch den Discus oophorus enthaltend, der das intensiv mit Eosin roth gefärbte homogene Ei umfasst. Die Theca interna ist gut ausgebildet, schmaler an den runden, breiter an den zusammenfallenden Follikeln, reichlich mit Gefässen versorgt; die Thecazellen liegen in 8-30 facher Reihe übereinander. Sie sind theilweise hydropisch gequollen, theilweise sind sie zusammengeschrumpft, der Kern zeigt fast ausnahmslos Chromatolyse.

Fall 34. Z., 21 J., II p. 19. 4. 05. Künstliche Frühgeburt, Wendung und Extraction. Perforirender Cervixriss, keine Temperatursteigerung $(37,5)$, septische Endometritis. Hochgradige Anämie. Exitus am 5. Tage des Wochenbettes. 
Das Keimepithel ist zum Theil erhalten, die Primordialfollikel sind ziemlich reichlich vorhanden, die Eizelle ist vielfach degenerirt, ebenso häufig die Follikelepithelien. Die decidualen Veränderungen der Albuginea sind in Rückbildang, die Zellleiber sind weit von einander entfernt, einzelne sind gequollen, andere in Auflösung, desgleichen die Kerne.

Die runden und mehr noch die zusammengefalteten Follikel haben eine gut entwickelte Theca interna mit vergrösserten Zellen, die alle Eigenschaften des vorhergeschilderten Falles aufweisen. Doch herrschen hier bereits melır die spindeligen Elemente vor. Einige atretische Follikel zeigen noch vergrösserte Zellen in der Theca interna. Sonst gleiche Befunde, wie vorher.

Fall 35 (No. 519). Knoll 1902. Spontane Uterusruptur mit Abriss des vorderen Vaginalgewölbes. Exitus am 6. Tage des Puerperiums in Folge Anämie. Formalinconservirung. Linkes Ovarium $(2,6: 1,9: 1,1)$ mit geschrumpftem Corpus luteum. Das rechte Ovarium ist ohne Corpus luteum, weist mehrere kleinere Cystchen von leicht gelblichem Aussehen auf.

Mlikroskopischer Befund: Die Albuginea besteht aus einem zellarmen Gewebe und ist durch Oedembildung stark auseinander gedrängt. Das Stroma ist nicht so gut gefärbt, wie man bei vom schwangeren Uterus stammenden Ovarien zu seben gewöhnt ist, es hat in seiner Ernährung offenbar durch die Anämie gelitten. Zahlreiche Primärfollikeln durchsetzen dasselbe, doch ist auch hieran ein Theil in Degeneration begriffen. Auffallend viel wachsende Follikel sind anzutreffen. Ausserdem sind cystische und atretische, zusammengesinterte Follikel vorhanden, die sich in einigen Stücken von den während der Schwangerschaft gefundenen unterseheiden. An den meisten cystischen Follikeln kann man deutlich noch die ehemalige Luteïnzellenschicht als eine gegen die Unterlage mehr oder minder scharf abgegrenzte Membran erkennen. Allein die Zellen haben zum grössten Theil das Charakteristische verloren; theils sind sie zu Grunde gegangen, von Kerne ist nichts mehr vorhanden, theils sind die Conturen ganz verschwommen, das Protoplasma hyalin oder fibrinös entartet, theils haben die Kerne eine mehr spindelförmige Gestalt. (Taf. VIII, Figur 21.) Von den letzteren Zellen ist schwer zu sagen, ob es sich um zurückgebildete Luteïnzellen handelt, oder ob es die nunmehr besser zur Geltung kommenden Zellen des bindegeweblichen Stützgewebes sind. Gegen das Lumen des Follikels zu sind die Zellen nicht mehr scharf abgegrenzt wie ehedem, es ragen vielmehr die Zellen ungeordnet durcheinander, abblätternd, sich auffasernd und sich auflösend hinein und bilden eine unebene Begrenzungslinie. Manchmal kann man auch einen fibrinösen Saum, ähnlich demjenigen des Nitabuch'schen Fibrinstreifens beobachten.

Fall 36. B., 36 J. alt, VIIl p., erkrankt nach einem unvollständigen Abort (Ende des 4. Monats) an einer Endometritis puerperalis, die trotz Ausräumung zu einer Allgemeininfection führt, der die Pat. am 7. Tage erliegt. Bei der Section fand sich ausser 
der Endometritis septica eine Miliartuberculose und eine Tuberculose der Genitalien. † 19. 1. 05 .

Mikroskopischer Befund: An der Oberfläche des Ovars erkennt man noch deutlich die decidualen Veränderungen, das Gewebe ist aufgelockert und bildet einzelne Fortsătze, doch sind die Kerne zerstört und die Conturen der Zellen nicht mehr zu erkennen. Das Stroma ist ausserordentlich follikelarm, dagegen sind mehrere grössere Corpora albicantia vorhanden. An den etlichen grösseren Follikeln, die zu sehen sind, ist das Follikelepithel abgestossen und liegt im Lumen, die Theca interna zeigt keine Besonderheiten. An den spärlichen atretischen Follikeln zeigen die Theca interna-Zellen Rückbildungserscheinungen, zum Theil nach innen einen hyalinen Saum. Sebr ausgeprägt scheinen hier die Theca-Zellen nicht gewesen zu sein, soweit man überhaupt aus puerperalen Ovarien auf die Frage Schlüsse zu ziehen berechtigt ist.

Fall 37. W., 31 J. IIIp., war bereits vor der Aufnahme in die Klinik wegen Fiebers in Behandlung gewesen, das mit einer rechtsseitigen Adnexerkrankung in Zusammenhang gebracht wurde. Spontane Entbindung (27. 2. 03) am Ende des 9. Monats, Abfall der Temperatur während 14 Tagen, dann erneuter Anstieg, Auftreten septischer Erscheinungen und Exitus am 35. Tage des Wochenbettes (3. 4. 03) an multiplen Abscessbildungen im Abdomen.

Die mikroskopische Untersuehung der zwei excidirten grösseren Stücke ergab, dass von Schwangerschaftsveränderungen in der Albuginea keine Spur mehr zu erkennen ist; Primärfollikel sind sehr spärlich, grössere Follikel werden auf den angelegten Schnitten überhaupt nicht gefunden. Dagegen zahlreiche Corpora atretica vorhanden, die nach innen $z u$ von einer krausenartig gefalteten hyalinen Membran begrenzt werden, die meist jedoch nur einen Theil der Peripherie einuimmt. Durch diese Lücke in der hyalinen Umgrenzung sieht man Spindelzellen in das Innere hinein ziehen, der Kern besteht in der Regel aus spindeligen Zellen. Es kann demnach an der Abkunft dieser Zellen von der Theca externa kein Zweifel bestehen; Schottländer hat sie von den grossen Zellen der Theca interna abgeleitet. Auch die nach aussen von der hyalinen Membran sich anschliessenden Zellen haben spindelförmige Gestalt und unterscheiden sich in nichts von den gewöhnlichen Stromazellen.

Ferner ist in der Ovarialsubstanz ein grosses weissliches Gebilde zu sehen, das als das Corpus luteum aus der vorhergegangenen Schwangerschaft anzusprechen ist. Bindegewebszüge ziehen in dasselbe hinein, Luteïnzellen sind hie und da noch als solche zu erkennen, sonst bilden sie eine gleichmässige weissliche Masse, in die Spindelzellen, Kernreste und Blutschollen eingelagert sind. Ausserdem durchziehen sie zahlreiche grössere und kleinere Gefässe.

\section{Zusammenfassung.}

Es wurde bereits Eingangs dieser Arbeit auf die Thatsache hingewiesen, dass während der Gravidität wohl noch ein Follikel- 
wachsthum, jedoch keine Follikelreifung mehr stattfindet. Das Follikelwachsthum geht jedoch, wie wir gesehen haben, nur bis zu einem gewissen Grade. Die Follikel erreichen selten über Erbsengrösse, dann verfallen auch sie der Atresie. Diese Follikel zeichnen sich bereits makroskopisch auf dem Durchschnitt durch die gelbliche Farbe ihrer Wandung aus, auch der Inhalt zeigt häufig diese Farbe. In den letzten 3-4 Monaten sind fast alle grösseren Follikel, d. h. jene, welche bereits einen Follikelhohlraum aufweisen, dem Untergang verfallen. Die Degeneration kann erst im Beginne sein und nur das $\mathrm{Ei}$ betreffen oder es können bereits Follikelepithelien mitsammt dem Eie verschwunden sein.

So lange der Follikel intact ist und wächst, kann man in der Regel eine Veränderung in der Theca interna nicht bemerken, es sei denn jene, welche an jedem Follikel auch ausserbalb der Schwangerschaft vor sich geht. Manchmal glaubte ich jedoch, dass auch am intacten Follikel die Schicht breiter und die Zellen grösser und fettreicher wären; allein da Variationen in der Ausdehnung der Schicht auch ausserhalb der Schwangerschaft nicht selten sind, so lässt sich eine Hypertrophie nur schwer feststellen. Häufig ]ässt sich bereits bei dem ersten $\Lambda$ uftreten degenerativer Veränderungen am $\mathrm{Ei}$ und Follikelepithel eine Grössenzunahme der Theca interna deutlich feststellen. Um so deutlicher tritt die Wucherung der Theca interna hervor, je weiter die Atresie fortgeschritten ist.

Die Atresie tritt unter zwei Formen auf, die zu recht verschiedenen Endproducten führen, die erste wollen wir die cystische, die zweite als die obliterirende Form bezeichnen.

Die cystische Form tritt hauptsächlich bei den mittleren und grösseren Follikeln ein. Die Resorption des Liquor folliculi unterbleibt, die intrafolliculäre Spannung ist gross genug, um ein Collabiren der Follikelwand zu verhindern. Das Follikelepithel verfällt der Chromatolyse und wird abgestossen und aufgelöst, ein gleiches Schicksal erfährt auch der Discus oophorus und das Ei. Man kann vielfach an ein und demselben Ovarium die verschiedensten Uebergangsstadien von der beginnenden Abstossung des Follikelepithels bis zu seinem vollständigen Schwunde beobachten. Wenn auch die Hypertrophie der Theca interna-Zellen bereits begonnen hatte, so lange das Granulosaepithel noch bestand, so tritt die Zellwucherung doch erst nach dem Verschwinden des Epithels in seiner ganzen Intensität zu Tage. An ein und demselben 
Follikel kann man bisweilen sehen, dass an der Stelle, wo das Follikelepithel noch erhalten ist, die Theca interna minder stark entwickelt ist, während sie an den epithelfreien Stellen mächtig gewuchert. Es ist der letztere Ausdruck keine Hyperbel. Manchmal sieht man 40-50 und noch mehr Zellen übereinander, da ist von vorn herein die Annahme einer Zellneubildung berechtigt. In der That kann man an den besonders stark entwickelten Stellen häufig Kerntheilungsfiguren beobachten. Ich gebe in Taf. VII, Fig. 22 eine solche aus einer stark vergrösserten Stelle der Taf. VII, Fig. 18 wieder. Diese Abbildung illustrirt auch die Eigenthümlichkeiten der genannten Zellen; man erkennt den grossen, unregelmässig geformten, epithelialen Zellleib der Zellen, der eine maschige Structur zeigt und lila gefärbt ist. Der Kern weist auffallend feine Vertheilung des Chromatins theils in Form feinster Netze, theils in kleinen Körnchen auf und enthält meist ein Kernkörperchen. Häufig ist das Chromatin besonders dicht um die Kernmembran angeordnet. Die Aehnlichkeit dieser Zellart mit den Zellen des Corpus luteum springt ohne Weiteres in die Augen, nur sind jene weit grösser $(20-30 \mu)$, während die der Theca interna in der Regel nur 15-18 $\mu$ haben und die grössten $20 \mu$ selten überschreiten. Aus diesen Maassen geht die beträchtliche Vergrösserung der ursprünglichen Theca interna-Zelle klar hervor. Es handelt sich demnach an der Theca interna in der Regel nicht allein um eine Hypertrophie, sondern auch um eine Hyperplasie der Zellen.

Anders verläuft der Process bei der obliterirenden Form. Diese befällt mit Vorliebe kleinere und mittelgrosse Follikel. Zuerst scheint die Resorption des Follikelwassers und damit Verringerung des intrafollikulären Druckes einzutreten. Ist der Druck auf die Follikelwand allseitig ziemlich gleichmässig, so falten sich die Wände in Form einer Krause ein. Meist ist dies jedoch nicht der Fall, der Druck von der einen und der anderen Seite herrscht vor, es kommt zu den verschiedensten Figuren. Befindet sich der atresirende Follikel in der Nähe der Wand eines grösseren Follikels, so erfolgt fast ausnahmslos die Abplattung in Form einer Sichel. Es scheint übrigens nicht allein der Druck des umgebenden Gewebes die Form der Atresie zu bedingen, es wirkt vielmehr das active Wachsthum der Theca interna-Zellen ebenfalls mit, die hypertrophirenden Zellen drängen an dieser und jener Stelle stärker gegen das Follikellumen vor. Dabei schieben sie das Follikel- 
epithel vor sich her, so weit dasselbe noch erhalten ist. Die Reste des Epithels, vielfach noch das deformirte Ei umschliessend, werden schliesslich gegen die Mitte gedrängt und sind dort bisweilen noch in Form von wenigen Zellen mit der hyalin entarteten Eizelle zu erkennen. Dieser Rest kann sich direct an die hypertrophischen Theca interna-Zellen anschliessen oder durch eine mehr oder minder breite hyaline Membran, die Glasmembran, davon gesehieden sein. Schliesslich gehen auch noch die letzten Reste zu Grunde, es bleibt ein hyaliner Kern, der von einigen spindelförmigen Zellen durchsetzt sein kann und manchmal in seinem Innern noch einen kleinen Hohlraum beherbergt, den Rest des Follikelraumes.

Die Theca interna-Zellen haben damit in der Regel eine zum Centrum radiäre Anordnung genommen: Die verschiedenen Radien können recht verschieden lang sein, nach der einen Seite doppelt so lang und länger. Ist die Abplattung des Follikels von 2 Seiten her erfolgt, hat er also eine langgestreckte Form, so erstrecken sich die Theca interna-Zellen weit, sehr weit in das Stromagewebe hinein, entweder sich fächerartig ausbreitend oder in langem Zuge zwischen den Stromazellen hineinkriechend. Auch bei anderen, die diese platte Form nicht haben, sind Ausläufer weit in das Gewebe hinein nicht selten. Besonders hervorzuheben ist, dass die Abgrenzung gegen das Stromagewebe nie scharf ist, dass vielmehr ganz allmälige Uebergänge vorherrschen.

Das Typische an der Follikelatresie während der Schwangerschaft ist die Hypertrophie und Hyperplasie der Theca interna-Zellen. Die Intensität dieser Vorgänge unterliegt individuellen Schwankungen und ist ausserdem bedingt durch das Alter der Schwangerschaft. Je älter die Schwangerschaft, desto intensiver die Theca-Luteinzellenentwicklung. Ich möchte noch in den verschiedenen Monaten. die einzelnen Vorgänge genauer beschreiben.

Bereits im 2. Monat lässt sich eine geringe Vergrösserung der Theca interna-Zellen constatiren, freilich kann sie um diese Zeit auch noch vollständig vermisst werden, wie die Beobachtung 2 zeigt, bei der es sich um eine heruntergekommene, schlecht genährte, 41 jährige Frau mit Carcinom handelte. Im 3. Monat tritt die Vergrösserung der Theca interna-Zellen deutlicher hervor, besonders stark ausgeprägt war es in Fall 4, wo sich die Zellen bereits weit in das Stroma vordringend nachweisen lassen.

Relativ gering fand sich die Vergrösserung der Theca interna 
in den Fällen aus dem 4. Monat ausgeprägt. Dabei handelt es sich um 3 Ovarien, die von Frauen mit über mannskopfgrossen Myomen stammen. Bei diesen ist die Anzahl der in den Ovarien sich vorfindenden Follikel bekanntlich auffallend gering. Ganz besonders ausgeprägt ist die Follikelarmuth in den vorliegenden Fällen, und in 2 Fällen konnte ich nur etliche atretische oder cystische Follikel auf zahlreichen Schnitten auffinden, welche eine mässige Entwicklung der Thecaluteïnzellen zeigten. Dass aber auch in einem Falle, wo Follikel reichlicher vorhanden sind und auch in Atresie befindliche angetroffen werden, die Theca interna-Entwicklung nur schwach ausgebildet sein kann, zeigt die Beobachtung 7 . Mit welchen Ursachen diese Erscheinung zusammenhängt, ob vielleicht in dem vorliegenden Falle die auffallende Blutarmuth verantwortlich gemacht werden muss, lässt sich nicht sicher entscheiden.

Von diesen Ausnahmen abgesehen, entwickelt sich proportional dem Alter der Gravidität die Theca interna mehr und mehr, tritt uns in voller Ausbildung in den letzten Monaten entgegen und erreicht ihr Maximum kurz vor der Geburt.

Im Wochenbett tritt alsbald eine Rückbildung der gewucherten Theea interna ein. Bereits in den ersten 3-4 Tagen kann man an Präparaten, die von nicht septischen Kranken stammen und die bald fixirt wurden, beobachten, dass die Theca interna-Zellen sich lockern und dass sie in ihrer Vitalität Schaden gelitten haben. Sie werden kleiner, schrumpfen, an der Innenfläche der Schicht macht sich ein hyaliner Saum bemerkbar. Am 7. Tage bereits sind die typischen Theca interna-Zellen vollständig geschwunden, an ihre Stellen sind kleine, zusammengesinterte, schmale, schlecht gefärbte Zellen getreten, wie dies am besten Fig. 21 auf Taf. VIII illustrirt; häufig ist die ganze Schicht der hyalinen Degeneration verfallen. Die Degeneration beginnt stets an den innersten Zellen und schreitet peripher weiter, aussen können sich spindelige Zellen noch längere Zeit erhalten.

Demnach geht der grösste Theil der Theca interna-Zellen hyalin zu Grunde. Es hat jedoch den Anschein, als ob sich einzelne Zellen wiederum zu gewöhnlichen Spindelzellen zurückbilden könnten, aus denen sie ehedem hervorgegangen sind. Einen ähnlichen Vorgang hat Sobotta bei dem Studium der Genese des Corpus luteum bei Kaninchen und Maus beobachten können.

Ausser den beiden bisher besprochenen Formen der Rückbildung von Follikel, zwischen denen es Uebergänge giebt, kommt 
264 Seitz, Die Follikelatresie während der Schwangerschaft eto.

noch in seltenen Fällen eine dritte Art vor, wie sie auf Taf. VI u. VIII in den Figg. 9 und 13 dargestellt ist. Da ich bereits ihre Ejgenthümlichkeiten an anderer Stelle ausführlich besprochen habe, so kann ich darauf verweisen und auf meine dortige Erklärung, dass die Bildung möglicherweise auch ausserhalb der Schwangerschaft vorkommt. Solche Gebilde könnten Veranlassung zu Verwechslung mit abgesprengten Theilen eines Corpus luteum geben. Man muss daher durch Serienschnittführung und durch Beachtung aller in Frage kommenden Momente die Befunde sichern.

Line besondere Erwähnung verdient noch die Theca-Luteïnzellenwucherung in dem Ovarialstroma. An dem atretischen Follikel mit beibehaltener Kugelform wuchern die Zellen in der Regel nicht so tief in das Stroma hinein. Dagegen sieht man an plattgedrückten Follikeln an den beiden Polen die epitheloiden Zellen weit in das Gewebe ausstrahlen und fast an allen atretischen Follikeln zieht sich in der einen oder in der anderen Richtung ein Strang $z$ wischen die Stromazellen hinein fort (Taf. VI u. VIII, Fig. 6, 16 und 17). Auch an Corpora atretica traten an der Peripherie die eigenthümlichen epitheloiden Zellen auf (Taf. VII, Fig. 19). Ob sie auch von Corpora fibrosa und albicantia, also den Ueberresten eines Corpus liteum ausgehen können, konnte jch nicht mit Sicherheit entscheiden, da sich aus dem Aussehen der Rückbildungsproducte allein nưr schwer ein Schluss ziehen lässt. Doch spricht die Kleinheit der Gebilde dafür, dass es sich nur um Corpora atretica gehandelt hat, sicher nicht um noch grössere Corpora albicantia.

Bisweilen lassen sich einzelne epitheloide Zellen mitten im. Stroma nachweisen. Ich spreche hier selbstverständlich nicht von jenen Zellengruppen, die beim Anschneiden eines atretischen. Follikels zuerst getroffen werden, solche Schnitte können Einlagerungen einzelner Zellen mitten ins Stroma vortäuschen; ich meine auch nicht die entlegenen Ausläufer von atretischen Follikeln, bei denen sich der Zusammenhang mit dem letzteren nachweisen lässt. Zuweilen trifft man einzelne Exemplare ohne jeden Zusammenhang mit einem Follikel oder dessen Ueberrest (Taf. VII, Fig. 23). Man trifft sie übrigens nicht häufig an und ich habe sie nur in den letzten Monaten gefunden. Hier muss man demnach eine directe Entstehung der epitheloiden Zellen aus dem Stroma annehmen. Für die Möglichkeit dieser Genese spricht auch der Umstand, dass an verschiedenen Stellen 
eine Grenze zwischen den epithelioiden Zellen und den Stromazellen gar nicht zu ziehen ist und dass diese unmittelbar in jene übergehen.

Ich habe bisher von diesen epitheloiden Zellen im Stroma und an der Peripherie von Corp. atretica Nichts in der Literatur zu ermitteln vermocht.

Ehe ich jedoch weiter auf die Deutung der epitheloiden Zellen eingehe, möchte ieh die Befunde, die ich an den 36 Ovarien gravider und puerperaler Fraven über das Vorkommen decidualer Veränderungen gemacht habe, kurz referiren.

Die deciduähnlichen Zellen in der Albuginea des Ovariums wurden von Schmorl, Schnell, Khinoshita, Rabl beschrieben und erfuhren eine besonders eingehende Würdigung durch Lindenthal. Mit dessen Befunden stimmen meine Erhebungen vollständig überein, wenn man von kleinen Verschiedenheiten Abstand nimmt. Auch in meinen Fällen trat in den ersten zwei Monaten nur eine Auflockerung, ödematöse Durchtränkung und Hyperämisirung der unter dem Keimepithel gelegenen Partien auf, die ersten ausgebildeten Deciduazellen konnte ich erst im 4. Monate feststellen. In den späteren Monaten treten die pirzel- und keulenförmigen Fortsätze an der Oberfläche auf, es kommt durch Berührung und Verwachsung der Fortsätze unter einander zu Inclusionen von Keimepithel, sodass man beim ersten Anblick Drüsenlumina vor sich zu haben glaubt. Meist ist, wie dies Taf. VIII, Fig. 20 bei langgestreckten Gebilden sehr deutlich zeigt, das Epithel der äusseren Seite platt, niedrig und durch die Dehnung auseinander gezogen, während die centrale Seite noch Epithel von regelmässiger Höhe aufweist. Ob solche mit Keimepithel ausgekleideten Hohlräume über die Schwangerschaft persistiren und Veranlassung zur Cystenbildung geben können, wie Lindenthal annimmt, scheint mir nicht unwabrscheinlich, doch konnte ich beweisende Beobachtungen nicht erheben. In den meisten hat zwar das Epithel ebenfalls gelitten, in einigen hatte es völlig lebensfrisches Aussehen.

Nach meinen Erfahrungen steht die In- und Extensität der proliferirenden Vorgänge in der Albuginea im Grossen und Ganzen zwar im Verhältniss zum Bestand der Schwangerschaft, allein man kann doch bei gleichaltrigen Stadien der Gravidität nicht unbedeutende Unterschiede beobachten. Dies ist nicht auffällig, wenn man beobachtet, dass auch die Blutversorgung der betreffenden Partien innerhalb gewisser Grenzen variirt. Sonst stimmen, wie ge- 
sagt, meine Befunde mit denen von Lindenthal so vollkommen überein, dass ich nicht näher darauf mehr einzugehen brauche.

Ich möchte noch auf den Bau der deciduaähnlichen Zellen etwas genauer eingehen, um zu zeigen, dass es sich bei meinen Beobachtungen von Luteïnzellen im Stroma 'nicht um Verwechslungen mit diesen Deciduazellen handelt. Für's erste schützt man sich vor einem solchen Irrthum, wie alle Autoren übereinstimmend annehmen, wenn man beachtet, dass die Deciduazellen unmittelbar unter dem Keimepithel oder jedenfalls in der Albuginea des Ovariums gelegen sind, die aus atretischen Follikeln hervorgegangenen Luteïnzellen aber in der Rindensubstanz, entfernt von der Oberfäche, liegen. Lindenthal macht ausdrücklich darauf aufmerksam, dass auch die Ueberreste der ehemaligen Deciduazellen an puerperalen Ovarien Veranlassung zu Verwechslungen mit Luteïnzellen geben können und verweist im Speciellen auf einen Befund von Scharfe an einem osteomalacischen Ovarium, den Scharfe nach der Ansicht von L. irrthümlich für Reste eines Corpus luteum anspricht.

Eine weitere Verschiedenheit zwischen den Deciduazellen und den epitheloiden Zellen besteht in ihrer Anordnung. Jene sind entweder im Stroma einzeln zerstreut, oder häufiger, in meist scharf umschriebenen Gruppen angeordnet, nicht selten sind die Zellen fischzugähnlich gestellt.

Der Hauptunterschied liegt jedoch in der Zelle selbst. Man braucht nur die Taf. VI, Fig. 14, die Deciduazellen aus der Oberfläche des Ovariums und Taf. VII, Fig. 24, welche stark vergrösserte (homogene Immersion) epitheloide Zellen mitten aus dem Stroma darstellt, zu vergleichen, um die Unterschiede ohne Weiteres zu bemerken. Die Deciduazellen sind viel grösser (meist grösser als die gezeichneten), enthalten weder Fett noch Luteïn, ihre Gestalt ist mannigfaltig, häufig langgestreckt, die Zellen sind durch Intercellularsubstanz häufig recht weit von einander getrennt, das Protoplasma ist mehr oder weniger homogen, bei Eosin-Hämatoxylin leicht bläulich gefärbt. Die epitheloiden Zellen dagegen, die wir in den Ausläufern von atretischen Follikeln und im Stroma treffen, gleichen ganz den in der verdickten Theca interna atretischer Follikel, wie sie in Taf. VII, Fig. 22 abgebildet sind. Der Kern sowie das Protoplasma verhalten sich gleich und wir dürfen sie daher ohne Bedenken, auch wenn ein Zusammenhang mit einem 
atretischen Follikel nicht mehr nachweisbar ist, für genetisch gleichwerthig ansehen.

Die Identität der beiden Zellarten (der epitheloiden Zellen mitten im Stroma und der Zellen der Theca interna atretischer Follikel) tritt beim Vergleich der Fig. 22 und 24 klar zu Tage. Um kurz ihre Genese und ihre Lokalisation zu präcisiren, empfiehlt es sich, für die erstere den Ausdruck Stromaluteïnzellen und für die letztere die Bezeichnung Thecaluteïnzellen zu gebrauchen.

Eine Verwechslung mit Deciduazellen könnte auch stattfinden mit jenen eigenth ümlichen grossen Zellen in Corpora fibrosa, die sich mit Körnchen gefüllt haben. Es sind nicht jene Reste der Corpora lutea, welche eine breite krauseartige Umhüllung aufweisen, sondern jene, die in Folge der helleren Farbe und der Armuth an zelligen Elementen aus dem übrigen Ovarialstroma hervorleuchten. Ich gab in Fig. 12, Taf. VIII eine Abbildung derselben. Kleinere, weniger stark beladene Zellen sieht man häufiger. Rabl, der die Zellen eingehend beschreibt, hält sie für Luteïnzellen und schildert sie folgendermaassen. "Es sind grosse kugelige Gebilde von $20 \mu$ Durchmesser, welche einen central gelegenen kugeligen Kern besitzen und von zahlreichen grossen Fetttropfen erfüllt sind. Das zwischen ihnen gelegene protoplasmatische Netzwerk erscheint farblos. An älteren Luteinzellen nimmt es allmählig eine ganz blasse, diffuse gelbliche Färbung an. An einzelnen Punkten des Netzes werden hierauf die Körnchen sichtbar." Es tritt Pigment in den Zellen auf, das Fett verschwindet um so mehr, je reichlicher das Pigment wird, die Zelle verliert ihre kugelige Gestalt und wird spindelförmig, aus der Luteinzelle wird eine Pigmentzelle. So wenig nun eine ausgebildete Pigmentzelle zu einer Verwechslung mit der Deciduazelle Veranlassung geben wird, um so eher können die Zellen während einer gewissen Entwicklungsphase verwechselt werden, namentlich dann, wenn man es mit nicht ganz gut conservirten Präparaten zu thun hat. Diese Art von Zellen stehen natürlich mit der Schwangerschaft weiter gar nicht in Beziehung, sie werden auch an nicht schwangern Ovarien beobachtet.

Ich möchte betreffs der Genese Rabl zustimmen. In einem Falle sah ich die Pigmentzellen um die ganze Circumferenz eines Corpus albicans herumlaufen (Taf. VII, Fig. 33 und 34). Theilweise lagen die Pigmentschollen extracellulär. Die mit Blutresten beladenen Zellen lagen alle an den Stellen, wo man sonst die "kleinen epitheloiden" 
Zellen findet. Es hat daher eine gewisse Wahrscheinlichkeit, dass diese Zellen das Blutpigment in sich aufgenommen und über ihre gewöhnliche Lebensdauer sich erhalten haben. Nicht ganz ausschliessen möchte ich jedoch die Annahme, die die meisten Autoren vertreten, dass die Pigmentzellen aus eingewanderten weissen Blutkörperchen hervorgegangen sind, die sich mit Blutresten beladen haben.

Kommt die Hypertrophie der Theca interna-Zellen in ähnlicher Weise nicht etwa unter pathologischen Verhältnissen oder sonst unter besonderen Umständen vor?

Ich möchte hier zunächst erwähnen, dass ich zweimal an den Ovarien Neugeborener, bei denen einzelne Follikel bis zu einer ungewöhnlichen Entwicklung gelangt waren, und die daher den Eindruck einer kleincystischen Degeneration hervorriefen, ähnliche Befunde erheben konnte. Diese frühreifen Eier platzen nicht, sondern gehen atretisch zu Grunde. An den atretischen Follikeln, namentlich denen von mittlerer Grösse, ist die Theca interna ausserordentlich dick, die Zellen haben an Grösse zugenommen, haben einen blassen Zellleib, der nicht selten ausgesprochene polyedrische Gestalt aufweist. Die Follikelepithelien sind entweder ganz oder theilweise erhalten oder sind vollständig abgestossen (Fig. 26, Taf. VIII). Dieses starke Hervortreten der Tun. interna hat bei Neugeborenen nichts Auffallendes, weil auch bei wachsenden Follikeln die Zellen dieser Schicht sich durch besondere Grösse und durch ihre losere Aneinanderreihung auszeichnen. Auch an dem Ovarium eines 1/2,jährigen Mädchens, das Follikel bis zu $1 / 2 \mathrm{~cm}$ Grösse aufwies, sah ich an einem atretischen mittelgrossen Follikel an einem grossen Theile des Umfangs eine stärkere Entwicklung der 'Theca interna-Zellen, während die übrige Peripherie durch einwachsendes einfaches Bindegewebe verschmälert wurde. Die cystisch erweiterten Follikel zeigen diese Verhältnisse weniger deutlich. Das Ovarium eines $1 \frac{1}{2}$ jährigen Mädchens liess an den atretischen Follikeln ebenfalls eine stärkere Entwicklung der Theca interna-Zellen erkennen. Soweit ich aus den Ovarien der von mir untersuchten Kinder mehr konnte ich leider nicht zur Untersuchung bekommen - zu urtheilen vermag, habe ich den Eindruck, ais ob mit dem zunehmenden Alter auch die Ausbildung der Theca interna und ihre Breite abnehme und mehr dem Zustande sich nähere, wie wir ibn beim Erwachsenen za sehen gewöhnt sind. Ich möchte noch ausdrücklich bemerken, dass auch beim Neugeborenen, wo die Entwicklung am stärksten zu sein scheint, die Zellen nie über eine 
gewisse Grösse hinausgehen, dass die epitheloide Form und namentlich der Gehalt an Fett ${ }^{x}$ ) nie so deutlich hervortritt wie während der Schwangerschaft an atretischen Follikeln oder gar wie an dem Corpus luteum oder an den Corpusluteum-Cysten. Nach den Untersuchungen von Stevens scheint die Follikelatresie bei Personen vor der Pubertät nicht wesentlich von der bei Geschlechtsreifen abzuweichen.

Ich habe mich ferner bemüht, eine grössere Anzahl von Ovarien von genitalkranken Frauen zu untersuchen und die Verhältnisse zu studiren. Zunächst lag es nahe, gerade bei Myomen, wo Veränderungen der Ovarien die Regel bilden, auf das Verhalten der Theca interna zu achten. An den Wänden der sich häufig vorfindenden kleinen Cystchen tritt die Theca interna in der Regel überhaupt nicht hervor, es hat vielfach den Anschein, als ob die Theca interna-Zellen in die Spindelzellen der Theca externa durch den erhöhten intrafolliculären Druck hineingepresst würden. Einige Male sah ich bei Cysten, an denen das Epithel verloren gegangen war, die Wand von einer reichlichen Anzahl kleinerer und grösserer Hämosiderinschollen durchsetzt. Hier urid $\mathrm{da}$ sind die Theca interna-Zellen etwas grösser als gewöhnlich, namentlich dann, wenn die Follikel zusammengefallen sind. Dann kann man sie auch zwischen den Spindelzellen des Ovarialstromas gelegentlich etwas tiefer hinein verfolgen; nie jedoch sah ich bei den Zellen ausgeprägte epitheloide Gestalt und Einlagerung von Luteïn und Fett. Am wachsenden Follikel konnte jeh bei einem jugendlichen Individuum ein Gebilde sehen, das mit dem in Fig. 8, Taf. VI wiedergegebenen die grösste Aehnlichkeit hatte, die Theca interna-Zellen traten deutlicher wie gewöhnlich hervor, zwischen ihnen waren einige kleinere Hämorrhagien. Auffallend ist bei fast allen Fällen von Myom die geringe Anzahl der vorhandenen Primärfollikel. Bei einer 26jährigen Person mit grossen intraligamentären Myomen fand ich eine Corpus luteumCyste.

Ebenso vermisste ich bei Carcinom des Uterus (5 Fälle) und bei Myosarkomen (2 Fälle) eine Entwicklung von Luteïnzellen. Besonders möchte ich noch hervorheben, dass ich auch in einem Falle von Osteomalacie diese Veränderungen nicht auffinden konnte. Bulius hatte auf Grund einer Beobachtung besonders starker Ent-

1) Lutein konnte ich nicht nachweisen, 
wicklung der Luteïzellenschicht bei einer Osteomalacischen, bei der jedoch Schwangerschaft bestand, den Verdacht ausgesprochen, dass es sich um eine specifische Veränderung bei dieser Krankheit handeln könne, hat jedoch auf Grund weiterer Beobachtungen diese Annahme selbst fallen lassen. Dass übrigens auch ohne Schwangerschaft ausnahmsweise eine Vergrösserung der Theca interna-Zellen vorkommt, lehrt der Fall Vogesser, über den noch im 3. Abschnitte dieser Arbeit genauer berichtet wird. Bei der Exstirpation des vom rechten Ovarium ausgehenden Ovarialkystoms zeigte das linke Ovarium ein etwa haselnussgrosses Hämatom an seiner Oberfläche, das excidirt wurde und das bei der mikroskopischen Untersuchung als ein sehr junges Corpus luteum sich erwies. In diesem Ovarium zeigten an einem atretischen Follikel, dessen Lumen in Form eines abgeplatteten Ovals noch erhalten war und dessen nächste Umgrenzung von einem zellarmen schlecht tingirten Bindegewebe gebildet wurde, die sonst kleinen, strahlenförmig angeordneten Zellen der Theca deutlich epitheloiden Charakter; der röthliche Farbenton des Protoplasmas bei der Hämatoxylin-Eosin-Färbung lässt sich zwar noch nicht erkennen, dagegen sieht man mit starker Vergrösserung an den grössten Zellen bereits die wabige Structur des Zellleibes.

Auch bei zwei Ovarien, welche von menstruirenden Frauen stammten, hatte ich den Eindruck, als ob die Zellen der Theca interna nicht allein an atretischen, sondern auch an wachsenden Follikeln etwas grösser als sonst seien; allein da es sich nur um zwei Beobachtungen handelt und geringere Grössendifferenzen, wenn sonstige Veränderungen speciell in dem Protoplasma fehlen, leicht zu Täuschungen Veranlassung geben können, möchte ich auf die Menstruationsveränderungen vorläufig kein besonderes Gewicht legen. Eine besondere Erwähnung bedürfen noch die Adnexerkrankungen auf gonorrhoischer Basis. Von ihnen ist bekannt, dass die Corpora lutea spuria recht häufig sich zu der Grösse der Corp. vera entwickeln und dass mit Vorliebe die Corpus luteum-Cysten bei diesen Erkrankungen gefunden werden. Abgesehen von jenen Zuständen, wo direct entzündliche Vorgänge sich in den Ovarien abspielen, trifft man nicht selten in den Ovarien eine leichte ödematöse Beschaffenheit des Stromas, die Zellen sind grösser und dicker, in den atretischen Follikeln tritt wohl auch die Masse der Theca interna-Zellen deutlicher hervor, allein zu einer ausgebildeten Luteïnzellenschicht kommt es in der Regel nicht. Die Beurtheilung der 
Verhältnisse ist hierbei meist recht erschwert durch sonstige Veränderungen im Stroma, wie kleinzellige Infiltration, Oedembildung etc.

Nach all diesen, wenn auch vorläufig noch spärlichen Befunden muss man annehmen, dass die Thecaluteinzellenentwicklung nichts für die Schwangerschaft ebensowenig wie für die Blasenmole und Chorionepitheliom allein Charakteristisches ist, sondern dass sie gelegentlich, wenn auch selten, bei anderen Zuständen auftreten kann. Trotz alledem muss jedoch betont werden, dass die Thecaluteinzellenentwicklung während der Schwangerschaft eine ungewöhnlich starke ist und dass diese Stärke der Entwicklung etwas Specifisches für die Schwangerschaft darstellt. Ich habe in einer vorläufigen Mittheilung (Centralbl. f. Gyn. 1905 No. 19) die Thecaluteinzelle mit der Deciduazelle in der Schleimhaut des Uterus verglichen. Auch die Decidua kann sich in der Uterusschleimhaut ohne Schwangerschaft unter besondern, hier nicht weiter zu erörternden Verhältnissen ausbilden - man denke nur an die Decidua menstrualis - allein in typischer Entwicklung mit den grossen charakteristischen Zellen und in weiter Ausdehnung wird sie doch wohl nur in der Schwangerschaft vorgefunden.

Es ist bisher die Thecaluteinzellenwucherung in ausgebildetem Grade nur bei 3 Zuständen beobachtet worden, wenn wir von den fraglichen Geschwulstbildungen aus Luteinzellen, über die wir im 2. Theil der Arbeit noch referiren werden und von den vorerwähnten seltenen Ausnahmefällen absehen, nämlich in der Schwangerschaft, bei Blasenmole und bei Chorionepitheliom. Allen 3 Zuständen ist gemeinsam die Anwesenheit fötaler Elemente, bei der Schwangerschaft die normalen Zotten, bei der Blasenmole die blasig degenerirten Zotten, bei dem Chorionepitheliom fehlen zwar ganze Zotten in der Regel, aber es sind die wichtigsten Bestandtheile der Zotten, die epithelialen Zellen derselben, das Syncytium und die Langhans'schen Zellen im mütterlichen Organismus vorhanden. Es Jiegt die Vermuthung nahe, dass die Anwesenheit dieser Gebilde zu der Entwicklung der Thecaluteïnzellen in einem ursächlichen Zusammenhange steht. Wir kommen auf diese Frage bei der Besprechung der Luteinzellenwucherung bei Blasenmole und Chorionepitheliom noch einmal zurück.

Wenn wir uns zuletzt über die Bedeutung der Thecaluteinzellenwucherung während der Schwangerschaft fragen, so müssen 
wir gestehen, dass wir leider eine sichere Deutung der Befunde nicht zu geben vermögen.

Wir haben bereits bei der Besprechung der Veränderung der Zellen der Theca interna an wachsenden und reifenden Follikeln und über die Bedeutung der vorbandenen Zelleinlagerungen berichtet, wollen jedoch die Ansichten der Autoren nochmals kurz streifen, da die Kenntniss der Funktion dieser Zellen naturgemäss die Grundlage für die Deutung der Thätigkeit der Thecaluteinzelleu an den atretischen Follikeln sein muss.

Die alte Ansicht, dass es sich bei den Zclleinschlüssen in den Zellen der Theca interna um einfache degenerative, also pathologische Processe handele, ist nicht mehr haltbar. An einem so lebensfrischen Organe wie an einem wachsenden Follikel sind solche fettige Degenerationen nicht möglich. Wir wissen, dass Fett denn um solches handelt es sich in der Hauptsache bei den Einschlüssen - auch unter ganz normalen Verhältnissen in verschiedenen Organen so in den Zellen der Nebennierenrinde, in den Zwischenzellen des Hodens, und in den Epithelien der Hodenkanälchen vorgefunden und als ein physiologisches Infiltrationsfett gedeutet wird. Besonders interessant ist die Thatsache, dass bei jugendlichen Individuen das Fett hauptsächlich in dem interstitiellen Gewebe des Hoden, im spätern Leben dagegen mehr in den Samenkanälchen sowohl bei den meisten Thieren, als auch beim Menschen auftritt. Herxheimer deutet den Befund so, dass bei jugendlichen Individuen das Fett im interstitiellen Gewebe als Reservematerial für den wachsenden Hoden dient, bei den geschlechtsreifen Individuen liegt das Fett hauptsächlich in den Hodenkanälchen und dient als Reservematerial bei der Bildung der Spermatozoen.

Auch die Fettansammlung in den Zellen der Theca interna der Follikel wird seit Pflüger, der sie zum ersten Male, wenigstens zum Theil, für aufgespeichertes Material ansah, um zur Bildung der bedeutenden Fettmenge, welche bei der Bereitung der Keime benöthigt wird, zu dienen, ziemlich allgemein als ein physiologischer Vorgang angesehen. (His, Born, Sobotta, Plato, Herxheimer u. A. mehr). Sobotta spricht die Ansicht aus, dass die Fettaufspeicherung dazu diene, um eine rasche Theilung der Zellen der Theca interna zu ermöglichen. Von hohem Interesse sind die Beobachtungen von Plato an Katzenovarien; er fand, dass die gegen das Stratum granulosum zu gelegenen Zellen viel ärmer an Fett 
seien als die peripheren und nimmt an, dass das Fett in gelöstem Zustande die Zona pellucida passire und sich im Eidotter niederschlage. $\left.{ }^{1}\right)$

Ueber die chemische Natur der Einschlüsse wissen wir nur soviel, dass es Fett oder fettähnliche Substanzen sind, die sich mit Osmiumsäure schwärzen und mit Sudan und Scharlachroth färben. Auch Lutein ist in den Zellen enthalten; die chemische Zusammensetzung dieses Körpers ist uns jedoch noch ganz unbekannt.

Ebenso steht es, wenn wir nach der chemischen Natur der in den Thecaluteïnzellen atretischer Follikel und in den Stromaluteinzellen gefundenen Zelleinschlüsse fragen. Es sind fettähnliche Substanzen, mehr lässt sich von ihnen bisher nicht sagen.

Gegenüber den Luteinzellen des Corpus luteum bestehen einige Verschiedenheiten. So fand Limon bei von ihm untersuchten Thieren, dass die Einlagerungen der interstitiellen Zellen, die er ja von den vergrösserten Thecazellen ableitet, sich mit Osmium schwarz färben, bei Berührung mit Xylol jedoch sofort wieder entfärben. Dadurch und durch den Mangel an Luteïn unterscheiden sie sich von den Zellen des gelben Körpers. Nach Frz. Cohn lassen die interstitiellen. Zellen gleicher Genese des Kaninchens bei der Färbung mit phosphorwolframsaurem Hämatoxylin deutliche Unterschiede in den Farbennuancen gegenüber den Zellen der gelben Körper hervortreten; diese tinktoriellen Verschiedenheiten sind gewiss von Interesse, allein sie gestatten uns vorläufig keinen weiteren Einblick in die chemische Natur der abgelagerten Körper; auch bedarf die ganze Frage noch einer breiteren Fundirung.

Auch ich bin mit dem Färbeverfahren an den Thecaluteinzellen nicht weiter gekommen: Die Einschlüsse färben sich mit dem Flemming'schen Osmiumgemisch schwarz, doch zeigen die Tröpfchen nur eine zarte Vertheilung und sind nicht so gross und so reichlich wie in den Luteïnzellen des Corpus luteum vertreten. Mit der Hämatoxylin-Eosin-Methode erkennt man recht gut die maschige Structur des Protoplasmas, wie in Taf. VII, Fig. 22 u. 24 zu sehen ist. An Gefrierschnitten giebt Färbung mit Sudan III

1) Nach neueren Untersuchungen ist die Betheiligung des Follikelepithols an der Dotterbildung für viele thierische Eier sicher festgestellt (Lubosch bei Triton und beim Nennauge, Milroy bei den Knochenfischen, Doflein bei Bdellostoma). Diese Befunde stehen mit den oben genannten in keinem Widerspruch. 
274 Seitz, Die Follikelatresio während der Schwangerschaft etc.

ziemlich rothe Farbe, an mit conc. Alcohol vorbehandelten Präparaten noch eine rothbräunliche Färbung (Taf. VII, Fig. 25).

Da eine innere Sekretion bei Zellen bindegeweblicher Abkunft wahrscheinlich rorkommt, ${ }^{1}$ ) so kann nicht mit Bestimmtheit in Abrede gestellt werden, dass eine solche auch bei den Thecaluteinzellen stattfindet. Diese wurde bekanntlich für die aus atretischen Follikeln hervorgegangenen interstitiellen Zellen verschiedener Thiere von Bouin, Limon und Frz. Cohn behauptet, das Gleiche von Regaud und Policard für die Thecazellen lebensfrischer Follikel des Hundes. Born und Fränkel-Cohn haben bekanntlich auch dem Corpus luteum eine innere Sekretion zugeschrieben; da dieses jedoch vorläufig als ein Gebilde epithelialen Ursprunges angesehen werden muss, kann es für uns aus der Discussion ausscheiden.

Nehmen wir an, es behielten Bouin-Limon und Frz. Cohn mit der Annahme einer inneren Sekretion Recht, es handelte sich um eine wirkliche interstitielle Drüse, so wäre, wenn wir die Verhältnisse auf das Ovarium des Menschen übertragen, einmal festzustellen, dass bei der Frau diese interstitielle Drüse unter gewöhnlichen Verhältnissen und während der längsten Zeit des Lebens gänzlich fehlt; denn wir sahen einerseits, dass bei den untersuchten Thieren, Kaninchen, Katze etc. die Thecazellen untergegangener Follikel in ihrer ursprünglichen Form und Grösse, mit allen ibren Eigenschaften erhalten bleiben und weiterhin fungiren, anderseits dagegen ist festgestellt, dass die Follikelatresie beim Menschen ohne nennenswerthe Hypertrophie der Zellen der Theca interna verläuft und dass der entstandene. Defect durch gewöhnliches Bindegewebe gedeckt, dem bisher noch kein Mensch eine sekretorische Function zugeschrieben hat. In der Schwangerschaft jedoch träte nach meinen Befunden diese interstitielle Drüse, von den ersten Monaten bis zum Ende der Schwangerschaft an Umfang und wohl auch an Intensität der Sekretion zunehmend in Function, um nach Ausstossung des Kindes innerhalb weniger Tage wieder $\mathrm{zu}$ verschwinden.

Es wäre in der That sehr verlockend, anzunehmen, dass während der Schwangerschaft die Thecaluteïnzellen die Aufgabe haben, ein für den normalen Ablauf der Gravidität wichtiges Sekret zu liefern. Die von Monat zu Monat zunehmende Hypertrophie und Hyperplasie der Zellen könnte man mit der mit der Dauer

1) Von anderen Autoren wird diese Annahme freilich wieder bestritten. 
der Schwangerschaft nothwendig werdenden Zunahme der Menge des Sekretes erklären. Endlich wenn man sich auf den Boden der Born-Fränkel'schen Theorie von der Function des Corpus luteum stellt, könnte man glauben, dass nach dem frühzeitigen Absterben des Corpus luteum nunmehr die morphologisch so ähnlichen Thecaluteinzellen vikariirend dessen Function übernehmen.

Allein das wäre vorläufig Hypothese, und, wie ich glaube, noch durch wenig Thatsachen gestützte Hypothese. Die Born-Fränkel'sche Theorie kann noch nicht als erwiesen angesehen werden, manche sehen sie bereits als widerlegt an (Sobotta, Lubosch) - ich will hier nicht weiter darauf eingehen --; selbst aber gesetzt, ihre Richtigkeit wäre experimentell erwiesen, so bestände für die Annahme eines vikariirenden functionellen Eintretens der Thecaluteïnzellen immer noch die Schwierigkeit der histogenetischen Verschiedenheit der beiden Zellarten. Es müssten in diesem Falle Zellen bindegeweblichen Ursprunges dasselbe Sekret wie diejenigen epithelialer Herkunft liefern, eine Annahme, die ebenfalls erst des Beweises bedürfte, Es sind zwar gerade am Ovarium und $z w a r$ bei der Maus von Plato, beim Hunde von Regaud und Policard an dem Follikelepithel dieselben fettartigen Einschlüsse beobachtet worden wie an den Thecazellen; allein die Identität der Einschlüsse ist durch ihre morphologische Aehnlichkeit allein noch nicht erwiesen.

Wir haben erwähnt, dass für die epitheloiden Zellen der Theca interna wachsender und reifender Follikel die Fettablagerungen am besten als Reservematerial und als Nährmaterial für das Ei aufgefasst werden. Diese Deutung kann für die atretischen Follikel um deswillen nicht zutreffen, weil das Ei sowie das Follikelepithel ausnahmslos zu Grunde gegangen ist. Will man dennoch an dieser Deutung der Fettablagerungen in den Zellen festhalten, so kann es nur insofern geschehen, als man sagt: die Theca interna-Zellen behalten ihre Fähigkeit, Fett aufzuspeichern, auch dann noch bei, wenn das Ei, dem dieses Fett unter gewöhnlichen Verhältnissen zugeführt wird, bereits zu Grunde gegangen ist. Das Nahrungsmaterial speichert sich in den Zellen auf, führt zu ihrer Vergrösserung und ermöglicht die rege Theilung in den Zellen, sodass schliesslich eine mächtige Schicht von Thecaluteïnzellen daraus entsteht. Die Wucherung der Thecaluteïnzellen ist um so reichlicher, je vollständiger das Follikelepithel verschwunden; mit dem Verschwinden des letzteren scheint die letzte Schranke für die Luteïn- 
zellen gefallen zu sein; im Sinne der vorerwähnten Theorie würde nunmehr nichts mehr von dem Fett dem $\mathrm{Ei}$ zugeführt werden, sondern alles zur Vergrösserung und Vermehrung der Thecaluteïnzellen selbst verwendet werden. Dass diese Wucherung der Zellen gerade mit der Schwangerschaft zusammenfällt, während sie sonst fehlt, lässt sich leicht an der erhöhten Blutzufuhr und der gesteigerten Ernährung des Ovariums während der Gravidität erklären. Von der reichlichen Blutversorgung giebt das Auftreten der deciduaähnlichen Zellen an der Oberfläche mit den erweiterten Capillaren und die blutüberfüllten Gefässe hinreichend Zeugniss.

Im Gegensatz zu dem üppigen Ernährungszustande der Thecaluteinzellen steht das Zugrundegehen des Eies und des Follikelepithels. Man sollte denken, dass unter diesen Bedingungen das Ei sich besonders gut zu entwickeln vermöchte. Aber gerade dadurch, dass alles Ernährungsmaterial die Thecazellen für sich in Beschlag nehmen, leidet schliesslich die Ernährung des Eies und des Follikelepithels. Bei dieser Betrachtung der Dinge erscheint die Wucherung der Thecaluteïnzellen als das primäre, die Nekrose des Eies als das secundäre. Beim Anblick solcher Bilder, wie in Taf. VIII, Fig. 4 drängt sich unwillkürlich dieser Gedanke auf. Wir hätten damit eine lokale Ursache für die Atresie aller grösseren Follikel während der Schwangerschaft, eine Erscheinung, die, wenn man nicht auf unwissenschaftliche teleologische Erklärungsversuche recurriren will, um so merkwürdiger ist, als alle anderen Theile der Sexualorgane zu dieser Zeit in einer progressiven Entwicklung begriffen sind.

Diese eben entwickelte Theorie hat jedenfalls das für sich, dass sie nur mit bisher bekannten Thatsachen rechnet. Wir wissen bestimmt, dass die Eier der grösseren Follikel in den späteren Monaten der Schwangerschaft zu Grunde gehen, wir können von den Zelleinschlüssen feststellen, dass es fettähnliche Substanzen sind. Das Vorkommen fetthaltiger Stoffe ist nicht allein vom Ovarium nachgewiesen, auch in der Zwischensubstanz des Hodens sind die gleichen Fetteinschlüsse aufgefunden; übrigens besteht über die Function der interstitiellen Zellen des Hodens eine ähnliche Controverse. Es scheint, dass alle Stromazellen im Ovarium die Fähigkeit in sich haben, sich in fetthaltige Luteinzellen umzuwandeln. Denn es kommen bereits ausserhalb der Schwangerschaft Zellen von kürzerer Gestalt, mit grösserem Zellleib vor, welche als interstitielle Zellen bezeichnet werden. Dann entwickeln sich 
die fetthaltigen Zellen der Theca interna wachsender Follikel aus den gewöhnlichen Stromazellen, ferner werden, wie wir gesehen haben, während der Schwangerschaft benachbarte Stromazellen in Thecaluteinzellen umgewandelt und endlich kann man mitten im Stroma ohne Zusammenhang mit Follikel oder deren Ueberreste solche fetthaltige Zellen auffinden. Es ist ferner bereits hervorgehoben, dass auch in nicht schwangerem Zustande Andeutungen von Fetteinlagerungen in die Zellen der Theca interna atretischer Follikel gelegentlich sogar in ähnlicher Weise wie während der Gravidität beobachtet werden. Aufällig ist ferner, dass auch bereits am Ovarium des Neugeborenen im geringen Maasse diese Einlagerungen an den Zellen atretischer Follikel festzustellen sind. Herxheimer giebt, allerdings mit aller Reserve an, an den Ovarien von Föten öfters an einigen Stellen im Stroma zwischen den Pflüger'schen Schläuchen fetthaltige Zellen und einige Mal bei ganz jungen Kindern eine ganz feine Vertheilung des Fettes in dem zwischen den kleinen Eiern gelegenen Stroma gesehen zu haben und deutet den Befund so, dass auch hier ähnlich wie im·Hoden, ein Reservematerial für das Wachthum der Eier aufgespeichert ist.

Wenn es sich um eine echte innere Sekretion von einem specifischen Producte, dann vermuthlich den Eiweisskörpern angehörig, handeln würde, so wäre es auffallend, dass sie beim Menschen und wahrscheinlich auch bei den Affen nur zeitweise, bei den anderen Thieren dagegen stets in Thätigkeit sein sollte. Immerbin liesse sich diese Thatsache durch den grossen phylogenetischen Abstand des Menschen von den Thieren, wo die interstitielle Drüse bisher gefunden wurde, erklären, es könnte mit der höheren Entwicklung auch die Sekretion der interstitiellen Ovarialdrüse unnöthig geworden sein.

Es scheint mir daher nach dem gegenwärtigen Stande unseres Wissens wahrscheinlicher, dass es sich nicht um eine innere Sekretion mit Production eines specifischen Sekretes, sondern nur um eine durch erhöhten Blutafflux und Einwirkung specifischer Schwangerschaftsreize, die an die Thätigkeit des Zottenepithels gebunden sind, bewirkte Hypertrophie und Hyperplasie der Zellen der Theca interna handelt, die mit einer physiologischen fettigen Infiltration der Zellen und Bildung von Luteïn einhergeht. Auch diese in atretischen Follikeln stattfindende und gegen Ende der Schwangerschaft an Ausdehnung zunehmende Ansamm- 
lung von Fett in den Thecaluteïnzellen kann man als Aufspeicherung von Reservematerial auffassen. Sämmtliche grösseren Follikel verfallen in den letzten 3-4 Monaten der Schwangerschaft der Atresie. Trotz dieser Thatsache sehen wir nach einer regelmässigen Entbindung bereits 6 Wochen die Menstruation, die man im Allgemeinen als Ausdruck der Ovulation ansieht, wieder auftreten und nicht selten bald darauf erneute Conception eintreten. Es müssen sich also innerhalb einer relativ kurzen Zeit die nach der Schwangerschaft noch erhaltenen kleineren Follikel bis zur vollständigen Reife entwickelt haben. Zur Ermöglichung eines so schnellen Wachsthums kann das aufgespeicherte Nährmaterial der Thecaluteïnzellen verwendet werden. In der That sehen wir im Puerperium die Thecaluteinzellen nur theilweise der hyalinen Degeneration verfallen und $\mathrm{zu}$ Grunde gehen, wahrend ein grosser Theil seino Einlagerungen abgiebt, seine früheren Dimensionen verliert und zu gewöhnlichen bindegewebigen Stromazellen sich zurückbildet (Taf. VIII, Fig. 21). Voraussichtlich ist diese Rückbildung der Luteïnellen im Puerperium ohne Zugrundegehen noch mehr ausgebildet als es nach den von mir untersuchten Fällen scheint, weil bei diesen Nekrose begünstigende Alterationen (Anämie, Fieber etc.) bestanden. Allein es wird aus naheliegenden Gründen sehr schwer fallen, ein ganz einwandfreies menschliches Material aus dieser Zeit $\mathrm{zu}$ bekommen.

\section{Luteïnzellenwucherung bei Blasenmole und Chorionepitheliom nnd die von Luteïnellen ausgehenden malignen Tumoren.}

In der Literatur ist wiederholt auf die Coincidenz von Ovarialtumoren mit Blasenmole bezw. mit Chorionepitheliom hingewiesen worden. Ohne dass auf diesen Befund Gewicht gelegt wurde, geschah dies in der Regel in älteren Beobachtungen; so werden Ovarialcysten erwähnt ron Gregorini, Jarotzki, WaldeyerSchaffraneck, M. Runge, Wilton, Kaltenbach, Rieck, Kreutzmann, Baumgart, Pfannenstiel u. A. m. Marchand hat wohl als erster mit Nachdruck auf diesen auffallenden Befund aufmerksam gemacht. E. Runge findet unter 144 Fällen von syncytialen Tumoren in 63 Fällen keine Angaben über das Ver. halten der Ovarien, in 24 waren die Ovarien mehr oder weniger cystisch degenerirt, bei 11 Fällen ergab der Tastbefund keine Veränderungen an den Eierstöcken, in 28 Fällen wurden bei Operationen oder Sectionen keine cystische Degeneration vorgefunden. 
Unter 28 Fällen von Blasenmole fehite in 16 jede Angabe über die Eierstöcke, in 12 zeigten sie cystische Entartung. Aus dieser Zusammenstellung geht hervor, dass zwar Blasenmole bezw. Chorionepitheliom häufig mit Ovarialcysten combinirt vorkommen, dass aber die cystische Degeneration der Ovarien in einer ganzen Reihe von Fällen fehlt. In jüngster Zeit hat Patellani im Centralbl $\mathrm{f}$. Gynäkologie alle Fälle von Blasenmole und Chorionepitheliom, bei denen Ovarialveränderungen festgestellt sind, zusammengestellt.

Mit grösserem Interesse wurden diese Ovarialcysten betrachtet, als man anfing, ihre histologische Eigenart zu studiren. Neumann erwähnt bereits das Vorkommen von Luteïnzellen in den cystischen Ovarien: das Stroma enthält grosse Gruppen von rundlichen zelligen Gebilden mit hellem Protoplasma und kleinen polygonalen Kernen, zwischen denen sich einzelne Septa von Ovarialstroma erstrecken. Nach Neumann, handelt es sich um zahlreiche im Entstehen begriffene Corpora candicantia. Die deciduaähnlichen Zellen stellen somit die gewucherten Elemente der Theca folliculi dar, zwischen denen die sogenannten Luteïnzellen liegen“. Neumann's Schilderung ist nicht ganz eindeutig, doch geht so viel hervor, dass er eine ungewöhnliche Wucherung der Elemente der Theca annimmt, eine Deutung, die sich auch bei späteren Untersuchungen als richtig erwiesen hat. Er selbst legt keinen Werth auf den Befund und bringt ihn namentlich in keinen causalen $\mathrm{Zu}$ samenhang mit der Entstehung der Blasenmole oder des Chorionepithelioms.

Die erste genauere mikroskopische Würdigung erfahren die Cysten durch Schaller and Pförringer bei einem Falle von Blasenmole im Jahre 1899. Die Cysten waren theils einfache Follikelcystchen, theils handelte es sich um Luteincysten. Die letzteren bestehen aus 2 Schichten, einer äusseren, aus kernreichem, festerem oder lockerem Bindegewebe und aus einer inneren aus einer vielschichtigen Lage von grossen, bald cubischen, bald runden, bald plattenepithelähntichen Zellen mit grossem, schön sich tingirendem Kern und diffus sich färbendem Protoplasma. Die innere Schicht ist eine typische Luteïnmembran. An manchen Stellen dringen die Zellmassen ohne von einer fibrösen Schicht begrenzt zu sein, weit in das Ovarialstroma vor und es finden sich, worauf besonders hingewiesen sein soll, "Ansammlungen solcher Zellen mitten im Ovarialstroma, bald in Form von rundlichen Massen, die in ihrem Innern bereits beginnende schleimige Erweichung 
zeigen können und die durch teinere und derbere Bindegewebsstreifen in verschieden starke Zellnester getheilt werden, bald in Form von lang sich hinziehenden Strängen, die sowohl in breiteren Bändern vereinigt, wie auch als einschichtige Verbände epitheloider Zellen in den Gewebslücken sich vorfinden. Zuweilen liegen die Zellen in directer Umgebung grösserer Lymphgefässe". Die Autoren glauben auf Grund dieser Befunde eine carcinomatöse Degeneration der Luteinzellen annehmen zu müssen. Auf die Unrichtigkeit der Deutung kommen wir zurück.

Aus der ausserordentlich reichlichen Anzahl der vorhandenen Luteincysten schliessen die Verfasser, dass nicht nur Corpora lutea vera, sondern auch falsche gelbe Körper (C. lut. menstruationis) an der Cystenbildung betheiligt sind; auffallend bleibe dabei immer, dass eine so grosse Zahl von Corpora lutea überhaupt vorhanden gewesen sein soll. Dass ungeplatzte Graaf'sche Follikel sich an der Cystenbildung betheiligen, halten sie nicht für wahrscheinlich. Schaller und Pförringer halten das Zusammentreffen der cystischen Degeneration der Ovarien und der Blasenmole für keine zufällige, sie glauben, die Erkrankung des Ovariums sei eine präexistente und wenn das bereits kranke $\mathrm{Ei}$ befruchtet werde, entwickele sich daraus eine Blasenmole.

Poten und Vassmer beschreiben bei einem Falle von Blasenmole ähnliche Befunde wie die erstgenannten Autoren. Auch sie fanden zungenförmige Ausläufer in das Ovarialgewebe sich hineinerstreckenả und ausserdem waren die grossen Zellen inselartig über das ganze Ovarialstroma zerstreut; auch diese Zellen werden für Luteïnzellen angesprochen. Ihre Herkunft ist unsicher; sie Jassen es unentschieden, ob es sich um mangelhaft zurückgebildete Reste ehemaliger Corpora lutea handelt oder ob hier eine selbstständige enorme Wucherung der Luteïnzellen vorliegt.

In diesem Falle erheben sich zunächst gegen die Deutung der inselartig im Ovarialgewebe gelegenen Zellen als versprengte Luteïnzellen gewichtige Bedenken. Es werden dort nämlich auch Excrescenzen an der Ovarialoberfläche beschrieben, die in ihren obersten Schichten aus Spindel- und Rundzellen sich zusammensetzen. Nach dem Ovarium zu folgte dann eine zahlreiche junge Capillaren zeigende Schicht: An einzelnen Stellen sah man breite Züge von Luteïnzellen bis unmittelbar unter die Oberfläche des Ovariums ziehen und hier in der Peripherie der Excrescenzen enden. Es gewann den Anschein, als ob hier Corpus luteum-Cysten die 
Oberfläche des Ovariums durchbrochen hatten und es dann durch den Reiz des ausgetretenen Inhaltes oder der noch weiter gewucherten Luteïnzellen zu einer circumscripten Entzündung gekommen war.

Man kann sich bei der Schilderung dieser letzten Befunde des Eindruckes nicht erwehren, dass es sich um eine Verwechslung der an Ovarien gravider Frauen häufig zu bcobachtenden Veränderungen in den obersten Schichten handelt, welche mit Bildung von Excrescenzen, ödematöser Durchtränkung des Gewebes und decjdualer Umwandlung bald auf weite Strecken, bald innerhalb scharf umschriebener kleinerer Bezirke, die zuweilen auch etwas entfernt von der Oberfläche des Ovariums gefunden werden, handelt.

Am ausführlichsten beschäftigt sich Stoeckel mit der vorliegenden Frage. In seiner Beobachtung (Blasenmole mit grossen doppelseitigen Ovarialtumoren, Totalexstirpation des inneren Genitale in Folge Incarceration des rechtsseitigen Tumors) fand er, dass dic Cysten zum grössten Theile Follikelretentionseysten sind in verschiedenen Stadien, mit einfach fibröser, meist epithelloser Wand, mit körnigen Gerinnungsmassen, manchmal mit Blut gefüllt, ferner zum Theil vielleicht auch stark erweiterte Lymphräume und Lymphgefässe. Zu einem grossen Theil handelt es sich jedoch um echte Luteincysten. An diesen kann man 4 Schichten unterscheiden; eine äussere schmale aus derbem Bindegewebe bestehende (Theca externa), dann eine zell- und blutgefässreiche Bindesubstanz (Theca interna), darauf die Luteïnzellenschicht und endlich nach innen ein Belag von Blut und Fibrinniederschlägen, durchsetzt von Bindegewebszellen. Diese Anordung erfährt jedoch häufig eine Abweichung insofern, als die inmerste Auflagerung fehlt, als die erste Sehicht nur schwach angedeutet ist oder ganz fehlt, und ferner insofern, als die zweite Schicht, die Theca interna und die Luteïnzellenschicht unmittelbar in einander übergehen. Es bleiben also für eine Reihe von Cysten nur 2 deutliche Schichten übrig, eine äussere bindegewebliche und eine innere Luteïnzellenschicht. Stöckel fand gleichfalls Luteïnzellen in kürzeren und längeren Zügen, in Haufen oder auch vereinzelt inmitten des Ovarialgewebes. Er erklärt sich im Gegensatz zu Schaller und Pförringer die Verlagerung der Luteïnzellen nicht durch actives Einwuchern in das Stroma, sondern durch Versprengung in Folge Einwachsens von Gefässen aus der Theca interna. Erleichtert wurde die Versprengung durch die hochgradige ödematöse Beschaffenheit des Stromas. 
Die Luteïnzellen in den Cysten, die sich von den Thecazellen nur durch die bedeutendere Grösse und durch die geringere Tinction unterscheiden, leitet Stöckel von den Bindegewebszellen der Theca interna $a b$ und stützt diese Ansicht neben der Aehnlichkeit in ihrem morphologischen Verhalten hauptsächlich damit, dass er an eincr Luteïncyste über der Luteïnmembran noch das Follikelepithel nachweisen konnte. Wenn ich auch seiner Deutung vollständig beistimme, so glaube ich doch nicht, dass man auf Grund des Nachweises von epithelialen Zellen, die schon stark in ihrer Structur gelitten haben, wie aus Beschreibung und Abbildung hervorgeht, die einen ungefärbten hellen Protoplasmahof haben, die in eine amorphe Fibrinmasse eingebettet sind, die das festere Gefüge der Basalzellen bereits gänzlich verloren haben und die endlich nur an einer einzigen Cyste auf eine kurze Strecke und dies dazu in cinem zweifellos pathologischen Falle, zu beobachten sind, so weitgehende Schlüsse in Bezug auf die Genese der Luteïnzellen zu ziehen berechtigt ist, wie es Stöckel that, der in dem Befunde eine wesentliche Stütze für die bindegewebliche Natur der Luteïnzellen des Corpus luteum erblickt. Es ist daher begreiflich, wenn R. Krukenberg in einem Falle von Chorioepitheliom seine besser erhaltenen "Belegzellen", die zweifellos Granulosazellen sind, in Ermangelung guter Vergleichsobjecte nicht ohne weiteres mit den von Stoeckel erwähnten Zellen zu identificiren sich getraut.

Stöckel beschreibt am linksseitigen Tumor neben einem Corpus luteum von regelmässiger Grösse und Structur ein zweites „kleines Corpus luteum“ und giebt davon eine Abbildung, das sich vor Allem auch dadurch auszeichnet, dass die Luteïzellen von seinen beiden Enden fächerartig auseinandergehen und sich weiter in das Stroma hineinerstrecken. Vergleicht man die Beschreibung uud Abbildung mit den in den Ovarien gravider Frauen erhobenen Befunden und stellt man sie im Speciellen mit unseren Fig. 6 (Taf. VI) u. 17 (Taf. VII) in Parallele, so ist ohne Weiteres klar, dass es sich hier um einen atretischen und zu beiden Seiten abgeplatteten Graaf'schen Follikel handelt, dessen Epithel zu Grunde gegangen und dessen Luteinschicht gewuchert ist. Gerade für die comprimirten Follikel, zumal für die in der Nähe des Corpus luteum oder einer grösseren Cyste gelegenen ist es charakteristisch, dass die Zellen an den beiden Polen besonders stark gewuchert sind und sich in das Bindegewebe hineinerstrecken, weil nur nach dieser Richtung die Bedingungen für ein weiteres Wachsthum günstig sind. 
Stoeckel fasst das Gesammtbild der Tumoren zusammen in die Worte: "Hochgradiges Oedem beider Ovarien mit den Symptomen starker Stauung im Blut- und Lymphgefässsystem; abnorm schnelle Follikelreifung und Corpus lateum-Bildung, die ohne Eröffnung der Follikel verläuft und in Folge dessen zu den beschriebenen Cystenbildungen führt." Er findet das Charakteristische für die gefundenen Eierstocksveränderungen bei Blasenmole , in einer Ausstreuung von Luteïnzellen über das ganze Organ bei abnormem Ablauf der Follikelreifung." Stoeckel drückt sich über einen causalen Zusammenhang der Ovarialveränderungen mit der Entstehung der Basenmole sehr reservirt aus, er ist vielmehr der Ansicht, dass die ödematöse Auflockerung des Ovarialstromas ein disponirendes Moment für die Luteïnzellenausstreuung schafft.

E. Runge hat die Ovarien bei 7 syncytialen Tumoren und bei einer Blasenmole untersucht und dabei Befunde erhoben, die mit denen von früher erwähnten ganz übereinstimmen. Auch er findet Luteïzellen in das Stroma versprengt. „Das diese zelligen Gebilde einhüllende Bindegewebe ist fast immer unverändert. Hin und wieder jedoch hat es sich um dieselben verdichtet und sich mit der Längsrichtung seiner Fasern concentrisch angeordnet, sō dass es gewissermaassen eine Kapsel um dieselben bildet." Oefters liegen in der Umgebung speciell grösserer Zellhaufen eigenthümlich gestaltete Gebilde, welche aus feinen, zumeist geschlängelten Bändern von hyaliner Beschaffenheit bestehen, die sehr an Residuen alter Corpora candicantia erinnern. Es macht den Eindruck, als ob man in diesen grössere Zellherden weisser Körper vor sich hat, deren ursprüngliches Gewebe nicht hyalin degenerirt ist, sondern sich unter Einwirkung irgend eines. Proliferationsvorganges in Luteingewebe umgewandelt bezw. in seinem ursprünglichen Aufbau verharrt hat." Es hält demnach Runge selbst für die scheinbar frei im Stroma liegenden Zellhaufen die Provenienz von Corpora candicantia für wahrscheinlich und schliesst für diese Fälle eine Versprengung der Zellen aus. Vergleicht man unsere Befunde an Ovarien gravider Frauen, so erkennt man obne weiteres, dass sich in der That die Zellen von ehemaligen Follikeln herleiten. Klarer tritt dies bei der Schilderung der gelb-bräunlichen Herde in der Cystenwand zu Tage, die keinen Zweifel darüber aufkommen lassen, dass es sich um aus Follikel hervorgegangene Gebilde handelte. Das Bild ist so, "wie es typische Corpora lutea vera im normalen Ovarium aufweisen." Die Entstehung der über das ganze Ovarial- 
stroma hin isolirt liegenden Herde von Luteïnzellen konnte Runge nicht sicher feststellen. Er nimmt als wahrscheinlich an, dass die Zellen "nicht nur in das umgebende Bindegewebe wuchernde Sprossen hineinsenden, sondern auch in die nächstliegenden Lymphspalten hineinwuchern und in ihnen sich weitere Wege bahnen." Er meint ferner, dass "vielleicht" auch normale Follikel und Primärfollikel für die Genese in Betracht kommen und dass auch die noch erhaltenen Zellen der Corpora albicantia von der Proliferation nit betheiligt sind. Den Process hält er entschieden für einen activen, „der auf einer äusserst starken Proliferationstendenz der Luteinzellen beruht." Absprengungen von Juteïnzellen durch Gefässe, wie Stoeckel zur Erklärung annimmt, hat er selten gesehen. Er kommt zu dem Schlusse, dass "es vielleicht nicht ganz unrichtig ist, wenn man sich dahin ausspräche, dass diese Eierstocksveränderungen nur bei syncytialen Tumoren bezw. Blasenmole vorkommen, dass es aber nicht unbedingt nöthig ist, dass sie immer Begleiterscheinungen derselben sein müssen."

L. Pick, der den von Jaffé genauer beschriebenen Fall kurz erwähnt, hebt die morphologischen Unterschiede zwischen den gewöhnlichen Corpus luteum-Cysten im Sinne von E. Fraenkel und den Luteïncysten bei Blasenmole hervor und bezeichnet die Ovarialveränderungen als eine Degeneratio polycystica ovariorum luteinalis. Der Befund stimmt mit denen von Stoeckel u. A. überein. Er legt dabei jedoch das Hauptgewicht weniger auf die Luteincystenbildung, als auf die Ueberproduction von Luteïnzellen überhaupt, sei diese nun in Form einfacher oder multipler Corpus luteumCysten gewöhnlicher Art oder in Form der Degeneratio polycystica luteinalis oder seien versprengte Zellen in das Ovarialstroma eingelagert. Und der Umstand, dass bei Blasenmole stets eine sehr reichliche Production von Luteïngewebe sich nachweisen lässt, drängt dazu, „einen causalen innern Zusammenhang zwischen diesen Befunden in den Ovarien und der Blasenmolenbildung in utero anzunehmen." Er stellt sich dabei auf den Boden der BornFränkel'schen Theorie von der Function des Corpus luteum.

L. Fränkel hat den Satz aufgestellt, das Corpus luteum habe ndie Function, die Insertion der Eier zu ermöglichen und ihre Weiterentwicklung zu sichern". Die Coincidenz von Ovarialtumoren und Blasenmole hält er für kein zufälliges Ereigniss; er nahm zu allererst an, dass in Folge der präexistirenden Eierstockserkrankung ein krankes Ei geliefert werde, aus welchem die Blasenmole her- 
vorgeht. Sodann, als diese Hypothese ihm nicht mehr haltbar schien, steltte er die These auf: "Die der Entwicklung des Eies vorstehende Drüse, das Corpus luteum, welches der dem Follikel eignen Schutzvorrichtung gegen Aussendruck entbehrt, wird durch den Druck der Geschwulst geschädigt und dadurch wird das primär gesunde Ei während und nach seiner Einbettung in den Uterus krank gemacht." Es ist also nach der Ansicht von Fränkel ein Minus von Luteïnsubstanz; welches die Blasenmolendegeneration des Eies verschuldet.

Die entgegengesetzte Meinung vertritt Pick und Jaffé, die ein Plus von Luteïnsubstanz für die Entstehung der Blasenmole sowohl als auch des Chorionepitheliom verantwortlich machen. Nach der Born-Fränkel'schen Theorie wird die Wucherung und nutritive Function des Chorionepithels durch das Sekret der Lateinzellen geregelt. Eine Leberproduction von Luteïngewebe, wie dies bei Blasenmole und Chorionepitheliom der Fall ist, wird ein Uebermaass chorioepithelialer Action im Uterus und hierdurch die Umwandlung des Eies zur Blasenmole, die bekanntlich stets mit einer Wucherung des chorioepithelialen Ueberzuges einhergeht, veranlassen. Die Ueberproduction von Luteïnsubstanz bei Blasenmole sieht Pick als Thatsache und rein objectives Gesetz an, die Deutung von der Wirkung der vermehrten Luteïnsubstanz erklärt er jedoch nur für eine persönliche Meinung.

Pick und Jaffé erklären die Verlagerung der Luteïnzellen durch Gefässabsprengung gleich Stoeckel, sie glauben aber nicht, dass der Vorgang an sich etwas für Blasenmole Specifisches ist, sondern dass er gelegentlich bei starker Entwicklung der Luteinzellenschicht unter Durchbrechung der Bindegewebskapsel auch ausserhalb der Schwangerschaft, wie die Befunde von E. Fraenkel zeigen, vorkommen kann.

Gottschalk führt die Blasenmolendegeneration des Eies auf primäre Störungen in der fötalen Zottencirculation zurück, die hier eine starke Stauung - in Folge Erschwerung und Behinderung des Blutrückflusses zum Embryo - veranlassen und so die Blutcirculation innerhalb der befallenen Zotten allmälig aufheben. Stärkere chorioepitheliale Wucherungen fehlen daher sehr häufig an den einzelnen Blasen; sie sind erst secundärer Natur und treten erst dann auf, wenn die zur Blasenmole degenerirten Zotten reichlicher vom mütterlichen Blute umspült werden. Bei dieser Auffassung können die häufig sich vorfindenden cystischen Degenerationen der 
Ovarien in keinem primär ursächlichen Verhältnisse zur Entstehung der Blasenmole stehen. Gottschalk bestreitet auch, dass es sich bei der polycystischen Degeneration der. Ovarien überhaupt um Luteïncystenbildung handelt. Durch den in Folge der Uterusausdehnung erschwerten Rückfluss des venösen Blutes komme es auch zu einer Stauung in den Ovarien, zu einer krankhaft gesteigerten Reifung von Follikeln mit einer vermehrten Bildung von Follikelflüssigkeit, also zur polycystischen Degeneration. Die Cysten seien aber keine echten Luteincysten, weil sie Luteïzellen in ihrer Wand führen. „Man übersieht dabei, dass jeder reifende Follikel eine Luteinzellenschicht aufweist und daher der Nachweis einer Luteïnellenschicht in der Cystenwand allein nicht ausreicht, die Cyste als aus einem wirklichen Corpus luteum hervorgegangen zu deuten." Gottschalk übersieht dabei zweierlei; einmal dass es ganz auf die Ausbildung und die Mächtigkeit der Luteïnzellenschicht ankommt, die in gleicher Stärke nie bei einem reifenden Follikel beobachtet wird, und 2. dass sich im Gegensatz zu der bisherigen Annahme eine Luteïncyste nicht allein aus einem Corpus luteum verum oder menstruationis bilden, sondern auch aus einem atretischen Follikel hervorgehen kann. Das Charakteristische der Luteïncyste ist die Luteïnzellenschicht. Wir werden später auf diese Verhältnisse noch näher eingehen. Und kein Untersucher der Cysten bei Blasenmole hat bisher gezweifelt, dass thatsächlich eine Luteïschicht eine grosse Anzahl von Cysten auskleidet.

Krebs beschreibt die Ovarien von 2 Fällen von Chorioepitheliom; in dem ersten Falle war das rechte Ovarium mikroskopisch ohne Abweichung, das linke enthielt eine Cyste, die Krebs für eine Luteincyste erklärt. In dem zweiten Falle waren ebenfalls einige Luteincysten vorhanden, doch wird von einer Luteïnellenversprengung nichts erwähnt. Ebensowenig bei einem dritten Falle, der ausführlich mitgetheilt wird.

In der Beobachtung von Fischer (Chorioepitheliom) war das rechte Ovarium von zahlreichen Cysten durchsetzt, von denen ejne citronengross war, das linke Ovarium wurde zurückgelassen, nachdem einige Cysten punctirt waren. Fischer erwähnt nur, dass „das ganze Ovarium von Bändern und Strängen gewucherter Luteinzellen durchsetzt ist" und nimmt "eine Bildung von Cysten aus dem Corpus luteum, aus Luteïngewebe" an, eine recht wenig klare Ausdrucksweise. 
Beide letztgenannten Autoren stellen sich auf den Pick'schen Standpunkt.

R. Krukenberg beschreibt ausführlich den Befund an den Ovarien eines Falles von Chorioepitheliom. Am linken Ovarium war ausser dem regelmässig gebauten Corpus luteum verum am distalen Pole eine kirschkerngrosse, bläuliche Cyste, welche mit einer verschieden dicken Schicht von Luteïnzellen ausgekleidet ist, über der, durch eine endothelartige Zelllage getrennt, kleinere epitheloide Zellen gelagert sind, die Krukenberg wahrscheinlich für Reste der Granulosazellen hält, die auch nach Abbildung und Beschreibung gar nichts anderes sein können.

Die Theca externa ist von der Luteïnzellenschicht nicht scharf getrennt und ist stark ödematös durchtränkt. Im Centrum eines Vorsprunges der Cystenwand beschreibt Krukenberg ein Gebilde, das zweifellos nach der Schilderung ein atretischer Follikel mit bindegewebigem Kern und Luteïnzellenwucherung ist, und ferner unweit von diesem einen zweiten ohne Bindegewebskern des gleichen Ursprunges. Krukenberg deutet jedoch den Befund unrichtig und nimmt eine Luteïnzellenversprengung an. Im rechten Ovarium finden sich 3 Corpora lutea spuria von 5,6 und $7 \mathrm{~mm}$ grösstem Durchmesser, von denen das erste eine deutliche Luteïnzellenschicht zeigt, die beiden anderen aber stark zurückgebildete Luteïnzellen aufweisen. Krukenberg hält die Gebilde offenbar für von der Menstruation herstammende gelbe Körper (geplatzte Follikel), während mir nach der Schilderung und meinen Beobachtungen die Entstehung aus ungeplatzten und atretischen Follikeln weit wahrscheinlicher erscheint.

Eine wichtige Arbeit ist die von Wallart. Derselbe giebt zunächst eine vortreffliche makro- und mikroskopiscbe Schilderung der Ovarien einer Frau, deren innere Genitalien wegen Chorioepithelioms, das sich an eine Blasenmole anschloss, exstirpirt wurden. Die Ovarien zeigten keine wesentliche Vergrösserung; die kleinen Cystchen wiesen zum grossen Theil eine Theca interna auf, deren Zellen durch Vermehrung and Wachsthum zu Luteïnzellen umgewandelt waren. Er leitet die Luteinzellen von den bindegewebigen Zellen der Theca interna ab, weil das Follikelepithel an manchen Cysten noch mehr oder minder vollständig erhalten ist. Je mehr die Granulosaschicht abnimmt, desto mehr nimmt die Luteïnzellenschicht $z u$, sie vermag erst dann richtig zu wuchern, wenn sie von der Granulosa völlig befreit ist. Wallart weist 
ferner mit Nachdruck darauf hin, dass Follikel unter Zugrundegehen der Granulosa zusammenfallen, dass sie von grösseren Follikeln, namentlich dann, wenn sie nahe dessen Peripherie gelegen sind, mehr oder minder stark zusammengedrückt werden, dass unter Umständen ihr ehemaliges Lumen nur mehr schwer zu erkennen ist, dass man jedoch aus der Art der Zellen und deren fächerartigen Anordnung die zu Grunde gegangenen Follikel feststellen kann. Alle diese Befunde von Wallart, die er hier ausführlich an dem Blasenmolenovarium giebt, kann ich für die Ovarien schwangerer Frauen aus fast allen Monaten vollauf bestätigen. Er selbst spricht die Ansicht aus, dass nicht allein bei Blasenmole, sondern auch bei jeder Schwangerschaft derartige Luteïnzellenhyperplasien vorkommen. Er begründet seine Annahme auf Befunde an 6 Paaren von Ovarien, welche von an verschiedenen Krankheiten verstorbenen Schwangeren und Wöchnerinnen herstammen. (Abortus im 6. Monat, gestorben am 10. Tage post abortum, künstliche Frühgeburt im 8. Monat, Tod am 5. Tage des Puerperiums, 3 nach einer Geburt am regelrechten Termin im Wochenbett, davon 1 am 5. und 8. Tage post part. an Sepsis gestorben und endlich eine im Anfange des 9. Monats niedergekommene und am Tage nach der Entbindung an Lungenödem verstorbene.) Es befinden sich unter diesen 6 Fällen demnach 5, welche erst mehrere Tage nach der Geburt an mehr oder minder schweren fieberhaften Erkrankungen gestorben sind. Nur 1 Fall ist einwandfrei, 2 weitere können zur Beweisführung noch zugelassen werden. Dass solch' ein Material zum Studium physiologischer Verhältnisse und zur Begründung des Ausspruches, während der Schwangerschaft schlechthin komme es zu einer Luteinzellenwucherung, nicht geeignet ist, darauf habe ich bereits ausführlich hingewiesen. (Centralbl. f. Gyn., 1905, No. 19.) Was die Schlussfolgerung von Wallart betreffs des Zusammenbanges von Blasenmole und den Luteïnzellenwucherungen anlangt, stimme ich ihm in jeder Beziehung zu.

Die bereits im ersten Abschnitt citirte Arbeit von Böshagen enthält keine eigene Beobachtung von Luteincysten bei Blasenmole oder Chorionepitheliom, doch äussert er sich in dem Sinne, dass bei Blasenmole eine abnorme Wucherung von Luteinzellen an solchen Stellen vorkomme, wo sie schon normaler Weise gefunden werden.

Birnbaum beschreibt die Ovarien einer 6 Wochen nach Aus- 
stossung einer Blasenmole bei einem Zwillingsei verstorbenen Frau, an denen er makroskopisch ausser "einem ungefähr kirschkerngrossen und mehreren kleineren mit Blut gefüllten Räumen" keine Cysten finden konnte. Die mikroskopische Untersuchung des einen Ovariums ergab keine Luteincysten und keine Luteïnellenversprengung, im anderen Ovarium, das 2 Corpora lutea enthielt, zeigte das eine Corpus luteum den bekannten Bau, das andere, "wesentlich kleinere" wich dagegen sehr ab. Es fehlte die Tunica fibrosa; Tunica propria und Luteïnschicht sind nicht überall scharf von einander zu trennen, die Luteïnzellen erstrecken sich mehr oder minder weit in Bändern und Streifen, in einzelnen Exemplaren in das Ovarialstroma hinein. Es ist sehr wahrscheinlich, dass es sich bei dem "wesentlich kleineren" Corpus luteum nicht um einen wahren gelben Körper gehandelt hat, sondern um einen solchen, der aus einem grossen atretischen Follikel hervorgegangen ist. Bei diesen ist bekanntlich Durchbruch von Luteïnzellen ein häufiges Ereigniss. Dieser Annahme steht das Vorhandensein eines Zwillingseies nicht im Wege, da die 2 Eier auch aus einem Follikel stammen können. Trotz dieses etwas kärglichen Luteïncystenbefundes es ist nur von der einen. Corpus luteum-Zellenversprengung dio Rede - führt auch Birnbaum die Genese der Blasenmole auf cine Hyperplasie des Luteïngewebes zurück. Freilich scheint er gewisse Bedenken gegen die Deutung gehabt zu haben, da ihm die alleinige Erkrankung des einen Eies (bei Zwillingsei!) sichtliche Schwierigkeiten macht und er sich damit behilet, dass er annimmt, dass sich nicht das gesunde, wohl aber "das in seiner ersten Anlage geschädigte zweite $\mathrm{Ei}$ unter dem Reize der vermehrten Luteïnsekretion zu einer Blasenmole" entwickelt.

Bamberg theilt einen Fall von Incarceration cystisch degenerirter Orarien bei Blasenmole mit, bei dem zur Behebung der Einklemmungserscheinungen eine Laparotomie nothwendig wurde. Die Ovarien waren beiderseits etwa apfelgross, enthielten nur kleinere Cysten, das Stroma war ungewöhnlich stark ödematös durchtränkt; die Cysten erwiesen sich bei der mikroskopischen Untersuchung als typische Luteïncysten, eine Zerstreuung der Luteïnellen über das Ovarialstroma war, wie ausdrücklich hervorgehoben wird, nioht festzustellen. Die Placenta war erst im Beginn der Blasenmolendegeneration, der $10 \mathrm{~cm}$ lange Fötus war ödematös. Bamberg stellt sich betreffs der Deutung des ätiologischen Zusammenhanges von Luteïncystenbildung und Blasenmole ganz auf den Pick- 
Jaffé'schen Standpunkt. Auffallend ist ihm die Kleinheit der gefundenen Cysten, ferner der Umstand, dass die meisten noch eine Faltung der Innenfläche aufweisen. Diese Erscheinungen erklärt er mit der erst beginnenden Entwicklung der Blasenmole, bei längerem Bestand wäre es zu einer pralleren Füllung der Cysten und dabei zur Ausgleichung der Fältelung gekommen.

Es sind wohl noch mehrere Fälle von Coincidenz von Blasenmole bezw. Chorionepitheliom und Luteïncysten der Ovarien ${ }^{1}$ ) in der Literatur bekannt, einzelne enthalten jedoch eine ungenügende mikroskopische Beschreibung der Ovarialcysten, so der von Malcolm und Bell beschriebene, andere waren mir im Original nicht zugängig; indess genügen die hier mitgetheilten zur Beurtheilung der Verhältnisse.

Ich lasse nach dem Literaturbericht zunächst eine eigene Beobachtung folgen:

Poliklinik 1904. No. 173. Frau Barbara M. 32 J. Xp. Die Geburten verliefen ohne Störung, letzte Geburt vor einem Jahre, vor zwei Jahren Abort im 2. Monat. 5 Kinder leben und sind gesund, 3 starben im frühen Alter. Periode war regelmässig, alle 4 Wochen $3-4$ Tage dauernd. Letzte Periode vom 10.-14. Nov. 1903, wälırend der jetzigen Schwangerschaft starkes Erbrechen, sonst keine Beschwerden.

Seit 3 Wochen bestehen zeitweise Blutungen in wechselnder Quantität und Qualität, rein blutig oder fleischwasserähnlich, 1-2 Tage lang, danı wieder aussetzend. Seit 10 Tagen ist Pat. in Behandlung eines Privatarztes, der sie mit zeitweiser Tamponade und mit Secale behandelte. Am 3. März 1904 wurde sie der geburtshülflichen Poliklinik zur weiteren Behandlung überwiesen.

Objectiver Befund: Mittelkräftige Frau von blassem Aussehen mit einem Stich in's Gelbliche. Puls 120, Temp. 37. Uterus als ein rundlicher, gleichmässig elastischer, weicher Tumor zu fühlen, der mit seinem Fundus etwa einen Querfinger breit über den Nabel hinaufragt. Kindstheile sind nicht zu fühlen, keine Herztöne zu hören, dagegen ist ein lautes Uteringeräusch festzustellen. Bei der Betastung des Uterus treten leichte Zusammenziehungen auf, doch lassen sich partielle Contractionen in Form circumscripter Verhärtungen, die nach Poten für die Diagnose einer Blasenmole von besonderer Bedeutung sind, weder spontan noch nach Palpation des Organs beobachten.

Nach Entfernung von zwei blutig durchtränkten Tampons wird zunächst eine Lysolspülung vorgenommen und dann die vaginale Untersucbung angeschlossen: Die Vagina ist weit, die Vaginalwand glatt, die Portio ist derb, wenig aufgelockert, steht in der Spinallinie, äusserer

1) D unger (Ziegler's Beiträge. Bd. 37. S. 279) beschreibt 2 Fälle von. Chorionepitheliom und 4 Blasenmolen, bei denen scheinbar nur bei einem Falle (2. Fall von Chorionepitheliom) eine mässige cystische Degeneration der Ovarien bestand. Er sieht das Primäre in der chorioepithelialen Wucherung und hält die Luteïncysten für secundär (Anm. bei d. Corr.). 
Muttermund für den Finger durchgängig, innerer geschlossen. Die Speculumuntersuchung ergiebt keine Besonderheiten. Gegenwärtig besteht kein Blutabgang. Vorsichtshalber wird eine Tamponade mit Jodoformgaze and mit Tampons ausgeführt, um eventuell eintretende weitere Blutverluste zu verhüten und die Wehenthätigkeit anzuregen; letztere wird ferner durch Verabreichung von Secale zu fördern gesucht. Dieses Vorgehen schien berechtigt, da mit Wahrscheinlichkeit die Diagnose auf eine Blasenmole gestellt wurde. Diese gründete sich auf folgende Momente: 1. das Missverhältniss zwischen Dauer der Schwangerschaft und der Ausdehnung des Uterus (Schwangerschaft von $3 \frac{1}{2}$ Monat, Fundus 1 Querfinger oberhalb des Nabels), 2. auf die merkwürdig weiche, teigige Consistenz des Organs, 3. auf den wiederholten Abgang von lackfarbenem Blut. Differentialdiagnostisch kamen drohender Abort event. mit Plac. praevia und Hydramnion in Betracht; ersterer konnte wegen der starken Ausdehnung des Uterus und der Härte der Portio und des unteren Uterinsegmentes ausgeschlossen werden, abgesehen davon, dass Plac praevia selten schon in so frühen Monaten Erscheinungen macht, gegen letzteres sprach die Consistenz des Uterus und die Anwesenheit der Blutungen. Da vorläufig nach dem Verbalten von Puls und Temperatur keine bedrohlichen Symptome bestanden, auch die Anämie nicht so hochgradig war, um bei der noch nicht sichergestellten Diagnose gleich zu einer mit Schwierigkeiten verbundenen Ausräumung der Gebärmutter zu schreiten, wurde vorläufig mit Tamponade und Secale auszukommen gesucht. Alsbald wurden wir jedoch durch Auftreten stürmischer Erscheinungen zu einem activeren Vorgehen gedrängt.

Bereits am nächsten Tage (4.3.04) in der Frühe stellte sich nach gut verbrachter Nachtruhe ein heftiger Schüttelfrost mit einer Temperatursteigerung auf $40,5^{\circ}$. und einem Puls von 160 ein. Pat. klagnt über wehenartige Schmerzen in der Unterbauchgegend. Das Abdomen ist weich, gut eindrückbar, nicht aufgetrieben, es besteht kein Erbrechen. Leichter Icterus.

$\mathrm{Da}$ es nach dem ganzen Symptomencomplex nicht zweifelhaft sein konnte, dass es sich um eine foudroyant einsetzende Zersetzung des Uterusinhaltes handelte, wurde beschlossen, die Gebärmutterhöhle digital auszuräumen. In leichter Chloroformnarkose (Gesammtverbrauch von Chloroform $5 \mathrm{~g}$ ) wurde nach Spülung der Scheide mit Lösung durch den in Folge der aufgetretenen Wehen nunmehr für einen Finger eben durchgängigen Cervicalcaual, der noch in einer Länge von etwa $3 \mathrm{~cm}$ erhalten war, eingegangen; eine Ausräumung erwies sich noch als unmöglich, weshalb mit dem Schultze'schen Dilatator der Cervicalcanal langsam $\mathrm{zu}$ einer Weite dilatirt wurde, dass 2 Finger bequem hindurch geführt werden konnten. Einrisse entstanden dabei nicht. Wie die Finger den inneren Muttermund passirt hatten, tasteten sie eine von der Uteruswand abgehobene, runde, teigige Masse, von der grössere Stücke entfernt wurden, die sich als alte, stark übelriechende Blutcoagula erwiesen. Durch starken Druck vom Fundus aus konnte nach und nach der ganze Uterusinhalt in den Bereich, der Finger gebracht und ausgeräumt werden. Der Hauptsache nach bestand die Masse aus altem Blut, etwa $1000 \mathrm{~g}$, darinnen fand sich der $12 \mathrm{~cm}$ lange, leicht macerirte Fötus und theils zwischen den Blutgerinnseln zerstreut, der Hauptsache nach in einem traubenförmigen Körper zusammenhängend, eine Blasenmole; ein kleiner Theil der Placenta war der blasigen Degeneration nicht verfallen und zeigte makroskopisch keine Veränderungen. Die 
mikroskopische Untersuchung konnte leider nicht vorgenommen werden, da die Angehörigen das Ausgeräumte entgegen der Anordnung beseitigten.

Da der Inhalt, namentlich in den unteren Abschnitten, weniger in den oberen, jauchig roch, wurde eine Uterusspülung mit Lysol und dann noch eine mit 50 proc. Alkohol vorgenommen und die Gebärmutter, die keine Contractionstendenz zeigte, mit Jodoformgaze austamponirt, trotzdem keine Blutung bestand. Die Gefässe waren offenbar bereits alle durch Thromben geschlossen. Auch bei der Ausräumung selbst war nur ganz wenig Blut verloren gegangen, dieses hatte jedoch ein auffallend clunkles, fast lackfarbenes Aussehen. Der Puls war vor wie nach der Operation frequent und klein, Campherinjectionen und Excitantien per os besserten seine Qualität nicht. Im Verlaufe der nächsten Stunden verschlimmerte sich die Herzthätigkeit trotz aller Excitantien, trotz Kochsalzinfusionen fortschreitend, Temperatursteigerung blieb bestehen und 5 Stunden nach der Ausräumung trat der Exitus letalis ein.

An der Diagnose konnte kein Zweifel sein: Bei der durch langdauernde Blutungen nach aussen und ins Uteruscavum geschwächten Frau trat eine putrid-septische Zersetzung des Uterusinhaltes ein; deren Anfänge wahrscheinlich schon mehr als 24 Stunden, d. h. seit der Uebernahme der Behandlung durch uns zurücklagen; diese führte trotz rascher Entfernung der zersetzten Massen zu einer. Allgemeininfection, der der geschwächte Organismus rasch erlag. Die angehüuften Blutmassen in der Gebärmutterhöhle boten den vorzüglichsten Nährboden für die Keime und wie der zündende Funke in einem Pulverfass wirkt, verbreitete sich explosionsartig Intoxication und Infection durch den Körper.

Die theilweise vorgenommene Section bestätigte den Befund: Acuter Milztumor, parenchymatöse Schwellung von Leber und Nieren. Der exstirpirte Uterus mit Anhängen wurde in Kaiserling'scher Flüssigkeit gehärtet.

Die Maasse des Uterus sind: Länge $19 \mathrm{~cm}$, Entfernung der Tubenansätze $13 \mathrm{~cm}$. Die Dicke der Uteruswand ist überall ziemlich gleichmässig, ungefähr $1 \mathrm{~cm}$. Der Sitz der Placenta, bezw. der Blasenmole ist an der hintern Wand und ist daran zu erkennen, dass noch einzelne Fetzen, zum grössten Theile aus Blutgerinnseln bestehend, der Innenfläche anhaften. In der Musculatur sieht man keine Bläschen, makroskopisch verhält sie sich wie die übrigen Partien der Muscularis. Zur mikroskopischen Untersuchung werden Stücke aus der Wand, wo die Blasenmole haftete, geschnitten.

Die wichtigsten Veränderungen sind an den Ovarien; beide Ovarien sind anmähernd gleich gross, haben nierenförmige Gestalt. Die Maasse des linken Ovarłums sind: Länge 12, Höbe 4, Breite $3 \mathrm{~cm}$. Die Oberfäche des Ovariums zeigt eine Reihe von halbkugeligen Hervorwölbungen, die durch mehr oder minder grosse Cysten gebildet werden. Die Cysten waren im frischen Zustande prall gefüllt, conservirt sind sie etwas zusammengefallen und ge- 
schrumpft; ihre Farbe ist theils hell, durchscheinend, theils gelblich, theils bräunlich grau. Am Hilus ist eine Stelle, welche eine auffallend gelbe Farbe aufweist.

Auf einem der Länge nach durch das Ovarium geführten Schnitt erkennt man, dass die ganze Zona parenchymatosa von Cysten eingenommen ist, etwa 20 an der Zahl, die ganz kleinen mit eingerechnet (Taf. IX, Fig. 27), 5 zeichnen sich durch besondere Grösse aus, sind etwas über wallnussgross und stark gegen die Peripherie hinausgeschoben. Ihre Wand ist an der Oberfläche des Ovariums sehr dünn; kaum $1 / 2 \mathrm{~mm}$ dick, ihr Inhalt ist durch die Härtung geronnen und hat ein gallertiges Aussehen von weisslicher und gelbweisslicher Farbe. Eine Cyste ist mit einem braunschwarzen Inhalt gefüllt. Die Verfärbung rührt von Blutbeimengung her. An vielen Cysten lässt sich von der Wand deutlich eine etwa $1 / 4 \mathrm{~mm}$ dicke Membran von gelblichem Aussehen abzichen, dieselbe ist zum Theil gefaltet, theilweise jedoch ganz glatt. Aber nisht in allen Cysten ist die Membran zu erkennen und abzuziehen, an einzelnen Cysten tritt sie nur an gewissen Stellen, meist an den central gelegenen Abschnitten der Peripherie hervor.

An dem distalen Ende des Ovariums ist ein gelber Körper von $0,8: 0,5 \mathrm{~cm}$ Grösse, der eine festere Consistenz zeigt und durch Farbe und Aussehen von dem übrigen Ovarialgewebe scharf absticht. Er ist der einzige Theil des Ovariums, der in der allgemeinen ödematösen Durchtränkung und Auflockerung des Ovarialgewebes durch sein festes Gefüge in die Augen fällt. Es handelt sich, wie die mikroskopische Untersuchung mit Sicherheit ergiebt, um das Corpus luteum.

Kleinere Cysten von Linsen- bis Kirschkerngrösse sind in grösserer Anzahl vorhanden, sie sind mehr in den centralen Theilen gelegen, auch in den Septen zwischen den Wänden der grösseren Oysten finden sich einzelne.

Das rechte Ovarium zeigt die gleichen Veränderungen; in der Grösse der Cysten, in ihrer Form, ihrer Farbe bestehen zwar kleine Variationen, doch sind sie ganz untergeordneter Natur; deshalb kann eine genauere Schilderung des rechten Ovariums füglich unterbleiben. Ein Corpus luteum ist im rechten Ovarium nicht aufzufinden.

Mikroskopische Untersuchung: Es wurden aus einer grossen Anzahl kleiner und grösserer Cysten Stücke, auch zusammenhängende Partien des Ovariums excidirt, in aufsteigendem Alkohol gehärtet, 
in Paraffin eingebettet und mit Hämalaun gefärbt, einzelne Schnitte auch nach van Gieson.

Die Untersuchung ergab nun, dass einige Cysten, und zwar meist kleinere, nichts anderes als cystisch degenerirte Follikel waren, ihre Wand zeigte den bekannten Bau der Follikelcysten ohne ein Luteinzellenband. Bereits Stoeckel wies darauf hin, dass neben typischen Luteïncysten auch gewöhnliche Follikelcysten vorkommen.

Die überwiegende Mehrzahl der Cysten jedoch zeigte einen davon abweichenden Bau. Die Wand derselben besteht deutlich aus 2 Schichten, einer äussern, die aus spindelförmigen Bindegewebsfasern, parallel zur Cystenwand verlaufend, besteht und spärliche Gefässe enthält und einer innern, die sich aus epitheloiden Zellen, in $6-8$ Reihen übereinander gelegen, zusammensetzt. Diese Zellen haben einen grossen Protoplasmaleib und einen meist schwach tingirten Kern; im Protoplasma sieht man an gut erhaltenen Partien gelbliche Einlagerungen, wie sie den Luteïnellen eigenthümlich sind. Meist aber hat die Färbbarkeit der Zellen stark gelitten, die Zellen sind auseinander gewichen, wie zusammengesintert (Fig. 28, Taf. IX). Zwischen den epitheloiden Zellen verlaufen einzelne Gefässe, deutlich an den Endothelien und an der Füllung mit Blut zu erkennen. Gegen das Lumen der Cyste zu wird diese Schicht abgegrenzt von einem Streifen einer homogenen Substanz, die die ganze Cyste in der Regel ausfüllt.

Die epitheloiden Zellen müssen nach ihrem Aussehen, ihrem Inhalt, ihrer Anordnung als Luteïnzellen angesprochen werden, wie dies aúch einmüthig von den bisherigen Untersuchern geschehen ist.

Häufig ist die Anzahl der über einander gelegenen epitheloiden Zellen nicht so gross, vornehmlich trifft dieses auf die grossen Cysten zu. Man hat vielfach den Eindruck, je grösser eine Cyste ist, desto weniger stark ist die Luteïnzellenschicht ausgeprägt, die Zellen sind durch den erhöhten Inhaltsdruck atrophisch zu Grunde gegangen. Gelegentlich decken die Wand nur nøch wenige Zellen, an andern Partien sind sie vollständig verschwunden und zwar findet sich dieses Verhalten auch an Cysten, wo andere Abschnitte der Peripherie noch mit mehr oder minder hoher Lage von Luteïzellen ausgekleidet sind.

Ist die Luteînschicht sehr hoch, so imponirt sie deutlich als Membran, die in der Regel glatt der Unterlage anliegt und meist keine Fältelung zeigt. Doch kommen auch stärker gefaltete Mem- 
branen vor. Indes halte ich dies für kein charakteristisches Zeichen einer Luteïncyste, wie viele Autoren gethan; denn in der Mehrzahl der Fälle handelt es sich erst um eine secundäre Erscheinung, indem die Membran sich bei Abnahme des Cysteninhaltes während der Härtung und durch Schrumpfung des ganzen Präparates in Folge der Conservirung in Falten legt.

Aus dem Umstande, dass die Pat. septisch zu Grunde ging und dass erst 2 Tage nach dem Tode die Sektion vorgenommen werden konnte, erklärt sich die stellenweise weit fortgeschrittene Degeneration und Nekrose des Gewebes. Andere Stellen sind hingegen wieder besser conservirt und lassen die Verhältnisse besser überblicken.

Neben den bisher geschilderten Cysten finden sich noch andere Gebilde, die für die Beurtheilung der Genese der Luteincysten von der grössten Bedeutung sind, das sind nämlich atretische Follikel, welche noch nicht cystisch entartet sind. Statt langer Schilderung verweise ich auf die Figur (Taf. IX, Fig. 30), die ein gutes Bild dieser Follikel giebt: aussen die theilweise degenerirte Theca externa, aul diese folgt eine Schicht von Luteïnzellen, die von den Zellen der Theca interna abstammen. Die Schicht ist verschieden breit, am breitesten an den beiden Polen, die Zellen zeigen radiäre Anordnung, doch sind die Zellen nur klein und zeigen kaum noch eine Andeutung zu einer Umwandlung zu Luteïnzellen. Reichliche Capillaren verlaufen dazwischen. An dem Präparate sind ferner auch noch die Follikelepithelien, bereits in $\mathrm{Ab}-$ blätterung begriffen, zu erkennen, von der Luteinschicht durch ein schmales Band einer hyalinen Zone getrennt. Aus der Form des Follikels ist ohne Weiteres klar, dass er eine seitliche Compression. erfahren hat.

An anderen Stellen ist das Follikelepithel ganz zu Grunde gegangen, die gegenüberliegenden Luteïschichten sind aneinandergerückt und man hat den Eindruck, als ob zwischen dem Stroma ein Nest von Luteinzellen eingelagert wäre, das von einer benachbarten Luteïnyste eingewuchert ist. Auf diese Weise erklären sich eine ganze Reihe von Luteinzellenanhäufungen im Stroma, an einzelnen lassen sich noch Reste von Follikelepithel nachweisen, bei wieder anderen kann man aus der Form und der Anordnung der Zellen einen bestimmten Schluss auf ihre Genese machen. Sind die Zellen in bindegewebigen Kapseln eingelagert und haben sie dabei in ihren Conturen stark gelitten, so haben sie in der 
Regel auch ihre Charakteristika verloren und es ist dann schwer zu entscheiden, ob es sich nur um abgelöste Epithelien eines Follikels oder um ehemalige Luteïnellen eines atretischen Follikes bandelt.

Wie steht es aber mit der Frage der Luteinzellenversprengung? Es ist kein Zweifel, dass die oben geschilderten Bilder durch mehr oder minder starke Compression der ursprünglichen Follikel und Zugrundegehen einzelner Zellen entstehen können. Beachtet man diese Momente nicht, so hat es den Anschein, als handele es sich um eingewucherte Lutcïnzellenhaufen. Ferner ist hervorzuheben, dass bei den vollständig comprimirten Follikeln sich die Luteïnzellen in der Längsachse des Follikels manchmal ausserordentlich weit mitten in das Stroma hinein erstrecken. Auf zur Längsachse senkrechten Schnitten hat man dann den Eindruck, als lägen die Zellen ohne Zusammenhang mitten im Ovarialgewebe. Nicht selten gelingt es durch Verfolgung einer grösseren Anzahl von Schnitten den Zusammenhang mit dem Luteïnfollikel oder der Cyste nachzuweisen. Bei der mangelhaften Conservirung der Präparate lässt. sich die Frage, ob Luteinzellen auch aus dem Stroma hervorgegangen sind, nicht entscheiden.

Die mikroskopische Untersuchung des Corpus lut. ergiebt folgenden Befund: Gegen die Umgebung ist das ganze Gebilde scharf abgegrenzt, die Theca externa und interna ist z. B. stark degenerirt und streckenweise von hyaliner Beschaffenheit, auch die bindegewebigen Septa sind theilweise nekrotisch. Die Luteïnzellen weisen zwar noch ihre typische Form auf, sind jedoch auseinander gefallen und sehen aus, als ob sie abblättern wollten, die Färbbarkeit hat stark gelitten. Bei starker Vergrösserung, sogar schon ohne Immersion erkennt man, dass eine grosse Anzahl von Bakterien von verschiedener Grösse und Gestalt in dem Gewebe deponirt sind; auch an anderen Stellen des Ovariums, besonders im Lumen der Gefässe erblickt man gelegentlich einzelne Bakterienhaufen. Ich lege denselben keine besondere Bedeutung zu, da es nicht sicher festzustellen ist, ob nicht erst secundär nach dem Tode bei der an Sepsis verstorbenen Frau die Einwanderung der Keime erfolgt ist. Dafür spricht die Verschiedenheit der Bakterien (auch spärliche Kokken finden sich darunter), ferner das Fehlen einer stärkeren Reaction des umgebenden Gewebes. Immerhin könnte diese auch bei so foudroyant verlaufenden Sepsisfällen, wie der vorliegende, fehlen.

Aus der vorausgegangenen Beschreibung und den eingefügten 
Abbildungen dürfte so viel mit Sicherheit hervorgehen, dass wir es in unserem Falle genau mit denselben Veränderungen zu thun haben, die von anderen Autoren wiederholt beschrieben wurden und unter dem Namen der Luteïncysten bekannt sind.

Fassen wir die bisher in der Literatur bei Blasenmole und Chorionepitheliom am Ovarium beobachteten Veränderungen zusammen, so handelt es sich in der Mehrzahl der Fälle um polycystische Degenerationen von verschiedener Ausdehnung und Grösse. Die Grösse der Tumoren ist jedenfalls nicht das Wesentliche, denn man findet solche von fast Mannskopfgrösse bis herab zu denen, die die Grösse eines Kirschkernes nicht übertreffen, also über die Dimensionen eines wachsenden Follikels nicht hinausgehen. In dem Falle von Birnbaum ist ausdrücklich gesagt, dass nur ein kirschkerngrosser und mehrere kleinere, mit Blut gefüllte Hohlräume vorhanden waren. Auch Krukenberg und Wallart erwähnen die auffallende Kleinbeit (Kirschkerngrösse) der gefundenen Cysten. Wiederholt wird berichtet, dass das andere Ovarium nur ganz gewöhnliche Grösse aufwies. In den Fällen, wo die Tumoren eine ungewöhnliche Grösse erreicht haben, liessen sich häufig Staungs- oder directe Einklemmungserscheinungen nachweisen. So erklärt Stoeckel die Grössendifferenz des rechten Ovariums in seinem Falle, das fast Mannskopfgrösse erreichte, gegenüber dem etwas kleineren linken durch die Einklemmung des rechtsseitigen Tumors. Auch in der Beobachtung von Bamberg, wo übrigens die Tumoren nur apfelgross waren, bestanden Incarcerationserscheinungen, die zur Laparotomie nöthigten. Es ist meines Erachtens nicht angängig, die relative Kleinheit der Cysten, wie dies Bamberg thut, mit der geringen Entwicklung der Blasenmole in causalen Zusammenbang zu bringen; denn diese Erklärung versagt sofort bei den Beobachtungen von Krukenberg, Wallart und Birnbaum, wo das Chorionepitheliom, bezw. die Blasenmole volle Ausbildung erfahren hatte.

Wir kommen daher zu dem Ergebniss, dass die Grösse der Cysten nichts Wesentliches, sondern nur etwas Accidentelles darstellt, dass ihre Grösse abhängt von verschiedenen nebensächlichen Momenten, unter denen die Incarceration gelegentlich eine Rolle spielt. Wichtiger und ungleich häufiger als diese sind die bei Blasenmole so häufig beobachteten Stauungserscheinungen. Wir sehen bei der blasigen Entartung des Eies recht häufig Oedeme der unteren Extremitäten auftreten. Kehrer, der über 50 Fälle 
von Blasenmole, die aus der Hebammenpraxis stammen, berichtet, findet die Oedeme in 30 pCt. aller Fälle verzeichnet; Dorland und Gerson's Zusammenstellung von 100 Fällen ergab in 19 Albuminurie und Oedeme. Die Entstehung der Oedeme ist z. Th. wohl nur auf Circulationsstörungen durch den Druck des schwangeren vergrösserten Uterus zurückzuführen, z. Th. auf nephritische Processe, die bekanntlich die Blasenmole nicht selten compliciren. Bei verschiedenen grösseren Ovarialtumoren fiel die ödematöse Beschaffenheit des Stromas auf. So bebt dies Stoeckel bei seinem Fall ausdrücklich hervor und sieht darin ein prädisponirendes Moment zu der Luteïnzellenabsprengung. Auch in unserem Falle war das Stroma reichlich ödematös durchtränkt. Es ist naheliegend, anzunehmen, dass bei den an den Extremitäten und an der Bauchwand nachweisbaren Circulationsstörungen auch die Ovarialsubstanz in Mitleidenschaft gezogen wird. Neben diesen circulatorischen Einflüssen und neben der Nephritis müssen zur Erklärung der ödematösen Beschaffenheit der Ovarialtumoren auch noch specifische Einflüsse wirksam sein, die mit der bei Blasenmole und Chorionepitheliom nachgewiesenen abnormen Wucherung des epithelialen Zottenüberzuges in Zusammenhang stehen. Die Häufigkeit der Nephritis bei Blasenmole wird ja bekanntlich ebenfalls mit der Ueberschwemmung des mütterlichen Organismus mit fötal-ectodermalen Elementen erklärt.

Wir sehen also im Gegensatz zu Pick, Jaffé u. A. die Ovarialtumoren nicht als das Primäre an, die secundär zu einer blasigen Entartung des Eies bezw. zur Entstehung eines Chorionepithelioms führen, sondern wir nehmen umgekehrt an, dass die Blasenmole und das Chorionepitheliom, die sich aus uns noch nicht näher bekannten Ursachen entwickeln, zur Cystenbildung und zur ödematösen Durchtränkung des Ovarialstromas führen und zwar einmal durch Circulationsstörungen mechanischer Natur und ferner durch chemische Stoffe, die wahrscheinlich mit der chorioepithelialen Wucherung der Zotten in einem Abhängigkeitsverhältniss stehen. Auch darf nicht vergessen werden, dass nicht alle Cysten Luteïncysten sind. So erwähnt Stoeckel ausdrücklich, dass daneben, ebenso wie in meinem Fall, gewöhnliche Follicularcysten und bei Stoeckel auch erweiterte Lymphräume vorhanden waren. Nach meinen Erfahrungen ist gerade der exacte Nachweis der Luteïnzellenschicht bei grossen Cysten sehr schwierig, häufig wohl unmöglich. Fast alle Autoren 
geben an, dass die Luteïnzellenschicht um so dünner wird, je grösser die Cyste ist. Wer wird bei ganz zusammengepressten Zellen noch mit Sicherheit zu sagen wagen, dass es sicher ehedem Luteinzellen gewesen. So ist dieses sicher unmöglich von der $\mathrm{Ab}$ bildung 2 und 5 von Jaffé zu sagen, wo 1 bezw. 2 Zellen von zweifelhafter Provenienz dem Stroma aufsitzen.

Was uns zu dieser Auffassung veranlasste, sind unsere Befunde an den Ovarien gravider Frauen aus allen Monaten der Gravidität, über die im ersten Theile ausführlich berichtet wurde. Nach diesen Befunden tritt bereits in den ersten Monaten, an Intensität bis zum Ende der Schwangerschaft zunehmend, eine Vergrösserung und Vermehrung der Zellen der Theea interna ein, die sich zu den ThecaLuteïnzellen umbilden.

Das Wesentliche der Ovarialveränderungen bei Blasenmole und Chorionepitheliom suchte man 1 . in der polycystischen Degeneration, 2. in der Hyperplasie der Luteïnellen, 3. in der Versprengung dieser Zellen in das Ovarialstroma hinein; gerade gegen den letzten Punkt hatten sich bereits einige Bedenken geltend gemacht, indem die Versprengung der Luteïzellen in verschiedenen Fällen vermisst wurde (Birnbaum, Bamberg).

Wir haben geringe cystische Degeneration der atresirenden Follikel in allen Stadien der Schwangerschaft, mit Vorliebe in der 2. Hälfte derselben feststellen können, stets war dabei die Theca interna hypertrophisch und die Zellen in Theca-Luteïzellen umgewandelt. Die Grösse der vorhandenen Follikel-Luteincysten schwankte, überschritt jedoch Kirschkerngrösse nicht. Wie bereits hervorgehoben, halten wir die Grössendifferenzen der Follikel-Luteïncysten für unwesentlich.

Die Hyperplasie der Theca-Luteïnzellen während der Schwangerschaft wird nach dem im 1. Theil der Arbeit Ausgeführten nicht mehr bestritten werden können. Es erfordert nur noch die Luteinzellenversprengung bei Blasenmole und bei Chorionepitheliom eine kurze Besprechung.

Die Versprengung kann einmal zu Stande kommen durch eine wirkliche Absprengung eines Stückes vom Corpus luteum. Ich stelle diese Möglichkeit durchaus nicht in Abrede. Ich selbst werde im 3. Theil der Arbeit über ausserhalb der Theca externa des Corpus lut. gelegene epitheloide Zellen und über eine directe Abtrennung einer Corp. luteum-Partie bei einem ziemlich jungen Corpus lut. menstruationis und ferner über Absprengungen an drei 
verschiedenen Stellen eines Corpus lut. graviditatis von 5 Monaten berichten. Es ist ferner von Zellverlagerung bis in oder über die Theca externa bei Corpus luteum-Cysten von E. Fraenkel und von Orthmann sowie von einem jungen Corp. lut. gravid. von H. Rabl berichtet. Allein was die wirklichen Absprengungen wie in dem Fall No. 7 von mir anlangt, so sind diese Beobachtungen sicher nicht häufig. Bei den an noch nicht scharf abgegrenzten jungen Corpora lutea und bei Corpus luteum-Cysten gemachten Beobachtungen handelte es sich immer nur um Verlagerungen in der allernächsten Nähe innerhalb oder nur wenig ausserhalb der Theca externa. Ein Gleiches gilt auch für eine Absprengung der Luteïnzellen durch dazwisschen wachsende Gefässe, wie sie Stoeckel und mit ihm Pick u. A. annehmen. Es kann durch ein Gefäss eine Partie Zellen etwas seitwärts und wenn die Zellen ganz an der Peripherie gelegen sind, etwas hinausgedrängt werden, zu einer wirklichen Verlagerung in einigermaassen entferntere Gewebstheile kann es jedoch nie kommen.

Die scheinbar versprengten Luteïnzellen können zweitens von atretischen Follikeln herrühren, die ihre Kugelform verloren und ganz zusammengesunken sind. Dabei kann das Lumen mehr oder minder vollständig ebenso wie der Inhalt verschwinden, namentlich wenn der atretische Follikel durch eine in der Nähe gelegene Cyste platt gedrückt ist. Diese Möglichkeit ist gerade bei der häufig stärker ausgesprochenen cystischen Degeneration des Blasenmolenovariums naheliegend (cf. Taf. VI Fig.6). Eine solche Luteïnzelleneinlagerung ins Stroma kann auch vorgetäuscht werden, wenn der atretische Follikel eben erst angeschnitten ist. Ich stimme Wall art bei, wenn er die Fig. 2 in der Arbeit von Stoeckel für einen atretischen Follikel und nicht für versprengte Luteïnzellen deutet. Die Anordnung der Zellen lässt eine andere Deutung nicht zu.

Nach meinen Erfahrungen, und es sind zwei Beobachtungen, worauf ich meine Annahme stütze, kann die Follikelatresie manchmal eigenartige Gebilde, die echten Corpora lutea ausserordentlich gleichen, hervorbringen, ich habe sie in Fig. 9 und 13 abgebildet. Sie können ebenfalls eine Luteinzellenversprengung vortäuschen.

Drittens können jedoch auch an Ort und Stelle aus den Stromazellen durch Metaplasie Luteïnzellen hervorgehen, die ich als Stromaluteïnzellen bezeichnet habe, wenigstens muss ich dies mit Bestimmtheit von den Ovarien Schwangerer aus den letzten 
Monaten behaupten. Diese Behauptung gründet sich auf die Beobachtung directer Uebergänge der Stromazellen in Luteïnzellen und auf den Nachweis, dass sich in den im Stroma zerstreuten Zellen kein Zusammenhang mit atretischen Follikeln feststellen liess. Auch genetisch hat die Annahme die Wahrscheinlichkeit für sich; denn wir wissen, dass sowohl die Zellen der Theca interna lebensfrischer Follikel als auch die Theca-Luteïnzellen verödender Follikel aus den Stromazellen ihren Ursprung nehmen.

Mit dem Nachweis der Umwandlung der gewöhnlichen Stromazelle an Ort und Stelle in eine Luteïnzelle fällt auch die Schwierigkeit für die Erklärung der thatsächlich im Stroma zerstreut liegenden and somit scheinbar versprengten Luteinzellen bei Blasenmole und Chorionepitheliom weg. Es widerspricht unsern Vorstellungen von der Gutartigkeit eines Processes, wie es das Blasenmolenovarium doch thatsächlich ist ${ }^{1}$ ), wenn wir Zellen in fremdes Gewebe, mehr oder minder weit, in diesem Falle tief in das Ovarialgewebe zerstreut finden. Es ist ja daher nicht zu verwundern, wenn Schaller und Pförringer bei solchen Befunden einen carcinomatösen Process - sie fassten die Zellen für Zellen des Corpus luteum und für epithelialen Ursprunges auf - ansahen.

Vielfach sind die Luteïncysten bei Blasenmole und bei Chorionepitheliom in einen Topf mit den aus einem Corpus luteum men-

1) Albert beobachtete einen Fall, wo sich zur Zeit der Ausstossung einer Blasenmole doppelseitige fast faustgrosse Ovarialkystome vorfanden. Nach Ablauf von 2 Monaten hatten sich diese spontan vollständig zurückgebildet (ref. nach E. Runge, l. c. S. 62). Jedenfalls ist noch kein einziger Fall von polycystischer Degeneration bei Blasenmole erwiesen, der maligne degenerirt ist. Dies ist um so auffälliger, da die Blasenmole nicht gerade eine seltene Erscheinung ist. Es ist natürlich nicht angängig aus dem Umstand, dass sich nach der Blasenmole häufig ein Chorionepitheliom, also eine in den meisten Fällen maligne Neubildung, entwickelt, den Schlnss zu ziehen, dass auch die dort gefundenen Ovarialtumoren maligne entartet sein müssten; sie enthalten wohl Lutëncysten, aber keine malignen Elemente. Es ist daher vorläufig gar kein Grund vorhanden, bei Frauen mit Blasenmole, sofern nicht durch Einklemmungserscheinungen (Fall Stoeckel, Bamberg) eine Indication vorliegt oder die Tumoren so gross sind, dass voraussichtlich functionirendes Ovarialgewebe nicht mehr vorhanden ist, die Ovarien zu exstirpiren, zumal es sich häufig noch um jugendliche Individuen handelt. Auch bei Chorionepitheliom ist keine Indication vorhanden, grundsätzlich wie E. Runge meint, die Ovarien zu entfernen, namentlich dann, wenn sie klein und makroskopisch unverändert sind. Auch kleine Cysten geben keine Anzeige zur Entfernung; denn maligne Elemente sind meines Wissens in den Tumoren nie beobachtet worden, auch keine Metastasen des Chorionepithelioms. 
struationis oder graviditatis hervorgegangenen Cysten, wie sie zuerst makroskopisch von Rokitansky, mikroskopisch von Eug. Fraenkel beschrieben worden sind, zusammengeworfen worden. Alle Autoren, die bisher Corpus luteum-Cysten beschrieben haben, (ich nenne ausser den beiden bereits erwähnten Autoren L. Fraenkel, Nagel, Langer, Orthmann, Amann, Oliva, Diepgen, Santi) nehmen an, dass sie sich aus Corpora lutea graviditatis, seltner menstruationis bilden, nie aber aus ungeplatzten Follikeln, also aus atretischen Follikeln hervorgehen. Ich glaube, Diepgen versteht eine Aeusserung von Pfannenstiel (l. c. S. 294) falsch, der sagt: "Meiner Ansicht nach besteht zwischen den Follikelcysten und den Corpus luteum-Cysten kein wesentlicher Unterschied; das eine Mal wird der ungeborstene, das andere Mal der geborstene Follikel betroffen." Pfannenstiel meint dies offenbar im ätiologischen Sinne und will damit nicht ausdrücken, dass die Corpus luteumCysten auch aus nicht geplatzten Follikeln hervorgehen können.

Die aus einem Corpus luteum hervorgegangenen Cysten haben daher mit den von uns geschilderten Luteïncysten gar nichts zu thun und es stiftet nur unnöthige Verwirrung, wenn sie bei den Erörterungen über cystische Entartungen der Ovarien bei Blasenmole und bei Chorionepitheliom immer wieder die Begriffe willkürlich durcheinander geworfen werden. Es wäre daher zweckmässig, für die aus einem gelben Körper hervorgegangenen Cysten die durchaus charakteristische Bezeichnung Corpus luteumCyste beizuhalten, für jene aus atretischen und ungeplatzten Follikeln hervorgegangenen zur schärferen Charakterisirung den Ausdruck Follikelluteïncyste zu gebrauchen.

Das willkürliche Durcheinanderwerfen der beiden Bildungen hängt zum grössten Theil wohl mit der Auffassung über die Genese des Corpus luteum zusammen. Diejenigen Autoren, welche das Corpus atreticum nur für ein Corpus luteum im Kleinen halten und es histiogenetisch mit diesem gleichstellen, d. h. es ebenfalls aus Bindegewebszellen der Theca interna entstehen lassen, erachten natürlich eine scharfe Trennung für unnöthig. Wir haben bereits an anderer Stelle auf das Unberechtigte eines derartigen Schlusses ausdrücklich hingewiesen und müssen auch hier für das Auseinanderhalten der Begriffe eintreten.

Die Follikelluteïncysten sind bisher nur in 3 Zuständen beobachtet worden: 1. in der Schwangerschaft, 2. bei Blasenmole und 3. bei Chorionepitheliom, bei den beiden letzten Zuständen 
meist, wenn auch nicht immer in beträchtlicherer Grösse. Es soll hiermit natürlich nicht in Abrede gestellt werden, dass grössere Follikelluteïncysten unter anderen Verhältnissen vorkommen können. Ich selbst glaubte an einem Ovarium bei Adnexerkrankung eine solche gefunden zu haben, allein die Structur-Verhältnisse waren nicht hinreichend klar, um dieses beweisen zu können.

Den genannten 3 Zuständen ist die Anwesenheit fötaler Elemente im mütterlichen Organismus gemeinschaftlich. Bei der Schwangerschaft sind es normale Zotten, bei der Blasenmole die entarteten Zotten und bei dem Chorionepitheliom sind es die epithelialen Abkömmlinge der Zotten, das Syncytium und die Langhans'schen Zellen. Sollte darin nur ein zufälliges Zusammentreffen liegen? Es ist das von vorherein nicht wahrscheinlich. Man nimmt an, dass von der Oberfläche der Placenta, im Speciellen von dem Syncytium Stoffe in den mütterlichen Organismus gelangen. Sie könnten Veranlassung zu der Wucherung der Zellen der Theca interna geben, die in dem mit Blut reichlich versorgten Organe mächtiger zu wachsen anfangen.

Wie im ersten Theil ausgeführt, nimmt die Entwicklung der Thecaluteïnellen mit fortschreitender Schwangerschaft continuirlich zu, um kurz vor der Geburt den Höhepunkt zu erreichen. Bei einer gewöhnlichen Schwangerschaft ist in den Monaten, in denen die Blasenmole aufzutreten pflegt, die Luteïnzellenwucherung in der Regel noch nicht so stark, wie sie wiederholt in dieser Anomalie des Eies gefunden wurde. Wir können daher annehmen, dass die entarteten Zotten einen besonders ergiebigen Reiz auf die Entwicklung der Thecaluteïnzellen ausüben. Der umgekehrte Schluss, den Pick u. A. gezogen haben, ist um deswillen nicht angängig, weil am Ende der Schwangerschaft die Luteïnzellenwucherung eine sehr starke, meist viel intensiver zu sein pflegt, als man sie je bei Blasenmole sieht und trotzdem bleibt die blasige Entartung des Eies aus. Die gleiche Erklärung gilt auch für das Chorionepitheliom.

Während der Schwangerschaft, der normalen sowohl wie der Blasenmolenschwangerschaft, sistirt die Eireifung, wahrscheinlich, weil die wuchernden Theca interna-Zellen dem Ei das Nährmaterial entziehen. Beim Chorionepitheliom ist es noch nicht sicher festgestellt, ob die Ovulation noch fortdauert; doch spricht manches für ein Sistiren der Ovulation, so die unregelmässigen Blutungen. Einigemal wurde vor dem Auftreten des Chorionepithelioms noch regelmässige Periode beobachtet; doch scheint dies nach einer 
304 Seitz, Die Follikelatresie während der Schwangerschaft etc.

flüchtigen Durchsicht der Literatur betreffs dieses Punktes selten zu sein. Es wäre sehr interessant, bei künftigen Untersuchungen von Ovarien bei Chorionepitheliomen auch auf diesen Punkt das Augenmerǩ zu richten. Das Sistiren der Ovulation ist keine Vorbedingung für die Erklärung der Thecaluteïnzellenwucherung bei Chorionepitheliom. Es kann anfänglich noch zu einer Reifung von Eiern kommen, zugleich neben einem reifen Ei können jedoch die übrigen Follikel bereits der Atresie verfallen.

Ausser den Follikelluteïncysten bei den vorgenannten Zuständen und den Corpus luteum-Cysten sind nun auch echte Neubildungen, von Luteïnzellen ausgehend, beschrieben, die wir hier noch anhangsweise erwähnen wollen.

Wir sehen von den wenigen bekannt gewordenen gutartigen Geschwülsten ab, welche sich aus dem Bindegewebskern des Corpus luteum durch ungewöhnliche Vergrösserung des normal vorhandenen Kerns gebildet haben, die fast sämmtlich den Fibromen zugerechnet wurden und die Grösse einer Wälschnuss nicht überragten. Solche Geschwülste wurden von Rokitansky, von Klob und von Klebs beschrieben. Da sie sicher nicht von den specifischen Elementen des Corpus luteum, den Luteïnzellen, ausgehen, braucht hier nicht weiter darauf eingegangen $\mathrm{zu}$ werden.

Nun sind auch einige bösartige Neubildungen, die angeblich von den Luteïnzellen ihren Ursprung genommen haben, bekannt geworden. Der erste Fall ist von Rokitansky veröffentlicht; bei einer 65 Jahre alten Frau fand sich ein kindskopfgrosser, tuberöser Tumor an der Stelle des linken Ovariums, der aus einer 8-12 mm dicken, gefalteten, weissröthlichen Rinde und aus einem von blassgelblichem, klebrigen Serum infiltrirten Bindegewebsmasse bestand. Rokitansky fasste die Geschwulst als ein Carcinom des Corpus luteum auf. Bereits Martin hat seinen Zweifeln betreffs der Genese der Geschwulst bei der 65jährigen Frau Ausdruck gegeben, denen sich Santi anschliesst. Das Alter der Patientin scheint zwar nach dem Bekanntwerden des Grousdew'schen Falles kein Gegenbeweis für die Abkunft aus einem Corpus luteum zu sein. Allein die mikroskopische Technik war zu jener Zeit (1859) noch viel zu wenig entwickelt, um so feine Differenzialdiagnosen bei auch jetzt noch so schwierig zu beurtheilenden Fällen zu stellen.

Maffucci leitet bei einem cystischen Adenosarkom des Ovariums den sarkomatösen Antheil des Tumors ab theils von der Theca der in Zerstörung befindlichen Follikel, theils von dem 
zwischen den Drüsenschläuchen befindlichen Bindegewebe, theils von einem speciellen Gewebe, welches Maffucei für jenes des Corpus luteum ansieht. In der Mitte der Geschwulst fanden sich gelbe Massen vor, die sich aus pigmentirten Zellen zusammensetzten, welche Rückstände des Corpus luteum waren. Die Einlagerungen scheinen jedoch nebensächlicher Natur gewesen zu sein, das Wesentliche ist das Adenosarkom gewesen, das sich nach der Ansicht des Autors selbst von dem intertubulösen Bindegewebe ableitete. Jedenfalls kann der Tumor nicht als eine specifische, von den Luteïnzellen ausgehende Geschwulst angesprochen werden.

Die Beobachtung von Schaller und Pförringer wurde bereits an anderer Stelle besprochen und gewürdigt. Es handelt sich um nichts anderes, als um die bekannte Thecaluteïn-Zellen-Wucherung bei Blasenmole.

Voigt beschreibt einen während der Schwangerschaft operativ entfernten malignen Ovarialtumor, von dem er annimmt, dass er vom Corpus luteum und zwar durch Wucherung der Luteïnzellen hervorgegangen ist. Der Tumor hatte ein stark in Degeneration begriffenes Centrum, das von Blutungen durchsetzt ist, an der Peripherie waren Zelleı von verschiedener Gestalt, mit einem und mehr Kernen, die als Luteïnzellen angesprochen werden, an der Aussenseite liess sich noch normales Gewebe nachweisen. Die Beschreibung und die beigegebenen Abbildungen sind nicht so, dass man mit Sicherheit den Schluss ziehen müsste, dass es sich nothwendig um Proliferationen von Luteïnellen handelt. Voigt scheint übrigens selbst von der Richtigkeit seiner Deutung nicht ganz überzeugt zu sein, da er auch einen anderen Ausgang für möglich hält und speciell wegen der erweiterten Blutcapillaren und der gewucherten Adventitia an ein Perithelioma ovarii denkt.

Wendeler erwähnt im Handbuch der Eierstockserkrankungen von Martin S. 416 einen Tumor seiner Beobachtung, nder gleichfalls durch seinen makroskopischen Aufbau frappant den Eindruck eines Riesen-Corpus luteum hervorrief, durch die histologische Untersuchung als Sarkom verificirt wurde". Wendeler nimmt an, dass es sich bei der in geschlechtsreifem Alter stehenden Person um ein Corpus luteum-Sarkom gehandelt hat. Leider ist über die Structur der Zellen, über die Einzelheiten im Aufbau nichts Weiteres angegeben.

Eine ganz eigenartige Beobachtung liegt von Grousdew vor, auf die wir etwas genauer eingehen müssen. 
Es handelte sich um eine 60jährige Patientin, bei der vor 10 Jahren die Menopause eingetreten war und "bei der zugleich mit fibromatöser Affection des Uterus (mit Blutungen) und Kystombildung (Kystoma glandulare proliferum) im rechten Ovarium, sowie mit kleincystischer Degeneration der Follikel und wiederum Kystombildung im linken Ovarium sich eine eigenthümliche Neubildung entwickelt hat, welche aus Luteïnzellen bestand." Die Neubildung des Luteingewebes war auf das linke Ovarium beschränkt. Die Ansammlungen der Luteïnzellen stellten theils solide Gebilde dar, theils lagen sie in den Wänden von ganz kleinen bis gut wallnussgrossen Cysten. Die Structur der Cystenwand war folgende: Aussen eine bindegewebige gefäss- und zellarme Schicht, dann die zweite und breiteste Sehicht jüngern zellreichen Bindegewebes, dessen einzelne Fasern unter einander filzartig verwirrt waren, sehr reich an Gefässen. "In ihren innersten Partien lagen in Form eines ununterbrochenen Streifens in bindegewebigen Schlingen ziemlich grosse, unregelmässig geformte Zellen, die sich durch das Vorhandensein von grobkörnigem dunkelgelbem Pigment mit einem Stich in's Gelbliche charakterisiren." In der 3. innersten Schicht bildeten die Luteïnzellen das vorwiegende Element; je näher die Zellen der Höhle lagen, desto grösser war ihr Umfang, desto deutlicher trat deren polygonale Gestalt hervor, desto gleichmässiger war das Pigment in deren Protoplasma vertheilt, und desto schwächer erschien ihre Färbung. Weder vom Endothel noch vom Epithel waren an der innern Schicht Spuren zu sehen. An einer 2. gleichgrossen Cyste (B) war die Luteïnzellenmasse noch grösser und die mittlere und innere Schicht gleich reich an diesen Zellen, die innere Schicht war ohne Beimengung von Bindegewebe und Gefässen, an der innern Peripherie die Luteïnzellen im fibrösen Zerfall begriffen. Den gleichen Bau wie die 2 erwähnten grössern Cysten zeigten die kleinen Cysten, welche in der Rindensubstanz des Ovariums in grösserer Menge sich vorfanden und ganz vereinzelt sich auch in der Gefässschicht nachweisen liessen.

Besonders interessante und für unsere Ansicht wichtige Befunde sind folgende zwei: 1. das Verhalten der gewöhnlichen Follikularcysten und 2. das Verhalten der Corpora candicantia. Die Follikularcysten zeigten denselben Bau wie gewöhnlich: mehr oder minder sklerosirtes Bindegewebe in den Wandungen, stellenweise noch erhaltenes Epithel, serösen Inhalt mit körnigem Detritus untermischt, 
aber , in den Wandungen vieler dieser Cysten war eine ununterbrochene, bisweilen ziemlich dicke Schicht gelber Zellen vorhanden."

In der Peripherie des Ovariums waren ausser den geschilderten kleinen Cystchen auch noch derbe Knötchen vorhanden, von denen die einen ein Gewebe von ausschliesslich weisser Farbe zeigten und sich als Fibrome oder Pseudopapillome erwiesen, die andern jedoch auch pigmentirte Einlagerungen enthielten, mikroskopisch sich als Corpora albicantia erwiesen, in deren Mitte oder in deren Nähe gelbe Zellen waren. Die Luteïnzellen lagen in einzelnen hauptsächlich an der Peripherie der Narbenkörper, entweder nur in dünner Schicht oder in grössern Conglomeraten beisammen, welche an der Oberfläche des Ovariums hervorragten und das Corpus albicans nach dem Centrum des letztern gleichsam verdrängten. Innerhalb der Corpora albicantia waren z. Th. nur wenige Luteinzellen, z. Th. auch grössere Ansammlungen. Waren nur wenige Zellen vorhanden, so zeichneten sich diese durch die deutlich polygonale Form und ihren bedeutenden Umfang, die gleichmässige Vertheilung des Pigmentes im Protoplasma, durch hellere Tinktion der Zelle und durch Anzeichen von karyokinetischer Theilung der Kerne aus, in grössern Conglomeraten waren die einzelnen Zellen kleiner und mehr abgerundet; ohne Mitosen, das Pigment körniger und dunkler und bei bedeutenderen Ansammlungen konnte man in der Mitte Einschmelzung der Zelle und Ausbildung einer Höhle feststellen. Es können auf diese Weise Luteincysten entstehen.

Grousdew sieht den Process als eine Neubildung an, die "aus den Corpora albicantia oder genauer aus Partien von Ovarialstroma, welche die Corpora albic. umgeben", sich entwickelt hat. Dieses Stroma, welches früher wahrscheinlich einen Bestandtheil der Theca folliculi gebildet hat, vermag nach langer Zeit der Ruhe noch Luteïnellen zu produciren, "nachdem die physiologische Bildung derselben im Ovarium bereits aufgehört hat. Die entstandenen Luteïzellen wuchern $z$. Th. in das Bindegewebe der Corpora albicantia hinein, z. Th. wachsen sie auch nach aussen in das umgebende Stroma."

Ausser aus den Corpora albicantia können sich Luteïnzellen auch entwickeln aus der Theca kleincystisch degenerirter Follikel. Durch Durchbruch einer Luteïnyste in ein benachbartes Kystom kann eine Combination beider Cystenarten entstehen. 
308 Seitz, Die Follikelatresie während der Schwangerschaft etc.

Grousdew bezeichnet die Luteinzellenwucherung als einen malignen Process und da er die Luteïnzellen für Abkömmlinge des Bindegewebes ansieht, nennt er die Neubildung Sarcoma ovarii cysticum luteïnocellulare. In dem beschriebenen Falle waren Uterus und Adnexe exstirpirt worden, die Patientin ging jedoch $1 \frac{1}{2}$ Jahre darauf an Spindelzellensarkom des Peritoneum zu Grunde. Dass jedoch zwischen dem Sarkom des Peritoneums und den Luteincysten des Ovariums wirklich ein Zusammenhang bestand, ist keineswegs erwiesen; denn das Sarkom wich in keiner Weise von gewöhnlichen Sarkomen ab und zeigte im Bau keine Aehnlichkeit mit der angeblichen Muttergeschwulst, so dass es viel weniger gezwungen erscheint, anzunehmen, dass sich das Sarkom des Peritoneums ganz unabhängig von der Luteïnzellenwucherung entwickelt hat, ebenso wie die Ovarialkystome in beiden Ovarien. Auch Grousdew hatte zuerst angenommen, dass es sich um einen gutartigen Process handelt; erst der schliessliche Ausgang führte eine Meinungsänderung, wie mir scheint, ohne genügenden Grund herbei.

Auch betreffs der Luteïncysten in Grousdew's Fall möchte ich mir noch ein paar Bemerkungen erlauben. Es waren im linken Ovarium ausser einem proliferirenden Kystom (in der Zeichnung mit $\mathrm{C}$ benannt), mehreren gewöhnlichen kleincystischen Degenerationen der Follikel und einigen kleinen Fibromen zwei grössere Luteincysten (A und B) und mehrere kleinere, welche in den centralen Theilen gelegen sind. Grousdew leitet bei der 60jährigen Pat., die bereits vor 10 Jahren in die Menopause eingetreten war, die Luteincysten nicht von Corpora lutea ab, und wir glauben mit Recht, sondern er führt sie auf Corpora albicantia zurück. Die in der Umgebung der Corp. albicantia liegenden Stromazellen haben die Fähigkeit beibehalten, sich zu Luteïnzellen umzuwandeln; durch Vermehrung der Luteïnzellen entsteht an Ort und Stelle eine reichliche Ansammlung der Zellen, die centralen Theile werden schlecht ernährt, werden schliesslich aufgelöst und auf diese Weise bildet sich ein centraler Hohlraum und eine Luteïncyste. Wir haben es demnach mit einer neuen Art von Luteincysten zu thun und zwar mit solchen, die aus Corp. albicantia hervorgegangen. Ich erkenne diesen Ursprung der Cysten aus Corp. albicantia als vollständig berechtigt oder vielmehr bei einer alten Frau als einzig möglich an, glaube aber betreffs der Art der Entstehung anderer Ansicht als Grousdew sein zu müssen.

Trotzdem es mir, wie ich glaube, gelungen ist, an den Ovarien 
Schwangerer nachzuweisen, dass Stromazellen, sogar ausserhalb des Bereiches der Theca interna, sich in Luteïnzellen (Stromaluteinzellen) umzuwandeln vermögen und ich somit die Möglichkeit auch für andere Fälle gerne zugebe, habe ich gegen diese Deutung in dem Falle von Grousdew Bedenken, kann einen Beweis für diese Genese nicht erblicken und glaube auch nicht, dass es dieser Annahme zur Erklärung bedarf.

Es handelt sich um Luteinzellen, jedoch nicht um junge lebensfähige Luteïnzellen, wie wir sie an den Follikelluteïncysten Schwangerer sahen, und auch nicht um jene, welche in den Corpus luteumCysten angetroffen werden; denn jene zeigen niemals die ausgesprochen gelbe Farbe, wie die Luteïnellen im Falle von Grousdew; ausserdem löst sich das Lutein dieser Zellen in starkem Alkohol fast vollständig. Dies müsste nothwendig auch bei den Ovarien in Grousdew's Falle geschehen sein, die ${ }^{1} 1 / 2$ Monate lang Alkohol lagen und bei der Einbettung wahrscheinlich die verschiedenen Concentrationen durchlaufen haben. Trotz alledem ist ihre Farbe noch leuchtend roth.

Es handelt sich nach der Beschreibung, nach der Farbe, nach dem Aussehen und nach der Localisation der Zellen um jene Luteïnzellen, die sowohl ausserhalb als während der Schwangerschaft innerhalb, an der Peripherie, und ausserhalb der Corpora albicantia gefunden werden und die durch Aufnahme von Blutpigment ihr charakteristisches Aussehen bekommen. Ich habe bereits früher (S. 280) diese Pigmentzellen näher beschrieben und sie in Uebereinstimmung mit $\mathrm{H}$. Rabl von Luteïnellen abgeleitet, während andere Autoren der Ansicht zuneigen, dass es sich um mit Pigment beladene weisse Blutkörperchen handelt. Ich darf vielleicht zur Illustration des Gesagten nocb eine Abbildung (Taf. IX, Fig. 33) aus dem Ovarium einer im 10. Monat Schwangeren (Herzinsufficienz und Nephritis) beifügen, an der man an der Peripherie eines Corpus albicans einen nur stellenweise unterbrochenen Kranz von Pigmentzellen sieht und welcher die grösste Aehnlichkeit mit der Figur (Taf. XI, Fig. 3) von Grousdew hat. Eine zweite Figur (Taf. IX, Fig. 35) möge veranschaulichen, dass auch ohne diese Pigmentzellenanhäufung eine Cystenbildung in einem Corpus albicans eintreten kann. Auf Serienschnitten Jässt sich nachweisen, wie sich allmählich im Centrum ein cystischer Hohlraum bildet.

Es ist eine bekannte Thatsache, dass sich diese Pigmentzellen 
in Corp. albicantia sehr lange Zeit über Jahre erhalten können. Es ist daher durchaus nicht ungerechtfertigt, die Entstehung der Pigmentzellenanhäufungen bereits in die Zeit ovarieller Thätigkeit zurückzuverlegen.

Das Auffallende an der Beobachtung von Grousdew ist nach meinem Dafürhalten daher nur die ungewöhnlich starke Anhäufung der Pigmentzellen, wie wir sie, um Missverständnissen vorzubeugen, bezeichnen wollen, die Einschmelzung der centralen Parthien an vielen Stellen und die Entstehung der eigenartigen Cysten. Die Stärke der Pigmentansammlung in Corpora albicantia hängt im Allgemeinen von den Resorptionsbedingungen ab. Wird der beim Platzen des Follikels entstandene Bluterguss rasch resorbirt, bestehen also günstige Verhältnisse, so vermissen wir die Anhäufung von Pigment in den centralen und peripheren Partien? des Corp. albicans; sind die Resorptionsbedingungen ungünstig, so bleibt Blutpigment z. Th. an Ort und Stelle liegen, z. Th. beladen sich die noch erhaltenen Luteinzellen und die benachbarten Stromazellen, vielleicht auch Leukocyten mit dem Pigment. Die Resorptionsverhältnisse sind nun in der That im linken Ovarium ungünstige gewesen; das geht aus den zahlreich vorhandenen Fibromen hervor, die im rechten Ovarium, mit Ausnahme eines einzigen, gefehlt haben.

Bei dieser Auffassung der Luteïnzellen ist klar, dass von einer malignen Degeneration, die ihren Ausgang von den Luteïnzellen genommen hat, keine Rede sein kann. Es fehlt auch das wichtigste Anzeichen maligner Degeneration, der Nacbweis der Kerntheilungen; einmal heisst es: "Mitose war nicht vorhanden" (S. 454), "die Anzeichen karyokinetischer Theilung" in Taf. XI, Fig. 5 vermisse ich. Es handelt sich z. Th. um die bei solchen Pigmentzellen nicht seltene Anwesenheit mehrerer Kerne, z. Th. um Fragmentationen der Kerne. Auch baben die Kerne insgesammt Hämatoxylin so spärlich aufgenommen, dass man ihnen eine besondere Proliferationsfähigkeit bestimmt absprechen muss.

Auch in einer Beobachtung von Michelazzi hatte die betreffende Frau bereits 17 Jahre lang keine Schwangerschaft mehr durchgemacht. Sie hatte ein Sarkom, das Michelazzi auf das Corpus luteum zurückführt. (Originalarbeit stand mir nicht zur Verfügung.)

Eine besondere Beachtung verdient ein Fall von Santi, weil bei ihm die Neubildung von dem Corpus luteum graviditatis aus- 
ging und zwar im 3. Monat auftrat. Die Geschwulst hatte ein Gewicht von etwa $1 / 2 \mathrm{~kg}$, das Centrum war von weichen, gelblichrothen, von Blutextravaten durchsetzten Massen gebildet, die Peripherie wies eine Rinde auf, von der Septa gegen die Mitte zogen. Die Septa wurden hauptsächlich von kleinen, runden, mit spärlichem Protoplasma ausgerüsteten Zellen gebildet, während dagegen in den Zwischenräumen grosse Zellen mit weichem Protoplasma und klarem Kerne lagen. Stellenweise gingen die beiden Zellarten ineinander äber. Santi erklärt den Tumor als ein Alveolarsarkom und leitet die kleinen Zellen von den proliferirten wahren Bindegewebselementen, die grossen entweder ebenfalls von diesen oder von den Luteinzellen ab. Einzelne der grossen Zellen hätten alle Charakteristika echter Luteïnzellen an sich getragen. Santi sieht "im Grunde genommen nur eine Uebertreibung eines Vorganges, welcher schon durch die Schwangerschaft selbst zur Uebertreibung eines gewöhnlichen Vorganges wird". Einen bestimmten histologischen Beweis für die Abstammung der Geschwulst vom Corpus luteum glaubt Santi selbst nicht erbracht zu haben. Die Frau ging 6 Monate nach der Entfernung der Geschwulst wenige Tage nach der Entbindung an Knotenbildung im Netz und am Uterus und an Kachexie zu Grunde (keine Autopsie).

Gegen alle diese Fälle lässt sich einwenden, dass der Beweis für die angenommene Genese der Tumoren nicht mit Sicherheit erbracht ist. Das sprechen fast alle Autoren mehr oder minder unverhohlen selbst aus. In allen Fällen handelte es sich um Sarkome, die an sich meist aus an Grösse und Aussehen variirenden Zellen zusammengesetzt sind. Solange der Nachweis, dass die Neubildung wirklich von den Luteïnzellen ausgeht, nicht in exacterer Form erbracht wird, können solche Fälle nicht als maligne Neubildungen von Luteïnellen angesprochen werden.

\section{Beitrag zur Histologie und Genese des Corpus luteum.}

Der Histogenese des Corpus luteum ist von jeher von den Forsehern ein grosses Interesse entgegengebracht worden. Die Streitfrage, die auch heute noch nicht definitiv gelöst ist, drehte sich im Wesentlichen darum: Ist das Corpus luteum epithelialen Ursprunges, stammt es vom Follikelepithel oder ist es bindegewebiger Herkunft, ist es aus den Zellen der Theca hervorgegangen? 
312 Seitz, Die Follikelatresie während der Schwangerschaft etc.

Die erstere Ansicht vertrat zuerst Bischoff, die letztere hat in v. Baer ihren Begründer gefunden. In der Folge haben sich die Mehrzahl der Untersucher auf Seite von v. Baer gestellt (His, von Koelliker, Spiegelberg, Paladino, Nagel, Benckiser, Hölzl, Schottländer, in neuerer Zeit Clark, Bühler, Doering u. A. m.). Für die epitheliale Abstammung der Luteïnzellen treten Langer, Pflüger, Schulin, Call und Exner, Belloy ein, ferner namentlich Sobotta, Stratz, Bonnet, Honoré, Marshall, Kreis, H. Rabl.

Die wichtigste Arbeit ist zweifellos die von Sobotta. Er hat zum erstenmal an einem ausserordentlich grossen Material (etwa 1000 geplatzte Follikel) bei der Maus und späterhin an kleinerem, aber ebenfalls einwandfreiem Material beim Kaninchen systematische Untersuchungen über die Entwicklung des Corpus luteum angestellt und dic einzelnen Stadien unmittelbar nach dem Platzen des Follikels bis zur vollen Ausbildung des Corpus luteum studirt. Er weist darauf hin, dass die erste Entwicklung des Corpus luteum sehr rasch vor sich gehe und dass man daher gleich die allerersten Entwicklungsstadien desselben beobachten müsse, um überhaupt eine Entscheidung über die bindegewebige oder epitheliale Natur der Zellen treffen zu können. Die Bestimmung des Alters des Corpus luteum aus dem morphologischen Verhalten allein sei nicht angängig, es muss verlangt werden, dass für jedes Corpus luteum das dazu gehörige Ei nachgewiesen werde und dass nach dessen Entwicklungsstufe das Alter des betreffenden Corpus luteum bestimmt werde. Ohne diesen Nachweis erbracht zu haben, komme man betreffs des Alters za ganz unrichtigen Schlüssen und meist sei das Alter des untersuchten gelben Körpers von den Untersuchern viel zu niedrig angegeben worden. Es könne auch sehr leicht $\mathrm{zu}$ einer Verwechselung mit einem atretischen Follikel kommen, wie das einer Reihe von Autoren passirt ist. Bei Säugethieren mit nicht besonders reichlicher Ovulation, vorzüglich aber beim Menschen sei es ausserordentlich schwer, ganz frühe Entwicklungsstadien des Corpus luteum anzutreffen und das Antreffen eines wenige Stunden alten Corpus luteum müsste als ein ungewöhnlich glücklicher Zufall angesehen werden. Nur wenn das Material diesen $\Lambda$ nforderungen genüge, ist man im Stande und berechtigt, Rückschlüsse auf die Provenienz des Corpus luteum zu machen. Namentlich hat nach der Ansicht von Sobotta auch der Name Luteinzellen verwirrend auf die Lösung der Frage einge- 
wirkt, insofern sowohl die bindegewebige, als auch die epitheliale Zelle des Follikels Fett und Luteïn in sich aufnehme bezw. bilden könne und dass demnach weder die Anwesenheit von Luteïn in einer Zelle, noch das morphologische Verhalten einen sicheren Schluss auf ihre Herkunft gestatten.

Auf Grund dieser Untersuchungen kommt Sobotta zu dem Resultate, dass das Corpus luteum im Wesentlichen ein epitheliales Gebilde ist, dass die Follikelepithelien nach Platzen des Follikels sich um ein Vielfaches vergrössern (reine Hypertrophie der Epithelien) und dass zwischen dieselben von der Theca interna Bindegewebszellen und Gefässsprossen hineinwüchsen.

Stratz, der fast gleichzeitig mit Sobotta Untersuchungen an einem reichlichen Material von Tupaja javanica, Sorex und Tarsius septrum angestellt hat und ebenfalls die dazu gehörigen Uteri und die Entwicklungsstadien der Eier gesehen hat, kommt zu denselben Ergebnissen wie Sobotta. Das Gleiche fand Bonnet beim Hund. Honoré fand an einem einwandfreien Material beim Kaninchen Mitosen im Epithel des völlig sprungreifen Follikels und auch am frisch geplatzten Follikel konnte er, wenn auch nur vereinzelt, noch Kerntheilungsfiguren im Epithel feststellen. Bei Fledermäusen fand van der Stricht, dass zur Zeit der Furchung des Eies im Corpus luteum neben Mitosen in den Endothelien der Gefässsprossen und Capillaren und den Bindegewebszellen regelmässig auch Kerntheilungsfiguren an den Epithelzellen (Cellules épithéliales à lutéine) beobachtet werden, auch an jenen, welcho bereits mit Fettkörnchen infiltrirt sind, wobei das Fett in der Regel bei der Mitose verschwindet; die Mitosen im Epithel dauern jedoch nur ganz kurze Zeit an. Die Fettinfiltration im Epithel des Corpus luteum tritt bei der Fledermaus auffallend frühzeitig auf; merkwürdiger Weise machen von den das Ei in den Eileiter begleitenden Epithelzellen gelegentlich einige dieselben Veränderungen, wie die im Follikel zurückgebliebenen Epithelzellen durch.

Marshall stellte bejm Schaf an einem ausreichenden Materiale die Abstammung des Corpus luteum von den Epithelien fest. Auffallend rasch vollzieht sich bei diesem Thiere die Entwicklung des Corpus luteum, schon nach 30 Stunden ist die Vertheilung der Elemente in definitiver Weise zu erkennen. Im Epithel sind einzelne Mitosen zu beobachten, die Fettinfiltration der Epithelien erfolgt relativ spät. Beim Schwein fand Kopsch-Menzer (Arbeit bisher noch nicht ausführlich veröffentlicht) die gleichen Verhältnisse und Fran z 
314 Seitz, Die Follikelatresie während der Schwangerschaft etc.

Cohn hat mit besonders sorgfältiger Färbetechnik beim Kaninchen an einem grossen Material mit Sob otta übereinstimmende Resultate gefunden.

Auch am Menschen sind neuere Untersuchungen vorliegend, die die epitheliale Abstammung des Corpus luteum ergaben. H. Rabl leitet die periphere, aus helleren und kleineren Zellen bestehende Schicht theilweise wenigstens von den Epithelien ab; van der Stricht sagt auf Grund von Beobachtungen am Corpus luteum menstruationis, dass von einem Zugrundegehen des Follikelepithels keine Rede sein kann, $\mathrm{Kr}$ eis fand Kerntheilungsfiguren der Epithelien an einem ganz jungen Corpus luteum und spricht sich ebenfalls für eine epitheliale Provenienz des gelben Körpers aus. Alle Untersuchungen an menschlichen Ovarien haben jedoch das Missliche, dass das Alter des Corpus luteum nicht genau bekannt ist, da die Menstruation nicht immer mit der Ovulation zusammenfällt und da aus der mikroskopischen Beschaffenheit kein genügender Rückschluss auf den Bestand des Corpus luteum gezogen werden darf, ferner, dass bei eingetretener Gravidität das Corpus luteum graviditatis erst viel zu spät zur Beobachtung kommt.

So war auch in einer Beobachtung von Rabl das Corpus lut. bereits 16 Tage alt, befand sich also schon in einem Zustand, der verlässliche Schlüsse betreffs seiner Abkunft nur mehr schwer zuliess. Ich kann aus eigener Beobachtung diese Schwierigkeiten in der Deutung der Befunde bestätigen. Das betreffende Präparat stammte von einer regelmässig menstruirten Frau, bei der ein Tag vor Eintritt der zu erwartenden Menstruation der Uterus wegen Myomen supravaginal amputirt und das linksseitige Ovarium mit einem anscheinend ganz frisch geplatzten Follikel mitentfernt wurde. Man hätte nun sicher erwarten können, ein ganz junges Stadium der Corpus luteum-Entwicklung beabachten zu können. Allein die sorgfältige mikroskopische Untersuchung ergab, dass es sich offenbar schon um ein älteres Entwicklungsstadium handelte, bei dem es völlig unmöglich war, eine Entscheidung über die Provenienz der Luteinzellen zu treffen.

Sehen wir vorläufig von der Entwicklung des menschlichen Corpus luteum ab, dessen systematische Erforschung sehr erschwert, wenn nicht ganz unmöglich ist, und wenden wir noch einmal unsere Aufmerksamkeit auf die Befunde bei den Säugethieren. Bine Reihe systematischer Untersuchungen, die die allerersten Entwicklungs- 
stadien des Corpus luteum bëi kleineren und grösseren Säugethieren (Schwein, Schaf) in Angriff nahmen, haben übereinstimmend ergeben, dass das Corp. luteum im Wesentlichen ein epithcliales Gebilde ist. Und die meisten der genannten Arbeiten sind mit einer Genauigkeit ausgeführt, dass sie auch der strengsten wissenschaftlichen Kritik gegenüber Stand halten und ich glaube, es wird keiner, der sich selbst die Mühe nimmt, die Arbeiten durchzulesen und zu studiren, sich ohne Weiteres über die Befunde hinwegsetzen dürfen. Um so auffallender ist es, wenn verschiedene Schriftsteller und zwar speciell aus den Reihen der Gynäkologen, ich nenne nur L. Pick, Jaffè und Andere mehr die Lehre von der epithelialen Abstammung der. Luteïnzellen kurzweg als etwas Ueberwundenes hinzustellen belieben. Sie stützen sich, soweit überhaupt nach einer Begründung gesucht wird, speciell auf die Arbeiten von Clark und von Doering, die beide beim Schwein Studien gemacht haben. Allein jene Forderungen, die Sobotta an eine wissenschaftliche Bearbeitung der Frage gestellt, sind hier nicht erfüllt. Noch weniger gilt dieses von den Befunden von Stoeckel an cystisch degenerirten, also pathologischen Ovarien bei Blasenmole, der aus schlecht erhaltenen Epithelresten über der Theca interna die bindegewebige Natur des Corpus luteum folgert. Sobotta hat die genannten Arbeiten und die etlicher Anderer einer eingehenden, scharfen Kritik nuterworfen (Anatom. Hefte, Bd. IX und XI) und ich kann mir daher ersparen, auf die Sache genauer einzugehen. Die gegentheilige Ansicht bat in $\mathrm{Nagel}$ (Anatom. Hefte, Bd. IX) einen Vertreter gefunden. Tch verweise daher auf diese manchmal recht lebhaft gehaltenen Abhandlungen ${ }^{1}$ ).

Nach dem gegenwärtigen Stande unseres Wissens muss man also das Corpus luteum als eine im Wesentlichen epitheliale Bildung ansehen, deren charakteristische Elemente aus den Epithelien des Graaf'schen Follikels entweder nur durch einfache Hypertrophie oder durch Hypertrophie verbunden mit einer mehr

1) Bei Fischen und Amphibien betheiligt sich nach den Untersuchungen von Bühler nur das. Bindegewebe an der Corpus luteum-Bildung. Dies hängt, wie Lubosch besonders betont, mit der Vergänglichkeit des Follikelepithels bei diesen Thieren zusammen; wenn seine hauptsächlichste Function, den Dotter des Eies zu bilden, beendet ist, verfällt es. Bei den dotterärmeren Eiern der Säugethiere erhält es sich und betheiligt sich mit an der Corpus luteumBildung. 
oder minder starken Vermehrung der Elemente, wie das regelmäsig bei der Fledermaus und beim Schaf, vereinzelt auch beim Kaninchen beobashtet wird, hervorgehen. Das Auftreten von Mitosen an den Epithelien bei Schaf und Fledermaus weist darauf hin, dass es sich um lebensfäbige Elemente handelt und dass daher von einem Zugrundegehen derselben keine Rede sein kann. Von Wichtigkeit ist auch der Nachweis von Fettkörnchen in den Follikelepithelien, die z. B. bei der Fledermaus schon vor dem Springen des Follikels sich zeigen und damit die directe Umwandlung in Luteïnzellen erkennen lassen.

Wenn das Corpus luteum epithelialen Ursprunges ist, so muss es scharf von dem Corpus atreticum unterschieden werden. Dasselbe gilt auch von den aus diesen Körpern hervorgegangenen Bildungen. Wir hätten demnach in den Thecaluteïnzellen atretischer Follikel (interstitiellen Zellen) bindegewebige Derivate, in den Luteinzellen des Corpus luteum dagegen epitheliale. Dieser Unterschied ist principiell wichtig. Beide Zellarten ähneln sich sehr stark, beide könnten auf den ersten Blick mit einander verwechselt werden. Einige Unterschiede bestehen aber zweifellos, die Thecaluteinzellen sind viel kleiner, sie enthalten bei einzelnen Thieren kein Luteïn.

Die Sekretion von epithelialen Zellen ist eine allbekannte Erscheinung; wenn man auf dem Standpunkte der epithelialen Theorie steht, so kann von diesem Gesichtspunkte aus gegen die BornFränkel'sche Theorie nichts eingewendet werden. Etwas schwieriger $\mathrm{zu}$ erklären ist schon die innere Sekretion der bindegewebigen Abkömmlinge; ob eine solche den bindegewebigen Zellen überhaupt zukommt, wird von vielen Autoren in Frage gestellt.

Das Hauptargument, das Sobotta gegen Untersuchungen an nicht systematisch ausgewähltem Material geltend gemacht hat, ist das, dass die Untersucher entweder schon ausgebildete gelbe Körper untersucht, oder dass es sich garnicht um wirkliche Corpora lutea, sondern um atretische Follikel (Corpora atretica, wie sie Kölliker nennt) handelt. Dass Corpora atretica eine grosse Aehnlichkeit mit gelben Körpern haben können, steht ausser Zweifel, und ebenso, dass auch thatsächlich wiederholt Verwechselungen mit solehen und umgekehrt untergelaufen sind. Das morphologische Aussehen eines Gebildes kann jedoch nicht ohne Weiteres zur Entscheidung einer histogenetischen Frage ausschlaggebend sein, wie das von einigen 
Autoren gethan wird. Fast alle Anhänger der bindegewebigen Theorie stellen sich auf den Standpunkt, dass eine principielle Scheidung zwischen Corpus atreticum und Corpus luteum nicht gemacht werden dürfe und dass nur quantitative Unterschiede vorliegen. Auf die Berechtigung dieser Annahme läuft im Grunde genommen der ganze Streit hinaus. Ist diese Ansicht richtig, so ist zweifellos das Corpus luteum ein bindegewebiges Gebilde; denn, darin sind alle Autoren einig und das geben auch die enragirtesten Anhänger der epithelialen Theorie zu, an dem atretischen Follikel geht das Granulosaepithel fast ausnahmslos zu Grunde. Ich sage fast ausnahmslos; denn wir haben an anderer Stelle bereits darauf aufmerksam gemacht, dass auch am verödenden Follikel das Epithel sich noch erhalten und dass Gefässschlingen zwischen dasselbe hineindringen können. Bereits Schulin hat diese Beobachtungen gemacht und sieht darin einen Uebergang zwischen der Bildung eines Corpus atreticum und eines Corpus luteum. Recht häufig habe ich die Vascularisation des noch erhaltenen Epithels an Ovarien Schwangerer gesehen (cfr. Taf. VIII Fig. 15 u. Taf. IX Fig. 30.) Ich habe bereits darauf hingewiesen, dass die merkwürdigen beiden kleinen Corpora lutea (Taf. VI Fig. 9 u. Taf. VIII Fig. 13) vielleicht durch die Persistenz des Granulosaepithels zu Stande gekommen sind. Warum sich manchmal das Follikelepithel lange erhält und von Gefässschlingen durchwachsen wird, kann ich nicht sicher entscheiden; es scheint der Blutreichthum der Theca folliculi eine Rolle zu spielen; dies würde auch das scheinbar gehäufte Auftreten an Ovarien Gravider erklären. Die Regel bleibt jedoch auch in der Schwangerschaft, dass das Epithel an atretischen Follikeln zu Grunde geht.

Diese Erscheinung ist am atretischen Follikel etwas Selbstverständliches. Das $\mathrm{Ei}$ ist zu Grunde gegangen, die Follikelepithelien zeigen bereits seit langem stellenweise Chromatolyse ihrer Kerne, auf den Tod des Eies folgt rasch der Tod der Epithelien oder meist ist das causale Verhältniss dies, dass die einsetzende Degeneration der Follikelepithelien dem Ei ein vorzeitiges Ende setzt.

Anders dagegen am reifen Follikel. Hier sieht man am Follikelepithel keine regressiven Metamorphosen, die Epithelien sind gut gefärbt, manchmal zeigen sie sogar Mitosen. Das Bersten des Follikels geschieht nach der nunmehr von fast allen Autoren 
acceptirten Annahme von Waldeyer durch die Vermehrung der Theca interna-Zellen und Verschieben des Discus oophorus gegen das Stigma. Berstet der Follikel, so löst sich das Ei rom Discus $a b$ und gleitet mit Epithelien bekleidet aus der Oeffnung heraus, während die Hauptmasse der Follikelepithelien im zusammensinkenden Follikel zurückbleibt. In den allerersten Stadien der Corpus luteum-Bildung ist noch nie Verfettung der Epithelien mit Sicherheit festgestellt. Wir haben an einem frisch geplatzten Follikel also noch ein lebensfrisches Epithel, während am verödenden unreifen Follikel dasselbe nekrotisch zu Grunde gegangen und der entstandene Defect durch garnichts anderes als durch das Bindegewebe der. Theca gedeckt werden kann. Bei dieser Betrachtung der Befunde erscheint es von vornherein wahrscheinlich, dass auch die daraus entstandenen Körper histogenetisch verschieden zu bewerthen sind.

Nun scheinen mir aber die Unterschiede zwischen dem Corpus luteum und dem Corpus atreticum nicht immer so scharfe zu sein, auch hier giebt es Uebergänge. Leopold erwähnt bereits in seiner Abhandlung über Menstruation und Ovulation "atypische" Corpora lutea, d. h. jene Corpora lutea, welche aus nicht geplatzten, jedoch mit Blut gefüllten und reifen oder der Reife nahen Follikeln herstammen. Wie es sich mit dem Ei und mit dem Follikelepithel verhält, erfahren wir leider nicht, da mikroskopische Untersuchungen nicht vorliegen. Es lässt sich deshalb ein bestimmter Rückschluss auf diese Gebilde nicht ziehen; es kann sich auch nur um gewöhnliche grosse atretische Follikel gehandelt haben, in die zufällig eine grössere Blutung erfolgt ist. Ich hatte Gelegenheit einen solchen Follikel zu untersuchen und erlaube mir, im Folgenden darüber zu berichten.

Fall 1. P., 26 Jahre alt, Nullipara, am 14. Dec. 1901 wegen einer linksseitigen Tuboovarialeyste laparotomirt. Die Menstruation war früher stets regelmässig gewesen, trat alle vier Wochen ein, dauerte 6 -7 Tage und verlief ohne Schmerzen und ohne Beschwerden. Seit 4 Jahren ungefähr besteht weisser Ausfluss. Die letzte Periode trat am 15. Nov. ein und dauerte bis zum Tage der Operation ununterbrochen an, am Anfang sehr reichlich, später an Stärke abnehmend.

Der exstirpirte Tumor hat die Grösse eines Gänseeies. In. der Cystenwand fand sich noch ein Rest von Ovarialsubstanz, in 
dem ein ziemlich frisch aussehendes, plattgedrücktes Corpus luteum von sichelförmiger Gestalt sich vorfand, das eine Länge von $9 \mathrm{~mm}$ und eine Breite von $2-3 \mathrm{~mm}$ hatte. In der Mitte ist ein Bluterguss, die Wand zeigt bereits bei der makroskopischen Besichtigung die bekannte Structur des Corpus luteum. Nach aussen zu ist an keiner Stelle eine Communication oder eine hochgradig verdünnte Stelle aufzufinden.

Mikroskopischer Befund: Die übrigen Partien des noch vorhandenen Ovarialstromas bieten nichts Besonderes; einzelne Primärfollikel sind aufzufinden.

Das vorher erwähnte Gebilde grenzt sich gegen das umgebende Gewebe wenig scharf ab. Die Spindelzellen der Theca externa gehen unmittelbar in die epitheloiden, dunkel gefärbten Zellen der Theca interna über. An der äussersten Peripherie sind ïberall jene "kleinen epitbeloiden Zellen", wie sie Rabl beschrieben hat, zwischen ihnen verlaufen Spindelzellen. Auf diese Zellen folgt eine Schicht grösserer Zellen, deren Contouren eckig, deren Protoplasmaleib schlecht gefärbt und vielfach leicht gelbliches Aussehen hat; die Kerne sind meist oval oder rund, enthalten ein deutliches Kernkörperchen. Die Zellen tragen ausgesprochen den Typus der Lateïnzellen, sind aber erheblich kleiner, als die Luteinzellen des Corpus lateum. Von der Peripherie her ziehen zwischen diesen Zellen schmale Züge bindegewebiger Zellen, manchmal nur aus wenigen Exemplaren bestehend. Das Centrum ist ausgefüllt von einem lockeren Fibrin, das nach aussen zu noch spärliche spindel- und sternförmige Zellen enthält, im Innern aus zusammengesinterten Blutresten besteht; einzelne Blutkörperchen lassen sich nicht mehr erkennen.

Es handelt sich sicher nicht um einen geplatzten Follikel; denn nirgends lässt sich eine Rupturstelle, oder auch nur eine verdünnte Stelle, die darauf hindeutet, erkennen; auch erreichen die Derivate rupturirter Follikel stets eine beträchtlichere Ausdehnung. Man kann das Gebilde als ein "atypisches" Corpus lnteum bezeichnen, wie Leopold gethan. Es ist also ein Mittelding zwischen einem Corpus luteum und einem Corpus atreticum. ob dabei das Follikelepithel zu Grunde ging, oder ob es zur Bildung des atypischen Corpus luteum verwendet wurde, lässt sich nicht mehr entscheiden, dazu ist das Gebilde bereits zu alt. Vom Ei selbst findet sich keine Spur mehr. Nach dem Verhalten 
des Blutergusses und dem Aussehen der Luteïnzellen zu schliessen, muss es schon mehrere Tage alt sein.

Ich möchte des Weiteren noch über zwei sehr junge menschliche Corpora lutea menstruationis berichten. Einmal sind die Details für die erste Zeit noch nicht hinreichend bekannt, dann kann nur auf diese Weise allmälig ein weiteres zuverlässiges Material zur Klärung des Verhältnisses von Menstruation und Ovulation beschafft werden. Für die Frage nach der Genese des Corpus luteum vermögen die beiden Fälle jedoch meines Erachtens nichts mehr zu leisten, da nur die allerjüngsten Stadien verwerthbar sind.

Fall 2. Frau P., 41 Jahre alt, war stets regelmässig menstruirt; wegen Myomen, welche bis über den Nabel hinaufreichen, wird der Uterus supravaginal amputirt und dabei das Ovarium, das einen anscheinend frisch geplatzten Follikel enthält, mit exstirpirt. Die Periode hätte am nächsten Tage eintreffen sollen. Die Berstung des Follikels muss bereits vor diesem Termine erfolgt sein, sicher ist nicht erst während der Operation seine Ruptur erfolgt.

Sofort nach der Operation wurde das Ovarium in 12 proc. Formalin fixirt.

Mikroskopischer Befund: Die Präparate wurden mit Hämatoxylin-Eosin und nach van Gieson gefärbt. Nach der letzteren Methode treten die Structurverhältnisse besonders scharf hervor.

Das Corpus luteum ist von keiner so scharf umschriebenen Kapsel begrenzt, wie wir dies an voll ausgebildeten gelben Körpern zu sehen gewöhnt sind. An den meisten Stellen grenzt sich zwar die Theca externa mit ihren spindelförmigen Zellen ziemlich deutlich von den grösseren Zellen der Interna ab, wie dies besonders bei der van Giesonfärbung hervortritt, wo die letzteren und die Luteïnzellen gelb, die ersteren dagegen roth gefärbt sind, an verschiedenen Partien jedoch, und zwar speciell an jenen, wo die bindegewebigen Septen des Corpus luteum abgehen, verschwimmen die Grenzen zwischen Theca externa und interna, oder vielmehr richtiger ausgedrüekt, die Theca internaZellen finden sich einzeln und in Bündeln zwischen die Spindelzellen der Faserschicht eingelagert. Man hat den Eindruck, als wären die grossen epitheloiden Zellen aus den Spindelzellen der Theca externa hervorgegangen. Dafür spricht, dass an manchen Stellen ein allmäliger Uebergang der spindeligen rothgefärbten Elemente in die gelben epitheloiden bei der van Gieson-Fürbung erkennbar sind. An wieder anderen Stellen sieht man zwischen den epitheloiden. Zellen nur mehr einige wenige bindegewebige rötlliche Fibrillen ziehen, in der Umgebung von Capillaren sind nur Zellen epitheloiden Charakters zu erkennen, die bis dicht an das Gefäss herangehen und von dem Lumen nur dureh die Gefässendothelien getrennt sind. Da die vergrösserten und polyedrischen Zellen mit Vorliebe in der unmittelbaren Umgebung auch grösserer Gefässe aufzufinden sind, so liegt die 
Annahme nahe, dass die überreichliche Blutversorgung und saftige Durchtränkung des Gewebes an der Vergrösserung und Quellung der bindegewebigen Zellen in erster Linie Schuld trägt. Die Kapsel des Corpus luteum zeicbnet sich stets durch eine grosse Anzahl von Gefässen aus; auffallend ist jedoch der Gefässreichthum gerade an den Stellen, wo die epithelioiden Zellen am meisten entwickelt sind und wo die Abgrenzung gegen die Theca externa am wenigsten scharf ist; hier sind die Gefässdurchschnitte meist rund, die Wände ganz dünn, die kleinsten Capillaren zahlreich, dagegen an den Partien, wo eine scharfe Abgrenzung von Luteïnzellen und den epitheloiden Zellen gegenüber den Spindelzellen der Theca externa erfolgt ist, sind die Gefässe weit spärlicher, ihr Lumen ist mehr abgeplattet und concentrisch zum Mittelpunkt des gelben Körpers gerichtet.

Diese kleinen (gegenüber den Luteïnzellen) epitheloiden Zellen haben von H. Rabl eine besonders weitgehende Berücksichtigung gefunden. Er konnte sie an den Corpora lutea vera (4 Beobachtungen) bis zu dem Alter von 2 Monaten nachweisen. Am deutlichsten waren sie bei einem Corpus lut. verum, das einer 10 Tage alten Schwangerschaft angehörte, und bei einer ebenfalls noch sehr jungen Schwangerschaft. Auch an einem jungen Corpus lut. spurium fanden sich die Zellen, wenn auch weniger zahlreich und nicht über die Tunica fibrosa hinausreichend, während sie bei den zwei erstgenannten jungen Graviditäten auch ausserhalb dieser Schichten beobachtet werden konnten. Bei den meisten Säugethieren scheinen sie zu fehlen, bei Kaninchen und Maus sind sie sicher nicht vorhanden. Wie unsere Beobachtung zeigt, kann das Auftreten der epitheloiden Zellen in und sogar ausserhalb der Tun. externa auch bei Corp. lut. spuria, nicht nur bei den vera stattfinden. Es handelt sich demnach nur um graduelle Unterschiede.

Rabl. glaubt, dass das Corpus luteum sich zwar der Hauptsache nach auch beim Menschen aus dem Follikelepithel bildet, dass jedoch auch diese peripher gelegenen epitheloiden Zellen sich in echte Luteinzellen umwandeln und auf diese Weise zu einer Vergrösserung der Masse des gelben Körpers führen können. Sobotta bestreitet die Beweiskraft der Rabl'schen Beobachtungen und weist darauf hin, dass auch das jüngste Corpus luteum verum von nur 10 Tagen schon viel zu alt sei, um mit Sicherheit Rückschlüsse auf die Genese der Luteïnzellen zu machen. Von dem Corpus spurium war das Alter nicht näher bekannt. Meine Beobachtung betrifft zweifellos ein jüngeres Corpus luteum als die von Rabl, allein etwas Bestimmtes betreffs seines Alters vermag ich nicht auszusagen. Sicher kann man nur sagen, dass es wohl 
schon älter als 1 Tag ist, denn sonst könnte nicht schon streckenweise eine ziemlich scharfe Abgrenzung gegen die Umgebung erfolgt sein.

Nachdem demgemäss das Corpus luteum bereits seine ersten Entwicklungsstadien hinter sich hat, lässt sich eine sichere Entscheidung betreffs der Genese der Luteïnzellen kaum mehr fällen. Ich möchte jedoch nicht unterlassen, noch ausdrücklich auf die Schwierigkeiten in der Deutung der Befunde hinzuweisen, an der einen Stelle glaubt man den sicheren Uebergang der epitheloiden Zellen in Luteïnzellen feststellen zu können, an einer anderen spricht alles dafür, dass die Luteïnzellen aus epithelialen Elementen hervorgegangen sind. Bei der richtigen Auswahl wird jeder je nach seinem Standpunkt im Stande sein, eine Stelle ausfindig zu machen, die für sich allein berücksichtigt die bindegewebige oder die epitheliale Genese der Luteïnzellen zu beweisen scheint.

Ich bilde in Fig. 32 (Taf. VII) eine Stelle ab, die mitten in einem Septum epitheloider Zellen, das zwisehen den ausgebildeten Luteïnzellen verläuft, gelegen ist und wo man erkennen kann, wie die epitheloiden Zellen ganz unmerklich in die Luteïnzellen übergehen. An anderen Stellen ist die Grenze zwischen beiden Zellarten haarscharf, auch da, wo die Züge epitheloider Zellen zwischen die ausgebildeten Luteïnzellen eindringen. Ich verweise auf Fig. 31 (Taf. VII), wo diese Verbältnisse deutlich festzustellen sind.

So nahe es liegt, die Fig. 32 und andere im Sinne der bindegewebigen Theorie zu verwerthen, häte ich mich doch dies zu thun, da ich Sobotta ganz Recht geben muss, dass solche Fragen nur an einem ganz grossen Material und nur in den allerersten Entwicklungsstadien gelöst werden können, die Lösung an menschlichem Material daher auf fast unüberwindliche Schwierigkeiten stösst.

Zur Vervollständigung der histologischen Befunde an dem erwähnten Corpus luteum spurium muss noch das Verbalten der ausgebildeten Luteïnzellen erörtert werden. Dieselben haben eine Grösse von $22-30 \mu$, besitzen polyedrische Gestalt. Der Zellleib ist im Verhältniss zum Kern sehr gross und nur blass gefärbt. Bei der Hämatoxylin-Eosin-Färbung ist der Kern blau, während das Protoplasma entweder ganz ungefärbt ist oder nur einen leicht röthlichen Ton, dies meist an der Berührungsfläche je zweier Zellen, erkennen lässt; bei der van Gieson'schen Methode zeigt der Zellleib gelblichen Ton und einen feinen reticulären Bau, während der 
Kern durch seine schwärzliche Farbe scharf contrastirt und namentlich auch das Kernkörperchen, meist in Einzahl vorhanden, deutlich hervortreten lässt. Im Protoplasma sieht man nur ganz vereinzelte fettige Einlagerungen, in Folge Behandlung mit absolutem Alkohol sind die meisten aufgelöst. Nur bei ganz wenigen Zellen fehlt der Kern, bei einzelnen sind die peripheren Zonen einer hyalinen Degeneration verfallen. Im Ganzen zeigen die Zellen volle Lebensfrische. Von Mitosen konnte ich nichts sehen.

Auf die Luteinzellenschicht folgt nach innen zu ein Fibrinkern von unregelmässiger, sternförmiger Gestalt. In dem Fibrinnetz sind die Reste rother Blutkörperchen in den peripheren Partien eingestreut, auch einige spindelförmige Zellen sind zu sehen, ganz jm Centrum ist eine Lücke und nur einige wenige sternförmige Zellen.

Ein besonderes Interesse beansprucht eine vom Corpus luteum getrennte Partie von Luteïnzellengewebe, die an dem einen Pole des gelben Körpers gelegen ist. Schon mit blossem Auge, besser mit der Lupe, erkennt man am gefärbten Präparate, dass eine Partie gleichgefärbten Gewebes durch eine Brücke von der Hauptmasse des Corpus luteum getrennt ist. Bei der mikroskopischen Betrachtung sieht man, dass die Partie sich aus drei voneinander isolirten Luteinzellenhaufen zusammensetzt, die voneinander durch die kleinen epitheloiden Zellen getrennt sind. Die zwei kleineren Haufen bestehen ausschliesslich nur aus Luteinzellen, der dritte grössere enthält in der Mitte einen schmalen Streifen gut gefärbter Spindelzellen. Die Luteïnzellen unterscheiden sich von denen der Hauptmasse in keiner Weise.

Die Gewebsbrücke, welche die abgesprengten Luteïnzellengruppen von der Hauptmasse trennt, besteht in den mehr central gelegenen Partien aus den spindelförmigen Zellen der Theca externa, in der hin und wieder einzelne und Gruppen der kleinen epitheloiden Zellen gelegen sind, und in der zahlreiche kleinere und grössere Gefässe verlaufen; im weiteren Verlaufe auf ein kurzes Stück von den kleinen epitheloiden Zellen und gegen die Peripherie hin wieder durch ein bindegewebiges, reichlich von Gefässen durchsetztes Stroma. Es ist demnach die Partie des Corpus luteum, wie man auf Schnitten durch die ganze Dicke des Körpers verfolgen kann, von der Hauptmasse ganz abgetrennt; in der Mitte auf eine kurze Strecke allerdings nur durch die kleinen epitheloiden Zellen. Nimmt man an, dass diese, wie Rabl thut, thatsächlich in Luteïnzellen sich umzuwandeln vermögen, so würde auf diese Weise noch eine 
schmale Brücke verbindenden Luteïngewebes betstehen bleiben. Da dies aber an einem im grösseren Theile ganz ausgebildeten und meist gegen die Umgebung scharf abgegrenzten Gebilde recht unwahrscheinlich ist, dürfen wir annehmen, dass sich auch hier, wie an anderen Stellen des Corpus luteum, die kleinen epitheloiden Zellen wieder zu Bindegewebszellen zurückbilden oder ihr Platz von solchen eingenommen wird.

Man kann den Befund kaum anders deuten, als dass es sich um eine Absprengung eines Theiles des Corpus luteum durch einwachsendes Bindegewebe handelt; wir kommen auf diese Frage noch einmal zurück.

Fall 3. Vog., 35 Jahre alt, hat 3 mal geboren. Menstruation alle 4 Wochen in einer Daver von 2-4 Tagen, mittelstark, auch noch in der letzten Zeit ganz regelmässig gewesen. Letzte Periode 17 Tage vor der Operation. Am 1. 2. 02 . Koeliotomie wegen eines Ovarialkystoms. Einige Tage vor der Operation waren plötzlich beim Aufstehen Schmerzen im Unterleib aufgetreten, die sie zum Aufsuchen der Klinik veranlassten. Sie verschwanden am selben Tage von selbst noch. Eine Stieldrehung liess sich am Tumor bei der Operation nicht nachweisen. Nach der Entfernung des vom rechten Ovarium ausgehenden Kystoms, wurde das andere Ovarium besichtigt, "das an seiner Aussenfläche ein haselnussgrosses Hämatom zeigte." Dasselbe wurde excidirt und mit feinstem Catgut die Wunde vernäht.

Mikroskopischer Befund: Die angefertigten Schnitte enthalten auch noch andere Partien des Ovariums. Es sind mehrere Follikel mit gut erhaltenem Follikelepithel, ferner einige atretische, deren Theca interna-Zellen etwas grössere Dimensionen zeigen, als gewöhnlich. Besonders an einem atretischen Follikel, speciell in einem Segmente desselben, sind die Zellen gross, polyedrisch, das Protoplasma hat Eosin stärker angenommen, so dass die Aehnlichkeit mit den Thecaluteinzellen der Schwangerschaft unverkennbar ist.

Das Hämatom ist ein ziemlich frisches Corpus luteum spur., dessen Rupturstelle an dem Schnitte schön zu sehen ist. Gegen die Umgebung ist die Grenze wenig scharf; auf die Tunica fibrosa folgt eine Partie lockeren Gewebes, in welche die kleinen epitheloiden Zellen eingelagert sind. Die Abgrenzung dieser Zellen ist weder nach aussen hin scharf, weil sie dort unvermerkt in die Stromazellen übergehen, noch nach innen, wo neben ihnen mehr 
oder minder ausgebildete Luteïnzellen gelegen sind. Zwischen den Luteïnzellen ziehen nur wenig Zïge der epitheloiden Zellen hinein. Die Luteinschicht ist ziemlich breit und nach innen stark gefaltet; in den Vertiefungen sind rothe Blutkörperchen, die noch recht gut erhalten sind, gelagert, sie erstrecken sich auch weiter gegen das Centrum zu, der centrale Kern besteht aus lockerem Bindegewebe, in denen rothe Blutkörperchen gelegen sind.

Die Luteinzellen machen einen lebensfrischen Eindruck, sind scharf von einander abgegrenzt, polyedrisch; der Zelleib zeigt maschige Structur und gelbliche Färbung (bei van Gieson), der Kern ist scharf umschrieben, enthält meist ein Kernkörperchen, Mitosen habe ich keine gesehen.

Das Corpus luteum ist jünger als das erst beschriebene; doch lassen sich Studien über seine Histiogenese nicht mehr anstellen.

Ein Interesse bieten die drei Beobachtungen auch wegen der Frage der Coincidenz von Ovulation und Menstruation. Der erste Fall kann für diese Frage nicht weiter verwerthet werden; denn es bestanden bereits mehr als 4 Wochen blutige Abgänge, die wohl mit der Tuboovarialcyste zusammenhingen. Dadurch wurde der Typus der Menstruation verdeckt. Interessant ist jedoch der Befund, dass sich in den. Ovarialresten der Cyste ein atypisches Corpus luteum jüngeren Alters befand, während das andere Ovarium weder einen sprungfertigen Follikel, noch ein frisches Corpus luteum enthielt. Es ist die Annahme wohl berechtigt, dass der Follikel, aus dem das atypische Corpus luteum sich entwickelt hatte, zur Ruptur prädestinirt gewesen wäre. Es erfolgte jedocb die Berstung nicht, weil vielleicht die Ernährung durch die andauernden Blutverluste oder auch durch die an sich ungünstigen Ernährungsbedingungen in der Cystenwand eine vollständige Reifung verhinderten.

Ein nicht minder grosses Interesse beansprucht Beobachtung 2 und 3. Bei Fall 2 wurde die Operation (supravaginale Amputation des myomatösen Uterus) einen Tag vor der zu erwartenden Regel bei einer regelmässig menstruirten Frau ausgeführt und bereits ein etwa 1-2 Tage altes Corpus luteum vorgefunden. Es ist denkbar, dass der sprungreife Follikel durch die Insulte bei der Untersuchung vorzeitig gesprungen ist; dadurch würde sich das Auffinden eines jungen Corpus luteum bereits 2-3 Tage vor der zu erwartenden Periode erklären. Jedenfalls ist die Beobachtung eher 
geeignet, die Ansicht jener zu stützen, welche ein Zusammenfallen von Ovulation und Menstruation, als von denen, welche jene bereits mehrere Tage vor Eintritt dieser annehmen (von den neueren Autoren L. Fraenkel, Lindenthal).

Die dritte Beobachtung lässt sich jedoch schwer nur in dem letztgenannten Sinne deuten. Bei einer alle 4 Wochen regelmässig menstruirten Frau findet man bei der Operation bereits 11 Tage vor der zu erwartenden Periode an einem gesunden Ovarium ein mindestens einen Tag altes Corpus luteum. Man kann ja auch hier annehmen, dass die Ruptur durch ungeschickte Palpation vorzeitig herbeigeführt wurde; allein die Wahrscheinlichkeit ist eine weit geringere, da 11 Tage ante terminum der Follikel schwerer bersten wird, als 2 oder 3 Tage vorher und dann, weil der Ovarialtumor von der anderen Seite ausging und deshalb das intacte Ovarium vor stärkeren Insulten voraussichtlich verschont blieb. Will man den Dingen nicht zu sehr Gewalt anthun, so ist es in der That wahrscheinlicher, dass hier eine intermenstruelle Ovulation vorliegt.

Es liegt mir fern, auf Grund dieser drei Beobachtungen weitgehende Schlüsse zu ziehen; allein zu einer weiteren exacten Begründung der Lehre von Ovulation und Menstruation werden sie immerhin erwünschtes Material darbieten.

Ich füge diesen drei Beobachtungen eine erst jüngst gemachte vierte an, welche ebenfalls einen Beitrag zur oben erwähnten Frage bildet. Bei einer 41 jährigen Frau, die 4 mal regelmässig geboren hatte, warde ein kleinfaustgrosses, gut gesticltes, nicht verwachsenes Ovarialkystom ohne Mühe entfernt, in dessen Wand ein sprungfertiger, $20 \mathrm{zu} 25 \mathrm{~mm}$ im Durchmesser zeigender Follikel sich vorfand. Die Frau hatte die Periode in der ersten Zeit alle vier Wochen, seit 3-4 Jahren stellte sie sich in kürzeren Pausen ein und zwar in der letzten Zeit alle 14 Tage bis 3 Wochen in mittlerer Dauer und Stärke. Die letzte Periode hatte genau 10 Tage vor der Operation geendet, bei der Koeliotomie fand sich der sprungfertige Follikel, im anderen gesunden Ovarium fand sich kein grösserer Follikel, der vicarirend hätte für den reifen und mit dem Kystom entfernten Follikel eintreten können. Trotzdem trat nun am 4. Tage nach der Operation eine Blutung auf, also 14 Tage nach der zuletzt dagewesenen Periode. Man hätte sie ohne Weiteres für die Menstruation ansehen können. Gäbe nun, wie die Born-Fränkel'sche Theorie annimmt, erst das Corpus luteum den 
Anstoss zur Menstruation, so hätte in unserem Fall nach der Ausschaltung des sprungreifen Follikels und der Unmöglichkeit der: Bildung eines Corpus luteum, die nächste Periode nothwendig ausbleiben müssen. Trotzdem aber trat sie regelmässig ein. Wie ist die Sache zu erklären? Nach meinem Dafürhalten kann es sich ebenso gut um einen Blutaustritt aus den Genitalien in Folge des operativen Eingriffes gehandelt haben, und nicht um eine regelmässige Menstruation.

Ich hüte mich, in denselben Fehler zu verfallen, den Lindenthal bei seinem Fall begeht. Bei der Operation platzt der nicht ganz reife Follikel, am 3. Tage nach der Operation tritt Blutung aus den Genitalien ein, die reichlich 4 Tage andauert. Die letzte Periode war 11 Tage vor der Operation gewesen. Er fasst die Blutung als die verfrühte Menstruation auf, die durch das vorzeitige Platzen des Follikels und Bildung eires Corpus luteum herbeigeführt ist. Meinem Falle kommt genau dieselbe Beweiskraft für das Gegentheil zu; es kommt aber nur darauf an, ob man eine postoperative Blutung ohne Weiteres als Menstruation bezeichnen darf.

Eine besondere Besprechung erfordert noch die Frage nach der Absprengung von Theilen des Corpus luteum.

Wir haben bei der Besprechung der Corpora lutea und speciell bei Fall 2 darauf hingewiesen, dass die Abgrenzung der kleinen epithelioiden Zellen gegen die Umgebung unscharf ist und dass an verschiedenen Stellen diese Zellen durch schmale Züge von gewöhnlichen Stromazellen von der Hauptmasse getrennt sind (Taf. VII, Fig. 31).

Unscharfe Abgrenzung gegen das Nachbargewebe findet sich auch einige Male bei Corpus luteum-Cysten erwähnt.

Orthmann weist darauf hin, dass bei den Corpus luteumCysten die Abgrenzung der Luteïnschicht gegen die Theca externa nicht immer scharf ist und deutet den Befund in der Weise, dass die Spindelzellen der Theca externa theilweise in die Falten der Luteïnschicht eindringen.

E. Fraenkel (Arch. 57. S. 515) erwähnt bei der Beschreibung der Corpus luteum-Cyste einer 35jährigen Frau, dass sich die stark pigmentirte Luteïnzellenschicht an vielen Theilen der Cyste nicht scharf von der Tunica fibrosa absetzt, sondern dass die Luteïnzellen in das Bindegewebslager der Tunica fibrosa in Form von Ballen oder langgestreckten Strängen hineinragen und 
328 Seitz, Die Follikelatresie während der Schwangerschaft etc.

erklärt den Befund dadurch, dass er annimmt, die Luteïnzellenschicht habe ursprünglich weiter herabgereicht, sei aber allmälig, wenn auch nicht in allen Abschnitten ihres Verlaufes zur selben Zeit und in der gleichen Stärke, durch das andringende Gewebe der Tunica externa ersetzt worden. Dadurch werden einzelne in ihrer Form wechselnde Zellcomplexe von der gelben Schicht abgeschnürt und liegen scheinbar ohne Zusammenhang mit dieser, aber durch ihre morphologischen und tinctoriellen Eigenthümlichkeiten als zu ihr gehörig erkennbar, zwischen den Bindegewebszügen der Tunica fibrosa. Die Figur auf Taf. 24 illustrirt seinen Befund.

Auch Beobachtungen von $\mathrm{H}$. Rabl sind für die Versprengung von Luteinzellen angeführt worden. Rabl sagt in seinem Vortrage in der gyn.-geburtsh. Gesellschaft zu Wien wörtlich: "Neu ist nur die Beobachtung, dass ausserhalb der Luteïnzellen, ihnen jedoch direct anliegend, kleinere Zellen, zu Gruppen geordnet, vorhanden sind, von denen es scheint, als ob sie sich vergrösserten und schliesslich das gleiche Aussehen, wie die centralen Luteïnzellen gewinnen würden. Da in einem Falle diese Zellen sogar ausserhalb der Kapsel des gelben Körpers gefunden wurden, können dieselben keine Bestandtheile des Follikels sein, aus welchen der gelbe Körper hervorgegangen war. In wahren gelben Körpern, welche älter als 2 Monate waren, konnten sie nicht mehr aufgefunden werden."

In der ausführlichen Arbeit in den Anatom. Heften, worauf sich jene Aeusserungen, so viel ich finden konnte, beziehen, beschreibt Rabl die Veränderungen näher und giebt in Fig. 28 die Randpartie eines Corpus luteum des Menschen aus der fünften Schwangerschaftswoche bildlich wieder und zeigt in der nächsten Figur den Uebergang dieser kleineren Zellen in Luteïnzellen. Er leitet demnach die Luteïnzellen für den Menschen von zwej Zellarten ab: 1. der Hauptsache nach von den Follikelepithelien gleich Sobotta und 2. von den kleinen epitheloiden Zellen der Theca interna. Wir werden auf diese Frage noch später zurückkommen.

Rabl fand die Zellen am reichlichsten an einem Corpus lut. gravid. von etwa 10 Tagen, das dem bekannten $\mathrm{Ei}$ von Peters angehört, am spärlichsten bei einem Corpus lut. von der fünften Schwangerschaftswoche. „Hier liegen sie (die Zellen) ausschliesslich innerhalb der fibrösen Schicht. Ueber den nach aussen vorspringenden 
Partien des Corpus lut. sind sie in 1-2 Zellen breiter Schicht angeordnet, können übrigens an dieser Stelle auch ganz fehlen. In den früher erwähnten Zwickeln dagegen bilden sie grössere Anhäufungen und dringen dort auch noch ein beträchtliches Stück zwischen die echten Luteïnellen vor. Bei Fall 1. (10 Tage alte Schwangersehaft) und an vereinzelten. Stellen von Fall 2 (ebenfalls sehr junge Gravidität) finden sich jene Zellmassen auch nach aussen von der Tunica fibrosa". An mehr als zwei Monate alten Corpora lutea sah Rabl diese Zellen nicht mehr. Auch vermisste er sie vollständig bei dem Corpus lut. der Maus und des Kaninchens.

Ausser diesen Verlagerungen einzelner epitheloider Zellen in und ausserhalb der T'unica fibrosa kommen, wie ich zeigen konnte, thatsächliche Absprengungen ganzer Partien vor. Bei der Beobachtung 2, S. 323 wurde bereits die Entstehung dieser abgesprengten Stücke bei einem sehr jungen Corpus luteum menstr. erwähnt. Ausserdem habe ich bei Corp. lut. gravid. von 4 Monaten (Fall 7, Gravid. tubar. isthmica) mehrere Absprengungen beobachtet; zwei davon sind in Fig. 10 auf Taf. VI wiedergegeben. Es bestanden ausserdem noch eine gleich grosse an anderer Stelle desselben gelben Körpers und mehrere kleinere, die nur eine Gruppe von 8-15 Luteïnzellen umschlossen. Die abgesprengten Stücke liegen, abgesehen von den kleinen, ausserhalb der bindegewebigen Kapsel. Stets werden jedoch die Zellgruppen in nächster Nähe des HauptCorpus luteum gefunden. Für die Beurtheilung der Luteinzellenversprengung bei Blasenmole und bei Chorionepitheliom sind diese Befunde von einer gewissen Bedeutung, stehen aber zweifellos wegen ihrer grösseren Seltenheit weit hinter den aus atretischen Follikeln hervorgegangenen Luteïnzellen zurück.

Es ist auch bereits an anderer Stelle darauf aufmerksam gemacht worden, dass auch durch eine eigenartige Form der $\Lambda$ tresie Corpus luteum-ähnliche Gebilde entstehen und so Versprengungen eines Corpus luteum vorgetäuscht werden können (cf. Taf. VI u. VIII, Figg. 9 und 13).

Wie durch zwischen das Corpus luteum einwachsendes Bindegewebe eine Absprengung von Partien des Corpus luteum erfolgen kann, so kann es umgekehrt durẹh Umwachsung von Ovarialstroma durch Corpus luteum-Gewebe in der Zeit der ersten Bildung zu einer Inclusion von Ovarialgewebe im ausgebildeten gelben Körper kommen, wie eine Beobachtung von E. Runge beweist. Er fand bei einem Falle von Blasenmole Einsprengung von Ova- 
rialgewebe, das Primärfollikel enthielt, das, nicht allzuweit von der Peripherie entfernt, allseitig von Luteïzellen umgeben war. Der gelbe Körper zeigt sonst keine Abweichung, soweit man dies an der beigefügten Figur sieht; es handelt sich dabei anch nicht um einen für Blasenmole specifischen Vorgang, wie übrigens auch Runge nicht meint. Es besteht Grund, anzunehmen, dass der Vorgang sich ebenso bei gelben Körpern ohne Blasenmole wiederholen kann.

Ich habe an meinem Material auch die Frage zu prüfen gesucht, wie lange denn das Corpus luteum und im Speciellen seine Luteïnellen lebensfrisch sind und von welcher Zeit ab sie einer regressiven Metamorphose verfallen. Diese Frage hat seit der Aufstellung der Born-Fränkel'schen Theorie von der Drüsenfunction des gelben Körpers erhöhtes Interesse bekommen. Nur bei einem lebensfrischen Organ wird man eine innere Sekretion voraussetzen können. Dann lässt sich vielleicht aus dem histologischen Verhalten des Corpus luteum auch ein gewisser Schluss auf sein Alter ziehen. Die makroskopische Untersuchung allein ermöglicht nur sehr unbestimmte Angaben. Beträchtliche Grösse, weiche Consistenz, stark gelbe Farbe, cystischer Hohlraum im Centrum sprechen für ein jüngeres, grössere Derbheit, dunklere Farbe und ein fester weisser Kern mehr für ein älteres Stadium des Corpus luteum; doch sind Variationen nicht selten.

Kreis hat 9 Corpora lutea spuria vom Menschen vom 1. Tag bis zur 5.-6. Woche mikroskopisch untersucht und gefunden, dass dasselbe um den 8.-10. Tag das Höhestadium seiner Entwicklung erreicht hat und von da ab sich wiederum zurückbildet, die reichlichste Versorgung mit Blutgefässen erfolgt gegen das Ende der 3. Woche. Am Ende der 2. Woche zeigen die Luteïnzellen Kreis nennt sie die Zellen der Membrana granulosa - regressive Veränderungen, die sich in Volumensverminderung, im Schrumpfen und Abblassen der Kerne, in der gelblichen Verfärbung des Protoplasmas äussern.

Kreis erwähnt an der Peripherie zwischen Tunica externa und interna und zwischen den Bindegewebssepten einen Rundzellensaum. Es kann wohl keinem Zweifel unterliegen, dass er dieselben Zellen beschrieben hat, die $\mathrm{H}$. Rabl viel richtiger als kleine epitheloide Zellen bezeichnet und die letzterer Autor nicht für eingewanderte Rundzellen, sondern für Zellen der Theca interna ansieht und zwar ganz mit Recht. Diesen Rundzellensaum fand Kreis an 
rischen Corpora lutea spuria stark ausgebildet, mit dem Alter nimmt er ab, ist um den 15.-20. Tag bereits recht schmal und ist um den 28. Tag vollständig verschwunden.

Kreis hat ferner noch 5 Corpora lutea vera untersucht, erwähnt aber von ihnen nur, dass „weder was die Grösse des ganzen Gebildes anbetrifft, noch was die Zusammensetzung der einzelnen Zonen anlangt, irgend welche Differenzen" zwischen den beiden Arten der beiden gelben Körper beständen und spricht die Vermuthung aus, ohne jedoch mikroskopische Belege dafür zu erbringen, dass die Entwicklung des Corp. lut. ver. bis zum 3. Monat anhält, von da ab die regressive Metamorphose nur ganz langsam eintritt, ${ }_{n}$ so dass im 9.-10. Monat ein Stadium vorhanden wäre, welches sonst ausserhalb der Gravidität bereits nach 3 Wochen erreicht ist". Voigt hat im Anschluss an einen angeblich von den Luteinzellen ausgehenden malignen Tumor die Veränderungen des Corpus luteum studirt und hat merkwürdiger Weise an allen Corpora lutea in Ovarien, die bei noch bestehender Schwangerschaft, theils durch Operation, theils durch Section gewonnen waren, nkeine Spur einer Degeneration" erkennen können, "alle zeigten die Erscheinungen einer noch in voller Frische bestehenden Neubildung, hier physiologischer Natur". Mit diesen Angaben stimmt der mikroskopische Befund freilich nicht ganz überein; denn dort heisst es: „das Protoplasma (der Luteïnellen) ist durch Eosin ziemlich intensiv, der Kern weniger stark durch Hämatoxylin gefärbt, seine Kernkörperchen jedoch haben den Farbstoff innigst aufgenommen". Diese Schilderung zeigt an, dass an den Zellen bereits regressive Veränderungen in Ausbildung begriffen sind. Auch damit stimme ich nicht überein, dass bei den gelben Körpern während der späteren Monate der Schwangerschaft „meistens ein kleiner, centraler, unregelmässig gestalteter Kern, aus lockerem Bindegewebe mit gut gefärbtem Kern in den Fibrillen bestehend, vorhanden ist". Meistens findet man einen festen derben fibrösen Kern. Die Degenerationsvorgänge beginnen nach Voigt erst mit dem Puerperium, erst hier fand er die sattsam bekannten regressiven Veränderungen am Corpus luteum. Ob das zur Verfügung stehende Material, das aus verschiedenen Schwangerschaftsstadien stammte, genügend war, erscheint fraglich, es stammte aus dem 1., 2., 3., 4. und 8. Monat der Gravidität, eine "verhältnissmässig geringe" Anzahl, wie Voigt selbst meint.

Rabl giebt in seinem Fall 3, der von einer Osteomalacischen Archiv fürr Gynäkologie. Bd. 77. H. 2. 
aus der 5. Woche der Schwangerschaft stammt, an, dass nnicht selten Degenerationen auch in den grossen Zellen sich finden; es treten im Zellkörper entweder zahlreiche klcinere oder nur wenig grössere homogene Klumpen auf, die sich mit Eosin und Saffranin sehr stark tingiren und wohl die Bezeichnung Colloidtropfen verdienen. Die Zellen werden schliesslich in einen grossen Haufen derartiger Tropfen umgewandelt, wobei allmälig auch der Kern seine Färbbarkeit für Hämatoxylin verliert and homogen wird". In diesem Fall fand also auch Rabl sehr frühzeitige Degeneration der Luteïnzellen. Im Allgemeinen scheint er jedoch der Ansicht zu sein, dass die regressiven Veränderungen sich erst später einstellen. Nach seiner Ansicht beginnen im Bindegewebs- und Gefässapparat die Rückbildungsübergänge "schon" um den 7. Monat; wann dieselben bei den Luteïnzellen einsetzen, entscheidet er nicht, da ihm Corpora lutea vera, die nachweislich älter als 9 Monate waren, nicht zur Verfügung standen.

Wendeler äussert sich in Martin's Handbuch der Erkrankungen der Eierstöcke dahin, dass das Corpus lut. ver. mit dem 3. und 4. Monat seine grösste Ausdehnung erreicht; nach dem 3. Monat beginnt der Rückbildungsprocess, der sich zunächst an den am weitesten von den starken Bindegewebssepten und grösseren Gefässen gelegenen Partien, und zwar auch durch eine Vermehrung der Bindegewebssprosse bemerkbar macht.

Dieselben Ansichten finden sich in den Lehrbüchern der Geburtshülfe.

Die Untersuchungen von Cornil erstrecken sich nur auf Corp. lut. spuria. Das in Fig. 1 wiedergegebene dürfte mit 3 Wochen zu hoch taxirt sein, zumal wenn man das um nur wenig ältere Corp. lut. in Fig. 2 damit vergleicht.

Wie bereits Kreis und H. Rabl hervorgehoben haben, betont auch Cornil, dass zwischen dem Corp. lut. menstr. und dem Corp. lut. gravid. kein wesentlicher Unterschied bestehe. Er weist im Speciellen darauf hin, dass das Corp. lut. menstr. dieselbe Grösse erreichen kann, wenn in Folge allgemeiner oder localer Erkrankungen eine ovarielle Hyperämie, so bei Typhus, passive Congestionen in den Genitalien bei Herzfehlern vorhanden sind. Hauptsächlich ist dies der Fall bei der chronischen Metritis und Endometritis, bei Schleimhaut- und myomatösen Polypen, bei Myomen. Auch Orthmann hat auf die auffallende Grösse des Corp. lut. spur. bei Myomen aufmerksam gemacht. Desgleichen 
berichtet Santi über zwei Fälle bei Fibromen. Auch ich habe wiederholt, zumal bei Myomen, Corpora lut. menstr. gefunden, die in ihren Maassen in Nichts hinter den während der Schwangerschaft zurückstanden.

Aus der Aehnlichkeit der Wirkung darf man wohl schliessen, dass das wichtigste Moment in der stärkeren Entwickelung des Corp. lut. grav. ebentalls in der Hyperämie des Ovariums zu suchen ist, die bisher wohl nur von Wenigen angezweifelt worden ist (z. B. yon Bisch off, L. Fraenkel). Von dem Bestehen einer solchen kann man sich leicht überzeugen und an fast allen mikroskopischen Schnitten fällt die reichliche Blutversorgung, vornehmlich der Rindenpartien, in die Augen.

Es dürfte demnach wohl definitiv die Ansicht, als ob zwischen den beiden Arten von gelben Körpern ein principieller Unterschied bestände, beseitigt sein. Die Grössendifferenzen erklären sich im Wesentlichen durch die grössere Gestalt der Luteïnzellen und diese wiederum aus dem reichlichen Blutzufluss intra graviditatem, abgesehen von accidentellen Ereignissen, wie die Grösse des Blutergusses, welche das Volumen des Körpers vergrössern.

Wenn ich nun weiter zur Besprechung meines eigenen Materials übergehe, so möchte ich zunächst der von $H$. Rabl beschriebenen kleinen epithelioiden Zellen Erwähnung thun, die für die Altersbestimmung des gelben Körpers zweifellos von Bedeutung sind. Die Zellen wurden auch bereits von älteren Untersuchern gesehen, doch ausschliesslich als Rundzellen angesehen, so auch von $\mathrm{K}$ reis. Diese Genese ist auszuschliessen, es handelt sich um Abkömmlinge der fixen Bindegewebszellen und zwar, wie ich annehme, sowohl der Zellen der Theca externa als auch der interna; der letzteren aber zweifellos vorherrschend.

Betreffs der Zeit, bis zu der man die kleinen epithelioiden Zellen verfolgen kann, stimme ich mit Rabl überein. Nur bei den Corpora lutea der ersten beiden Fälle (1. Theil der Arbeit, Gravidität von 6 und 7 Wochen) waren die Zellen an der Peripherie in grösseren und kleineren Gruppen noch aufzufinden, ferner bei den vorher beschriebenen jungen Corp. lut. menstr. Bei einer 3 Monate alten Tubarschwangerschaft fehlten sie bereits vollständig. In den bindegewebigen Septen jedoch, welche zwischen die Luteïnzellen hineinziehen, konnte ich Zellen längere Zeit nachweisen, sie wurden noch bei einer Schwangerschaft von 3 (Fall 3) und von $3 \frac{1}{2}$ Mo- 
334 Seitz, Die Follikelatresie während der Schwangerschaft eto.

naten (Fall 4) gefunden, bei einer 4 monatlichen Graviditas isthmica (Fall 7) vermisst.

Rabl schreibt diesen kleinen epitheloiden Zellen die Fähigkeit $\mathrm{zu}$, sich in Luteïnzellen umzuwandeln und auf diese Weise zu einer nachträglichen Vergrösserung des Corpus luteum beizutragen. Dabei hält er aber an der epithelialen Abkunft der Hauptmasse der Luteinzellen in Uebereinstimmung mit den Sobotta'schen Untersuchungen an Maus und Kaninchen fest. Ich kann seine Angaben bestätigen, dass man an den verschiedensten Stellen junger Corp...lut. einen directen Uebergang der einen Zellart in die andere wahrzunehmen glaubt und dass auf Grund der morphologischen Befunde allein in der That diese Deutung ihre Berechtigung hat. Es geht demnach scheinbar ein Theil der Luteïnzellen beim Menschen aus den Thecazellen hervor. Diese Annahme der doppelten Abkunft scheint auf den ersten Blick freilich etwas merkwürdig. Allein man hat den Eindruck, als ob die Grenzen zwischen den epithelialen Granulosazellen und den bindegewebigen Thecazellen keine so scharfen und unüberschreitbaren sind, wie wir in andern Organen von den zwei verschiedenen Zellarten anzunehmen berechtigt sind, und vielleicht behält Wendeler Recht, der auch das Granulosaepithel aus den Stromazellen ableitet.

Was das erste Auftreten regressiver Veränderungen speciell in den Luteïnzellen anlangi, so komme ich auf Grund meines Materiales zu dem Resultate, dass die ersten Rückbildungserscheinungen bereits früher sich einstellen, als man bisher gemeint hat. Die Beschreibung der Corp. lutea ist bereits bei den einzelnen Fällen ausführlich geschehen und ich brauche nur darauf zurückzuverweisen. Bereits bei einem 6 Wochen alten Corpus lut. gravid. (Fall 1) und ganz besonders bei dem 7 Wochen alten Körper (Fall 2), desgleichen bei Fall 22 aus dem 2. Monat der Gravidität, ferner bei einem hier nicht näher beschriebenen Corpus lut. vom Ende des 2. Monats bestanden schon weitgehende regressive Veränderungen. Namentlich auffallend war dieses Verhalten bei Fall 2. Die Präparate waren zugleich mit einem Corpus lut. vom Ende der Schwangerschaft geschnitten worden und in beiden Fällen waren die Befunde so ähnlich, dass ich vermuthete, es wäre eine Verwechselung untergelaufen. Die Untersuchung eines neuen Stückes ergab aber dasselbe Resultat. Nach meinen Erfahrungen muss ich demnach sagen, dass die gelben 
Körper bereits am Ende des 2. Monats in Rückbildung begriffen sind und dass speciell an den Luteinzellen bereits regressive Metamorphosen einsetzen.

Die Rückbildung geht übrigens in den folgenden Monaten nur recht langsam vor sich, die Befunde an den Luteïnzellen im vierten Monat können meist nicht sicher von dem im 6. Monat unterschieden werden. Es scheinen auch Variationen nicht selten zu sein; so trifft man - gleich gut conservirte Präparate vorausgesetat die Luteinzellen das eine Mal mehr zusammengesintert und abblätternd, das andere Mal fest einander anliegend und eine compacte Masse bildend, bald sind die Conturen der Zellen ganz verschwommen, das Protoplasma zerfallend und auffasernd, bald sind die Grenzen scharf zu erkennen, das Protoplasma hat eine mehr gleichmässig homogene Beschaffenheit angenommen und sich intensiv mit Eosin gefärbt. Mit welchen Factoren diese Verschiedenheiten zusammenhängen, lässt sich im einzelnen Falle nicht sicher entscheiden; zweifellos spielt die Blutversorgung, die früher oder später eintretende Obliteration der Gefässe eine wichtige Rolle.

Wenn ich auch bekennen muss, dass das einwandfreie Material aus den ersten Monaten der Schwangerschaft nicht gross und zu endgültigen Schlüssen nicht hinreichend ist, so lässt sich doch mit Bestimmtheit Folgendes feststellen:

1. Es beginnen die regressiven Veränderungen an den Luteïnzellen schon früher, als man im Allgemeinen angenommen hat, bereits im 2. Monat gegenüber dem 3. und 4. Monat. Das Corpus luteum soll erst am Ende des 3. bezw. am Anfange des 4. Monats oder gar erst in der Mitte der Schwangersehaft seine grösste Ausdehnung erreicht haben. Das wäre auffällig, wenn mikroskopisch die Rückbildungserscheinungen schon am Ende des 2. Monats beginnen. Nach meinen Messungen hat das Corpus luteum das grösste Volumen bereits am Ende des 2. bezw. Mitte des 3. Monats und von da ab beginnt langsam die Verkleinerung; doch sind in der zweiten Hälfte der Schwangerschaft wesentliche Grössendifferenzen nicht vorhanden (cfr. umstehende Tabelle). 2. Das Volumen des Corpus luteum unterliegt nicht geringen individuellen Schwankungen. 3. Es besteben grosse Unterschiede in dem Auftreten degenerativer Erscheinungen an den Luteïnzellen. Wenn ich zweifellose regressive Metamorphose bereits Ende des 2. Monats gesehen habe, so schwankt die Intensität dieses Processes in den einzelnen späteren Monaten ausserordentlich. Man darf zur Beurtheilung dieser Verhältnisse 
nur absolut frische Präparate, keine von Sectionen verwenden, um ein richtiges Urtheil zu bekommen. Man sieht Fälle, in denen sich die Luteïnzellen aus einem 4 Monate alten Corpus luteum nicht von dem am Ende der Schwangerschaft unterscheiden.

Maasse der Ovarion und Corpora lutea.

\begin{tabular}{|c|c|c|c|c|c|c|c|}
\hline 学 & 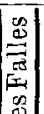 & $\begin{array}{l}\text { Alter } \\
\text { und }\end{array}$ & Gravidität & & $0 \mathrm{va}$ & $\mathrm{cn}$ & Corpus luteum. \\
\hline & $\left|\begin{array}{l}0 \\
\dot{0} \\
|z|\end{array}\right|$ & Geburt & & & linkes & rechtes & \\
\hline 1 & 1 & $\begin{array}{l}27 \mathrm{~J} . \\
\text { I p. }\end{array}$ & $\begin{array}{l}\text { Tubargravid. } \\
\text { von } 6 \text { Wochen }\end{array}$ & $\begin{array}{c}\text { Koeliotomie } \\
\text { wegen Ruptur }\end{array}$ & $\begin{array}{c}\text { stark in Adhäs. } \\
\text { eingebettet, } \\
\text { Gröss. unbestimmt }\end{array}$ & $4,5: 1,4: 1,6 \mathrm{~cm}$ & $\begin{array}{l}r: 2,0: 1,8 \mathrm{~cm}, \text { mit cyst. } \\
\text { Hohlraum von } 0,7: 0,5 \mathrm{~cm} .\end{array}$ \\
\hline 2 & 22 & - & 1.-2. Monat & Leichenpräp. & $5: 3,5: 1,5 \mathrm{~cm}$ & $4: 3: 1 \mathrm{~cm}$ & 1. $1,75: 1,5 \mathrm{~cm}$ \\
\hline 3) & 2 & $\begin{array}{l}41 \mathrm{~J} . \\
\text { VIII p. }\end{array}$ & $\begin{array}{l}\text { Gravidität } \\
\text { ron } 7 \text { Wochen }\end{array}$ & $\begin{array}{l}\text { Carcinoma } \\
\text { cervicis, } \\
\text { Totalexstirp. }\end{array}$ & $1,7: 0,6 \mathrm{~cm}$ & $2: 1,3: 0$ & 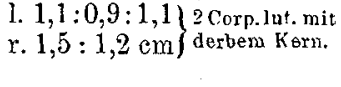 \\
\hline 4 & 23 & $\begin{array}{l}34 \mathrm{~J} . \\
\text { III p. } \\
-\end{array}$ & $\begin{array}{l}\text { 1. Tubargrav. } \\
\text { von } 21 / 2 \text { Mon. } \\
\text { r. Tubargrav. }\end{array}$ & $\begin{array}{c}\text { Operation } \\
\text { Leichenpräp. }\end{array}$ & $\begin{array}{c}3: 2,5: 1,7 \mathrm{~cm}, \\
\text { ohne Adhäsionen } \\
3,8: 2,8: 1 \mathrm{~cm}\end{array}$ & $4,5: 3,7: 1,2 \mathrm{~cm}$ & $\begin{array}{l}\text { l. } 2,5: 2 \mathrm{~cm}, \text { mit cyst. } \\
\text { Hohlraum }(0,6: 0,5 \mathrm{~cm}) \text {. } \\
\text { r. } 2,0: 1,2 \mathrm{~cm}, \text { solide. }\end{array}$ \\
\hline $\begin{array}{l}6 \\
7\end{array}$ & $\begin{array}{r}24 \\
4\end{array}$ & $\begin{array}{c}- \\
\text { Ju- } \\
\text { gendl. }\end{array}$ & $\begin{array}{l}\text { 2.-3. Monat } \\
\text { Grav. } 3 \text { Man. } \\
\text { Gravidität } \\
\text { von } 31 / 2 \text { Mon. }\end{array}$ & $\begin{array}{l}\text { Spirituspräp. } \\
\text { Leichenpräp. }\end{array}$ & $\begin{array}{c}4: 2,5: 1,0 \mathrm{~cm} \\
4,5: 2,25: 1,5 \mathrm{~cm}\end{array}$ & $\begin{array}{c}3,5: 2,5: 0,51 \mathrm{~cm} \\
4: 3: 1,75 \mathrm{~cm}\end{array}$ & $\begin{array}{l}\text { r. } 0,9: 0,8 \mathrm{~cm}, \text { solide. } \\
\text { r. } 1,8: 1,5 \mathrm{~cm}, \text { mit solidem } \\
\text { Kern. }\end{array}$ \\
\hline 8 & 5 & ma. & $\begin{array}{c}\text { Gravidität } \\
\text { von } 31 / 2 \text { Mon. }\end{array}$ & $\begin{array}{l}\text { Myome, } \\
\text { Operation }\end{array}$ & $5: 2,5: 0,5 \mathrm{~cm}$ & nicht entfernt & - \\
\hline 9 & 6 & - & Grav. 4 Mon. & $\begin{array}{l}\text { Myome, } \\
\text { Operation }\end{array}$ & $4: 2: 0,7 \mathrm{~cm}$ & nicht entfernt & \\
\hline 10 & 7 & - & $\begin{array}{l}\text { Grav. tub. } \\
\text { isthm. } \\
\text { von } 4 \text { Mon. }\end{array}$ & Operation & $3: 2: 1,2 \mathrm{~cm}$ & $4: 2,5: 1,0 \mathrm{~cm}$ & $\begin{array}{l}\text { l. } 0,5: 0,3 \mathrm{~cm} \text {, mit solidem } \\
\text { weisslichen Kern. }\end{array}$ \\
\hline 11 & 8 & - & $\begin{array}{c}\text { Gravidität } \\
\text { von } 4 \frac{1}{2} \text { Mon. }\end{array}$ & Operation & nicht entfernt & $6: 3: 2 \mathrm{~cm}$ & $\begin{array}{l}\text { r. } 1: 1,5 \mathrm{~cm}, \text { mit eyst. } \\
\text { Hohlraum }(0,3: 0,5 \mathrm{~cm}) .\end{array}$ \\
\hline 12 & 9 & - & $\begin{array}{l}\text { Gravidität } \\
\text { von } 5 \text { Mon. }\end{array}$ & Operation & nicht entfernt & $5: 3: 0,8 \mathrm{~cm}$ & r. $1,5: 1,5 \mathrm{~cm}$, solide. \\
\hline 13 & 26 & 一 & $\begin{array}{c}\text { Gravidität } \\
\text { von } 4--5 \text { Mon. }\end{array}$ & Leichenpräp. & $3: 2,75: 0,8 \mathrm{~cm}$ & $3: 2,75: 0,8 \mathrm{~cm}$ & r. $1,2: 1,1 \mathrm{~cm}$, solide. \\
\hline 14 & 10 & 一 & $\begin{array}{l}\text { Gravidität } \\
\text { von } 6 \text { Mon. }\end{array}$ & $\begin{array}{l}\text { frisch ent- } \\
\text { nommen }\end{array}$ & $5,5: 1,5: 0,6 \mathrm{~cm}$ & $4,1: 2: 0,6 \mathrm{~cm}$ & r. $1,1: 0,9 \mathrm{~cm}$, solide. \\
\hline 15 & 11 & $28 \mathrm{~J}$. & $\begin{array}{l}\text { Grav. } 7 \text { Mon. } \\
\text { Eklampsie }\end{array}$ & $\begin{array}{l}\text { frisch ent- } \\
\text { nommen }\end{array}$ & $3: 2: 0,5 \mathrm{~cm}$ & $3: 2: 1 \mathrm{~cm}$ & $\begin{array}{c}\text { r. } 1: 1 \mathrm{~cm} \text {, mit kleinem } \\
\text { Spalt. }\end{array}$ \\
\hline 16 & $12 \mid$ & $\begin{array}{l}39 \mathrm{~J} . \\
\mathrm{XI} \text { p. }\end{array}$ & $\begin{array}{l}\text { Grav. } 8 \text { Mon. } \\
\text { Nephritis, } \\
\text { Herzfehler }\end{array}$ & $\begin{array}{l}\text { frisch ent- } \\
\text { nommen }\end{array}$ & $2,5: 1,5: 1,5 \mathrm{~cm}$ & $2: 0,9: 1,5 \mathrm{~cm}$ & 1. $1,2: 1,2 \mathrm{~cm}$, solide. \\
\hline 17 & 13 & $\begin{array}{l}37 J . \\
\mathrm{X} \text { p. }\end{array}$ & $\begin{array}{l}\text { Grav. } 9 \text { Mon. } \\
\text { Eklampsie }\end{array}$ & $\begin{array}{l}\text { frisch ent- } \\
\text { nommen }\end{array}$ & $2,5: 1,1: 0,8 \mathrm{~cm}$ & $2, \overline{5}: 1,3: 0,6 \mathrm{~cm}$ & 3. $0,7: 0,7 \mathrm{~cm}$, solide. \\
\hline 18 & 14 & $\begin{array}{l}33 \mathrm{~J} \\
\text { VIII p. }\end{array}$ & Grav. 10 Mon. & $\begin{array}{l}\text { Uterusruptur, } \\
\text { Operation }\end{array}$ & $4,5: 3 \cdot 1,0 \mathrm{~cm}$ & $6: 2,5: 0,9 \mathrm{~cm}$ & $\begin{array}{l}\text { 1. } 0,7: 0,5: 0,6 \mathrm{~cm} \\
\text { solide. }\end{array}$ \\
\hline 19 & 15 & $\begin{array}{l}32 \mathrm{~J} . \\
\text { IV p. }\end{array}$ & Grav. 10 Mon. & $\begin{array}{l}\text { Uterusruptur, } \\
\text { Operation }\end{array}$ & $7,8: 3: 0,4 \mathrm{~cm}$ & - & \\
\hline 20 & 16 & $\begin{array}{l}48 \mathrm{~J} . \\
\text { Viel- } \\
\text { geb. }\end{array}$ & Grav. 10 Mon. & $\begin{array}{l}\text { Uterusruptur, } \\
\text { frisch ent- } \\
\text { nommen }\end{array}$ & $8,5: 1: 0,5 \mathrm{~cm}$ & $5: 3,5: 0,6 \mathrm{~cm}$ & r. $1,4: 1,2 \mathrm{~cm}$, solide. \\
\hline
\end{tabular}




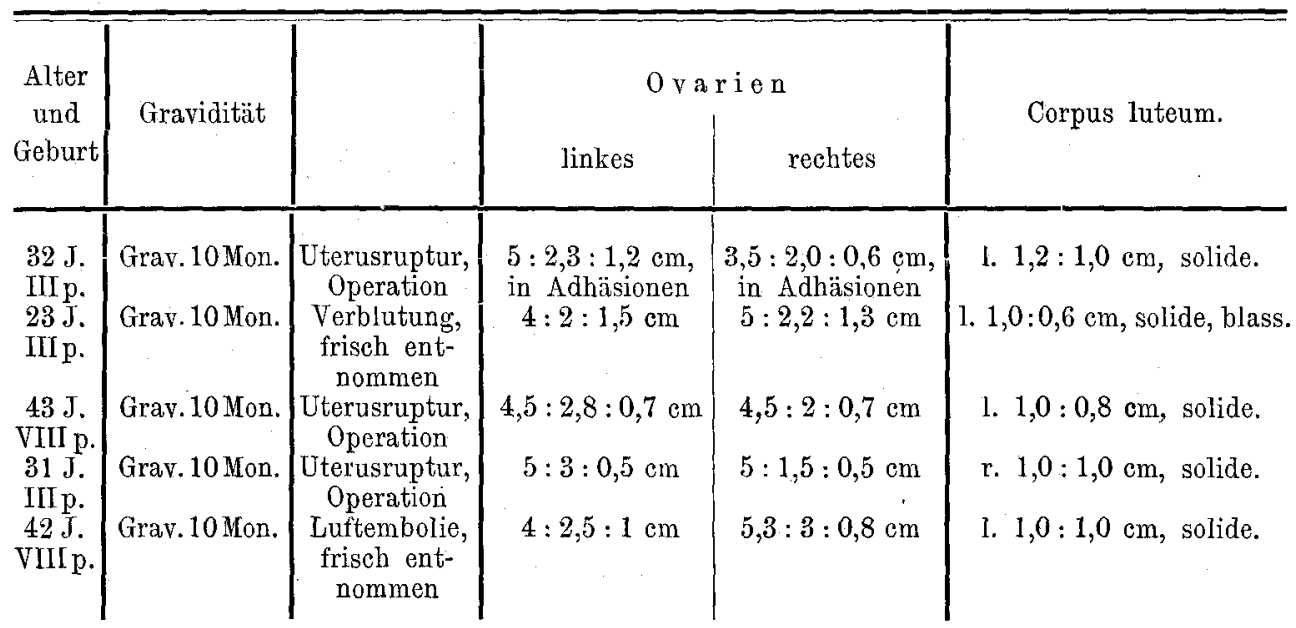

Wenden wir diese Befunde auf die Born-Fränkel'sche Theorie an, so ist zunächst festzustellen, dass dieselben für die ersten 2 Monate nichts enthalten, was gegen sie spricht. Immerhin könnte sich der Einfluss nur auf die ersten 2 Monate erstrecken; auffällig ist ferner, dass ein Organ, dem eine so wichtige Function im mütterlichen Organismus znkommen soll, in seinen specifischen Elementen so grossen Variationen vornehmlich betreff der regressiven Metamorphose unterliegt.

Anhangsweise will ich über die Messungsergebnisse der Ovarien gravider Frauen berichten. Es ist dies vielleicht deshalb von einem gewissen Interesse, weil einzelne Autoren anzunehmen geneigt sind, der Eierstock allein participire an der allgemeinen Hypertrophie der Genitalorgane während der Schwangerschaft nicht. Bischoff sagt sogar: „die Eierstöcke beim schwangeren Uterus verschrumpfen, sind trocken, blutleer," Andere nehmen dagegen eine Vergrösserung an, J. Veit vergleicht die Hypertrophie und die Formveränderung des Eierstockes in der Schwangerschaft mit jener bei Myomen, Ahlfeld's Messungen ergaben als Dimension $7-10 \mathrm{~cm}$ Länge, 1,5 bis $2 \mathrm{~cm}$ Breite (cit. nach $\nabla$. Rosthorn in v. Winckel's Handbuch I. 1, S. 569). Diese Messungen sind wohl an frischen Präparaten angestellt. Mir stehen nur die Maasse von conservirten Ovarien zur Verfügung, es kann daher nur ein Vergleich mit ebensolchen brauchbare Werthe ergeben. Martin fand an 10 in Sublimat gehärteten und in Alkohol conservirten Ovarien gesunder, nicht schwangerer Frauen, folgende Maasse: Länge 3,16, Höhe 1,92, 
Dicke 1,12 cm. (Die Farre-Waldeyer-Krause'schen Zahlen sind $3-5,2-3,5$ und $1,0-1,5 \mathrm{~cm}$.)

Rechnet man bei den 25 Fällen die linken und die rechten Eierstöcke zusammen, im Ganzen 4.3 Eierstöcke, so ergeben sich folgende Mittelzahlen: Länge 4,67, Höhe 2,33, Dicke $0,95 \mathrm{~cm}$. Es sind demnach die Werthe nicht unerheblich grösser als bei Martin. Klarer tritt dieses Verhältniss zu Tage, wenn man aus Martin's und meinen Fällen den mittleren Rauminhalt berechnet. Bei den Eierstöcken ausserhalb der Schwangerschaft ergeben sich 6,8, während der Schwangerschaft 10,24 ccm. Es findet demnach in der That eine beträchtliche Grössenzunahme der Ovarien während der Schwangerschaft statt, die auf eine reichlichere saftige Durchtränkung und grössere Blutzufuhr und consecutiv auf deciduale Veränderungen an der Ovarialoberfläche sowie auf die Hypertrophie und Hyperplasie der Thecaluteïnzellen in und ausserhalb atretischer Follikel zurückzuführen ist.

Es ist mir eine angenehme Pflicht, meinem hochverehrten Chef, Herrn Geheimrath v. Winckel für die gütige Ueberlassung des werthvollen Materials und für die liebenswürdige Durchsicht der Arbeit meinen verbindlichsten Dank auszusprechen.

\section{Nachtrag bei der Correctur.}

In einem der letzten Hefte dieses Archivs erschien unterdessen eine Arbeit von L. Fraenkel: "Vergleichend histologische Untersuchungen über das Vorkommen drüsiger Formationen im interstitiellen Eierstocksgewebe", in welcher der Autor zu dem Resultate kommt, dass das interstitielle Gewebe bei vielen und gerade auch bei den hochstehenden Säugern (Menschen und menschenähnlichen Affen) ganz fehlt. Ich kann mir natürlich über die Befunde bei den verschiedenen Species kein Urtheil erlauben, da mir mit Ausnahme von Kaninchen, Meerschweinchen und Katze, wo die einschlägigen Verhältnisse durch die Arbeiten von H. Rabl, Limon und Frz. Cohn bereits längst bekannt sind, keine eigenen Beobachtungen zur Verfügung stehen, doch möchte ich mir zu den Befunden am menschlichen Ovarium einige Bemerkungen gestatten.

Ich stimme zunächst Fraenkel darin bei, dass es am Ovarium nicht gravider Frauen eine interstitielle Drüse nicht giebt. Unter interstitieller Drüse verstehe ich in Uebereinstimmung mit 
Fraenkel und den anderen Autoren den Complex epithelioider Zellen, die aus atretischen Follikeln hervorgegangen sind. Man sieht ausserhalb der Schwangerschaft unter pathologischen Verhältnissen wohl hie und da an atretischen Follikeln grössere Zellen der Theca interna, welche den Typus von Luteinzellen tragen. Doch sind das nach meinen Erfahrungen nur sehr vereinzelte Vorkommnisse. Dagegen kann ich Fraenkel nicht, zustimmen, wenn er auch das Vorkommen der interstitiellen Drüse an den Ovarien. gravider Frauen völlig in Abrede stellt. Ich glaube in meinen vorausgegangenen Ansführungen für die Existenz einer solchen genügend Beweise erbracht zu haben. Man könnte höchstens darüber streiten, ob es berechtigt ist, die durch Wucherung der Zellen der Theca interna hervorgegangenen Gebilde als interstitielle Drüse zu bezeichnen. Dazu ist einmal festzustellen, dass die interstitielle Drüse auch bei den von Fraenkel beschriebenen Species von Säugethieren eine recht verschiedene Structur aufweisen kann. Man braucht zu diesem Zwecke nur die verschiedenen Figuren der von ihm gegebenen Abbildungen mit einander zu vergleichen, um die weitgehenden histologischen Verschiedenheiten wahrzunehmen. So ist die Figur 8, welche die interstitielle Drüse von Cebus capucinus darstellt, total verschieden von der vorhergehenden Abbildung, die aus dem Ovarium von Canis azarae stammt. Besonders instructiv ist in dieser Beziehung die Abbildung 6 der Franz Cohn'schen Arbeit, wo man den directen Uebergang des interstitiellen Gewebes in die gewucherte Theca des atretischen Follikels im Ovarium eines jugendlichen Kaninchens beobachten kann. Das Charakteristische bei der Entstehung der interstitiellen Drüse im Sinne von Limon und Franz Cohn besteht darin, dass nach Zugrundegehen des Eies und des Follikelepithels, event. sogar vor Eintritt dieses Ereignisses, eine Vergrösserung der Zellen der Theca interna eintritt, dass diese epithelioide Gestalt annehmen und in ihrem Protoplasma feine Fettkörnchen und kleine Mengen von Lutein enthalten. Diese Gebilde sind gegen das umgebende Bindegewebe mehr oder minder scharf abgegrenzt und persistiren bei verschiedenen Thieren offenbar sehr lange Zeit. Diese Charakteristica treffen bei den von mir beschriebenen Gebilden in jeder Beziehung zu. Es geht das Ei und das Follikelepithel zu Grunde, die Zellen der Theca interna hypertrophiren und hyperplasiren, sie enthalten in ihrem Protoplasma Fett und spärliches Luteïn. Es ist dabei unwesentlich, ob das Follikellumen erhalten bleibt oder, 
wie das öfters der Fall ist, vollständig verschwindet. Dass diese Charakteristika der Zellen zutreffen, geht zur Genüge aus meinen Beschreibungen und den beigefügten Abbildungen hervor. Es ist ferner nicht richtig, wenn Fraenkel behauptet, die Capillaren seien in diesen Gebilden nicht zahlreicher als sonst. Der Reichthum an Capillaren ist stets ein ungewöhnlicher und fällt an den gegebenen $A$ bbildungen ohne Weiteres in die Augen. Auch die Form der Zellen ist in der Regel polygonal und bei starker Vergrösserung ist die wabige Struetur des Protoplasmas ohne Weiteres erkennbar.

Es ist daher kein Grund einzusehen, warum diese Gebilde, die genau dieselbe Genese haben und die morphologisch den gleichen Gebilden an einzelnen Thieren stark ähneln, nicht ebenfalls als interstitielle Drüse aufgefasst werden sollten. Die Frage, ob es sich dabei wirklich um eine Drüse und eine innere Sekretion handelt, die den Namen "interstitielle Drüse" rechtiertigen würde, ist natürlich etwas ganz anderes. Ich bin mit Fraenkel der Ansicht, freilich aus etwas anderen Gründen wie er, dass ihnen eine derartige Function nicht zukommt.

Fraenkel ist geneigt, den Begriff Luteïnzelle nur für die Zellen des Corpus luteum zu reserviren. Es ist um die Definition der Luteïnzelle eine recht schwierige Sache und es hat der schwankende Begriff zweifellos, namentlich bei der Frage nach der Genese des Corpus luteum, schon recht viele Verwirrung angerichtet. Das Typische der Luteïnzelle ist, daran müssen wir festhalten, um üborhaupt eine Einigung in der Nomenclatur zu erzielen, ihre epithelioide Gestalt und ihr Gehalt an Fett und Lutein. Nun aber kommen diese Charakteristika nicht allein den Zellen des Corpus luteum, sondern auch, wie bekannt, den Zellen der Theca interna wachsender und atretischer Follikel zu und gelegentlich während der Schwangerschaft auch umgewandelten Stromazellen. Ich hielt es daher für zweckmässig, nach ihrer Provenienz die ersteren als Thecaluteinzellen, die letzteren als Stromaluteinzellen za bezeichnen. Auch Fraenkel erkennt an, dass gelegentlich während der Gravidität gewöhnliche Stromazellen ein "luteïnartiges Aussehen" erlangen.

Die vorerwähnte Deutung der Gebilde als interstitielle Drüse hat vor mir bereits Wallart gegeben. Fraenkel versieht jedoch dessen Befunde an verschiedenen Stellen mit Fragezeichen (S. 458) und spricht ihnen jede Beweiskraft ab. Es ist ja zweifellos diese 
Skepsis gegen die Wallart'schen Befunde, die an Ovarien "von an schweren Krankheiten (u. a. Sepsis) verstorbenen Wöchnerinnen“ Fraenkel (S. 458) berechtigt und jch selbst habe bereits im Centralblatt f. Gynäk. (1905, No. 19) auf die Unzulänglichkeit seines Materials ausdrücklich hingewiesen ${ }^{1}$ ). Allein auch meine vorläufige Mittheilung, die in einer Fussnote auch erwähnt wird und die zu den gleichen Resultaten an einem einwandfreien Material kam, war bereits erschienen. Wenn es mir gelingen sollte, Fraenkel durch meine ausführliche Arbeit von der Anwesenheit der „interstitiellen Drüse" im Ovarium des schwangeren Weibes zu überzeugen, so wäre mir das immerhin noch bald genug.

Unterdessen ist ferner eine vorläufige Mittheilung (Note istologiche sulle modificazioni delle ovaia in gravidanza, Bollettino della società medico-chirurgica di Pavia, seduta del 31. Marzo 1905) und die ausführliche Arbeit (Annali di Ostetr. e Ginecol. 1905) von C. Pinto erschienen, die eine Bestätigung Wallart's und meiner Untersuchungen enthält. Die Untersuchungen, die der Hauptsache in der Universitätsfrauenklinik in Tübingen ausgeführt wurden, umfassen 10 Fälle, davon 5, die Schwangerschaften vom 1.-4. Monat betreffen, ferner 1 Schwangerschaft ad terminum einer Osteomalacischen und 4 Ovarienpaare von Wöchnerinnen. Auch Pinto findet, auch bereits in den ersten Monaten der Schwangerschaft, eine Hypertrophie and Hyperplasie der Zellen der Theca interna und schliesst sich am Schlusse seiner Arbeit wörtlich meinen diesbezüglichen Ausführungen im Centralbl. f. Gyn. No. 19 an. Auch Pinto ist der Ansicht, dass wir es bei der Follikelatresie am schwangeren Ovarium des Menschen genau mit denselben Gebilden zu thun haben, wie bei der von Limon-Bouin und Frz. Cohn beschriebenen Follikelatresie verschiedener Nagethiere ausserhalb der Schwangersehaft, die zu der Bildung der sog. „interstitiellen Drüse“ führen. Betreff der Function dieses Organs verhält er sich sehr skeptisch.

Die an der Peripherie jüngerer Corpora lutea zu findenden

1) Es scheint den Präparaten von Wallart vielleicht dooh eine grössere Beweiskraft zuzukommen, als ich nach der Provenienz der Ovarien und auf Grund seiner Mittheilung allein anzunehmen berechtigt war. Ich gebe dieser Annahme Ausdruck auf Grund einer Besprechung mit Herrn Prof. v. Herff gelegentlich meiner Demonstration einschlägiger Präparate auf dem Gyn. Con gress zu Kiel, der mir mittheilte, dass er die Präparate selbst gesehen habe und für sie eintrete. 
„kleinen epithelioiden" Zellen bezeichnet er, wie mir scheint, passend mit dem Namen Paraluteïnzellen und nimmt in Uebereinstimmung mit Rabl und mir eine Umwandlung in Luteinzellen an. Es handelt sich um eine Art von Reserve für die Bildung neuer Elemente. Die namentlich an jüngeren Corpora lutea gefundenen homogenen Kugeln möchte Pinto am liebsten als hyaline oder colloide Substanz auffassen, hält aber die Möglichkeit nicht für ausgeschlossen, dass es sich um Secretionsproducte handeit. Für mich besteht an der hyalin degenerativen Natur der homogenen Kugeln, die sehr wohl von den Fett- und Luteïneinschlüssen zu scheiden sind, kein Zweifel. Auch in Betreff der Pigmentzellen in den Corp. albicantia stimmen unsere Ansichten überein.

Wenn wir beide unabhängig von einander in Betreff der erwähnten Fragen zu erfreulich übereinstimmenden Resultaten gekommen sind, so kann ich seiner Ansicht in zwei anderen wesentlichen Punkten nicht zustimmen. Einmal stellt er in Abrede, dass eine Umwandlung einzelner Stromazellen in Luteïnzellen während der Schwangerschaft vorkommt. Er giebt zwar zu, dass die Abgrenzung der Zellen der vergrösserten Theca interna gegen die Umgebung unscharf ist (Seite 17 u. 32 des Sonderabdruckes), er findet deciduaähnliche Zellen nicht nur in der Albuginea, sondern auch, wenn auch viel seltener, im Ovarialgewebe und fasst die Bildung als eine Reaction der Stromazellen auf den Schwangerschaftsreiz auf. Die luteinartige Beschaffenheit verschiedener Stromazellen scheint ihm entgangen zu sein. Es hängt dies vielleicht damit zusammen, dass $P$. vorwiegend Ovarien aus den ersten Monaten der Schwangerschaft (4 andere stammten von an fieberhaften Krankheiten verstorbenen Wöchnerinnen, deren Ovarien zum Studium dieser Verhältnisse ungeeignet sind, nur 1 stammt von einer Schwangerschaft von regelmässigem Ende [Osteomalacie], doch standen P. in diesem Falle nur von anderer Seite überlassene Schnitte zur Verfügung) untersucht hat, und dass um diese Zeit, wie jch zeigen konnte, die Tendenz zur luteïnoiden Umwandlung minder deutlich zu Tage tritt, als in den letzten Monaten. Mit denselben Umständen scheint die zweite Annahme von Pinto, der ich nicht beistimmen kann, zusammenzuhängen, dass zwar im Ovarium bei Blasenmole, nicht aber im Ovarium bei normaler Schwangerschaft eine Umwandlung der Zellen der Theca interna zu echten Luteïnzellen stattfindet. Sein Urtheil gründet sich in Betreff der Blasenmole weniger auf eigene Beobachtungen - denn 
er besitzt nur einige wenige Schnitte aus einem Blasenmolenovarium (S. 15) - als hauptsächlich auf die Berichte und die Beschreibungen in der Literatur. Die Abbildung 4, welche den Unterschied zwischen einer Luteïncyste eines ungeplatzten Follikels bei Blasenmole gegenüber einer solchen Cyste während einer gewöhnlichen Schwangerschaft illustriren soll, beweist natürlich gar nichts; denn dergleichen Cysten atretischer grösserer Follikel kommen auch ohne Blasenmolendegeneration des Eies und sogar ohne Schwangerschaft vor; ich brauche zum Beweise dieser Behauptung nur auf die von mir beschriebenen Corpus luteum-ähnlichen Bildungen (S. 318) zu verweisen.

Man hat nach dem hier Erwähnten den Eindruck, als ob Pinto einen principiellen Unterschied zwischen den Ovarialveränderungen bei Blasenmole und bei gewöhnlicher Schwangerschaft annehmen will, ein Eindruck, der auch beim Lesen der ausführlichen Arbeit erhalten bleibt. Am Schlusse kommt er jedoch trotzdem zu der Ansicht, dass zwischen den beiden Processen nur graduelle Verschiedenheiten bestehen: bei der gewöhnlichen Schwangerschaft handelt es sich um die Ueberproduction epitheloiden Gewebes, bei der Blasenmole um Ueberproduction von Luteïnewebe, mit der eine Oedemisirung des Stromas und eine stärkere seröse Transsudation in das Follikellumen einhergeht, die eben zu der Degeneratio polycystica luteinalis ovariorum führt.

Hierbei verwickelt sich Pinto in einen Widerspruch; denn entweder ist das bei gewöhnlicher Schwangersehaft im Ovarium sich vorfindende epitheloide Gewebe wirklich nur ein solches und ist verschieden von dem Luteingewebe, dann besteht zwischen den Ovarialveränderungen bei Schwangerschaft und Blasenmole ein principieller Unterschied, oder aber das epitheloide Gewebe verwandelt sich während der Schwangerschaft bereits in Luteingewebe, dann kann es sich nur um quantitative Verschiedenheiten handeln. Pinto hält nun in der Arbeit an einer scharfen Trennung zwischen dem epitheloiden Gewebe bei gewöhnlicher Schwangerschaft und dem Luteingewebe fest, sieht sich aber am Schlusse der Arbeit durch die objectiven Befunde gezwungen, die principielle Scheidung der beiden Processe fallen zu lassen und kommt so zu dem gleichen Resultate wie ich. Er hält auch an der Ansicht fest, dass die Ovarialveränderungen bei Blasenmole secundärer Natur, hauptsächlich Folgen der gestörten Circulation sind und dass die primäre Ursache in der Degeneration der Zotten zu suchen sei. 
Endlich gedenke ich noch mit Freude der Arbeit von Hofbauer im letzten Hefte dieses Arehivs, der übereinstimmend mit den Befunden von Herxheimer in den Stromazellen der Ovarien Neugeborener und in besonders reichem Maasse gleich. mir an grösseren atretischen Follikeln Fetteinschlüsse in den Zellen der Theca interna nachweisen konnte.

\section{Literatur.}

A mann, J. A., Mikroskropisch-gynäkologische Diagnostik. Wiesbadon. 1897. Baer v., De ovi mammalium et hominis genesi epistola. Lipsiae. 1827.

Bajardi, Annali di Ostetricia e di Ginecologia. Aprile, Maggio. 1886, cit. nach Cosentino.

Bamberg, Incarceration cystisch degenerirter Ovarien bei Blasenmole. Monatsschr. f. Geb. u. Gyn. Bd. 20. H. 3. Septbr. 1904, S. 359.

Baumgart, Blasenmole bei beiderseitigem Ovarialkystom. Centralbl. f. Gyn. 1902. No. 4. S. 96.

Beigel, Zur Naturgeschichte des Corpus luteum. Dieses Archiv. 1878. Bd.13.

Belloy, Recherches sur l'origine des corpes jaunes etc. Compt. rend. de l'assoc. des anatomistes. 1899. Paris. Cit. nach Sobotta.

Benckiser, Zur Entwicklnngsgeschichte des Corpus luteum. Dieses Archiv. Bd. 23. 1884 .

Benckiser, Ueber das Vorkommen von indirecten Kerntheilungen im Corpus luteum. Dieses Archiv. Bd. 25. 1885. S. 482.

van Beneden, Contribution à la connaissance de l'ovaire des mammifères. Arch. de Biol. T. I. 1880.

Bischoff, Entwicklungsgesehichte des Kanincheneies (Braunschweig 1842), des Hundeeies (1845), des Meerschweinchens (1852), des Rehes (1854).

Birnbaum, Blasenmole bei einem Zwillingsei und Luteïnzellenverlagerung in einem Blasenmolenovarinm. Monatsschr. f. Geb. u. Gyn. Bd. 19. H. 2. S. 175. Febr. 1904.

Böshagen, Ueber die verschiedenen Formen der Rückbildungsproducte, der Eierstocksfollikel und ihre Beziehungen zu den Gefässveränderungen des Ovariums etc. Zeitschr. f. Geb. u. Gyn. Bd. 53. H. 2. S. 323. 1904.

Bouin, P., Les deux glandes à sécrétion interne de l'ovaire, la glande interstitielle et le corps jaune. Revue méd. del'Est. 1902. Cit. n. Frz. Cohn.

Bouin, P., Atrésie des follicules de Graaf et formation des faux corps jaunes. Note prélim. Bibliogr. anat. T. VII. 1899. Cit. nach Sobotta.

Bühler, Entwicklungsstadien menschlicher Corpora lutea. Verhandl. d. anat. Gesellsch. 14. Versamml. zu Pavia. 1900.

Bulius, Osteomalacie und Eierstock. Hegar's Beitr. z. Geb. u. Gyn. Bd. 1. H. 1. S. 138. 1898.

Bulius u. Kretschmar, Angiodystrophia ovariorum. Stuttgart. 1897.

Call u. Exner, Zur Kenntniss des Graaf'schen Follikels und des Corpus luteum beim Kaninchen. Sitzungsber. d. Wiener Academie. Bd.71. Abth. 3. 1874. Cit. nach Benckiser. 
Glark, Ursprung, Wachsthum und Ende des Corpus luteum. Nach Beobachtungen am Ovarium des Schweines und des Menschen. Archiv f. Anat. n. Physiol. Anat. Abth. 1898. S. 95.

Cohn, Frz., Zur. Histologie und Histogenese des Corpus luteum und des interstitiellen Ovarialgewebes. In.-Diss.' Breslau. 1903 u. Arch. f. mikrosk. Anat. u. Entwicklungsgesch. Bd. 62. 1903.

Cohn, Frz., Bemerkungen zur Histologie und Drüsenfunction des Corpus luleum. Eine Erwiderung an Lubosoh. Anatom. Anzeiger. Bd. 25. 1904. N. 2 u. 3.

Cuzzi o Berté, Contributo all' anatomia dell' ovaio della donna gravida. Rivista olinica. Ginglio. 1884. Cit. nach Cosentino.

Cornil, Notes sur l'histologie des corps jaunes de la femme. Mnn. de gynécol. Bd. 52. 1899.

Cosentino, Sulla quistione della sriluppo e della maturazione del follicolo di Graaf durante la gravidanza. Archivio di ostetr. $\theta$ Ginecol. Anno IV. 1897. p. 1 .

Diepgen, 3 Corpus luteum-Cysten. Hegar's Beitr. z. Geb. u. Gyn. Bd. 8. S. 52.1904.

Doering, Beitrag zur Streitfrage über die Bildung des Corpus luteum. Anat. Anzeiger. Bd. 16. 1899.

Dorland und Gerson, Cystic disease of the chorion. Amer. Journ. of obstet. 1896. June. p. 905.

Fischer, Chorionepitheliom und Luteïncysten. Deutsche med. Wochenschrift. 1905. No. 4. S. 142.

Flemming, Ueber die Bildung von Richtungsfiguren in den Säugethiereiern beim Untergang Graaf'scher Follikel. Arch. f. Anat. u. Physiol. Anat. Abth. 1885. S. 221.

Fränkel, Eugen (Hamburg), Ueber Corpus luteum-Cysten. Dieses Archiv. Bd. 48. Heft 1. S. 1. 1894 und Bd. 57. Heft 3. S. 511. 1899.

Fraenkel, Ladwig, Der Bau der Corpus luteum-Cysten. Dieses Archiv. Bd. 56. Heft 2. S. 355.1898.

Fraenkel, Ludwig, Die Function des Corpus Iuteum. Dieses Archiv. Bd. 68. Heft 2. S. 438. 1903.

Fraenkel, L. und Franz Cohn, Experimentelle Untersuchung über den Einfluss des Corpus luteum auf die Insertion des Eies. Anatom. Anzeiger. Bd. 20. 1901.

Fraenkel, L., Weitere Mittheilangen über die Function des Corpus luteum: Sitzungsbericht der geb.-gyn. Gesellsch. zu Wien vom 15. Decbr. 1903. Centralbl. f. Gyn. 1904. S. 621 und 661.

Grohe, Ueber das Wachsthum des menschlichen Eierstockes. Virch. Archiv. Bd. 26. 1863.

Grousdew, Proliferirende, aus Luteïnzellen bestehende Ovàrialgeschwülste. Dieses Archiv. Bd. 70. Heft 3. S. 445. 1903.

Halban, Sitzungsbericht d. geb.-gyn. Gesellsch. zu Wien. 15. Decbr. 1903. Centralbl. f. Gyn. 1904. S, 628.

Harz, Beitrag zur Histologie des Ovariums der Säugethiere. Arch. f. mikroskopische Anatomie. Bd. 22. 1893.

Heape, The menstruation of semnopithecus entellus. Proceeding royal so- 
ciety. Vol. 54. 1894 u. Philos. transact. of the royal society of London. Vol. 188. 1897. Cit. nach Sobotta (Anat. Hefte. II. Abth. Bd. 8. 1898) und Centralbl. f. Gyn. 1898. S. 773.

Herxheimer, Fettinfiltration und Fettdegeneration. Lubarsch und Ostertag's

Ergebnisse d. allg. Path. n. path. Anatomie. 8. Jahrg. 1902. S. 625.

His, W., Beobachtungen über den Bau des Säugethiereierstockes. Archiv für mikroskop. Anat. Bd. 1. S. 151. 1865.

Hölzl, Ueber die Metamorphose des Graaf'schen Follikels. Virchow's Arch.

Bd. 143. 1893.

Honoré, Recherches sur l'ovaire du lapin et sur la formation du corps jaune. Arch. de biol. Tome 16. 1899.

Jaffe, Blasenmole und Eierstock. Ein Beitrag zur Pathologie des Corpus luteum. Dieses Archiv. Bd. 70. Heft 3. S. 462.

Janosik, Die Atrophie der Follikel und ein seltsames Verhalten der Eizelle. Archiv f. mikrosk. Anat. Bd. 48.

Ihm, Die Bedeutung des Corpus luteum. Referat mit Lit. Monatsschr. f. Geb. u. Gyn. Bd. 21. Heft 4. S. 515. April 1905.

Kehrer, Ueber Traubenmole. Dieses Archiv. Bd. 45. S. 478. 1894.

K inoshita, Ueber grosszellige deciduazellenähnliche Wucherungen auf dem

Peritoneum und den Ovarien bei intrauteriner Schwangerschaft. Monatsschrift f. Geb. u. Gyn. Bd. 8. 1898.

Koelliker, Ueber die Entwicklung des Graaf'schen Follikels. Sitzungsbericht d. phys.-med. Gesellsch. Würzburg. 1898.

Koelliker, Ueber Corpora lutea atretica bei Säugethieren. Verhandl. der anat. Gesellsch. Kiel. 1898. n. Handbuch der Gewebelehre.

Kopsch, Corpus luteum vom Schwein. Verhandl. d. anat. Ges. Bonn. 1901. Krebs, Chorionepitheliom und Ovarialtamor. Centralbl. f. Gynäkol. 1903.

No. 44. S. 1297.

Kreis, Die Entwicklung und Rückbildung des Corpus Iuteum spurium beim Menschen. Dieses Archiv. Bd. 58. Heft 2. S. 411. 1899.

Krönig, Befruchtung intra puerperium. Centralbl. f. Gyn. 1893. S. 455.

Krukenberg, R., Ueber die Diagnose des malignen Chorionepithelioms nach

Blasenmole. Zeitschr. f. Geb. u. Gyn. Bd. 53. H. 1. S. 76.1904.

Langer, Ueber Corpus luteum-Abscesse. Dieses Arch. Bd. 49. S. 87. 1895.

Lebedinsky, Zar Lehre von der Atresie der Graaf'schen Follikel. Centralbl.

f. Gyn. 1879. No. 5. S. 108.

Leopold, Ueber Menstruation und Ovulation. I. Anat. Theil. Dieses Archiv. Bd. 21. Heft 3. S. 347. 1883.

Leopold und Mironoff, Beitrag zur Lehre ron der Menstruation und Ovulation. Dieses Archiv. Bd, 45. 1894.

Limon, Etude histologique et histogénique de la glande interstitielle de l'ovaire.

Thèse de Nancy. 1901. Ref. in Schwalbe's Jahresbericht der Anatomie und Entwicklungsgeschichte. Neue Folge. Bd. VII. Lit. von 1901. III. Abth. S. 387.

Lindenthal, Ueber die Decidua ovarii und ihre Beziehungen zu gewissen Veränderungen im Ovarium. Monatsschr. f. Geb. u. Gyn. Bd. 13. H. 6. S. 707. Juni 1901. 
Mac Lie od, Contribution à l'étude de la structure de l'ovaire des nammifères. Arch. de biol. Tome I. 1880 und Tome II. 1881.

Magnus, Die Bedeutung des Corpus luteum für die Schwangerschaft. Norsk. Mag. for Lägevid. p. 1138. 1901. Ref. Centralbl. für Gyn. 1902. No.34. S. 911.

Malcolm und H. Bell, Chorion-epithelioma following hydatiform mole in a patient with bilateral ovarian cysts. Transact. London obst. Vol. 45 for 1903 . p. 483.

Mandl, Beitrag zur Kenntniss der Function der weiblichen Keimdrüse. Chrobak's Festschr. Wien 1903.

Mandl, Verhandlungen der geb.-gyn. Gesellschaft zu Wien. 13. XII. 1903. Centralbl. f. Gyn. 1904. S. 632.

Marshall, Preliminary communication on the oestrous cycle and the formation of the Corpus luteum in the sheep. Cit. nach Sobotta:

Meigs, Obstetric, the science and the art. Philadelphia 1849. Cit. nach Cosentino.

Montuoro, Sulle cellule midollari dell' ovajo del caniglio. Arch. Ital. di Anat. e di Embriologia. Vol. II. p. 45. 1903.

Nage 1, W., Das menschliche Ei. Archiv für mikroskop. Anat. Bd. 31. S.342. 1888.

Nagel, W., Beitrag zur Anatomie gesunder und kranker Ovarien. Dieses Arch. Bd. 31. H. 3. S. 335.1887.

Nagel, W., Die weiblichen Geschlechtsorgane. Handbuch der Anatomie des Menschen. Herausgegeb. von R. v. Bardeleben. Bd.7. Th. II. Abth.I. Jena 1896.

Nagel, W., Ueber die neueren Arbeiten auf dem Gebiet der Anatomie der weiblichen Geschlechtsorgane. Anatom. Hefte. (Merkel u. Bonnet.) 2. Abth. Bd. 8. S. 251. 1898.

Oliva, Contributo allo studio della pathologia del corpo luteo. Arch. jtal. di gynaec. Napoli 1901. No. 1. p. 1 und Anatomischer Anzeiger. Bd. 18. 1900.

Orthmann, Zur Pathologie des Corpus luteum. Verhandlung. der Deutschen Gesellsch. f. Gyn. Bd. 7. S. 351. 1897.

Orthmann, Corpus luteum-Cysten in Martin's Handbuch der Erkrankungen des Eierstocks. S. 333.

Paladino, Ulteriori ricerche sulla distruzione e rinovamento continuo del parenchimo ovarico nei mammiferi. Napoli 1887.

Patellani, Centralbl. f. Gyn. No. 13. 1905.

Pfannenstiel, Erkrankungen des Eierstocks und Nebeneierstocks in Veit's Handbuch d. Gyn. Bd. 3. I. S. 393. Wiesbaden 1898.

Pflüger, Der Eierstock der Säugethiere und des Menșchen. Leipzig 1863.

Pick, L., Zur Frage der Eierstocksveränderungen bei Blasenmole. Centralbl. für Gyn. No. 34. 1903.

Plato, Zur Kenntniss der Anatomie und Physiologie der Geschlechtsorgane. Arch. f. mikrosk. Anat. Bd. 50. 1897.

Popp, Castration bei Osteomalacie. Diss. Froiburg i. Br. 1895.

Poirier Charpy, Traité d'Anatomia umana. T. V. Paris 1901. Cit. nach Montuoro. 
Poten und Vassmer, Beginnendes Syncytiom mit Metastasen, beobachtet bei Blasenmolenschwangerschaft. Dieses Archiv. Bd. 61. H. 2. S. 205. 1900.

Quain, Elements of Anatomy. Splanchnology by E. A. Schaefer and Johnson Symington. Vol. IIl. Part IV. 10. Ausgabe. 1896.

Rabl, H., Beitrag zur Histologie des Eierstocks des Menschen und der Säugethiere etc. Anat. Hefte. (Merkel u. Bonnet.) 1. Abth. ${ }^{1}$ ) Bd. 11. H. 34 bis 37. S. 111. 1899.

Rabl, H., Ueber Atresie der Follikel und Bildung des Corpus lutenm beim Menschen. Wiener gyn. Gesellsch. Centralbl. f. Gyn. No. 17. S. 486. 1899.

Regaud u. Policard, Phénomènes sécrétoires, formations ergastoplasmiques et participation du noyau à la sécrétion dans les cellules des corps jaunes chez le hérisson. Compt. rend. soe. de biol. T. 53. p. 470. 1991.

Regaud u. Policard, Sécrétion des cellules folliculeuses d'un produit particulier et accumulation de ce produit dans le protoplasma de l'ovule chez le chien. Compt. rend. soc. de biol. T. 53. p. 449. 1901.

Regaud u. Policard, Notes histologiques sur l'ovaire des mammifères. (Communic. prélim.) in Compt. rend. ass. anat. 3. Sess. p. 45-61. Lyon 1901. Ref. Zoolog. Jahresbericht f. 1901. S. 41.

Regaud u. Policard, Fonction glandulaire de l'épithélium ovarique et de ses diverticules tubuliformes chez la chienne in Compt. rend. soc. de biol. Paris. T. 53. p. 615-616.

Rokitansky, Ueber die Abnormitäten des Corpus luteum. Allgem. Wiener med. Zeitung. No. 34 u. 35.1859.

Romiti, Trattoto di Anatomia. V. VII. Cit. nach Montuoro.

Ruge, Georg, Vorgänge am Eifollikel der Wirbelthiere. Morphol. Jahrb. Bd. 15. S. 491.1889.

Runge, E., Ueber die Veränderungen des Ovariums bei syncytialen Tumoren und bei Blasenmole etc. Dieses Archiv. Bd. 69. H. 1. S. 33. 1903.

Santi, Pathologie des Corpus luteum. Monatsschr. f. Geb. u. Gyn. Bd. 20. Heft 1. S. 76 und Heft 2. S. 143. Juli und August 1904.

Scanzoni, Ueber die Fortdauer der Ovulation während der Schwangerschaft. Beiträge zur Geburtskunde u. Gynäkol. Würzburg. 1886, und Lehrbuch der Geburtshülfe. 1853. S. 324.

Schaeffer, Bildungsanomalien weiblicher Geschlechtsorgane. Dieses Arehiv. 37. Heft 2. S. 199. 1890.

Scharfe, Osteomalacische Ovarien. Hegar's Beiträge zur Geb. u. Gyn. Bd. 3. Heft 2. 1900. S. 248.

Schauta, Verhandlungen der geb.-gyn. Gesellschaft zu Wien. 16. Dec. 1903. Centralbl. f. Gyn. 1904. S. 660.

Schmorl, Ueber grosszellige Wucherungen auf dem Peritoneum und den

1) Ioh mache ausdrücklich darauf aufmerksam, dass es 2 Abtheilungen der Anatomischen Hefte giebt und dass das Ausserachtlassen dieses Umstandes beim Citiren ausserordentliche Schwierigkeiten verursacht, wie ich aus eigener Erfahrung weiss. 
Ovarien bei intrauteriner Schwangerschaft. Monatsschr. f. Geb. u. Gyn. Bd. 5. Heft 1. S. 46. Januar 1897.

Schnell, Bindegewebszellen des Ovariums in der Gravidität. Zeitschrift für Geb. u. Gyn. Bd. 40. Heft 2. S. 267. 1899.

Schottländer, Beitrag zur Kenntniss der Follikelatresie etc. Arch. f. mikroskopische Anat. Bd. 37. S. 192.

Schottländer, Ueber den Graaf'schen Follikel, seine Entstehung beim Menschen und seine Schicksale bei Menschen und Säugethieren. Arch. für milirosk. Anat. Bd. 41. S. 219. 1893.

Schulin, Morphologie des Ovariums. Arch. für mikroskop. Anat. Bd. 19. S. 242. 1881 .

Soitz, Ludwig, Die Luteïnzellenwucherung in atretischen Follikeln - eine physiologische Erscheinung während der Schwangerschaft! Vorläufige Mittheilung. Centralbl. f. Gyn. 1905. No. 9.

Seitz, Ludwig, Zur Frage der Luteïnzellenwucherung in atretischen Follikeln während der Schwangerschaft. Centralbl. f. Gyn. 1905. No. 19.

De Sinety, De l'ovaire pendant la grossesse. Comptes rendus de l'académie des sciences. Bd. 85. a. p. 345. 1877 und Gazette des hôpitaux. 1877. p. 727.

Skrobansky, Beitrag zur Immunisirung mit Eierstock. Münchener medic. Wochenschr. 1903. No. 44. S. 1913.

Skrobansky, Dissert. St. Petersburg. 1901.

Skrobansky, Sitzungsbericht d. geb.-gyn. Gesellsch. zu Wien. 16. Dec. 1903. Centraibl: f. Gyn. 1904. S. 657.

Slaviansky, Zur normalen und pathologischen Histologie des Graaf'schen Bläschens. Virchow's Archiv. Bd. 51. 1870.

Slaviansky, Quelques donnces sur le développement et la maturation des vésicules de Graaf pendant la grossesse. Annal, de la gynécologie. IX. p. $81-92$.

Sobotta, Die Bildung des Corpus luteum bei der Maus. Anat. Anzeiger. Bd. 10. No. 15. S. 482.1895.

Sobotta, Ueber die Bildung des Corpus Iuteum bei der Maus. Archiv für mikrosk. Anat. Bd. 47. 1896.

Sobotta, Ueber die Bildung des Corpus luteum beim Kaninchen. Auatom. Hefte. I. Abth. Bd. 8. 24.-27. Heft. S. 469. 1897.

Sobotta, Ueber die Entstehung des Corpus luteum der Säugethiere. Anat. Hefte (Merkel u. Bonnet). II. Abth. Bd. 8. S. 923. 1898.

Sobotta, Noch einmal zur Frage des Corpus luteum. Arch. f. mikrosk. Anat. Bd. 53. 1898.

Sobotta. Ueber die Entstehung des Corpus luteum der Säugethiere. Anatom. Hefte (Merkel u. Bonnet). II. Abth. Bd. 11. S. 246. 1901.

Sobotta, Ueber das Corpus luteum der Säugethiere. Verhandl. der anatom. Gesellsch. Tübingen. 1899.

Sobotta, Das Wesen, die Entwicklung und die Function des Corpus luteum. Sitzungsberichte d. physik. med. Gesellsch. z. Würzburg. 1904. No. 2. Spiegelberg, Ueber die Bildung und Bedeutung der gelben Körper im Eierstock. Monatsschr. f. Geburtsk. u. Frauenkrankh. Bd. 26. 1865. 
Steffeck, Zur Entstehung der epithelialen Eierstocksgeschwülste. Zeitschr.

f. Geb. u. Gyn. Bd. 19. H. 2. S. 236. 1890.

Steinhaus, Menstruation und Ovulation. Leipzig. 1890.

Stevens, The fatum of the ovum and Graafian follicle in pre-menstrual life.

Transact of the obstetr. societ. of London. Vol. 45. for. 1903. p. 465.

Stoeckel, Ueber die cystische Degeneration der Ovarien bei Blasenmole, zu-

gleich ein Beitrag zur Histogenese der Luteïnzellen. Sonderabdruck aus

der Festschr. 1. Fritsch. Leipzig. 1901. Breitkopf u. Härtel.

Strassmann, In y. Winckel's Handbuch der Geburtshülfe. Bd. I. H. 1.

S. 107 u. 143.1903.

Stratz, Der geschlechtsreife Säugethiereierstock. Haag. 1898.

van der Stricht, La rupture du follicule ovarique et l'histogénèse du corps jaune. Compt. rend. de l'assoc. des anat. Lyon. 1901. Cit. nach Sobotta.

Voigt, Fall von Kaiserschnitt nach Porro in de $\vec{i}$ Schwangerschaft wegen malignen Ovarialtumoren nebst Beitrag zur Pathologio des Corpus luteum.

Dieses Arch. Bd. 49. S. 43. 1895.

Wagener, Bemerkungen über den Eierstock und den gelben Körper. Arch. f. Anat. u. Phys. Anat. Abth. 1879.

Waldeyer, Eierstock und Ei. Leipzig. 1870.

Waldeyer, Das Becken. Bonn. 1899. S. 507 u. in Hertwig's Handb d. Entwickelungsgeschichte.

Wallart, Ueber Ovarialveränderungen bei Blasenmole und bei normaler

Schwangerschaft. Zeitschr. f. Geb. u. Gyn. Bd. 53. S. 36. H. 1. 1904.

Wallart, Zur Frage der Ovarialveränderungen bei Blasenmole und bei normaler Schwangerschaft. Centralbl. f. Gyn. 1905. No. 13.

Wendeler, Zu den Krankheiten der Eierstöcke. Handbuch von Martin. 1899. Ferner:

Bühler, Beitrag zur Kenntniss der Eibildung beim Kaninchen und der Markstränge des Eierstockes beim Fuchs und Menschen. Zeitschr. f. wissensch. Zoologie. Bd. 30. S. 377. 1902.

Bühler, Rückbildung der Eifollikel bei Wirbelthieren. I. Fische. Morphol. Jahrb. Bd. 30. S. 377. 1902.

v. Franqué, Ueber Urnierenreste im Ovarium etc. Zeitschr. f. Geb. u. Gyn. Bd. 39. S. 499. 1896.

Lubosch, Untersuchungen über die Morphologie des Neunaugeneies. Jenaische Zeitschr. f. Naturwissensch. Bd. 38. 1903.

Lubosch, Das Corpus luteum der Säugethiere und seine Beziehungen zu dem der Anamnier. Anatom. Anzeiger. Bd. 25. No. 16 u. 17. 1904.

Rieländer, Das Paroophoron. Habilit. Schrift. Marburg 1904.

\section{Erklärung der Abbildungen auf Tafel VI-IX.}

Figur 1, Tafel VI. Wandpartie eines atresirenden grösseren Follikels mit dem Discus oophorus aus dem 8. Monat der Schwangerschaft. Aussen die Spindelzellen der Theca externa, darauf die Theca interna mit reichlichen Capillaren und Umwandlung der Zellen in Thecaluteïnzellen, am stärksten ausgebildet 
im rechten Abschnitt. Die äusserste Lage der Granulosaepithelien zeigt noch lineäre Anordnung, die Epithelien des Discus befinden sich in den centralen Partien in Chromatolyse und schliessen grosse Lücken zwischen sich ein; an den peripheren Lücken (Epithelvakuolen) sind die Epithelien ringförmig angeordnet. In der Mitte des Discus das hyalin degenerirte Ei. Färbung mit Hämatoxylin-Eosin. Vergrösserung: Zeiss $16 \mathrm{~mm}$. Oc. 4. Bod.

Figur 2, T a fel VI. Intacter wachsender Follikel vom Ende der Schwangerschaft (Fall Hegele). Ein Follikelraum ist noch nicht vorhanden, um das Ei die Zona pellucida, Dotter und Keimfleck deutlich erkennbar. Es ist dies der grösste intacte Follikel, den ich am Ende der Schwangerschaft auffinden konnte.

Figur 3, Tafel VIII. Ein Stück aus der Wand eines grösseren Follikels aus dem letzten Monate der Schwangerschaft. Links die Tun. externa, daraufnach rechts zu die epitheloiden Zellen der Tun, interna und auf dieser nach innen innen noeh eino schmale Lago bindegewebiger Zellen, das Granulosaepithel ist abgestossen. Vërgrösserung: $8 \mathrm{~mm}$. Oc. 4. B.

Figur 4, Tafel VIII. In Atresie befindlicher, $\lambda$ artig zusammengesunkener Follikel aus dem Fall1. (Tubar-Grav. von 6 Wochen). Man erkennt deutlich die Theca interna, dio an manchen Stellen besonders stark entwickelt ist und das degenerirende Follikelepithel gegen das Lumen drängt. Auf dem Schnitte ist das Ei oder dessen Ueberrest nicht getroffen. In dem oberen Theil erscheint durch Uebereinanderschieben der Zellen das Stratum granulosum verdickt. Zeiss. Obj. $16 \mathrm{~mm}$. Oc. 4.

Figur 5, T a fel VIII. Grösserer Follikel in Atresie von Fall4 (Schwangerschaft von $3^{1 / 2}$ Monaten), der Follikel hat seine runde Gestalt verloren. Aussen die Tun. ext., nach innen die epitheloiden, etwas auseinander stehenden Zellen der Tun. interna. Das Follikelepithel hat sich von der Tun. int. theilweise in Stücken abgehoben (zum Theil arteficiell bei derHärtung), die innerste Lage der Follikelepithelien ist fest und lineär, die weiteren gegen das Lumen zu gelegenen Zellen blättern $a b$ und lösen sich auf; einige kleine Fipithelvakuolen. Der Discus und das Ei ist auf dem Schnitte nicht getroffen. Di $\theta$ Fig. lässt klar die Entstehung der Thecaluteïnzellen aus den Zellen der Theca interna erkennen. An einer Stelle (links unten) ist an der Innenfläche der Theca ein schmaler hyaliner Saum. Vergrösserung: Zeiss. $16 \mathrm{~mm}$. Oc. 2.

Figur 6, Tafel VI. Ein atretischer Follikel desselben Falles mit ausgesp rochener'Thecaluteïnzellenentwicklung. Man sieht das schmale langgestreckte Lumen des plattgedrückten Follikels, das nach innen von einem hyalinen Saum umgeben ist, der nur mehr ganz spärliche Spindelzellen entbält. Die Zellen der Theca interna sind vergrössert, haben epitheloide Gestalt und ihr Zellleib hat sich blauröthlich gefärbt. Die Zellen lassen sich namentlich nach rechts zu weit in das Stroma hin verfolgen (weiter als die Fjgur zeigt). Nach unten zu sieht man den Abschnitt eines grossen Follikels, der mit einem homogenen Inhalt gefüllt, dessen Epithel verschwunden und in dessen Wand ebenfalls die epitheloiden Zellen liegen. Der kleinere atretische Follikel ist durch die Nähe der grossen abgeplattet; das Stroma zwischen den beiden Follikeln ist stark ödematös. Färbung mit Hämatoxylin-Eósin. Vergrösserung: Zeiss. $16 \mathrm{~mm}$. Oc. 2 . 
Figur 7, T a fel VI. Zwei Blatgefässdurchschnitte aus demselben Ovarium. Das Lumen der Gefässe ist mit Zellen mit chromatolytischen Kernen (Follikelepithelien) angefüllt. Das Stroma zejgt hyaline Degeneration. Färbung mit Hämatoxylin-Eosin. Vergrösserung: Zeiss. Obj. $3 \mathrm{~mm}$. Oc. 4.

Figur 8, Tafel VI. Im Beginn der Atresie befindlicher grösserer Follikel von Fall 6 (Gravid. von 4 Mon. bei multiplen Myomen). Aussen die Theca ext., nach innen die Theca interna, in welche links ein Bluterguss erfolgt ist; dadurch wird das Follikelepithel gegen das Follikellumen vorgebuchtet. Das Follikelepithel in schmaler Schicht mit kleinen Epithelvakuolen, die basalen Zellen noch fest der Unterlage aufsitzend, am Discus eine grössere Epithelvakuole. Ei auf dem Schnitte nicht getroffen, ist degenerirt. Färbung mit Hämatoxylin-Eosin. Vergrösserung: Zeiss. $16 \mathrm{~mm}$. Oc. 2.

Figur 9, Tafol VI. Eigenartiger atretischer Follikel von demselben Fall; das Gebilde hat die grösste Aehnlichkeit mit einem echten Corp. lut. Oben ist es von dem Stroma durch einen Zug lockeren, zellarmen Bindegewebes getrennt, rechts und seitlich ziehen spindelige Zellen und Gefässe in sein Inneres hinein. Die Zellen selbst sind gross, unregelmässig, ihre Umrisse unscharf, der Kern rundlich, z. Th. schlecht gefärbt und sehen aus wie Luteïnzellen. Zwischen ihnen sind einzelne spindelige Zellen. Färbung mit Hämatoxylin-Eosin. Vergrösserung: Zeiss. $16 \mathrm{~mm}$. Oc. 6. K. (K bedeutet Kasten, d. h. in gleicher Höhe mit dem Objecttisch gezeichnet.)

Figur 10, Tafel VI. Zwei akgesprengte Gruppen von Luteïzellen von Fall 7 (Gravid. tub. isthmica von 4Monaten), die von dem Haupt-Corpus luteum durch eine an Blutgefässen reiche bindegewebige Zone getrennt sind. Die versprengten Zellen gleichen vollständig in ihrem Aussehen den Luteinzellen des Haupt-Corpus luteum. Färbung mit Hämatoxylin-Eosin. Vergrösserung: Zeiss. Obj. $16 \mathrm{~mm}$. Oc. 4. K.

Figur 11, Tafel VI. A tretischer Follikel von Fall9. (Gravid. vom 5.Monat.) Ganz aussen das Stromagewebe, darauf eine hellere, zellärmere Zone mit mehreren Blutgefässen, dann die Thecaluteïnzellenschicht, am breitesten rechts. Zwischen den Bindegewebszügen sind grössere und kleinere Gruppen von polyedrischen, violett gefärbten Zellen in radiärer Anordnung 20 sehen. Der centrale Kern ist zellarm und enthält nur spärliche, von aussen hereingewachsene Spindelzellen. Färbung mit Hämatoxylin-Eosin. Vergrösserung: Zeiss. Obj. $8 \mathrm{~mm}$. Oc. 4 . K.

Figur 12, Tafel VIII. Schnitt aus dem Ovarium von Fall 10. (Gravid. von 6 Mon.) Zwischen dem Stromagewebe liegen grosse, meist ovale Zellen, die einen kleinen gut tingirten Kern und einen wie gebläht aussehenden, mit Granula angestopften Zellleib haben; die Granula haben theilweise gelbliche Farbe, dazwischen Capillaren. Es handelte sich um mit Pigmentkörnern beladene alte Luteïnzellen aus den Ueberresten eines Corpus luteum. Färbung mit Hämatoxylin-Eosin. Vergrösserung: Zeiss. Obj. $8 \mathrm{~mm}$. Oc. 4.

Figur 13, Tafel VIII. Eigenartiges Corpus atreticum von Fall 11 (Gravid. im Anfang des 7. Monats beiEklampsie), das genau dieselben Zellen wie das Corp. lut. enthält. Es ist von der Umgebung durch eine blutgefässreiche Theca ab- 
gegrenzt, von der aus einzelne Bindegewebszüge mit kleinen Gefässen von verschiedenen Seiten gegen die centralen Theile ziehen. Färbung: HämatoxylinEosin. Vergrösserung: Zeiss. Okj. $16 \mathrm{~mm}$. Oc. 4.

Figur 14, Tafel VI. Deciduaähnlich $\theta$ Zellen aus der Oberfläche desOvariums (Fall 12, Grav. von 8 Monaten); die Deciduazellen sind in 2 grössere Gruppen in der Albuginea gelegen, einzelne auch isolirt im Stroma. Sie zeichnen sich durch ihre Grösse und ihre polyedrische Gestalt aus, ihr Zellleib ist (im Gegensatz zu den Thecaluteïnzellen) gleichmässig blaugrau gefärbt, zwischen den Zellen ziemlich breite Intracellularräume; reichliche Gefässversorgung.

Figur 15, Tafel VIII. Abschnitt eines grösseren atresirenden Follikels von Fall 12(Gravid. von 8Monaten). Aussen ist die Theca ext., darauf die schmale'Theca int., die in den oberen Abschnitten etwas grössero Breite annimmt, sehr blutgefässreich, mit polyedrischen Zellen. Gegen das Follikelepithel grenzt sie sich nur stellenweise durch eine Art Membrana propria ab, stellenweise gehen die beiden Lagen unvermittelt ineinander über. Aus der Th. interna ziehen zarte Blutgefässe in die Granulosa, an einer Stelle sieht man das längsgetroffent Gefäss direct von der einen Schicht in die andere übertreten. In den central gelegenen Partien der Granulosa sind Follikelepithelien ausgefallen, sodass das Ganze ein zottiges Aussehen bekommt. Färbung mit Hämatoxylin-Eosin. Vergrösserung: Zeiss. $16 \mathrm{~mm}$. Oc. 4. B.

Figur 16, Tafel VIl. Parthie aus dem Ovarium des Falles 13 (Grav. im 9. Monat, Eklampsie). Nach unten zu ist eine angeschnittene Parthie des langgestreckten Follikels und einkleines Corpus albicans zu sehen, oben sind die Ausläufer eines Corpus albicans. Der ganzeZwischenraum ist ausgefüllt von Thecaluteïnzellen, die sich auch noch weit nach rechts zwischen die Stromazellen hinein erstrecken. Capillaren und spärliche Spindelzellen sind zwischen den Juteïnzellen eingelagert. Färbung mit Hämatoxylin-Eosin. Vergrösserung: Zeiss. Obj. $8 \mathrm{~mm}$. Oc. 3. K.

Figur 17, Tafel VII. Corpusatreticum von demselben Falle. Nur an zwei Stellen (s. unten und oben) ist die Theca externa in der Figur getroffen; nach innen zu folgt die breite Schicht der Theca interna-Zellen, die eine radiäre Anordnung zeigen. Der Zellleib zeigt häufig hyaline Umsäumung und, was aus der Abbildung weniger hervorgeht, leicht wabige Structur, die Kerne sind verschieden gross, mässig tingirt, zum Theil verschwunden. Sehr zahlreiche Capillaren verlaufen zwischen den Zellen. Das Centrum wird gebildet von einem breiten hyalinen Band, das in der Mitte eine Gruppe stark gefärbter Zellen, die Reste des Granulosaepithels, einschliesst. Das hyaline Band ist die verbreiterte Glasmembran. Färbung mit Hämatoxylin-Eosin. Vergrösserung: Zeiss. Apochr. $8 \mathrm{~mm}$. Oc. 4. B.

Figur 18, Tafel VII. Cystische Form der Follikelatresie mitLuteïnzellenhypertrophie aus Fall 14 (Ende der Gravidität). Man siehtaussen die Theca externa, die Zellen der Theca interna haben sich zu typischen Luteïnzellen umgewandelt. Die Begrenzung gegen die Umgebung ist hier sehr scharf. Dio Thecaluteïnzellen sind durch Spindelzellen und Capillaren in Gruppen von vier und mehr Exemplaren getheilt. Nach innen, vor der Luteïnschicht, folgt ein schmaler Saum, der in den äusseren Parthien uoch reichliche Spindelzellen, in den 
inneren dagegen ganz hyalin entartet ist. Die Follikelhöhle ist mit einem homogenen Inhalt gefüllt. Färbung mit Hämatoxylin- Eosin. Vergrösserung: Zeiss. Obj. $16 \mathrm{~mm}$. Oc. 4 .

Figur 19, Tafel VII. Ausgebildetes Corpus atreticum mit Lutë̈nellen in den peripheren Parthien aus demselben Ovarium. Das ganze Gebilde ist oben und unten durch einen Streifen lockeren Gowebes von der Umgebung abgegrenzt, in der Mitte des unregelmässigen hyalinen Kernes erkennt man als letzten Ueberrest des Follikellumens einen Z-ähnliclien Streifen. Rechts ist die Luteïnzellenentwicklung am weitesten fortgeschritten; sie erstrcckt sich noch weiter als zu sehen ist, in das Stroma hinein. Weiter ist die Wand eines grösseren Follikels. der noch Epithel trägt, angeschnitten. Färbung mit Hämatoxylin-Eosin. Vergrösserung: Zeiss Obj. 8 am. Oc. 4.

Figur 20, 'Tafel VIII. Aus der Oberfläche des Ovariums von Fall 19 (Ende der Schwangerschaft). Drüsenartiger Einschluss des Keimepithels durch Volumenvermehrung der Albuginea. Die Tarthie jst hier auffällig zell- und blutgeässarm, hier nur ödematöse Durchtränkung zu erkennen. Die äussere Seite des Keimepithels ist durch Dehnung ganz niedrig geworden, an der inneren dagegen hat das Epithel seine natürliche Höhe beibehalten. Zeiss. Obj. $8 \mathrm{~mm}$. Oc. 2. (C.)

Figur 21, Tafel VIIL. Aus der Wand eines grösseren Follikels von Fall 35 (7. Wochenbettstag). Das Lumen des Follikels wird begrenzt von einem unregelmässigen hyalinen Saum, welcher noch einigospärlicheZellen enthält. Auf diesen Saum folgt nach aussen zu eine breite Lage von Zellen, welche der frühoren Thecaluteïnschicht entspricht. Die Zellen sind zum Theil mebr oder minder hyalin degenerirt und gehen zu Grunde, zum Theil wandeln sie sich in gewöhnliche Stromazellen unter Abgabe des Fettes und des Luteïns zurück. Verschiedene Blutcapillaren. Nach aussen von dieser Schicht die Theca externa, die an der getroffenen Stelle ebenfalls hyaline Entartung aufweist. Färbung mit Hämatoxylin-Eosin. Vergrösserung: Zeiss. 0bj. $8 \mathrm{~mm}$. Oc. 6 . K.

Figur 22, Tafel VII. Starke Vergrösserung der Thecaluteinzellen aus der Wand eines cystischen atretischen Follikels von Fall15 (Ende derSchwangerschaft). Man erkennt den polyedrischen Zellleib, das Protoplasma zeigt eine wabige Structur und ist mit Eosin lila gefärbt. Die Kerne zeigen unregelmässige Vertheilung ihres Chromatins, zum Theil in Form eines Netzes, zum Theil punktförmig, zum Theil ist es auch stärker in der Kernmembran vertheilt. Die in der Mitte gelegene grosse Zelle zeigt Mitose ihres Kernes. Links unten ist eine bindegewebige Zelle, welche die ersten Anfänge der Umwandlung zu einer Thecaluteinzelle zeigt. Färbung mit Eosin-Hämatoxylin. Vergrösserung: Zeiss. Apochr. Immers. Oc. 4. (C). K.

Figur 23, 'Tấl VII. Stromaluteïzellen aus Fall 14(Ende der Gravidität). Die Luteïnzellen sind mitten im Stroma zwischen den gewöhnlichen Bindegewebszellen gelegen, ein Zusammenhang mit einem atresirenden Follikel oder einem Corpus atreticum war nicht festzustellen. Färbung mit Hämatoxylin-Eosin. Vergrösserung: Zeiss. Obj. $8 \mathrm{~mm}$. Oc. 6. K.

Figur 24, Tafel VII. Dieselben Zellen bei sehrstarker Vergrösserung; sie haben genau dasselbe Aussehen wie die Thecaluteïnzellen. In der Mitte eine Ca- 
pillare, zwischen und neben Luteïnzellen Stromazellen. Färbung mit Hämatoxylin-Eosin. Vergrösserung: Zeiss. Apochr. Immers. Oc. 4 (C) K.

Figur 25, Tafel VIJ. a) Eine isolirte, sehr grosse Thecaluteïnzelle, mit Osmium behandelt. Man sieht ganz kleine Fettkörnchen im Protoplasma; Kern mit Kernkörperchen.

b) Mehrere neben einander liegende Thecaluteïnzellen, mit Sudan III behandelt. Die Präparate waren vorher behufs Einbettung in Paraffin durch Alkohol (theilweise Lösung des Fettes) gegangen, so dass das Protoplasma nur eine rothbraune Farbe (statt der rothen Farbe) angenommen. Vergrösserung: Zeiss. Apochr. Immers. Oc. $4^{1}$ ).

Figur 26, Tafel VIII. Atretischer grösserer Follikel aus dem Ovarium eines Neugeborenen, zur Hälfte dargestellt. Das Follikellumen ist langgestreckt, Follikelepithel verschwunden, ebenso Ei. Die Zellen der Theca interna, namentlich rechts starl vermehrt, mit rcichlichen Capillaren. Weiter aussen ist die Theca externa, oben Anschnitt eines grösseren Gefässes.

Figur27, T a fel IX. Längsschnitt durch das Blasenmolenovarium in natürlicher Grösse; man sieht an der Peripherie die grösseren Cysten, gegen das Centrum zu liegen die kleineren. An der grossen nach unten gelegenen Cyste hebt sich die Wandbekleidung (von gelblicher Farbe) ab.

Figur 28, Tafel IX. Eine Partie aus der Cystenwand des Blasenmolenovariums. Aussen ist die bindegewebige 'lheca, ihr sitzt eine Schicht epitheloider Zellen mit zahlreichen Capillaren auf, die Luteïnzellen, die in ihrer Integrität bereits stark gelitten haben (Sepsis); gegen den Follikelraum grenzt eine hyaline Membran ab. Vergrösserung: Zeiss. Obj. $16 \mathrm{~mm} \mathrm{Oc.} 4 \mathrm{~B}$.

Figur 29, Tafel IX. Gefaltete Luteïnmembran aus demselben Ovarium. Aussen Theca externa (ohne scharle Zellcontouren), in der Mitte Theca interna mit einer mässigen Anzahl epitheloider zerfallender Zellen, innen schmaler hyaliner Saum.

Figur 30, Tafel IX. Theil eines in Atresie befindlichen Follikels aus dem Blasenmolenovarium. Aussen die Theca externa, daranf die Theca interna, deren Zellen leicht epitheloid sind, jedenfalls aber noch keinen ausgesprochenen Luteïnellentypus tragen. Vom Granulosaepithel ist die Schicht durch eine schmale hyaline Membran mit spärlichen Spindelzellen getrennt. Die EpitheJien sind stark abblätternd, zwischen dieselben ziehen von der Theca interna aus Blutcapillaren. Ei nicht mehr aufzufinden.

Figur 31, Tafel VII. Kleines Stück aus der Peripherie eines jungen Corp. lut. menstr. (III. Theil, Fall 2); unten sieht man ein Stück des Corp. lut., die Zellen gross, Zellleib otwas blass; daran schliessen sich nach oben die „kleinen epitheloiden" Zellen an, sodann die Spindelzellen und die Gefässe der Tunica externa; jenseits jener wieder eine Gruppe von epitheloiden Zellen. Färbung mit Hämatoxylin-Eosin. Vergrösserung: Zeiss. Apochr. $8 \mathrm{~mm}$ Oc. $2(\mathrm{C}) \mathrm{K}$.

1) An Gefrierschnitten eines frisch gewonnen Falles trat die rothe Farbe sehr deutlich zu Tage. 
356 Seitz, Die Follikelatresie während der Schwangerschaft etc.

Figur 32, Tafel VII. Eine Stelle aus demselben Corpus luteum, wo die „kleinen epitheloiden Zellen (rechts) scheinbar ohne Weiteres in die Luteïnzellen (links) übergehen.

Figur 33, Tafel VII. Corpus albicans aus dem Ovarium einer Gravida, in dessen Peripherie stellenweise eine starke Anbäufung von Pigmentzellen zu erkennen ist.

Figur 34, Tafel VII. Dieselben Pigmentzellen bei starker Vergrösserung.

Figur 35, Tafel IX. Cystenbildnng in einem Corpus fibrosum (Gravidität von 4 Monaten bei multiplen Myomen). Aussen das Ovarialstroma, dann ein Ring helleren Gewebes, weiter nach innen verdichtet sich das Gewebe wieder etwas mehr. Zeiss $0 b j .16 \mathrm{~mm}, 0$ c. 2 (C) $\mathrm{K}$. 
है
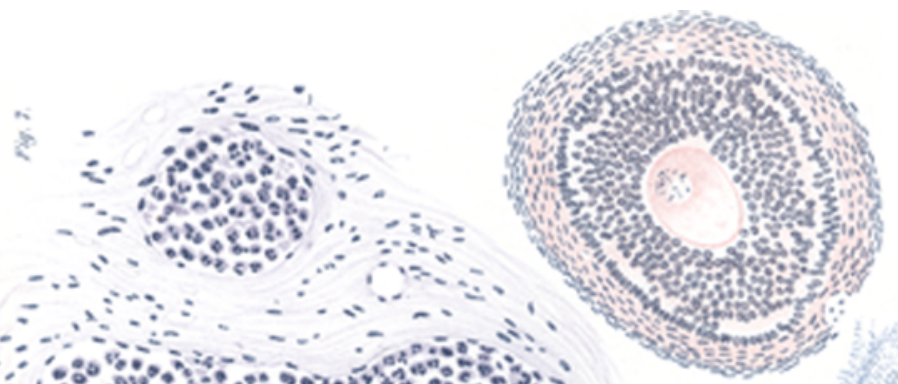

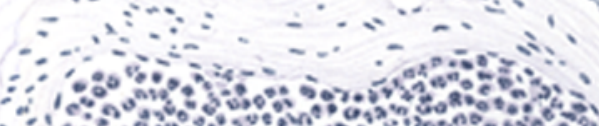

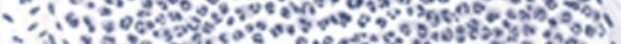

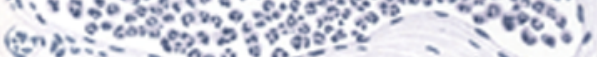

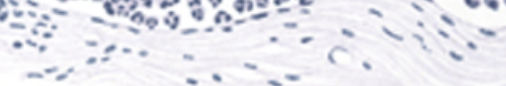

3

3 4 (3)

(3)

3.

How

Sing

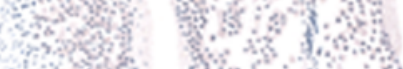

wat 40

ros:

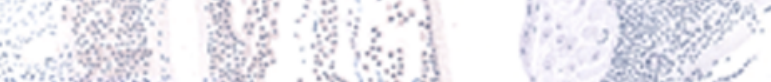

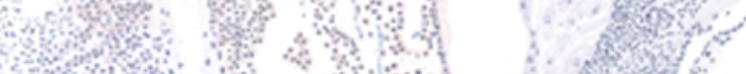

सर

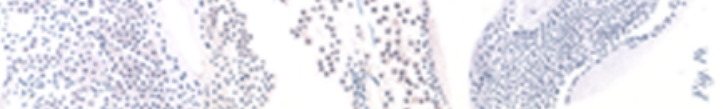

W.

$心$
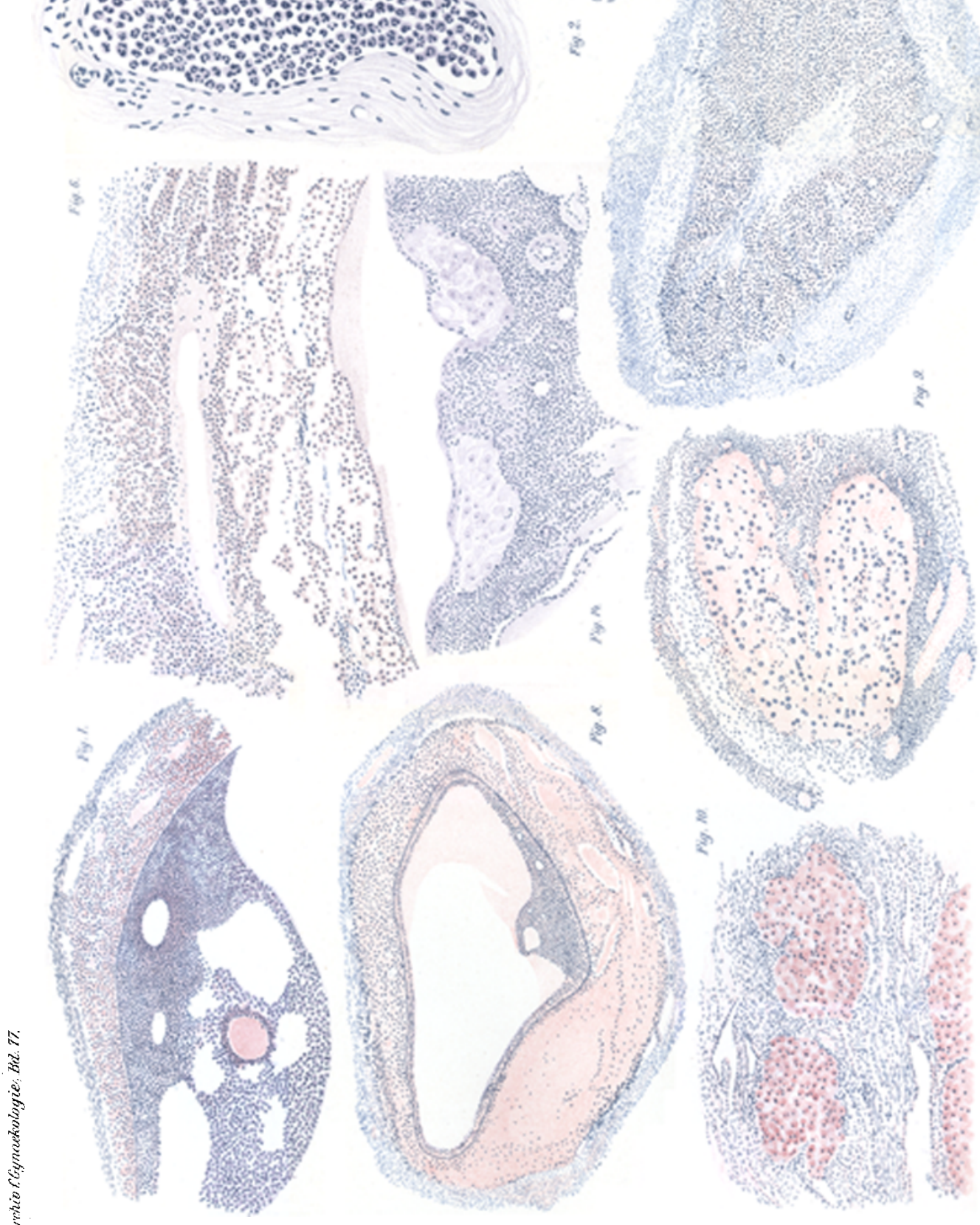

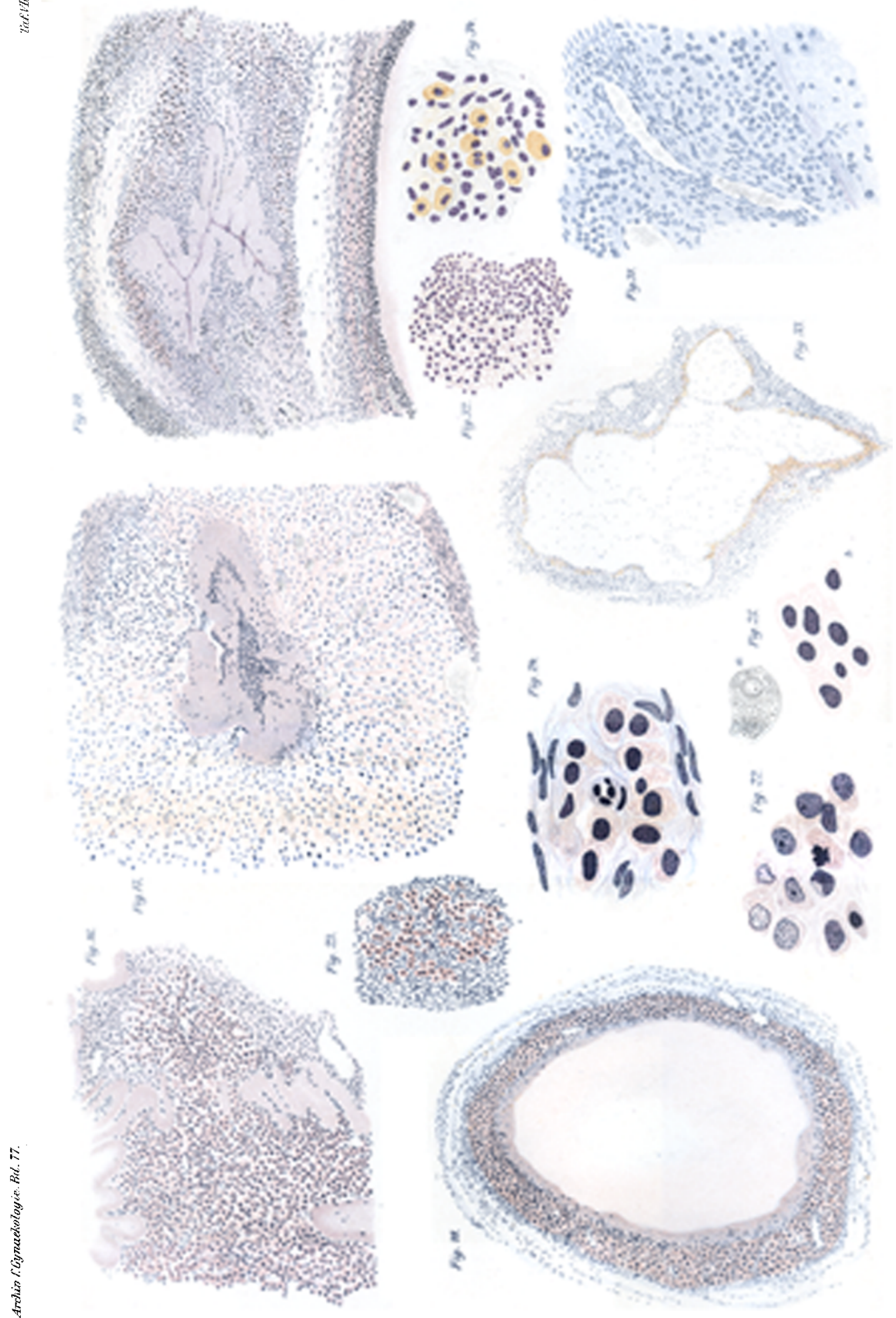

Axy

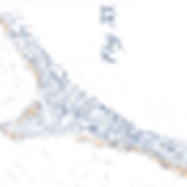



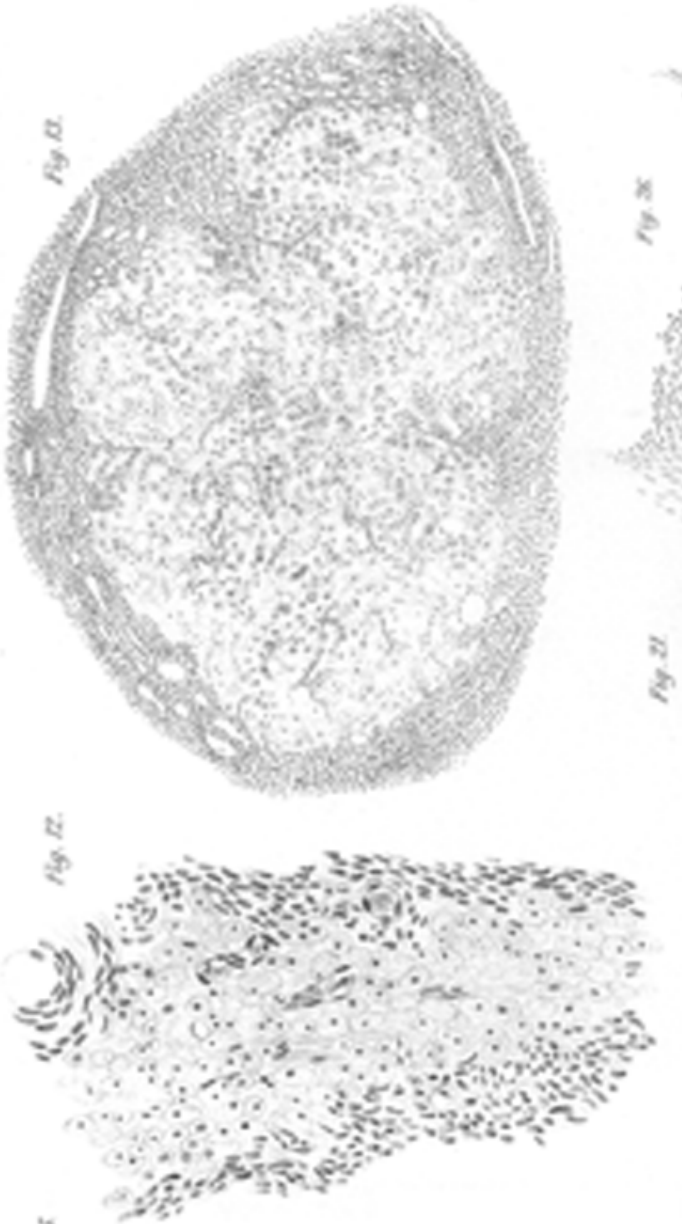

sic

3

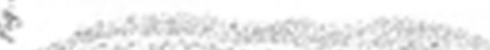

Q8.
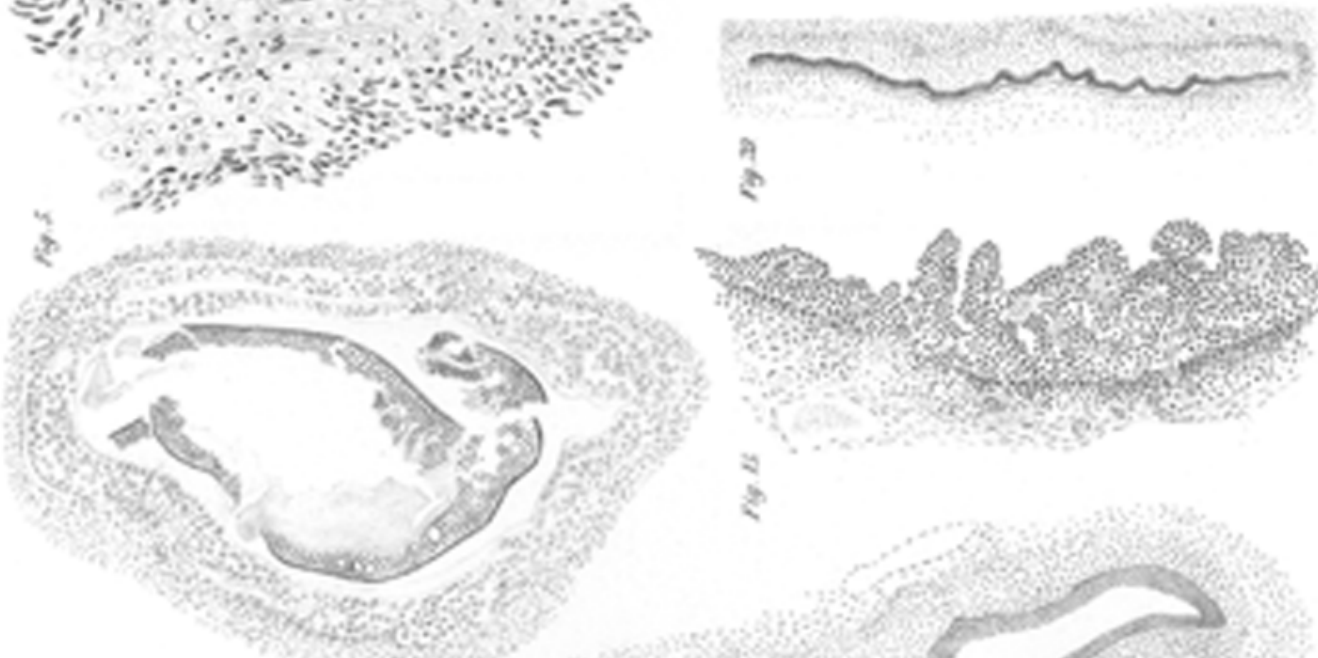

ค

8

2
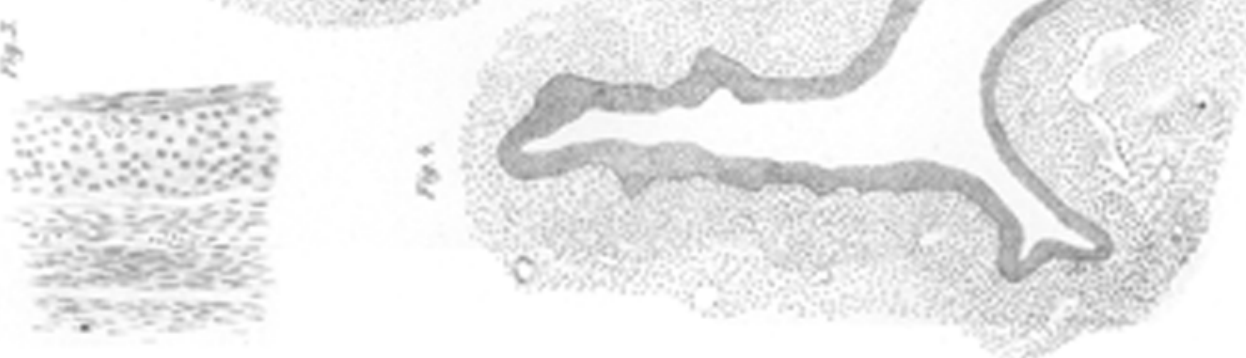


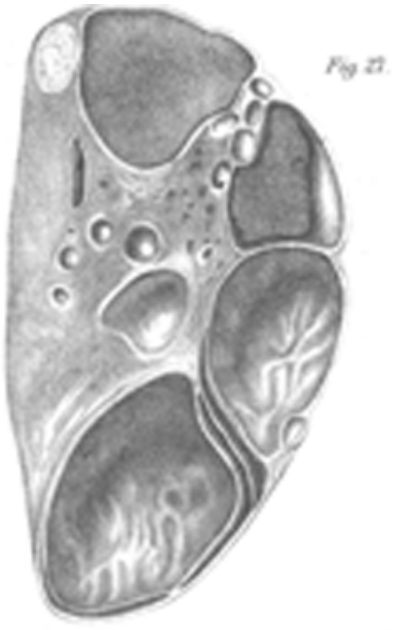

Fo as:

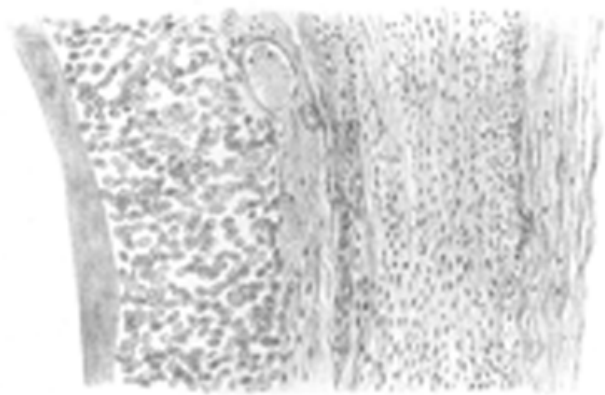

$$
\text { Rys }
$$
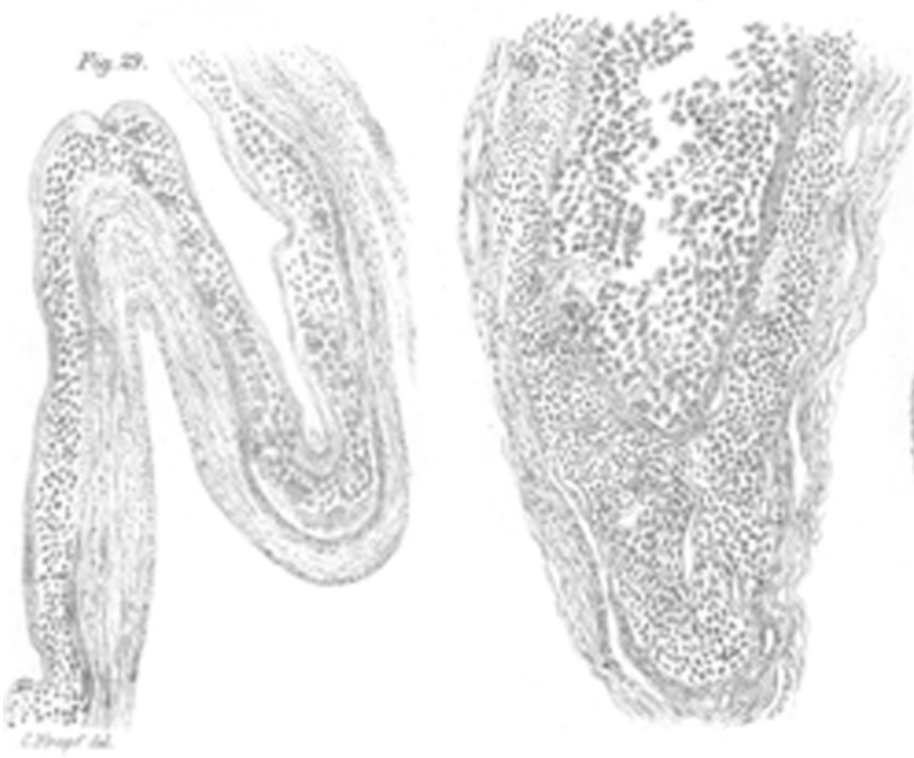

Fin w5

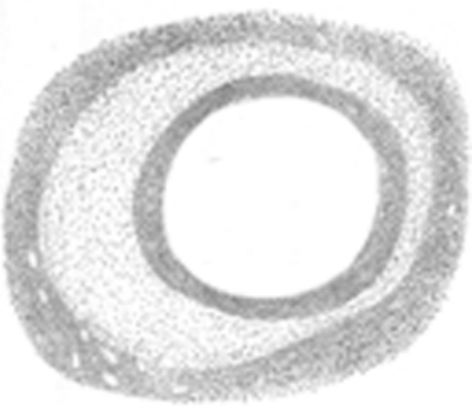

